\author{
Universidade de São Paulo \\ Instituto de Física
}

\title{
Fotodetectores infravermelhos de alta eficiência baseados em poços quânticos crescidos por epitaxia de feixes moleculares
}

\author{
Fernando Massa Fernandes
}

Orientador: Prof. Dr. Alain André Quivy

Tese de doutorado apresentada ao Instituto de Física para a obtenção do título de Doutor em Ciências

Banca Examinadora:

Prof. Dr. Alain André Quivy (IFUSP)

Prof. Dr. Manfredo Harri Tabacniks (IFUSP)

Prof. Dr. Davies William de Lima Monteiro (UFMG)

Prof. Dr. Evaldo Ribeiro (UFPR)

Prof. Dr. Marcos Henrique Degani (UNICAMP)

São Paulo 
Cada busca, cada descoberta, cada solução é um objetivo a alcançar nesta caminhada e se transformou na razão final deste trabalho. 
"A minha esposa amada Eliane pelo amor incondicional e dedicação e a todos que me apoiam na realização dos meus sonhos. A minha família que sempre esteve do meu lado, em especial minha mãe, exemplo de caráter e dedicação profissional." 


\section{Agradecimentos}

Agradeço ao meu amigo Álvaro, companheiro de laboratório na jornada do doutorado, por dividir comigo as dificuldades e vitórias do dia a dia de trabalho.

Aos técnicos Paulinho e Geraldão, pela dedicação, apoio e amizade, e a todo o pessoal que passou pelo laboratório MBE, com os quais tive a honra de trabalhar.

Agradeço a todos que auxiliaram nas etapas de processamento dos fotodetectores: Maria Helena e Ângelo Gobi, do LNLS em Campinas, ao professor Ronaldo Manzano da Escola Politécnica da USP, e em especial ao Totó do LPD da Unicamp, cuja ajuda foi fundamental na fabricação dos fotodetectores.

A todo o pessoal do INCT Disse, que tanto incentivaram este trabalho, e em especial à Professora Patrícia Lustosa da PUC do Rio de Janeiro, por todo o incentivo e apoio, principalmente nos seis últimos meses de doutorado.

Agradeço em especial ao Professor Alain, meu orientador, pela dedicação, perseverança e competência, que contribuíram fundamentalmente para minha formação profissional, e que serviram de exemplo para todos os alunos que passaram pelo laboratório MBE. 


\section{Resumo}

Fotodetectores baseados em poços quânticos (QWIPs - Quantum-Well Infrared Photodetectors) possuem inúmeras aplicações nos campos da medicina, engenharia, defesa e monitoramento meteorológico e ambiental. O espectro de absorção dos QWIPs possui alta seletividade do comprimento de onda, e esse tipo de fotodetector é a escolha atual para a fabricação de câmeras de alta resolução operando no infravermelho. Atualmente, o Brasil enfrenta uma limitação na importação desse tipo de tecnologia, imposta pelos países mais desenvolvidos, devido à possibilidade de ser usada em aplicações militares. Neste trabalho, propomos o desenvolvimento e a fabricação de novos fotodetectores baseados em transições intrabanda em poços quânticos crescidos por epitaxia de feixes moleculares sobre substratos de GaAs. O crescimento epitaxial dos poços quânticos foi investigado, e as amostras foram analisadas por fotoluminescência (PL, Photoluminescence) de modo a verificarmos a qualidade e reprodutibilidade das heteroestruturas produzidas. O cálculo dos níveis de energia e das funções de onda dos poços quânticos foi feito por meio da implementação numérica do método da matriz de transferência [21] no software Mathematica. Esse método também foi aplicado ao cálculo autoconsistente envolvendo a dopagem da estrutura. A partir dos valores das energias de confinamento e das funções de onda obtidas pelo programa, algumas grandezas físicas puderam ser estimadas tais como o coeficiente de absorção teórico, a corrente de escuro e o ruído. Também foi implementado um modelo para o cálculo dos níveis de energia de uma impureza hidrogenóide dentro de um poço quântico de GaAs com barreiras de AlGaAs. Acredita-se que esse sistema possua melhores características de ruído em relação a um QWIP comum, no qual as impurezas estão completamente ionizadas [25] [26] [27]. O processamento das amostras para a fabricação dos fotodetectores foi desenvolvido e otimizado, e envolveu técnicas convencionais de fotolitografia, para a formação por ataque químico das estruturas de pequenos fotodetectores singelos sobre a amostra, e a deposição de filmes finos metálicos para a obtenção dos contatos (ôhmicos). Foram desenvolvidas e implementadas várias técnicas de caracterização para determinar o comprimento de onda de operação, a responsividade, o ruído intrínseco, e a corrente no escuro (dark current) dos QWIPs fabricados. No inicio deste projeto de doutorado, nenhuma das técnicas de caracterização estava disponível no laboratório. A caracterização completa dos QWIPs foi feita medindo-se o coeficiente de absorção e a resposta espectral por espectroscopia no infravermelho por transformada de Fourier (FTIR), a fotocorrente foi medida com um corpo negro, a corrente de escuro usando curvas I-V, e o ruído com um analisador de espectros. As medidas foram realizadas em função da voltagem de polarização (bias) aplicada, em diferentes valores de temperatura. Foram crescidas várias amostras de QWIPs, para absorção nas janelas atmosféricas de $3 \mu \mathrm{m}$ a $5 \mu \mathrm{m}$ e de $8 \mu \mathrm{m}$ a $12 \mu \mathrm{m}$. A curva de absorção de cada amostra foi medida, e a caracterização optoeletrônica completa foi realizada em dois desses QWIPs, para a região de $8 \mu \mathrm{m}$ a $12 \mu \mathrm{m}$. O melhor resultado foi obtido em um QWIP com o pico de absorção em $9,3 \mu \mathrm{m}$, que apresentou detectividade de $5 \times 10^{10} \mathrm{~cm} . \mathrm{Hz}^{1 / 2} / \mathrm{W}$ para $10 \mathrm{~K}$ e $4 \times 10^{9} \mathrm{~cm} . \mathrm{Hz}^{1 / 2} / \mathrm{W}$ para $70 \mathrm{~K}$. 


\section{Abstract}

Photodetectors based on quantum wells (QWIPs - Quantum-Well Infrared Photodetectors) have numerous applications in the fields of medicine, engineering, defense, meteorology and environmental monitoring. The absorption spectrum of QWIPs has high wavelength selectivity, and this type of photodetector is the current choice for the fabrication of high-resolution cameras operating in the infrared. Currently, Brazil faces restrictions to import such a technology, imposed by the developed countries, due to its possibility of being used in military applications. In this thesis, we propose the development and optimization of photodetectors based on intraband transitions in quantum wells grown by molecular beam epitaxy (MBE) on GaAs substrates. The epitaxial growth of the quantum wells was investigated, and the samples were analyzed by photoluminescence (PL) to verify the quality and reproducibility of the heterostructures. The calculations of the energy levels and wavefunctions of the quantum wells were done by numerical implementation of the transfer matrix method [21] in the Mathematica software. This method was also applied to the self-consistent calculations involving the doping of the structures. From the values of the confinement energies, the wave functions could be obtained as well, and some physical quantities such as the theoretical absorption coefficient, the dark current and noise could be estimated. A model was also developed for the calculation of the energy levels of a hydrogenoid impurity inside a GaAs quantum well with AlGaAs barriers. It is believed that this system could have better noise characteristics when compared to a common QWIP in which the impurities are completely ionized [25] [26] [27]. The sample processing for the manufacture of the photodetectors was developed, optimized, and involved conventional photolithography techniques to define the physical size of the devices (followed by wet etching) as well as metallic film deposition to obtain ohmic contacts. Several characterization techniques were developed and installed to determine the wavelength of operation, the responsivity, the intrinsic noise and the dark current of the QWIPs manufactured in our laboratory. When this PhD project started, none of the characterization techniques was available in the lab. A complete set of experimental data was achieved by measuring the absorption coefficient and the spectral response by Fourier transform infrared spectroscopy (FTIR), the photocurrent using a blackbody, the dark current using I-V curves, and the noise with a spectrum analyzer. The measurements were performed as a function of the bias voltage at different temperatures. Several QWIPs samples were grown for absorption in the atmospheric windows from $3 \mu \mathrm{m}$ to $5 \mu \mathrm{m}$ and from $8 \mu \mathrm{m}$ to $12 \mu \mathrm{m}$. The absorption curve of each sample was measured, and full characterization was performed on two QWIPs, in the region of $8 \mu \mathrm{m}$ to $12 \mu \mathrm{m}$. The best results were obtained in a QWIP with peak absorption at $9.3 \mu \mathrm{m}$, which showed a detectivity of $5 \times 10^{10} \mathrm{~cm} \cdot \mathrm{Hz}^{1 / 2} / \mathrm{W}$ at $10 \mathrm{~K}$ and $4 \times 10^{9} \mathrm{~cm} \cdot \mathrm{Hz}^{1 / 2} / \mathrm{W}$ at $70 \mathrm{~K}$. 


\section{Sumário}

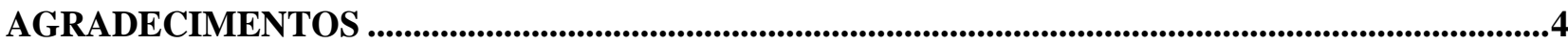

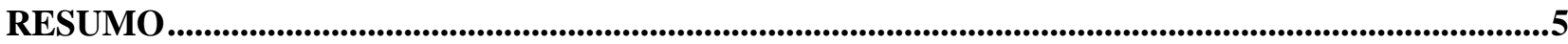

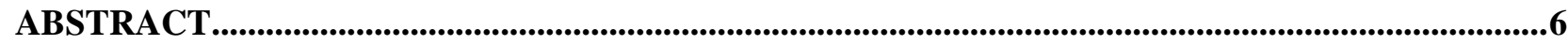

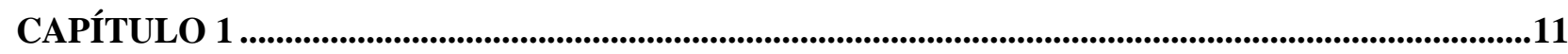

INTRODUÇÃ

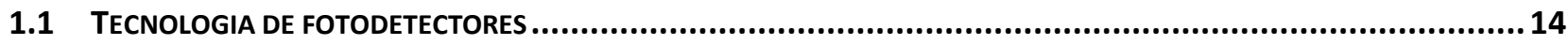

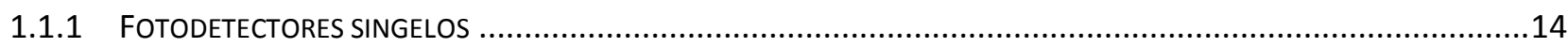

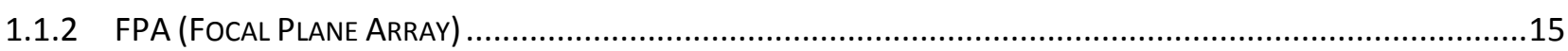

1.2 APLICAÇÕES E MOTIVAÇÃO DA PESQUISA EM FOTODETECTORES INFRAVERMELHOS.......................................16

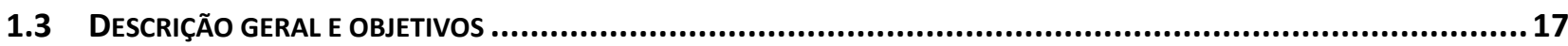

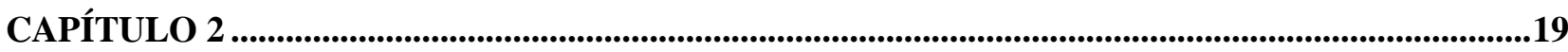

PRINCÍPIOS DE FOTODETECTORES DE INFRAVERMELHO .................................................19

2.1 Fí́SICA DOS FOTODETECTORES

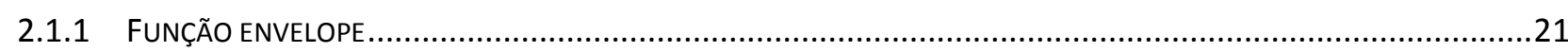

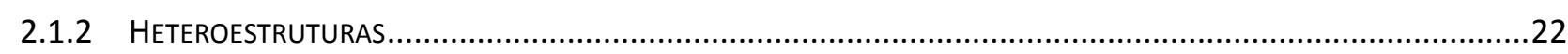

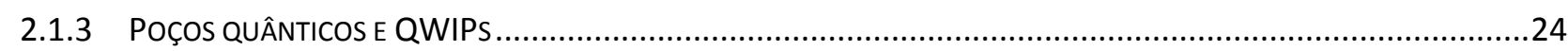

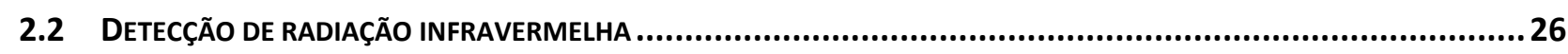

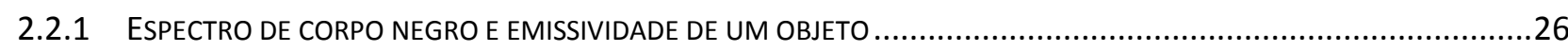

2.2.2 DIFERENÇA DE TEMPERATURA, EMISSIVIDADE E ABSORÇÃO EM BANDA ESPECÍFICA .........................................27

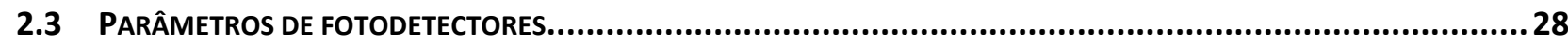

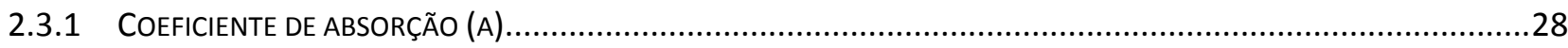

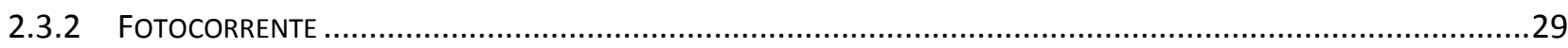

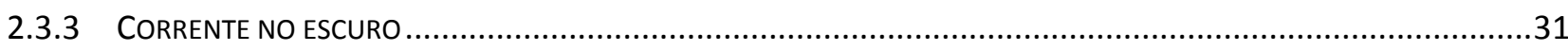

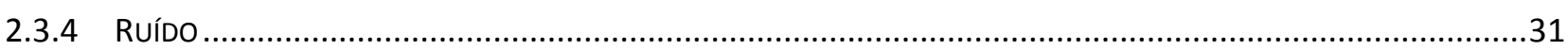

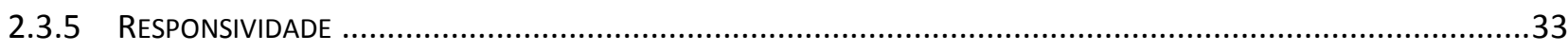

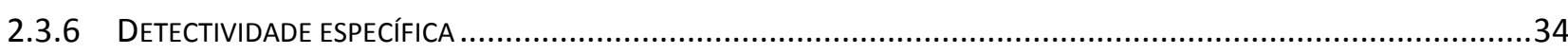

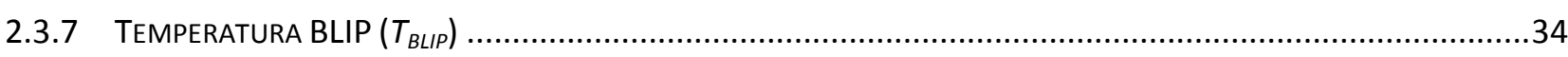

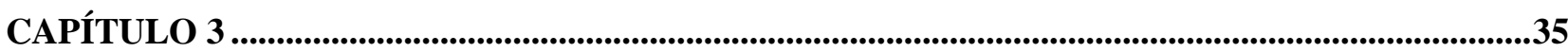

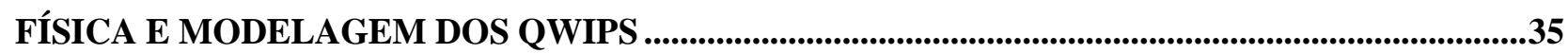

3.1 NÍVEIS DE ENERGIA E AUTOFUNÇÕES DE UM POÇO DE POTENCIAL ARBITRÁRIO..............................................35 


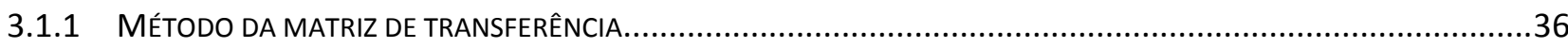

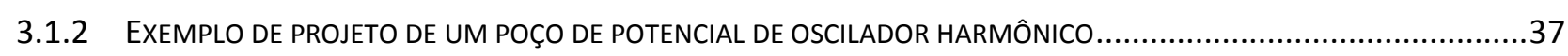

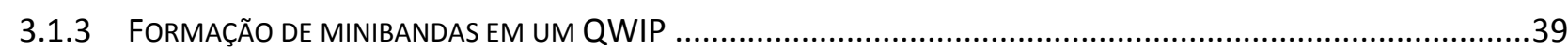

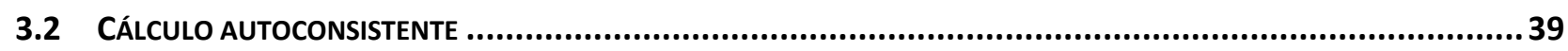

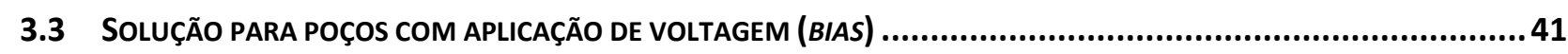

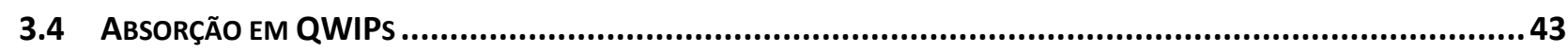

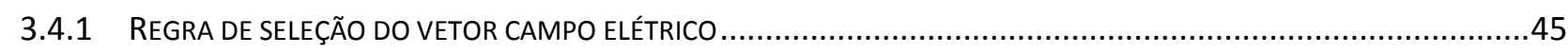

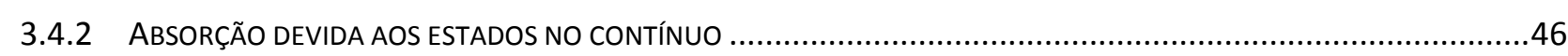

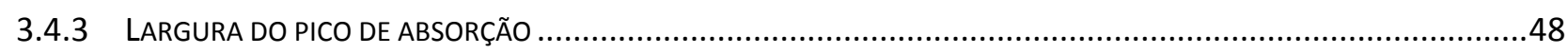

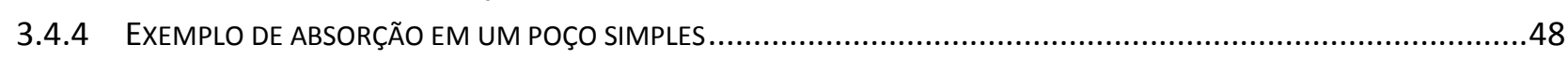

3.5 ESTADOS ZERO-DIMENSIONAIS DE IMPUREZAS CONFINADAS EM POÇOS QUÂNTICOS .....................................51

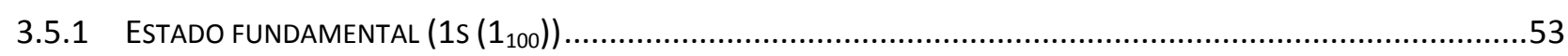

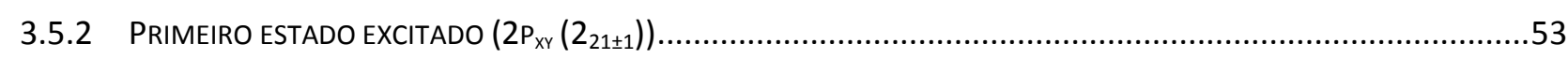

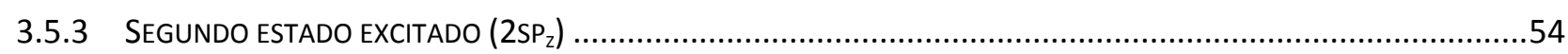

3.5.4 PROJETO DE UM QWIP BASEADO EM TRANSIÇÕES ZERO-DIMENSIONAIS DE IMPUREZAS .....................................55

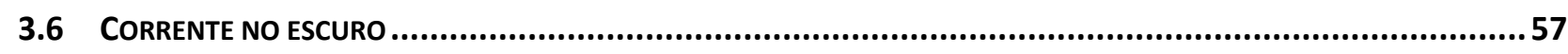

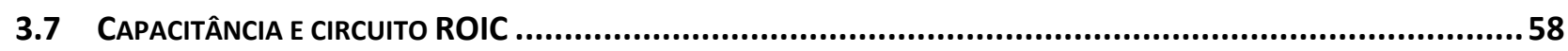

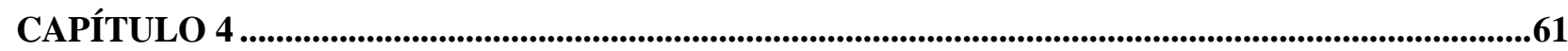

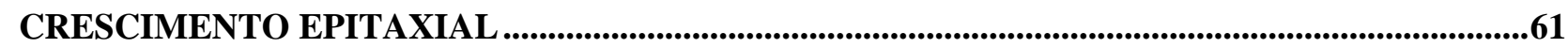

4.1 O SISTEMA MBE

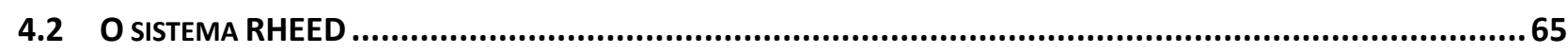

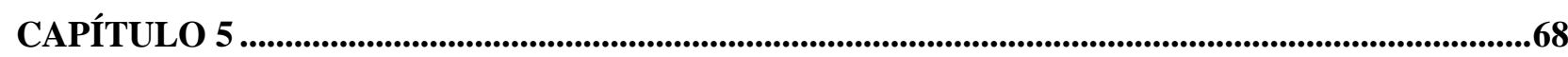

QWIPS CRESCIDOS POR MBE .........................................................................................................................68

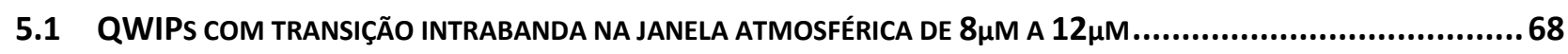

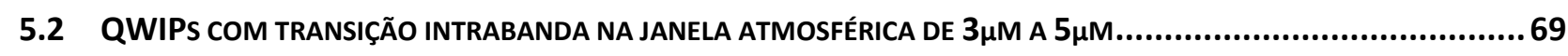

5.3 AMOSTRAS DE QWIPS PARA TRANSIÇÃO ENTRE ESTADOS ZERO-DIMENSIONAIS .......................................70

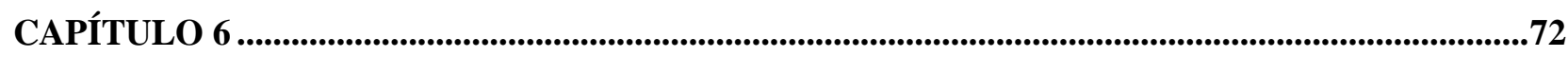

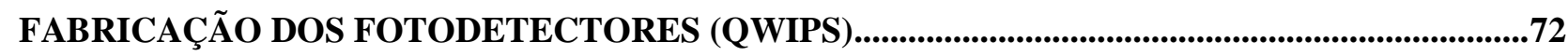

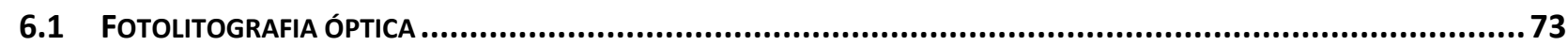

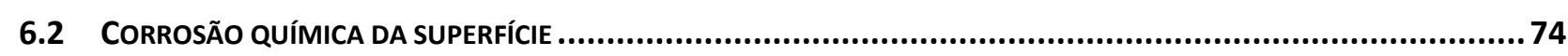

6.3 DEPOSIÇÃo DOS CONTATOS METÁLICOS E RECOZIMENTO TÉRMICO RÁPIDO …...........................................74

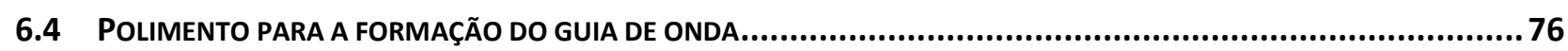

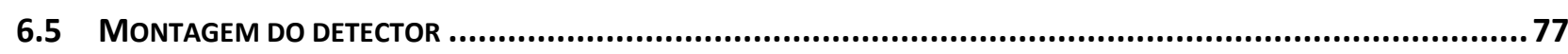




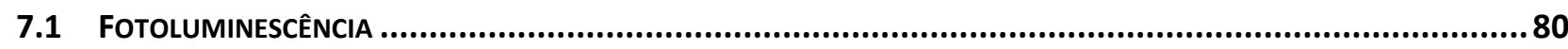

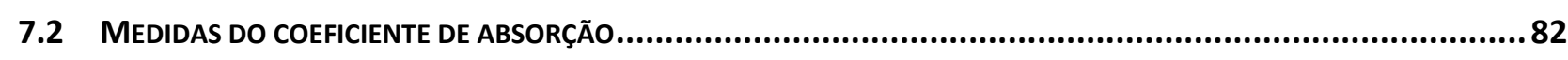

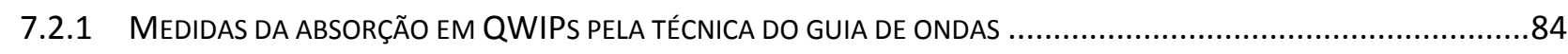

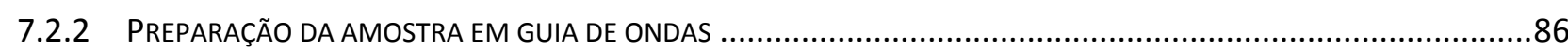

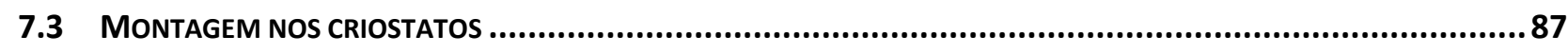

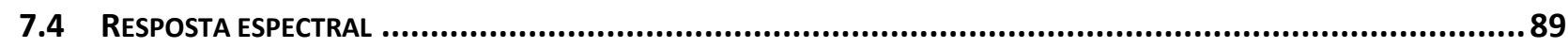

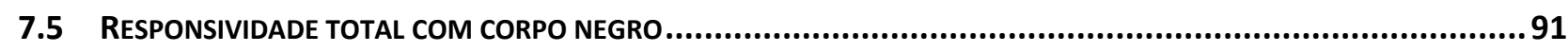

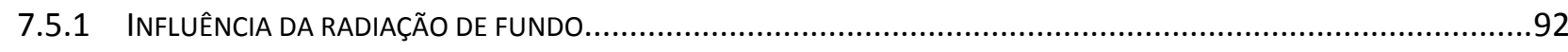

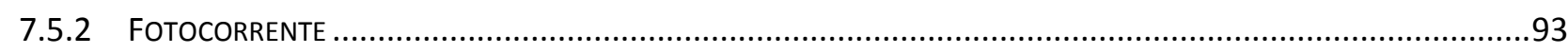

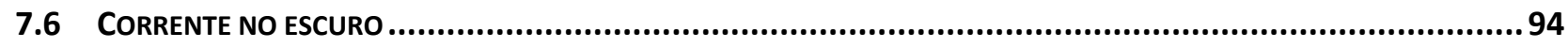

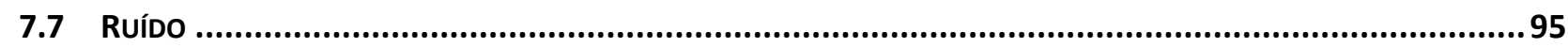

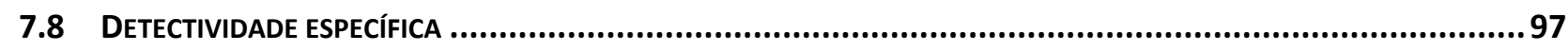

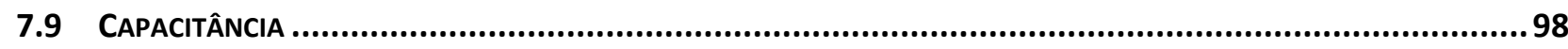

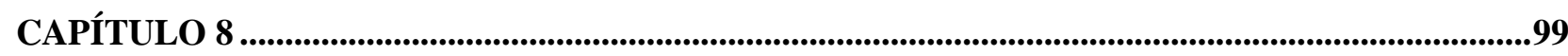

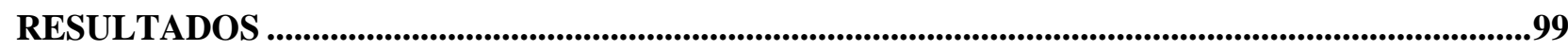

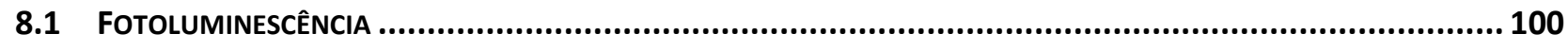

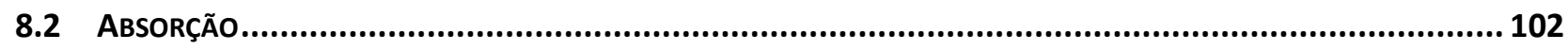

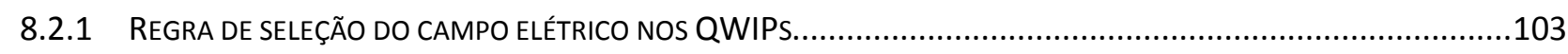

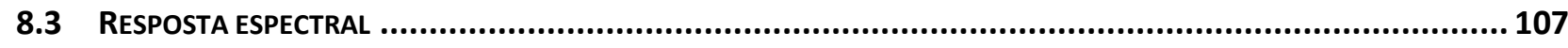

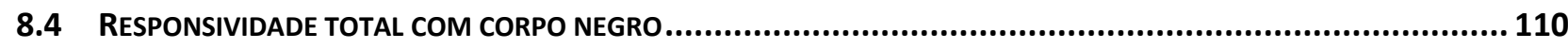

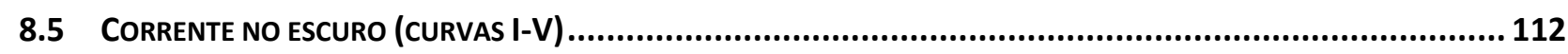

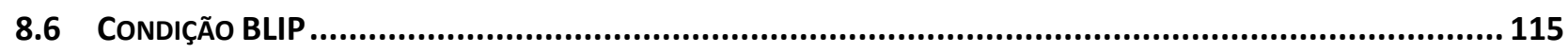

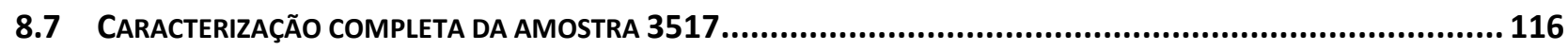

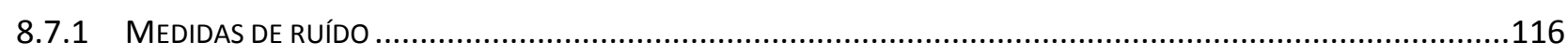

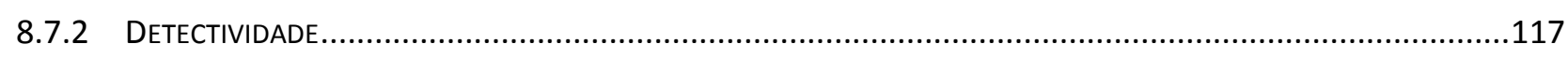

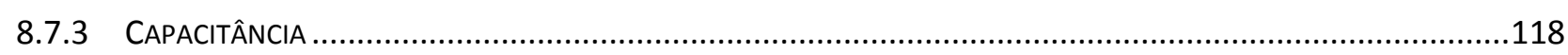

8.8 MECANISMOS DE TRANSPORTE EM QWIPS DEDUZIDOS A PARTIR DAS MEDIDAS DE RUÍDO............................. 120

8.8.1 ANÁLISE DO RUÍDO E DETERMINAÇÃO DA VELOCIDADE DE SATURAÇÃO EM QWIPS.......................................122

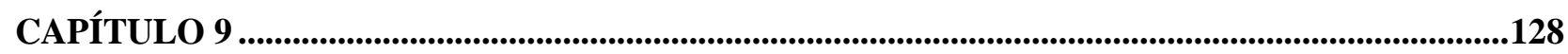

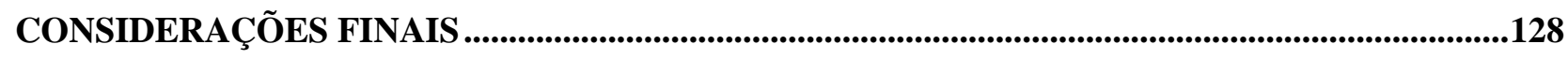

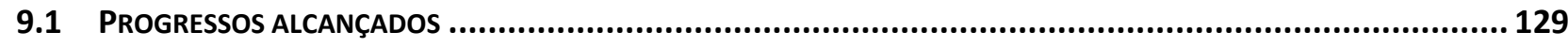

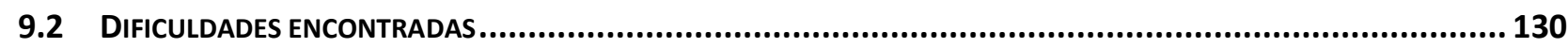

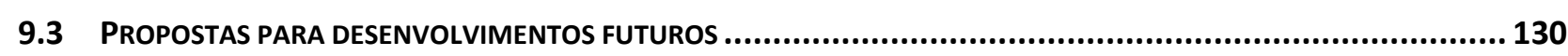


APÊNDICE .132

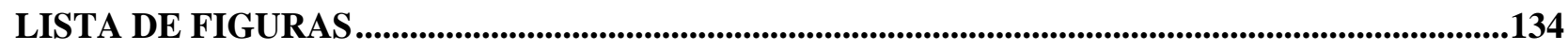

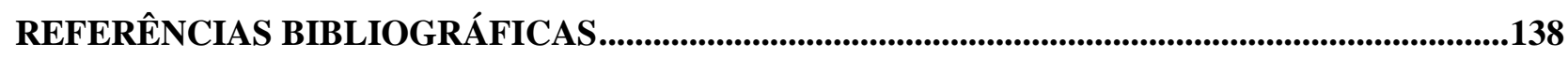




\section{Capítulo 1}

\section{Introdução}

Este trabalho possui como principal objetivo o desenvolvimento, a fabricação e a caracterização de fotodetectores infravermelhos baseados em transições intrabanda (ou intersubbanda) em poços quânticos (QWs, quantum wells), usando como material os arsenetos da família III, que podem ser crescidos com altíssima qualidade e homogeneidade pela técnica de epitaxia por feixes moleculares (MBE, molecular-beam epitaxy).

\section{Breve introdução histórica}

A detecção da radiação infravermelha pode ser feita por meio de um termômetro simples ou, mais usualmente, por meio da conversão da radiação incidente em um sinal elétrico. A história dos detectores infravermelhos começou no início do século 19, após a descoberta da radiação infravermelha por Hershel, em 1800. Seguindo os passos de Newton um século antes, Hershel utilizou um prisma de vidro para projetar o espectro da luz sobre uma mesa, e fez medidas das temperaturas em cada cor utilizando um termômetro de mercúrio. O termômetro de Hershel levava 16 minutos para fazer uma medida e tinha resolução de $0,5^{\circ} \mathrm{C}$. Movendo o termômetro no sentido da cor vermelha, percebeu que a temperatura aumentava. Ao mover além do vermelho, notou que o efeito persistia e que a temperatura continuava aumentando. Ele encontrou uma região além do vermelho visível que correspondia a um máximo na temperatura. Essa região é chamada atualmente de infravermelho.

A radiação infravermelha esta geralmente associada à radiação eletromagnética emitida ou absorvida devido ao movimento vibracional de moléculas, e corresponde a radiação eletromagnética que cobre o intervalo de comprimentos de onda entre $0,75 \mu \mathrm{m}$ e $1000 \mu \mathrm{m}$. O infravermelho se estende da região de baixo comprimento de onda, adjacente à região da luz visível, até os valores de alto comprimento de onda, próximos à região das micro-ondas (Figura 1).

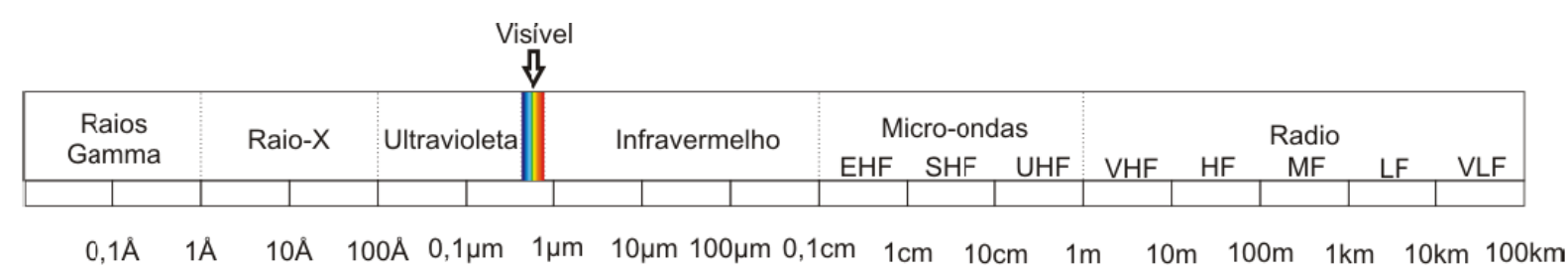

Figura 1: Espectro de radiação eletromagnética. 
É conveniente dividir o infravermelho em várias regiões, de acordo com o comprimento de onda. Essa divisão varia com os autores e com as aplicações. Aqui utilizamos a mais usual, como mostra a tabela abaixo (Tabela 1).

\begin{tabular}{|ccc|}
\hline Região & Abreviatura & Limites $(\mu \mathrm{m})$ \\
\hline $\begin{array}{c}\text { Near infrared } \\
\text { (infravermelho } \\
\text { próximo) }\end{array}$ & NIR & 0,75 a 1,4 \\
$\begin{array}{c}\text { Short-wavelength } \\
\text { Infrared } \\
\text { (infravermelho de } \\
\text { ondas curtas) } \\
\begin{array}{c}\text { Mid infrared } \\
\text { (infravermelho } \\
\text { médio) }\end{array}\end{array}$ & SWIR & 1,4 a 3 \\
\hline $\begin{array}{c}\text { Far infrared } \\
\text { (infravermelho } \\
\text { longínquo) }\end{array}$ & FIR & 3 a 30 \\
\hline
\end{tabular}

Tabela 1: Divisão do espectro infravermelho.

\section{Princípios de operação dos fotodetectores}

O princípio de operação dos detectores infravermelhos pode ser térmico ou quântico. Em detectores térmicos, a região ativa do detector é aquecida pela radiação incidente, suas propriedades físicas são alteradas (por exemplo, sua resistência elétrica), e a variação da grandeza física monitorada pode ser convertida em uma resposta elétrica correspondente, como no caso dos termopares (efeito Seebeck) e bolômetros (efeito termorresistivo). Existem diferentes tipos de detectores infravermelhos térmicos: os principais são as termopilhas, os bolômetros, e os detectores piroelétricos. Em detectores infravermelhos quânticos (ou fotônicos), a operação está associada diretamente à interação entre a radiação eletromagnética incidente e os portadores de carga do material. A absorção ocorre por meio de transições quânticas entre níveis discretos ou bandas de energia, quando o fóton absorvido possui energia igual à diferença de energia entre os dois estados inicial e final. Detectores que funcionam segundo esse princípio são chamados de fotodetectores, são geralmente fabricados a partir de materiais semicondutores, e trazem como principais vantagens a velocidade de resposta (pode ser inferior a $10^{-12}$ segundo) e a possibilidade de resolução espectral (sensibilidade ao comprimento de onda).

Os materiais semicondutores são caracterizados pela presença de um intervalo de energias proibidas, que separa os elétrons de valência dos estados de condução em duas bandas distintas. Esse intervalo de energias proibidas é denominado gap. Esses materiais podem ser dopados para formarem semicondutores extrínsecos, dando origem a níveis de energia discretos dentro do gap. A dopagem muda fundamentalmente as propriedades do semicondutor, de modo a obtermos 
fotodetectores com diferentes especificações de funcionamento a partir dos mesmos materiais semicondutores básicos. Podemos formar também ligas diferentes de materiais semicondutores, combinando-os em diferentes proporções (formando assim ligas ternárias ou quaternárias com composições diferentes), ou ainda, podemos formar diferentes heteroestruturas por meio da união entre camadas de materiais semicondutores de natureza diferente. Todas essas possibilidades proporcionam uma imensa variedade de tipos de fotodetectores que podem operar em diferentes faixas do espectro infravermelho.

Existem quatro tipos principais de fotodetectores infravermelhos: os fotodetectores intrínsecos (sem dopagem), os fotodetectores extrínsecos (com dopagem) e os fotodetectores infravermelhos baseados em poços quânticos (QWIPs) e em pontos quânticos (QDIPs - Quantum-Dot Infrared Photodetectors). Nesses dois últimos tipos (QWIPs e QDIPs), o princípio de detecção envolve a transição ressonante de elétrons (ou buracos) entre níveis discretos (ou entre um nível discreto e o contínuo) formados pelo confinamento quântico devido à junção de camadas de semicondutores diferentes com dimensões da ordem do comprimento de onda de de Broglie do elétron. Os primeiros a serem investigados e desenvolvidos foram os QWIPs, no início dos anos 80 [1], e mais recentemente surgiram os QDIPs [2]. Entre os fotodetectores infravermelhos formados por heteroestruturas, os QWIPs e QDIPs são considerados os que possuem maior potencial de aplicação em câmeras infravermelhas. Isso se deve ao desenvolvimento maduro das técnicas de crescimento epitaxial, que permitem o crescimento de QWIPs e QDIPs com altíssima qualidade e homogeneidade. Porém, esses tipos de fotodetectores possuem o inconveniente da necessidade de serem resfriados a temperaturas criogênicas para operarem eficientemente.

Dentre os fotodetectores infravermelhos mais utilizados comercialmente estão os detectores intrínsecos formados pela liga ternária $\mathrm{HgCdTe}$. Os fotodetectores formados por essa liga apresentam alta detectividade à temperatura ambiente e o seu pico de absorção pode ser ajustado numa ampla faixa de comprimentos de onda alterando-se a composição da liga (o que altera o gap do material). Porém, esses fotodetectores apresentam inconvenientes na sua fabricação (alta pressão de vapor durante o crescimento, baixa energia da ligação Te-Hg), que dificultam bastante o desenvolvimento de aplicações, além de elevar consideravelmente o custo final de qualquer tecnologia baseada nesse tipo de sensor [3].

A facilidade de fabricação, robustez do material e uniformidade são características fundamentais para a obtenção de FPAs (Focal Plane Arrays) de boa qualidade com grande área de absorção que possibilitem a fabricação de câmeras infravermelhas com imagens de alta resolução. Em especial, as ligas semicondutoras baseadas em arseneto de gálio (GaAs), como AlGaAs e InGaAs, apresentam essas vantagens para a fabricação de QWIPs e QDIPs, devido à grande maturidade alcançada no crescimento epitaxial e no processamento de amostras baseadas em GaAs [4].

A absorção em QWIPs com dopagem do tipo n (os mais comuns) é dependente da polarização da radiação incidente, e esses QWIPs possuem a desvantagem de terem baixa detectividade para incidência normal de radiação. Essa limitação é conhecida como regra de polarização em QWIPs, e pode ser superada com a fabricação de uma rede de difração na superfície, de modo a melhorar o 
acoplamento ótico com a radiação incidente. Uma outra possibilidade é usar uma dopagem do tipo p (buracos no lugar de elétrons), pois esta regra de polarização não vale para a banda de valência. Porém, a utilização de dopagem do tipo $\mathrm{p}$ em QWIPs prejudica outras figuras de mérito do detector, pois a massa efetiva do buraco é bem maior que a do elétron.

Os QWIPs, em geral, possuem a vantagem de terem a banda de absorção espectral inerentemente estreita, a largura à meia altura é cerca de $20 \%$ do comprimento de onda, e o comprimento de onda de absorção pode ser facilmente ajustado, variando a largura ou composição do poço quântico durante o crescimento por MBE [5]. No caso dos QDIPs, os pontos quânticos são formados de maneira espontânea (Self assembling) durante o crescimento de uma fina camada de InAs depositada sob tensão sobre um substrato de GaAs, o que dificulta o controle preciso da forma e do tamanho dos pontos, dando origem a um espectro de absorção mais largo e com controle limitado do comprimento de onda da absorção. Embora os QDIPs possam operar sob incidência normal e em temperaturas mais altas que os QWIPs, eles ainda possuem uma detectividade menor que a obtida em geral com os QWIPs, em razão da sua baixa eficiência quântica. Como são capazes de operar em bandas estreitas, os QWIPs possibilitam a detecção de certos gases que absorvem no infravermelho, assim como a fabricação de sensores e FPAs operando eventualmente em várias bandas simultaneamente. Isto possibilita a fabricação de sistemas mais compactos e permite, entre outras coisas, fazer a distinção entre um objeto e o fundo da imagem (quando os dois possuem a mesma temperatura), e determinar a temperatura de um objeto à distância. No estado da arte atual, FPAs de alta resolução (1024 x 1024 pixels), que operam em duas ou três bandas simultaneamente, vêm sendo fabricados a partir de QWIPs baseados em GaAs [5][6].

\subsection{Tecnologia de fotodetectores}

Do ponto de vista comercial, podemos encontrar fotodetectores em duas configurações básicas dependendo da sua aplicação final: detectores singelos e FPAs. A maioria das aplicações para detectores infravermelhos está relacionada à realização de imagens no infravermelho utilizando-se FPAs.

\subsubsection{Fotodetectores singelos}

Chamamos de fotodetector singelo um dispositivo formado por um único fotodetector. Um detector singelo passa por um processamento, para definir o seu tamanho físico e sua geometria, por uma etapa de metalização para a formação de contatos elétricos e, eventualmente, por uma etapa final suplementar para depositar um filme anti-refletor ou gravar uma rede de difração de maneira a melhorar o acoplamento óptico. O detector completamente processado é então encapsulado, e pode ser acoplado a um filtro de radiação e a um sistema de refrigeração (Figura 2). 


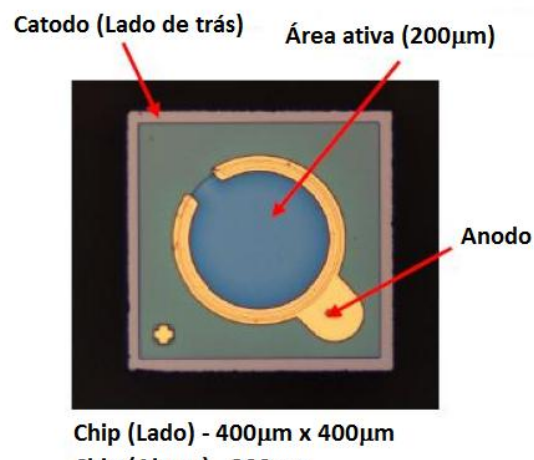

Chip (Altura) - 300 $\mu \mathrm{m}$

(a)

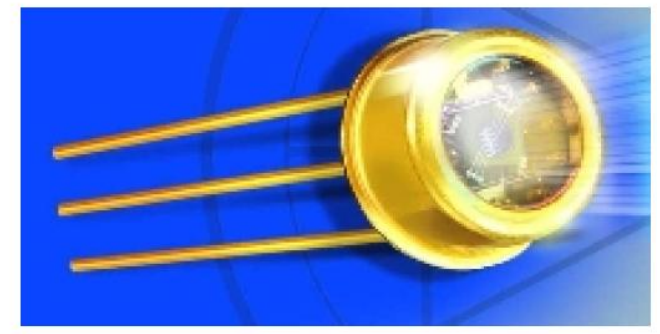

(b)

Figura 2: Detectores singelos: (a) Fotodetector processado; (b) Encapsulamento.

\subsubsection{FPA (Focal Plane Array)}

Em câmeras infravermelhas, FPAs são usados para a formação da imagem. Um FPA é uma matriz bidimensional de pequenos fotodetectores individuais, onde cada um dos fotodetectores corresponde a um pixel (picture element) da imagem (Figura 3).

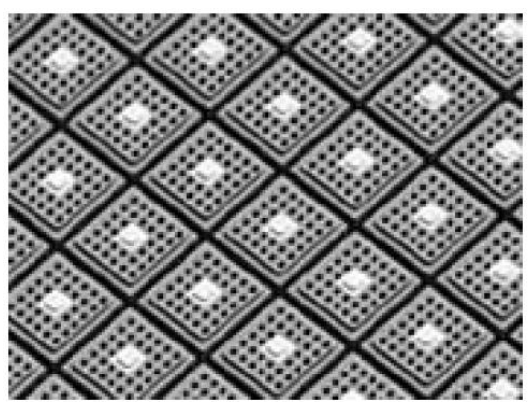

(a)

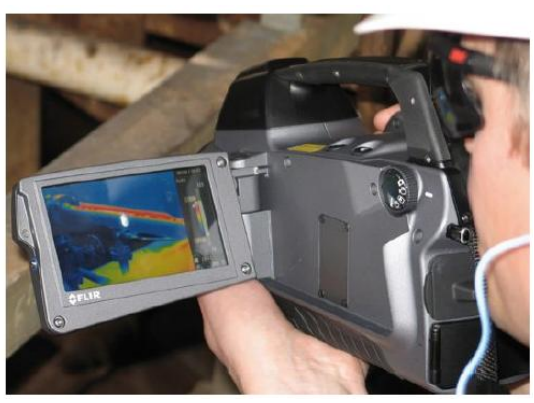

(b)

Figura 3: Fabricação de câmeras de radiação infravermelha: (a) FPA de QWIPs com rede de difração e contatos metálicos [7]; (b) Câmera infravermelha portátil funcionando com um FPA.

Uma matriz bidimensional de fotodetectores (FPA) recebe a radiação incidente na direção normal à sua superfície. Na Figura 3 (a), são mostrados detalhes dos pixels que compõem um FPA (640x512) fabricado a partir de QWIPs [7]. Cada pixel possui $24 \mu \mathrm{m}$ de lado, e na sua superfície é fabricada uma rede de difração para que o sistema possa ser usado em incidência normal. No centro de cada detector é depositado um pequeno contato metálico por onde fluirá a corrente elétrica gerada pela absorção da radiação incidente. Neste caso, o segundo contato metálico é 
comum, a todos os detectores do FPA e se encontra na parte traseira do dispositivo. QWIPs com dopagem do tipo $\mathrm{n}$ operando com radiação incidindo normalmente à superfície exibem geralmente absorção desprezível (regra de polarização em QWIPs), pois a absorção da radiação ocorre apenas para a componente com polarização perpendicular ao plano dos poços quânticos. No caso dos FPAs de QWIPs, o recurso comumente utilizado para superar essa limitação é a construção de uma rede de difração na superfície dos QWIPs, como ilustrado na Figura 3 (a).

\subsection{Aplicações e motivação da pesquisa em fotodetectores infravermelhos}

Fotodetectores infravermelhos possuem aplicações em diversas áreas: na indústria, na medicina, em defesa, no monitoramento ambiental e na ciência (Figura 4). Equipamentos militares envolvendo a detecção de radiação infravermelha estão sendo desenvolvidos, desde a segunda guerra mundial, para uso em visão noturna e, mais recentemente, na guiagem de mísseis e na detecção de veículos invisíveis ao radar, mas que emitem calor. Câmeras infravermelhas têm sido utilizadas em satélites meteorológicos e também na agricultura [8] e no monitoramento ambiental [7]. No ambiente industrial, destacam-se as aplicações no monitoramento de equipamentos e processos, no monitoramento de instalações elétricas e hidráulicas (http://www.flir.com/thermography/americas/us/) e na indústria petroquímica. Na engenharia de sistemas, no projeto e ensaio de máquinas, muitas vezes é essencial o mapeamento da distribuição de calor ou de perdas (isolação térmica). Devido à sua sensibilidade espectral, ou seja, à capacidade de detecção em uma banda específica de comprimentos de onda, os fotodetectores baseados em QWIPs podem ser utilizados no monitoramento de gases do efeito estufa, gases tóxicos ou inflamáveis $[9,10]$. Na medicina, a utilização de detectores infravermelhos ocorre em função da variação de temperatura sofrida por um órgão ou região do corpo que são afetados por uma enfermidade ou ferimento, devido à diminuição do fluxo sanguíneo (trombose, embolia) ou ao aumento do fluxo sanguíneo nessa área (reprodução acelerada de células cancerígenas, Figura 4 (a) [11]).

Em função da grande quantidade de aplicações dos fotodetectores infravermelhos e do alto grau de desenvolvimento econômico e industrial do Brasil, algumas empresas nacionais já estão desenvolvendo tecnologia própria de fabricação de câmeras infravermelhas (www.optovac.com.br). Porém, essas câmeras desenvolvidas no país ainda dependem da importação de FPAs de baixo desempenho (com menor resolução e maior tempo de resposta), que são baseados em bolômetros possuindo uma tecnologia inferior aos modernos FPAs baseados em fotodetectores. Essa limitação ocorre pela imposição de rígidas restrições à importação dessa tecnologia de ponta, pelos países mais desenvolvidos, devido às possíveis aplicações militares. 


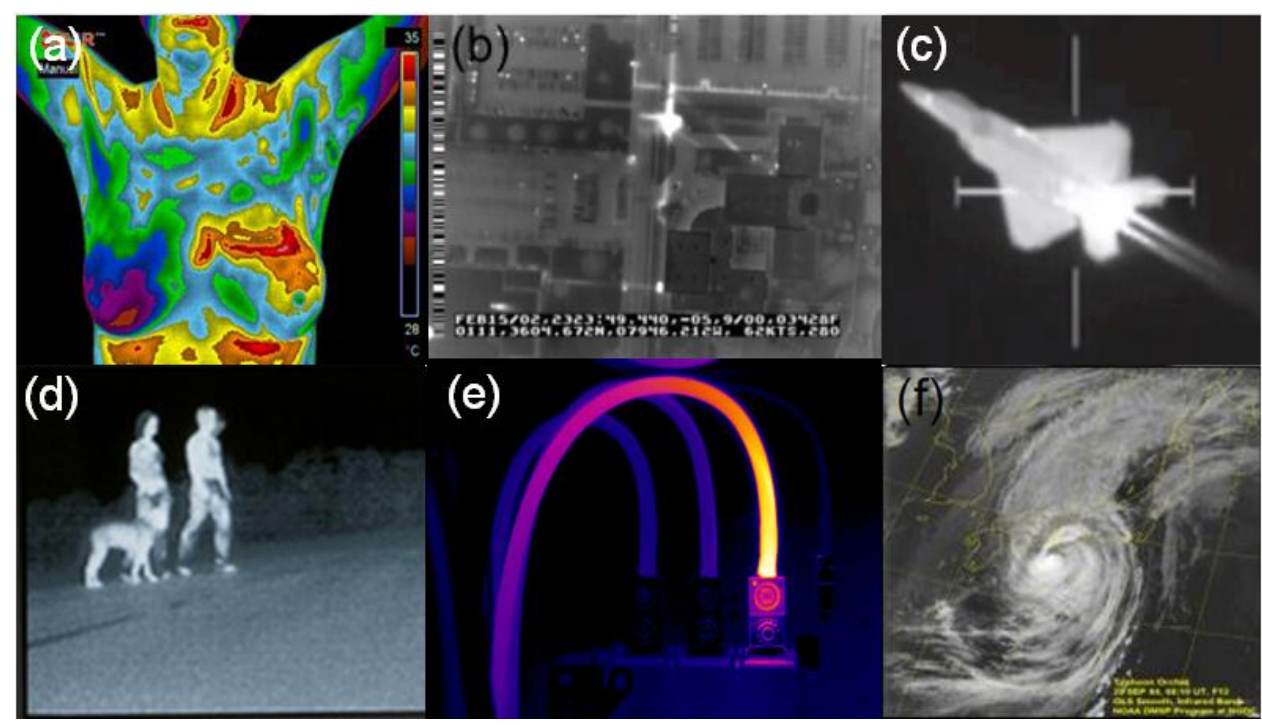

Figura 4: Aplicações de fotodetectores de radiação infravermelha: (a) Imagen de uma paciente com câncer de mama; (b) Visualização remota da tubulação de ar quente no teto de um edifício; (c) Imagen no infravermelho de um jato de ataque F-22 (invisivel ao radar, mas com intensa assinatura no infravermelho); (d) Câmera infravermelha de visão noturna; (e) Dissipação de calor em circuitos elétricos, para a prevenção de falhas; (f) Imagem no infravermelho obtida por satélite meteorológico.

\subsection{Descrição geral e objetivos}

O objetivo desta tese de doutorado é o desenvolvimento e a fabricação de novos fotodetectores baseados em poços quânticos. Para atingir essas metas, o crescimento epitaxial dessas estruturas precisou ser investigado e otimizado, e ferramentas matemáticas e experimentais foram desenvolvidas para auxiliar cada etapa da produção e da caracterização deste tipo de dispositivo. Partindo das especificações de operação do fotodetector a ser desenvolvido, o projeto da estrutura foi elaborado com base nos modelos matemáticos e cálculos implementados. $\mathrm{O}$ crescimento epitaxial da estrutura completa da amostra foi realizado a partir dos parâmetros físicos determinados na fase anterior. As amostras crescidas foram processadas e transformadas em dispositivos que puderam então ser avaliados em nível elétrico e óptico. O desenvolvimento de fotodetectores de boa qualidade depende de uma boa sintonia entre as 3 etapas principais: otimização do crescimento epitaxial, qualidade e reprodutibilidade do processamento das amostras, e caracterização completa e de qualidade dos dispositivos para maximizar a eficiência quântica e diminuir o ruído no dispositivo final. No início do trabalho, nenhuma técnica de caracterização de fotodetectores estava disponível no Laboratório de Novos Materiais Semicondutores (LNMS). Progressivamente, diversos projetos foram sendo aprovados para a compra de equipamentos e melhoria da infraestrutura do laboratório. Na medida em que os recursos e equipamentos foram chegando, foram realizados esforços conjuntos para a implementação das técnicas de caracterização indispensáveis para o bom andamento das pesquisas. 
A técnica de crescimento MBE disponível no LNMS possibilita a obtenção de QWIPs com bom controle do comprimento de onda de detecção que podem ser crescidos com excelente qualidade e homogeneidade. Essa técnica permite o crescimento de poços quânticos com interfaces abruptas, e também possibilita o estudo de vários parâmetros de crescimento assim como a obtenção de poços com perfis de potencial variados, de modo a estudar o desempenho dos dispositivos.

A tese foi dividida em 9 capítulos: este capítulo apresentou uma breve introdução à radiação infravermelha, incluindo aspectos históricos e tecnológicos assim como as motivações para o desenvolvimento da tecnologia de fotodetectores e, mais particularmente, dos QWIPs. Os capítulos 2 e 3 são capítulos mais teóricos: o capítulo 2 apresenta os princípios físicos gerais envolvendo a tecnologia de fotodetectores de infravermelho, enquanto que o capítulo 3 aborda os detalhes da modelagem dos fotodetectores baseados em poços quânticos. O capítulo 4 é dedicado à descrição da técnica MBE e dos processos de crescimento. As principais estruturas QWIPs crescidas durante este trabalho foram descritas no capítulo 5, e o processamento dessas estruturas para fabricação dos fotodetectores foi explicado no capítulo 6. No capítulo 7 são apresentadas todas as técnicas de caracterização óptica e elétrica desenvolvidas para a caracterização dos fotodetectores, enquanto que o capítulo 8 apresenta em detalhes os resultados das medidas de caracterização, com os comentários e a análise dos resultados. Finalmente, no capítulo 9, são feitas as considerações finais sobre os resultados e a pesquisa desenvolvida durante o doutorado. 


\section{Capítulo 2}

\section{Princípios de fotodetectores de infravermelho}

\subsection{Física dos fotodetectores}

Os fotodetectores podem ser fabricados a partir de semicondutores intrínsecos ou extrínsecos, ou podem ser obtidos a partir de heteroestruturas de poços quânticos ou de pontos quânticos. $\mathrm{O}$ seu princípio de operação é a transição de elétrons (ou buracos) entre níveis de energia por meio da absorção de fótons da radiação incidente. O tipo de transição define o tipo de fotodetector. A promoção de elétrons (ou buracos) para a banda de condução (valência) ou ainda para o contínuo de uma mesma banda, assim como a ionização de impurezas, provoca uma mudança na condutividade elétrica da região ativa devido à absorção da radiação incidente.

De uma maneira geral, a transição eletrônica entre níveis de energia pode ocorrer por meio de três processos físicos: absorção, emissão e emissão estimulada. Cada um desses processos físicos dá origem a um tipo de dispositivo optoeletrônico. O processo de absorção leva aos fotodetectores. No processo de emissão, um elétron na banda de condução decai para um nível de menor energia (geralmente na banda de valência) por meio da emissão de um fóton, e esse processo de emissão leva aos LEDs (Light Emitting Diodes) que estão presentes na maioria dos equipamentos eletrônicos do nosso cotidiano. Na emissão estimulada, um fóton incidente interage no interior de uma cavidade óptica com um elétron em um nível discreto de energia (ou na banda de condução), provocando o decaimento radiativo desse elétron em fase com o fóton incidente para um nível de energia inferior (ou a banda de valência), sendo esse o princípio de operação dos lasers.

Em um fotodetector baseado em um semicondutor intrínseco, a transição ocorre de um nível na banda de valência para um nível na banda de condução. Quando um elétron absorve um fóton com energia igual ou maior que a energia do gap do material do fotodetector, esse elétron é excitado através do gap para um nível dentro da banda de condução (Figura 5 (a) e (b)). Após a excitação do elétron para o nível na banda de condução ocorre a termalização (Figura 5 (b)) que consiste em uma sequência de interações elétron-fônons (seta cinza) por meio das quais o elétron retorna ao nível de menor energia. Em fotodetectores extrínsecos, a transição ocorre por meio da ionização de um nível de impureza presente dentro do gap do semicondutor dopado (Figura 5 (c)). Ao introduzir na estrutura de um semicondutor uma certa densidade de impurezas (dopantes), de modo a gerar uma "falta" ou um "excesso" de elétrons na estrutura cristalina, essas dão origem a níveis de energia intermediários dentro do gap do material. Esse material semicondutor dopado é chamado de semicondutor extrínseco. Quando a dopagem do material semicondutor provoca a 
"falta" de um elétron na estrutura do material, ela dá origem a um nível de energia aceitador de elétrons próximo à banda de valência do material (nível de buracos). Esse tipo de dopagem é denominado dopagem do tipo p. Quando a dopagem com certo átomo de impureza provoca a "sobra" de um elétron na estrutura, esse elétron a mais dará origem a um nível de energia doador de elétrons (nível de elétrons), próximo à banda de condução. Esse tipo de dopagem é denominado dopagem do tipo $n$.

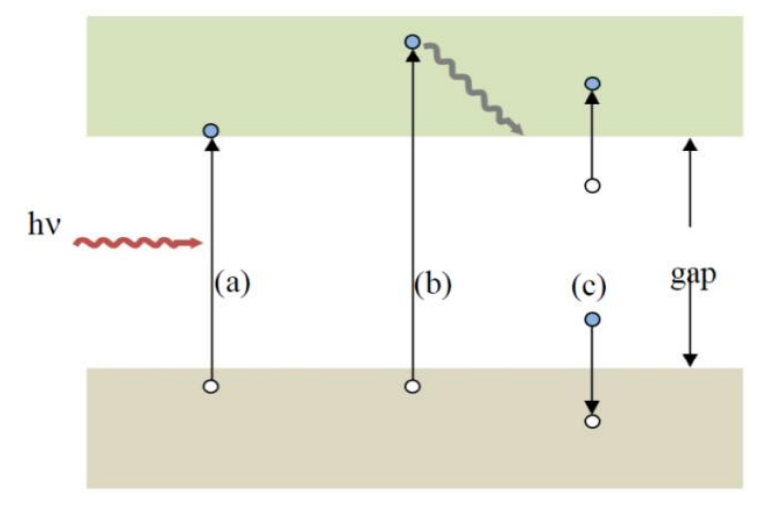

Figura 5: Absorção em semicondutores. (a) e (b) fotodetector intrínseco. (c) fotodetector extrínseco.

O gap de um semicondutor corresponde à diferença entre o máximo da banda de valência e o mínimo da banda de condução. Para compreender as propriedades ópticas de um semicondutor, é necessário conhecer a sua estrutura eletrônica de bandas. Para valores do vetor de onda iguais ou próximos de zero $(\mathrm{K} \approx 0)$, podemos considerar a aproximação de bandas parabólicas, onde as bandas obedecem às relações $E_{c}(K)=E_{c}(0)+\frac{\hbar^{2} K^{2}}{2 m_{e}^{*}}$, para a banda de condução, e $E_{v}(K)=$ $E_{v}(0)+\frac{\hbar^{2} K^{2}}{2 m_{v}^{*}}$, para a banda de valência.

Em um semicondutor de gap indireto (Figura 6), como o Si, a transição óptica ocorre devido à transição de um elétron na banda de valência, com vetor de onda $\Gamma$, para um estado da banda de condução, com um vetor de onda X (Figura 7), onde a diferença entre o vetor de onda inicial e final se deve ao espalhamento envolvendo um fônon da rede cristalina. A transição óptica no caso de um semicondutor de gap indireto deve portanto ser intermediada por um fônon, processo que é menos eficiente em relação a uma transição direta. Por isso, quando se deseja produzir dispositivos ópticos, a maioria dos semicondutores usados possui um gap direto. No caso do GaAs, que é um semicondutor de gap direto, a transição ocorre no ponto $\Gamma$ da zona de Brillouin. A banda de buracos no GaAs é formada por duas bandas (degeneradas) $\Gamma_{8}$, uma de buracos pesados e uma de buracos leves, e uma banda que reflete a interação spin-orbita $\Gamma_{7}$ (Figura 7). 


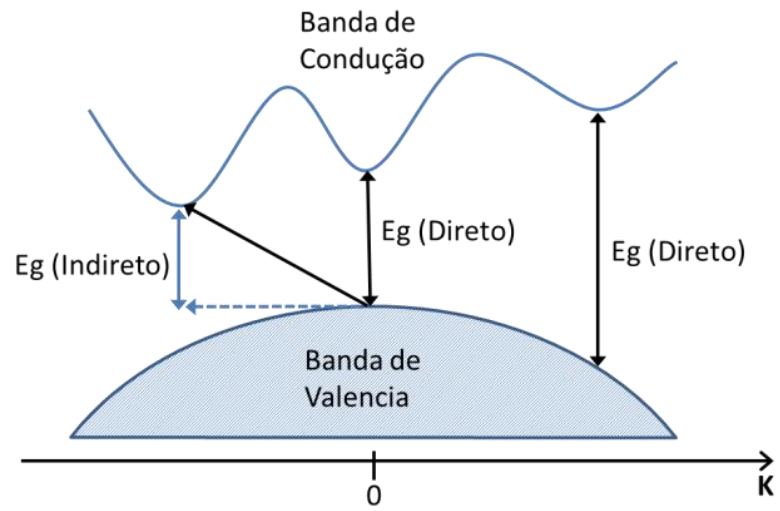

Figura 6: Ilustração das transições de gap direto e indireto.
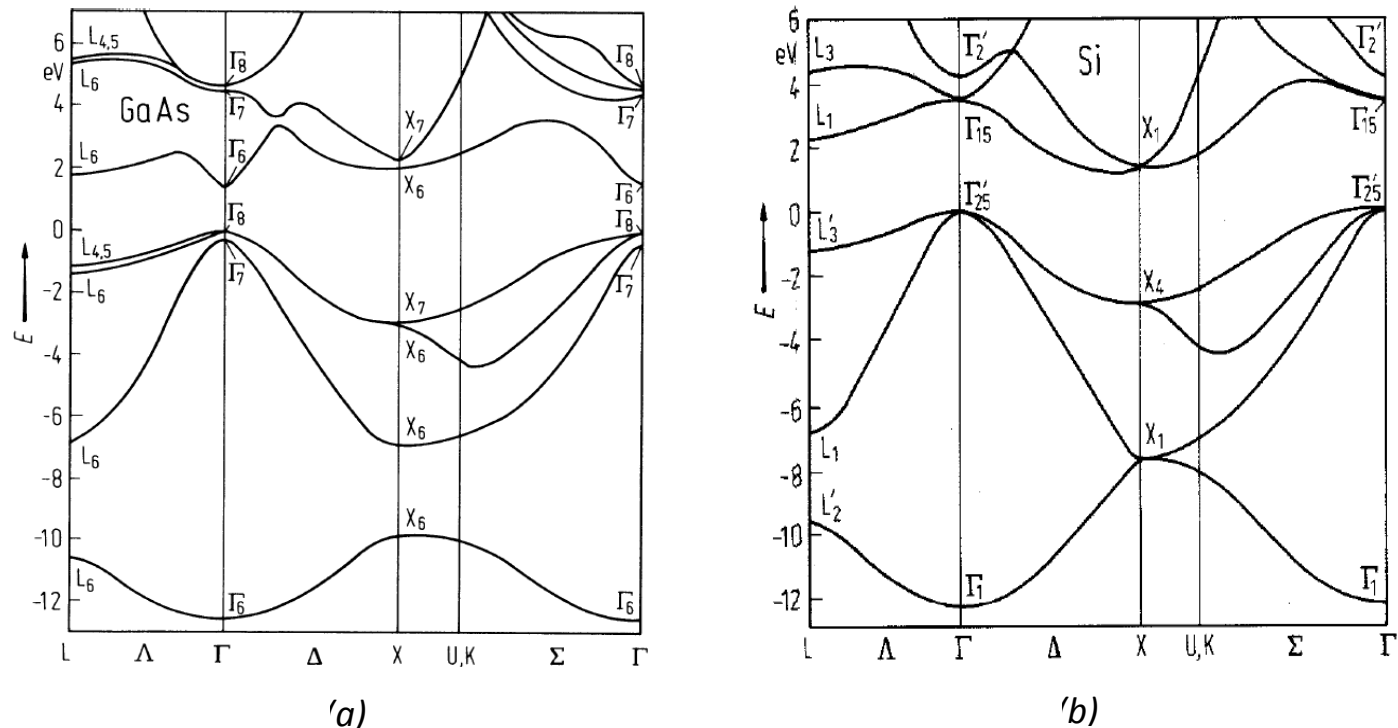

Figura 7: (a) Estrutura de bandas do GaAs; (b) estrutura de bandas do Si [12].

\subsubsection{Função envelope}

Um modelo matemático completo que descreva quanticamente uma estrutura cristalina é extremamente complicado, pois deve envolver a interação entre as funções de onda atômicas dos constituintes da estrutura. Mesmo um modelo mais simplificado do tipo tight binding, que envolve a combinação linear de orbitais atômicos, ainda se mostra muito complexo para o cálculo de propriedades gerais dos semicondutores e para a previsão de propriedades optoeletrônicas e de transporte. De um modo geral, as funções de onda que descrevem os elétrons no semicondutor podem ser separadas em duas partes: uma parte que descreve o ordenamento atômico de alta frequência, e uma parte moduladora que descreve as propriedades gerais não atômicas da estrutura. Essa função, que modula a função de caráter atômico da estrutura, é chamada função envelope. Portanto, se quisermos estudar as propriedades de interesse em dispositivos, basta conhecer a função envelope do sistema. Essa função é definida de forma simples em cada banda 
do material, considerando que um elétron pode se mover livremente entre o contínuo de estados em cada banda. Assim, dentro dessa aproximação, um elétron em uma banda contínua, em um material semicondutor maciço (bulk), será descrito simplesmente por uma função de onda plana (Equação 2.1). Essa aproximação é definida como uma aproximação de massa efetiva, pois ao considerarmos o fundo da banda como sendo o zero de energia, estamos introduzindo uma simplificação que deve ser compensada atribuindo-se aos portadores de carga uma massa efetiva $m^{*}$ diferente da massa $\mathrm{m}_{0}$ do elétron (Equação 2.2).

$$
\begin{gathered}
\Psi=a \cdot \cos (k \cdot z) \quad \text { Equação } 2.1 \\
-\frac{\hbar^{2} \cdot \nabla^{2} \Psi}{2 \cdot m^{*}}+V_{c} \Psi=E \Psi \quad \text { Equação } 2.2
\end{gathered}
$$

Para um elétron livre $V_{c}=0$ e $E=\hbar^{2} k^{2} / 2 m^{*}$.

Dentro dessa aproximação de massa efetiva, para obtermos a energia de ionização de um nível de impureza (doadora ou aceitadora) em relação ao fundo da respectiva banda, aplicamos o modelo do átomo de hidrogênio, que nos permite calcular aproximadamente a energia de ionização da impureza (Equação 2.3).

$$
E=-\frac{m^{*} \cdot e^{4}}{2 \cdot(4 \cdot \pi \cdot \varepsilon)^{2} \cdot \hbar^{2}}
$$

Equação 2.3

onde $m *$ é a massa efetiva e $\varepsilon$ a permissividade do material.

\subsubsection{Heteroestruturas}

A formação de heteroestruturas semicondutoras é um aspecto fundamental na fabricação de fotodetectores baseados em poços e pontos quânticos. As heteroestruturas são formadas quando unimos dois materiais semicondutores com gaps diferentes, como no caso do GaAs (gap menor) e AlGaAs (gap maior) (Figura 8 (a)). Nesse caso, o alinhamento dos gaps dos dois materiais forma uma barreira de potencial na interface entre o GaAs e o AlGaAs (Figura 8 (b)). 


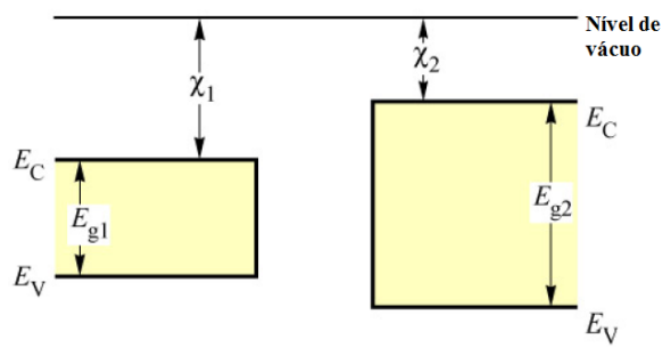

(a) Semicondutores separados

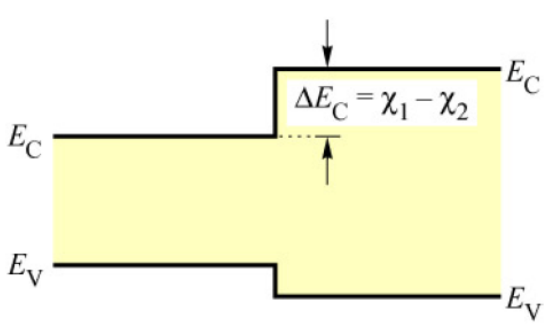

Figura 8: Formação de uma heteroestrutura. (a) Semicondutores separados, com gaps diferentes, $E_{g 1}$ e $E_{g 2}$. (b) Estrutura das bandas dos semicondutores unidos $\left(\chi_{1}\right.$ e $\chi_{2}$ correspondem à afinidade eletrônica dos semicondutores 1 e 2 respectivamente).

A barreira de potencial na interface de uma heteroestrutura é dada por um parâmetro conhecido como o band offset entre os materiais. $\mathrm{O}$ band offset é dado a partir da diferença $\Delta E_{g}$ entre os gaps dos dois materiais, e fornece a altura das barreiras $\Delta E_{c}$, na banda de condução, e $\Delta E_{v}$, na banda de valência do sistema. Como exemplo, para a interface AlGaAs/GaAs: [41]

$$
\begin{aligned}
& \Delta E_{c}=0,67 \cdot \Delta E_{g} \\
& \Delta E_{v}=0,33 \cdot \Delta E_{g}
\end{aligned}
$$

Equação 2.4

$\mathrm{O}$ alinhamento entre os gaps dos materiais pode ser descrito segundo o modelo da afinidade eletrônica de Anderson [13]. Nesse modelo, como o próprio nome diz, o alinhamento ocorre em função da afinidade eletrônica $\left(\chi_{\mathrm{i}}\right)$ em cada material em relação ao alinhamento do nível zero do vácuo (Equação 2.5). Esse é um modelo empírico, que depende fundamentalmente de uma boa medida experimental do valor da afinidade eletrônica em cada material. Modelos teóricos que descrevam esse efeito ainda são bastante discutidos, já que boas medidas experimentais desses valores nos semicondutores são difíceis.

$$
X_{1}-\Delta E_{c}-X_{2}=0 \quad \text { Equação } 2.5
$$

A união exata em nível atômico de materiais semicondutores em heteroestruturas só é possível para materiais e ligas que possuem parâmetros de rede muito parecidos, como no caso do GaAs $(a=5,65 \AA)$, AlAs $(a=5,66 \AA)$ e a liga ternária $\mathrm{Al}_{\mathrm{x}} \mathrm{Ga}_{1-\mathrm{x}} \mathrm{As}$. Para semicondutores com diferentes parâmetros de rede, como GaAs e InAs $(a=6,06 \AA)$, a formação de uma heteroestrutura é dificultada pelo surgimento de uma tensão elástica na estrutura. 


\subsubsection{Poços quânticos e QWIPs}

Por meio da utilização de técnicas sofisticadas de epitaxia de materiais, podemos intercalar finas camadas de um material semicondutor de gap menor entre camadas espessas de um material de gap maior, levando assim a heteroestruturas. Quando a espessura das camadas de material de menor gap torna-se suficientemente pequena (da ordem do comprimento de onda de de Broglie dos portadores de carga), suas bandas passam a apresentar níveis discretos de energia, correspondendo a estados confinados, ao invés de um contínuo de energias. Esse confinamento quântico unidimensional dá origem a estruturas chamadas poços quânticos. Na Figura 9 está representado um exemplo do que acontece no caso de poços quânticos de AlGaAs/GaAs, mostrando estados confinados e seus níveis de energia na banda de condução $\left(E_{c 1}\right.$ e $\left.E_{c 2}\right)$ e na banda de valência $\left(E_{v 1}\right.$ e $\left.E_{v 2}\right)$.

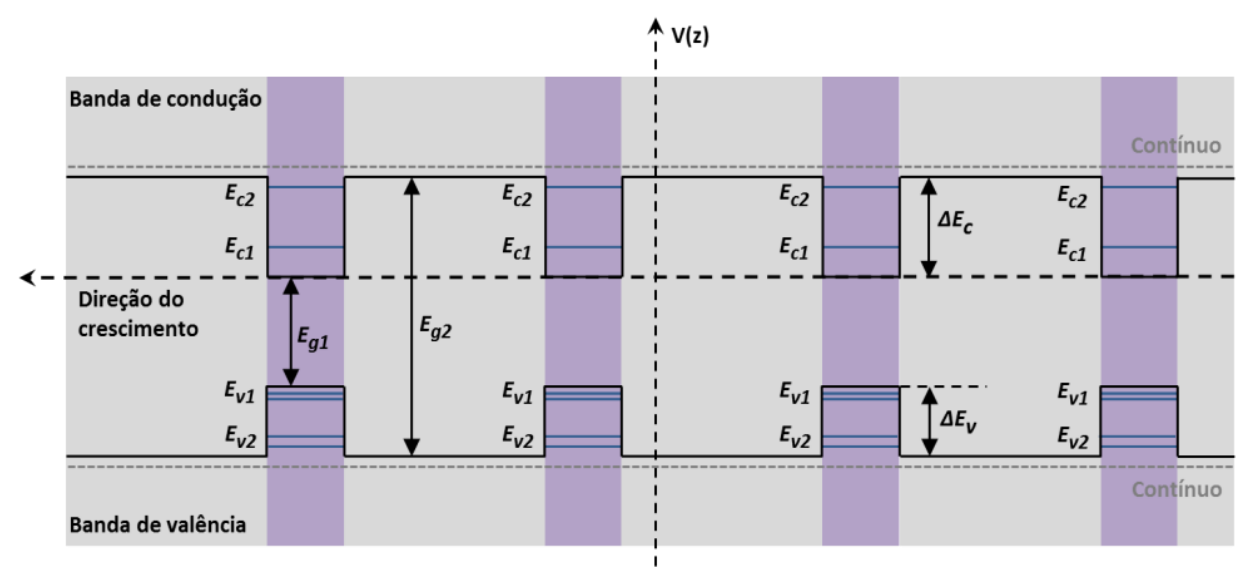

Figura 9: Efeito do confinamento em poços quânticos isolados. $E_{c 1}$ e $E_{c 2}$ são os níveis de energia discretos na banda de condução, e $E_{v 1}$ e $E_{v 2}$ são os niveis de energia discretos na banda de valência (na banda de valência os níveis são degenerados).

O confinamento dos portadores no poço ocorre na direção do crescimento (as camadas de materiais são extremamente finas na direção do crescimento), enquanto que os elétrons permanecem livres ao longo do plano paralelo ao poço. Assim, para um certo estado "n", a energia desse estado possui uma componente $E_{n}$, proveniente do confinamento na direção de crescimento $\mathbf{z}$, e uma componente que corresponde à energia de uma partícula livre em x e y (Equação 2.1). Portanto, de um modo geral, podemos escrever a energia de um estado do poço quântico como sendo dada pela equação 2.6.

$$
E\left(n, K_{x}, K_{y}\right)=E_{n}+\frac{\hbar^{2}}{2 \cdot m^{*}} \cdot\left(K_{x}^{2}+K_{y}^{2}\right)
$$

Equação 2.6

Os QWIPs são classificados em três tipos principais, dependendo do tipo de transição envolvida na absorção dos fótons. Quando a transição ocorre a partir de um nível discreto de energia em uma banda para outro nível discreto em outra banda, trata-se de uma transição 
interbanda (típica de fotodetectores intrínsecos). Se a transição ocorre entre dois níveis de uma mesma banda, chamamos essa transição de intrabanda. No caso da transição ocorrer de um estado confinado para o contínuo, fora da barreira de potencial, chamamos essa transição de "ligado para contínuo" (bound to continuum). Estas duas últimas transições são típicas de QWIPs e QDIPs. As transições do tipo interbanda, em geral, estão localizadas no infravermelho próximo, dependendo do valor do "gap". As transições do tipo intrabanda possuem um interesse especial, pois dão origem a transições na região do infravermelho médio. Nessa região estão localizadas duas importantes janelas atmosféricas (3-5 $-5 \mathrm{~m}$ e $8-12 \mu \mathrm{m})$, assim chamadas por serem regiões de baixa absorção de radiação infravermelha pela atmosfera terrestre, que permitem a observação remota de objetos. A Figura 10 ilustra o espectro de absorção da atmosfera terrestre no nível do mar. Nessa região também estão localizadas as bandas de absorção de vários gases de interesse para as pesquisas ambientais (poluição, efeito estufa), como $\mathrm{CO}_{2}, \mathrm{CH}_{4}, \mathrm{O}_{2}, \mathrm{O}_{3}$, e os óxidos nitrosos $\left(\mathrm{NO}_{\mathrm{X}}\right)$.

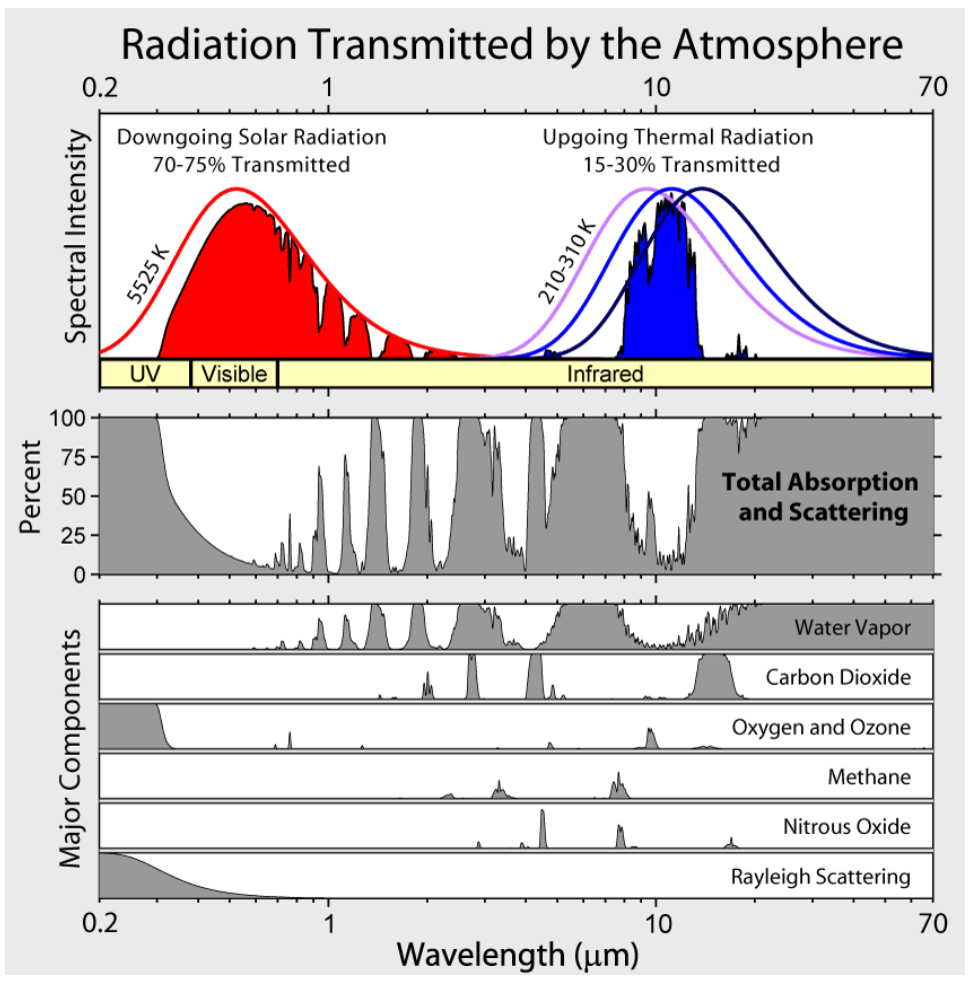

Figura 10: Espectro de transmissão e absorção da atmosfera terrestre.

Nos QWIPs com transição intrabanda a absorção dos fótons incidentes ocorre por meio da transição de elétrons entre estados confinados do poço quântico (ou entre um estado confinado e o contínuo). Nesse tipo de transição os poços devem ser dopados, de modo a produzir uma densidade de portadores de carga capaz de popular o estado fundamental (e eventualmente alguns estados superiores) dos poços. Isso permite que o elétron proveniente de uma impureza popule um nível de energia inferior e seja promovido para um nível de energia superior, por meio da absorção de um fóton. 


\subsection{Detecção de radiação infravermelha}

\subsubsection{Espectro de corpo negro e emissividade de um objeto}

Todo corpo, a qualquer temperatura maior que o zero absoluto, emite um espectro característico de radiação eletromagnética. Esse espectro depende basicamente da temperatura do corpo e da emissividade da sua superfície. A emissividade é um parâmetro (que varia entre 0 e 1) que leva em conta os aspectos gerais da superfície que influenciam suas características emissivas (como a rugosidade). Para todo corpo em equilíbrio térmico com o ambiente, a radiação emitida pelo corpo é igual à radiação absorvida do ambiente: esse princípio leva à relação $\mathrm{A}=\varepsilon$, sendo $\mathrm{A}$ a absortividade e $\varepsilon$ a emissividade. A radiação total do ambiente que incide na superfície do corpo é igual à radiação absorvida pelo corpo mais a radiação refletida de volta para o ambiente $(1=\mathrm{A}+$ $\mathrm{R}$, onde $\mathrm{A}$ é a absortividade e $\mathrm{R}$ a refletividade). Um corpo que é um emissor ideal de radiação térmica $(\varepsilon=1)$ também será um absorvedor ideal de radiação $(A=1)$. Um corpo com essas características é chamado de corpo negro. Um corpo negro possui emissividade igual a um, e emite um espectro de radiação térmica ideal, dado pela lei de Planck (Equação 2.7). Onde $L(\lambda, T)$ é a emitância espectral radiante, $\lambda$ é o comprimento de onda em $\mathrm{cm}$ e $T$ é a temperatura absoluta. A Figura 11 exibe a curva característica de emissão de um corpo negro. Um corpo negro pode ser aproximado por uma abertura em uma cavidade em equilíbrio térmico, para deixar sair à radiação.

$$
L(\lambda, T)=\frac{2 \cdot c}{\lambda^{4} \cdot\left(e^{\frac{h \cdot c}{\lambda \cdot k_{B} \cdot T}-1}\right)}\left(\frac{\text { fótons }}{s . c m^{2} \cdot s r \cdot \lambda}\right) \quad \text { Equação } 2.7
$$

A radiação térmica exibe um comportamento tal que o comprimento de onda do pico do máximo de radiação emitida se desloca para valores menores do comprimento de onda à medida que a temperatura do corpo negro aumenta. Esse comportamento é dado pela lei do deslocamento de Wien (Equação 2.8).

$$
\lambda_{\max } \cdot T=2,898 \cdot 10^{-3} \mathrm{~m} \cdot \mathrm{K}
$$

Equação 2.8

sendo $\lambda_{\max } \mathrm{o}$ comprimento de onde para o qual a intensidade da radiação é máxima. 


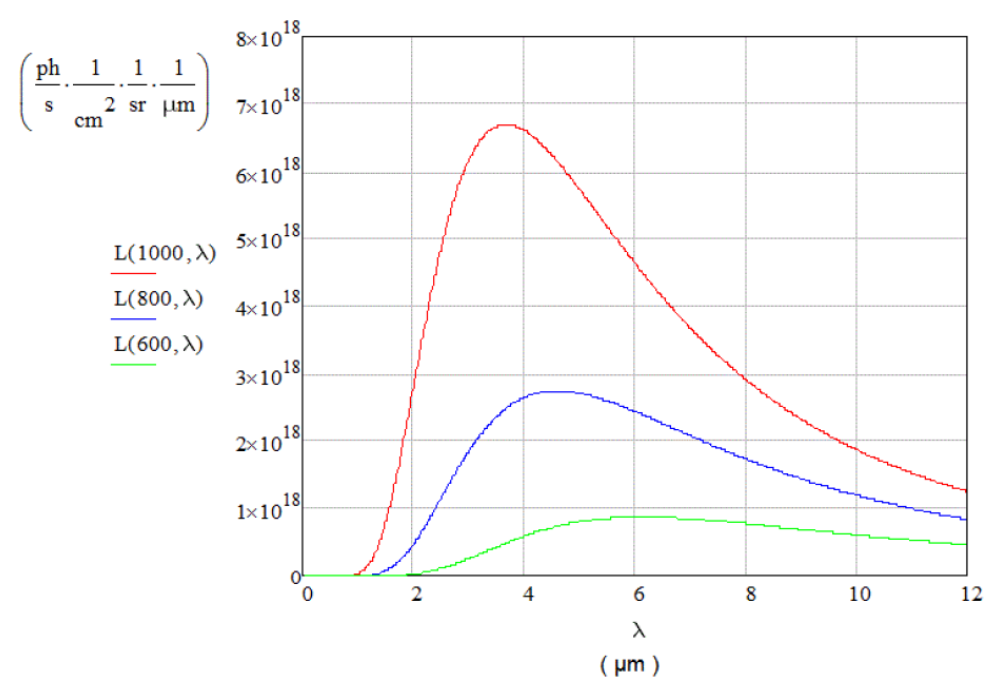

Figura 11: Lei de Planck para a radiação de corpo negro ( $T=1000,800$, $600 \mathrm{~K})$. O deslocamento do máximo das curvas segue a lei de Wien.

$\mathrm{Na}$ maior parte dos casos, um corpo não ideal qualquer exibe um espectro semelhante ao de um corpo negro, porém com a intensidade total reduzida por um fator constante, dado pelo valor da emissividade do corpo $(\varepsilon<1)$. Um objeto que exibe essa propriedade é chamado de corpo cinza (Equação 2.9).

$$
\varepsilon \cdot L(\lambda, T)=\varepsilon \cdot \frac{2 . c}{\lambda^{4} \cdot\left(e^{\frac{h \cdot c}{\lambda \cdot k_{B} \cdot T}}-1\right)} \quad \text { Equação } 2.9
$$

\subsubsection{Diferença de temperatura, emissividade e absorção em banda específica}

Podemos definir o modo de operação de um fotodetector mediante três princípios básicos de funcionamento. Um fotodetector pode ser sensível ao contraste de temperatura (Figura 12 (a)) ou ao contraste de emissividade (Figura 12 (b)), seguindo a lei de Planck. Um fotodetector também pode exibir uma sensibilidade espectral em um determinado intervalo de comprimentos de onda, quando, por exemplo, a radiação proveniente do ambiente é absorvida nesse intervalo (por um gás de efeito estufa, por exemplo, Figura 12 (c)). 


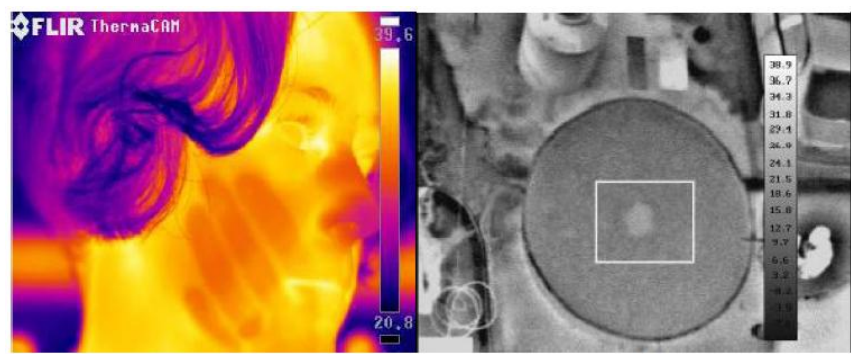

(a) (b)

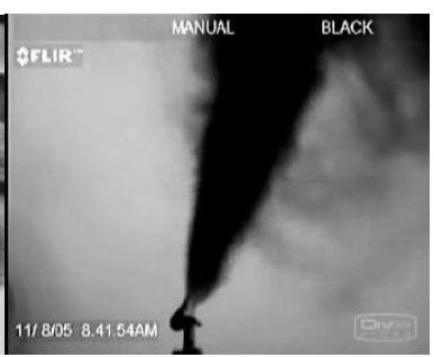

(c)

Figura 12: Métodos de deteç̧ão no infravermelho: (a) Diferença de temperatura de partes do corpo humano, com cabelos e nariz mais frios; (b) Tanque de água com mancha de óleo, na mesma temperatura, mas com emissividades diferentes; (c) Gás (invisivel ao olho humano) saindo de uma chaminé e detectado pela absorção da radiação infravermelha do ambiente.

\subsection{Parâmetros de fotodetectores}

\subsubsection{Coeficiente de absorção $(\alpha)$}

Quando os fótons que incidem sobre um material possuem energia suficiente para excitar os elétrons desse material, esses fótons são absorvidos. Na medida em que a radiação se propaga ao longo de uma direção no interior de um material, o fluxo de fótons decai exponencialmente $(\phi(x)$ $=\phi_{0} \cdot e^{-\alpha x}$ ) devido à sua absorção ao longo do caminho dentro da estrutura (Figura 13). A intensidade da absorção da radiação no material ou numa heteroestrutura depende do coeficiente de absorção $\boldsymbol{\alpha}$. Quanto maior o coeficiente de absorção, maior será a quantidade de elétrons fotogerados para um dado volume de material.

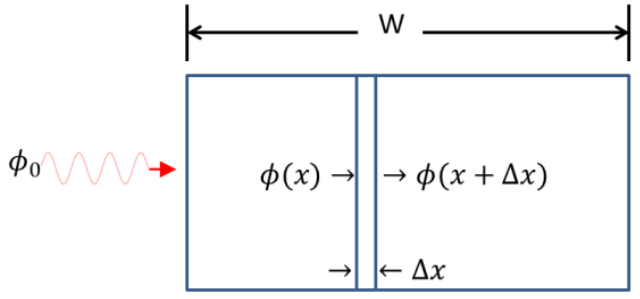

(a)

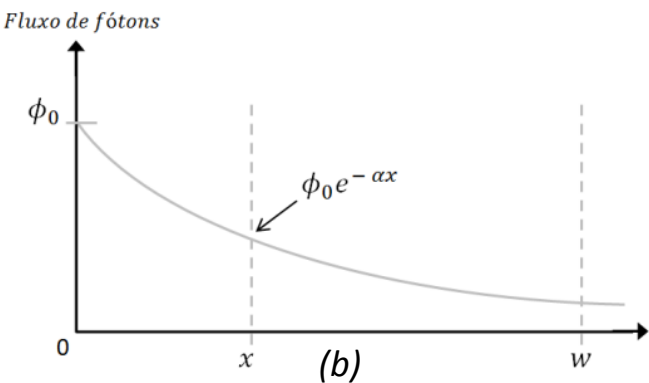

(b)

Figura 13: (a) Esquema da absorção de radiação dentro de um material. (b) Variação do fluxo de fótons dentro do material; $\phi_{0}$ e $\phi(x)$ são o fluxo de fótons fora e dentro do material (após penetrar uma distância $x$ ), respectivamente. 
Fundamentalmente, a eficiência da absorção depende das funções de onda descrevendo os 2 estados, inicial e final, envolvidos na transição. $O$ valor do coeficiente de absorção também depende diretamente da densidade de elétrons disponíveis e que podem sofrer uma transição para um nível de energia superior ao absorverem um fóton. A Figura 14 mostra o valor do coeficiente de absorção do GaAs a 300K, em função do comprimento de onda da radiação incidente, para dois valores de dopagem [14].

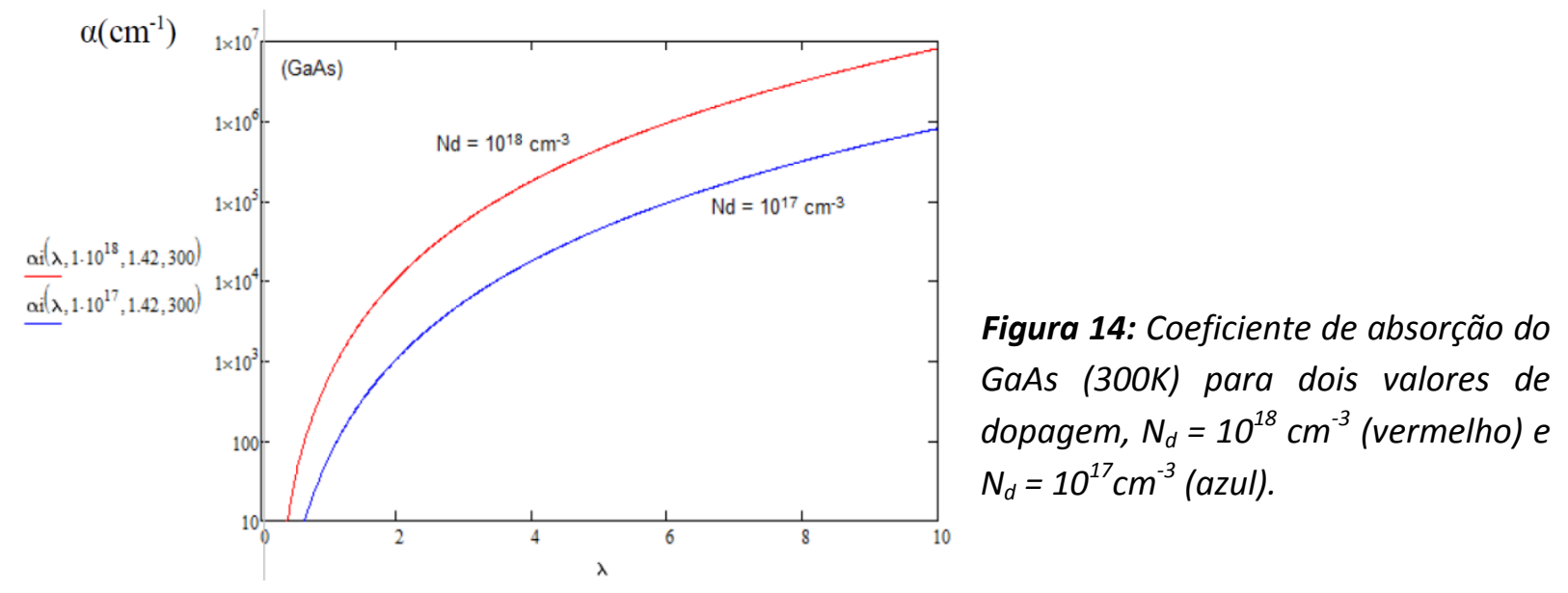

\subsubsection{Fotocorrente}

A corrente total medida em fotodetectores é formada pela corrente de escuro e pela fotocorrente. A corrente de escuro é devida aos portadores de carga gerados termicamente e à injeção de portadores a partir dos contatos dopados, pela aplicação de uma voltagem de polarização (bias). A fotocorrente é gerada a partir dos portadores de carga que são promovidos do estado inicial (geralmente o estado fundamental) pela absorção de fótons da radiação infravermelha incidente. A absorção dos fótons da radiação de interesse promove o aumento da concentração de portadores de carga livres (que formam a fotocorrente), o que provoca um aumento na condutividade elétrica do meio. A Figura 15 ilustra a configuração de amostras de QWIPs processadas, com a formação de estruturas de "mesas" sobre o substrato que correspondem aos fotodetectores. Quando uma voltagem de polarização é aplicada entre os dois contatos elétricos (quadrados amarelos) envolvendo a região ativa do fotodetector, os elétrons fotoexcitados para a banda de condução (fotoelétrons) percorrem a estrutura entre os contatos, dando origem à uma fotocorrente, que é detectada juntamente com a corrente de escuro. 


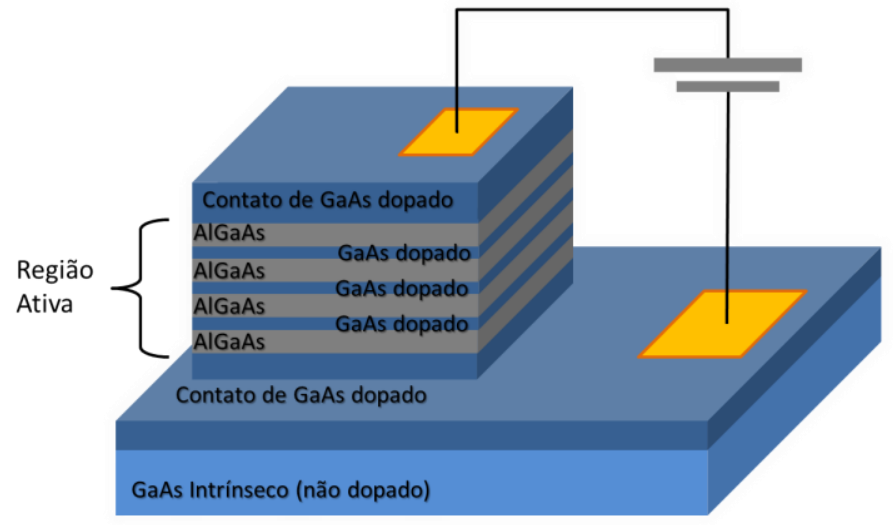

Figura 15: Ilustração do esquema da estrutura de um QWIP processado, com uma mesa (contendo a região ativa) e os dois contatos elétricos.

A Figura 16 ilustra os mecanismos da fotocorrente gerada em um QWIP ao aplicarmos uma voltagem de polarização no dispositivo. Os elétrons fotogerados podem ser promovidos diretamente para um estado fora do poço (no contínuo) (Figura $16(a)$ ) ou podem ser excitados para um estado ligado (próximo ao contínuo) de onde podem acessar o contínuo por excitação térmica, ou podem tunelar através da barreira e contribuir para a fotocorrente (Figura $16(b)$ ). Quando a distância entre os poços é suficientemente pequena, os estados ligados dão origem a uma "minibanda de condução" que funciona como um canal de condução para a fotocorrente.

(a)

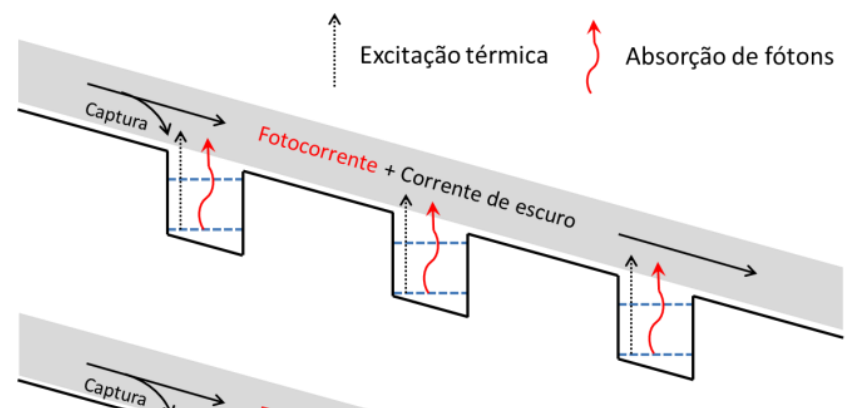

(b)

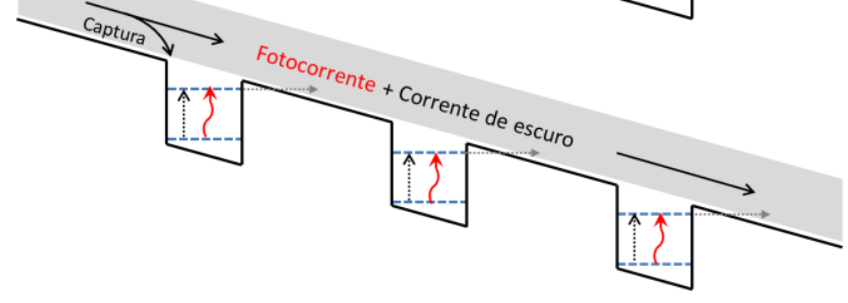

Figura 16: Mecanismos de fotocorrente em QWIPs. (a) Fotocorrente gerada pelos elétrons promovidos diretamente para um estado no contínuo. (b) Fotocorrente gerada pelos elétrons promovidos para um nível excitado do poço de onde podem tunelar ou acessar o contínuo por excitação térmica.

A equação 2.10 apresenta a equação da fotocorrente, onde $e$ é a carga elétrica fundamental, $\mu(T, N)$ é a mobilidade dos portadores que é uma função da temperatura $T$ e da dopagem $N, n_{F}$ representa a densidade de portadores gerados pela incidência da radiação sobre a amostra, $F$ é o 
campo elétrico, $A$ é a área do dispositivo e $L$ é o caminho óptico percorrido na região ativa do fotodetector. $\mathrm{O}$ valor de $n_{F}$ depende da potencia incidente $\Phi_{0}$, da eficiência quântica $\eta$ e do tempo de vida $\tau$ dos portadores gerados. A eficiência quântica é a razão entre o número de portadores efetivamente gerados e o número de fótons incidentes. O tempo de vida dos portadores representa o tempo que os portadores fotogerados permanecem disponíveis para a fotocorrente antes que sejam recapturados.

$$
I_{F}(F)=e \cdot \mu(T, N) \cdot n_{F} \cdot F \cdot A
$$

onde,

$$
n_{F}=\eta \cdot\left(\frac{\Phi_{0}}{\hbar \cdot \omega}\right) \cdot\left(\frac{1-\exp (-\alpha \cdot L)}{A \cdot L}\right) \cdot \tau
$$

\subsubsection{Corrente no escuro}

A corrente no escuro $\left(\mathrm{I}_{\mathrm{d}}\right)$, como o nome diz, corresponde à corrente gerada a partir da aplicação de uma voltagem de polarização, na ausência de radiação (Equação 2.11). Nos semicondutores, essa corrente se deve principalmente à densidade de portadores $n^{*}(T, F)$ gerados termicamente segundo a lei de distribuição de Fermi-Dirac. Quanto maior a temperatura, maior será a condutividade elétrica do material e a corrente de escuro. A voltagem aplicada produz um campo elétrico que altera diretamente a velocidade de deriva dos portadores, aumentando assim a corrente de escuro.

$$
I_{d}=n^{*}(T, F) \cdot e \cdot \mu(T, N) \cdot F \cdot A \quad \text { Equação } 2.11
$$

No caso da voltagem de polarização ser suficientemente grande, também pode ocorrer a geração de portadores por ionização por impacto (Impact Ionization), ou por tunelamento através do gap do material.

\subsubsection{Ruído}

O ruído elétrico total presente nestes dispositivos provém de várias fontes, externas e internas, e corresponde por definição a qualquer variação de um parâmetro em torno do seu valor médio. O ruído total é dado pela raiz quadrada da soma dos quadrados de todas as fontes de ruído [15], e é proporcional à raiz quadrada da largura da banda de frequências ( $\Delta f$ ) analisada na medida. Algumas fontes de ruído não podem ser evitadas, como no caso do ruído intrínseco do detector e da variação da taxa de incidência dos fótons. As fontes de ruído intrínseco podem vir da agitação térmica dos átomos do material ou do movimento aleatório dos elétrons. Existem várias fontes de ruído externo, provenientes, por exemplo, da rede elétrica, dos cabos, da radiação ambiente e dos próprios equipamentos utilizados nas medidas. A maioria das fontes de ruído externo podem ser 
eliminadas, ou consideravelmente reduzidas, por meio de cuidados específicos na montagem experimental e pelo rastreamento das fontes conhecidas de ruído nos equipamentos utilizados. $\mathrm{O}$ ruído é inevitável em qualquer sistema e deve ser mantido o mais baixo possível.

Dentre as várias fontes intrínsecas de ruído em detectores, o ruído 1/f, o ruído Johnson, o ruído Shot e o ruído de geração-recombinação $(G R)$ dominam em fotodetectores infravermelhos. O ruído da corrente é definido como sendo o valor rms (root mean square) da variação da corrente em relação ao seu valor médio.

O ruído 1/f é sempre presente em qualquer dispositivo semicondutor. Seu valor é inversamente proporcional à frequência. A origem do ruído 1/f ainda é muito discutida, mas recentemente foi apresentada uma possível explicação [16] de que sua origem pudesse estar relacionada com a interação aleatória entre os portadores de carga que circundam as impurezas em semicondutores dopados. Basta se afastar das baixas frequências para que ele se torne desprezível em relação às outras fontes de ruído.

O ruído Johnson (Térmico ou Nyquist) é gerado em todos os elementos resistivos, e está ligado à agitação térmica dos portadores de carga no material devido ao aquecimento Joule $\left(R I^{2}\right)$. O ruído Johnson $i_{J n}$ introduzido na corrente é dado por meio da relação:

$$
i_{J n}^{2}=\frac{4 \cdot k_{B} \cdot T}{R} \cdot \Delta f \quad \text { Equação } 2.12
$$

O ruído Shot vem da natureza discreta da carga elétrica e da flutuação do número de fótons que chegam na superfície do detector [15]. O ruído Shot $i_{S n}$ é dado por:

$$
i_{S n}^{2}=2 . e . I . \Delta f \quad \text { Equação } 2.13
$$

onde I é a corrente total no dispositivo e " $e$ " a carga do elétron.

O ruído de geração-recombinação $(G R)$ introduz o efeito da variação aleatória da densidade de portadores em detectores fotocondutivos como os QWIPs [15]. O ruído GR depende de dois mecanismos independentes: da taxa de geração de portadores e da taxa de recombinação (ou seja, do tempo de vida médio deles). Os portadores são gerados aleatoriamente e possuem um tempo de vida que varia aleatoriamente em torno do valor médio. A equação 2.14, que dá o valor do ruído $G R$, é bastante parecida com a equação do ruído Shot, porém introduz o ganho fotocondutivo G e o fator 4 , ao invés do fator 2 , de modo a contabilizar as duas origens diferentes do ruído,

$$
\begin{aligned}
\boldsymbol{i}_{G R \boldsymbol{n}}^{2} & =4 \cdot \boldsymbol{e} \cdot \boldsymbol{I} \cdot \boldsymbol{G} \cdot \Delta \boldsymbol{f} \quad \text { Equação } 2.14 \\
\boldsymbol{G} & \equiv \frac{\boldsymbol{\mu}(\boldsymbol{T}, \boldsymbol{N}) \cdot \boldsymbol{\tau}_{c} \cdot \boldsymbol{F}}{\boldsymbol{L}}=\frac{\tau_{c}}{\tau_{t}}
\end{aligned}
$$


sendo $\mu$ a mobilidade, $\tau_{c}$ o tempo de vida de um portador excitado, $F$ o campo elétrico, $L$ o comprimento da região ativa do fotodetector, e $\tau_{t}$ o tempo de transito que um portador de carga demora para passar pela região ativa.

A geração de portadores pode ser de origem térmica ou devida à absorção de fótons incidentes, de modo que o ruído $G R$ pode ser dividido em uma parte dependente da fotocorrente, que inclui um fator de Bose [15], e uma parte dependente da corrente de escuro, que depende fortemente da temperatura [17]. O ruído $G R$ intrínseco provocado pela geração térmica de portadores é geralmente o fator limitante na operação de fotodetectores infravermelhos, e é especialmente crítico no caso dos QWIPs. De fato, em QWIPs, o ruído GR (térmico) é modificado por um termo que deve levar em conta a probabilidade de recaptura dos portadores pelos poços quânticos. Esse ruído é o fator limitante da operação dos QWIPs, e é conhecido como ruído da corrente no escuro $I_{d n}$ (dark current noise). O valor desse ruído é uma função da corrente de escuro $I_{d}$, e depende intrinsecamente da probabilidade de recaptura pelos poços, $p_{c}$, e do tempo $\tau_{t}$ de trânsito através de um período do QWIP (Equação 2.15) [17][18][19][20].

$$
\begin{gathered}
I_{d n}=\sqrt{4 \cdot e \cdot I_{d}(F) \cdot G \cdot \Delta f \cdot\left(1-\frac{p_{c}}{2}\right)} \quad \text { Equação } 2.15 \\
P_{c}=\frac{\tau_{t}}{\tau_{t}+\tau_{c}}
\end{gathered}
$$

Esse valor deve ser minimizado ao projetarmos um QWIP, de modo a obtermos boas condições para a operação do dispositivo. A abordagem mais eficiente para minimizarmos o ruído intrínseco total ao projetarmos um QWIP é atuarmos na diminuição da corrente de escuro.

\subsubsection{Responsividade}

A função básica de um fotodetector é a conversão de uma radiação incidente em um sinal elétrico (corrente ou voltagem). A responsividade $R$ é definida como a razão entre o sinal elétrico gerado e a potência da radiação incidindo sobre o fotodetector (Equação 2.16). Em geral, a responsividade é dada em A/W mas, dependendo da aplicação, pode ser dada em V/W ou em função do número de fótons por segundo que chegam sobre o detector.

$$
R=\frac{\text { Fotocorrente }}{\text { Potencia IR }} \quad\left(\frac{A}{W}\right)
$$




\subsubsection{Detectividade específica}

A responsividade é um parâmetro que não é afetado pelo ruído do fotodetector e, dessa forma, não nos permite avaliar a qualidade real do fotodetetor em operação. A relação sinal/ruído também não nos fornece um fator de qualidade para avaliarmos o desempenho intrínseco dos fotodetectores, pois podemos melhorar essa relação apenas aumentando a potencia da fonte. Um parâmetro que leva em conta essas características, e nos permite avaliar a qualidade do fotodetector sem depender de fatores externos e geométricos, é a detectividade específica (dada por meio da equação 2.17). Nesse parâmetro o sinal é normalizado em relação ao ruído $\left(I_{n d}\right)$ e a área da região ativa $\left(A_{d}\right)$. A detectividade específica nos fornece um modo quantitativo de avaliarmos a qualidade dos nossos fotodetectores.

$$
D_{b b}^{*}=\frac{R \cdot \sqrt{A_{d}}}{I_{n d} / \sqrt{\Delta f}}\left(\frac{c m \cdot H z^{1 / 2}}{W}\right) \quad \text { Equação } 2.17 \text { * }
$$

\footnotetext{
* O subscrito bb (black body) no símbolo da detectividade refere-se à caracterização utilizando-se um corpo negro como fonte de radiação).
}

\subsubsection{Temperatura BLIP $\left(T_{B L I P}\right)$}

Os parâmetros mais importantes para avaliar o desempenho de fotodetectores infravermelhos são a detectividade específica e a temperatura BLIP (Background Limited Performance). A condição BLIP ocorre quando a corrente de escuro no fotodetector é igual à fotocorrente gerada pela radiação de fundo (geralmente uma cena homogênea a 300K). Para operar em condição ótima, um fotodetector deve sempre operar a uma temperatura abaixo da temperatura BLIP. A intensidade da radiação de fundo (Background) que chega ao detector depende obviamente do ângulo sólido (field of view) com que o detector "enxerga" o ambiente. $\mathrm{Na}$

Figura 17 estão apresentados os espectros de potência da radiação (proveniente do ambiente a $300 \mathrm{~K})$ que chega sobre a superfície de um detector para três ângulos de abertura diferentes (ângulos de visada): $120^{\circ}, 90^{\circ}$ e $60^{\circ}$.

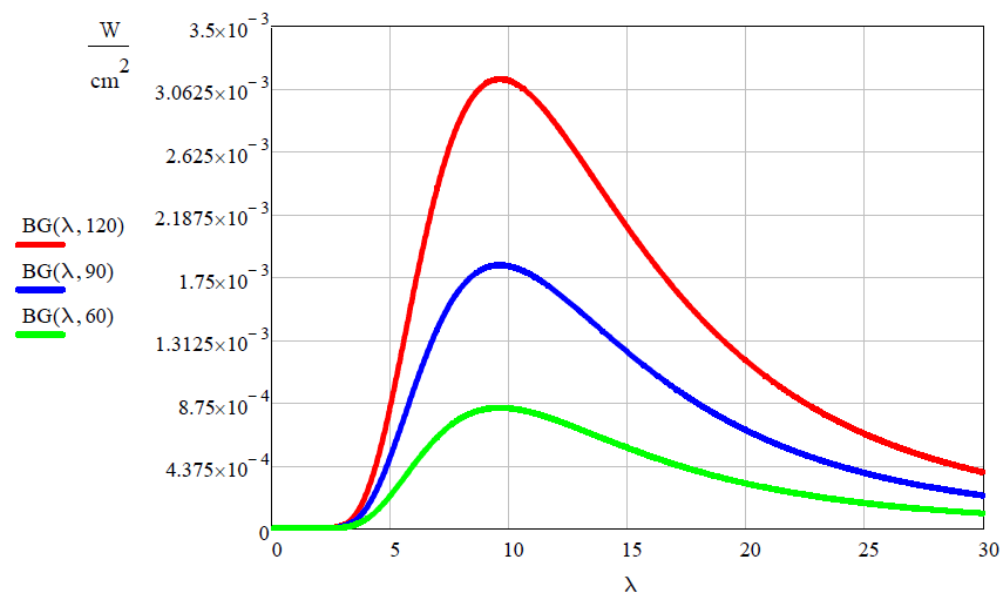

Figura 17: Potência da radiação de fundo a 300K para vários ângulos de abertura do detector. 


\section{Capítulo 3}

\section{Física e modelagem dos QWIPs}

Neste capítulo, são discutidos os aspectos básicos da física dos QWIPs e apresentadas as ferramentas teóricas desenvolvidas neste trabalho de doutorado. Foram implementados cálculos e modelos que permitiram projetar e prever o comportamento de certas estruturas, de modo a dominarmos o projeto de QWIPs para uma ampla gama de aplicações.

Começamos pela implementação de modelos envolvendo poços quânticos de GaAs cercados por barreiras de AlGaAs. O GaAs e o AlGaAs são materiais disponíveis no sistema de crescimento epitaxial presente em nosso laboratório, e são materiais que possuem parâmetros de rede tão parecidos que a presença da baixíssima tensão na rede cristalina é geralmente desprezada, o que simplifica consideravelmente a implementação dos modelos e melhora a qualidade das estruturas crescidas.

O modelo numérico implementado nos possibilita calcular o comprimento de onda de absorção e as funções de onda para um poço de potencial arbitrário. Ele permite ao usuário entrar uma função matemática qualquer, que representa a curva do potencial do poço desejado, e realiza automaticamente a discretização do potencial a partir dos parâmetros escolhidos pelo usuário. Esse método pode ser aplicado ao cálculo autoconsistente, que envolve estruturas dopadas, e também ao cálculo de novas estruturas não disponíveis na literatura. A partir dos valores das energias de confinamento e das funções de onda obtidas pelo programa, foi possível realizar a modelagem de alguns parâmetros de operação dos QWIPs, tais como o coeficiente de absorção teórico, a corrente no escuro e o ruído.

\subsection{Níveis de energia e autofunções de um poço de potencial arbitrário}

Dentre as diversas aplicações dos QWIPs, uma das principais especificações de projeto é a chamada banda de operação, ou seja, a faixa de comprimentos de onda em que o detector será sensível. Essa especificação pode surgir da necessidade da observação através da atmosfera, operando dentro das janelas de transparência atmosférica, ou quando houver a necessidade de operação em uma banda de absorção específica de um determinado gás, por exemplo.

O comprimento de onda da absorção depende basicamente da energia dos estados confinados no interior dos poços quânticos que compõem a estrutura do QWIP. O cálculo dos níveis de 
energia e das funções de onda dos poços quânticos foi feito por meio da implementação numérica do método da matriz de transferência.

\subsubsection{Método da matriz de transferência}

O método da matriz de transferência permite obter as soluções da equação de Schrödinger para um poço de potencial unidimensional com perfil arbitrário. A essência do método consiste em tratar um perfil de potencial unidimensional qualquer como uma sequência de $n$ pequenos intervalos discretos de potencial constante $V_{n}$ [21]. Para cada intervalo $V_{n}$ constante, teremos então uma função de onda dada pela equação 3.1 , com um vetor de onda característico dado pela equação 3.2 .

$$
\begin{array}{ll}
\Psi_{n}=A_{n} e^{i k_{n} z}+B_{n} e^{-i k_{n} z} & \text { Equação } 3.1 \\
k_{n}\left(E_{i}\right)=\sqrt{\frac{2 \cdot m_{n}^{*} \cdot\left(E_{i}-V_{n}\right)}{\hbar^{2}}} & \text { Equação } 3.2
\end{array}
$$

Aplicando-se a condição de continuidade entre duas funções de onda, como condição de contorno na interface entre dois intervalos discretos de potencial $n$ e $n+1$, obtemos uma relação algébrica entre os coeficientes $A_{n}, B_{n}, k_{n}$ e $A_{n+1}, B_{n+1}, k_{n+1}$. Podemos expressar essa relação entre os coeficientes numa forma matricial dada por:

$$
\left[\begin{array}{l}
A_{n+1} \\
B_{n+1}
\end{array}\right]=\left[F_{(n+1)(n)}\right] \cdot\left[\begin{array}{l}
A_{n} \\
B_{n}
\end{array}\right]
$$

onde $\left[F_{(n+1)(n)]}\right.$ é definida como a matriz de transferência, sendo

$$
\left[F_{(n+1) n}\right]=\left[\begin{array}{cc}
\left(1+P_{(n+1) n}\right) e^{i k_{n+1} h_{n+1}} & \left(1-P_{(n+1) n}\right) e^{i k_{n+1} h_{n+1}} \\
\left(1-P_{(n+1) n}\right) e^{-i k_{n+1} h_{n+1}} & \left(1+P_{(n+1) n}\right) e^{-i k_{n+1} h_{n+1}}
\end{array}\right]
$$

onde,

$$
P_{n(n+1)}=\frac{m_{n} k_{n+1}}{m_{n+1} k_{n}}
$$

A relação pode se propagar de um intervalo para o seguinte, sendo $m_{n}$ e $m_{n+1}$ as massas efetivas e $k_{n}$ e $k_{n+1}$ os vetores de onda dados pela equação 3.2. Os índices $n$ e $n+1$ correspondem, respectivamente, a dois intervalos adjacentes de potencial constante. Se iniciarmos a partir do primeiro intervalo e propagarmos essa relação até o último $(N+1)$, obtemos: 


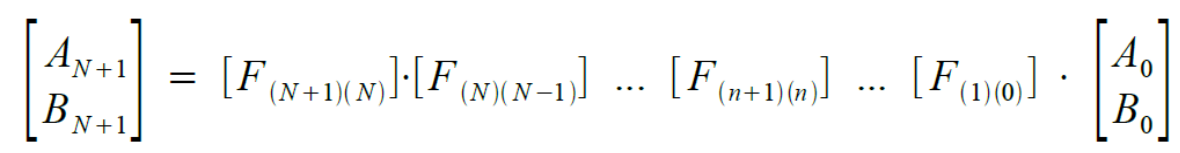

Impondo a condição $(E<V)$ nas extremidades, teremos então na barreira de potencial funções de onda que decaem exponencialmente. Isso implica que os coeficientes $B_{N+1}$ e $A_{0}$ devem ser iguais a zero nas extremidades. Reescrevendo o produto das matrizes $F_{(n+1)(n)}$;

$$
\left[F_{(N+1)(N)}\right] \cdot\left[F_{(N)(N-1)}\right] \ldots\left[F_{(1)(0)}\right]=\left(\begin{array}{ll}
f_{11} & f_{12} \\
f_{21} & f_{22}
\end{array}\right)
$$

teremos assim:

$$
\left[\begin{array}{c}
A_{(N+1)} \\
0
\end{array}\right]=\left(\begin{array}{ll}
f_{11} & f_{12} \\
f_{21} & f_{22}
\end{array}\right) \cdot\left[\begin{array}{c}
0 \\
B_{0}
\end{array}\right]
$$

Tomando a solução não trivial, as autofunções do potencial devem satisfazer a condição $f_{22}=$ 0 . O termo $f_{22}$ é uma função complexa. Na prática, o programa procura pelas raízes do módulo dessa função. As raízes encontradas correspondem às energias $E_{i}$ dos autoestados dentro do poço. Após encontrar as energias, o programa substitui os valores das energias obtidas nas matrizes $\left[F_{(n+1)(n)}\right]$ (que foram calculadas e armazenadas), e obtém as funções de onda $\Psi_{\text {in }}$ em cada intervalo do potencial. A função de onda total $\Psi_{i}$ (do estado i) é então formada pela composição das funções de onda calculadas para cada intervalo da discretização.

O método da matriz de transferência foi implementado utilizando-se o programa Mathematica. Esse método exige uma precisão numérica especialmente alta, e o cálculo computacional torna-se cada vez mais complexo e demorado na medida em que aumentamos o número de intervalos utilizados na discretização do potencial. O tempo computacional aumenta aproximadamente de forma fatorial de acordo com o número de intervalos utilizados na discretização.

\subsubsection{Exemplo de projeto de um poço de potencial de oscilador harmônico}

Uma proposta para o desenvolvimento dos QWIPs foi utilizarmos como ponto de partida um perfil de potencial com soluções conhecidas, como o potencial do oscilador harmônico simples. A partir da especificação do comprimento de onda da absorção, estabelecemos o perfil do potencial parabólico em um poço quântico real de $\mathrm{AlGaAs} / \mathrm{GaAs}$ não infinito. Um comprimento de onda de absorção em $\lambda=9 \mu m$ está dentro de uma das janelas atmosféricas (Figura 10). Esse valor equivale a uma transição de energia de $138 \mathrm{meV}$. Para o poço parabólico infinito, a frequência natural de 
oscilação será $\omega=138 \mathrm{meV} / \hbar$ e as energias serão dadas por $E_{n}=(n+1 / 2) \hbar \omega$. Nesse caso, temos então $E_{0}=69 \mathrm{meV}$ e $E_{1}=207 \mathrm{meV}$.

Em QWIPs, os melhores resultados para a fotocorrente são conseguidos quando o primeiro estado excitado possui um nível de energia ligeiramente mais baixo que a altura da barreira [21]. Por esta razão, estabelecemos que a altura da barreira deveria ser de $220 \mathrm{meV}$, ligeiramente acima do nível $E_{1}(207 \mathrm{meV})$. Por outro lado, se diminuirmos mais a diferença entre a altura da barreira e o nível $E_{l}$, o confinamento no nível $E_{l}$ será menor, o que provocará a diminuição da intensidade da absorção dos fótons incidentes. Para uma barreira de 220meV, devemos ter uma concentração de $\mathrm{Al}$ de aproximadamente $24 \%$ na liga $\mathrm{AlGaAs}$ para uma temperatura de $77 \mathrm{~K}$ (a temperatura influencia o gap do material). O perfil do potencial foi obtido a partir da equação

$$
V(z)=\frac{1}{2} \beta \cdot z^{2}, \text { onde } \beta=m_{0.24}^{*} \cdot\left(\frac{138 m e V}{\hbar}\right)^{2}
$$

com $m^{*}{ }_{0.24}$ sendo a massa efetiva na barreira de AlGaAs (24\% de Al na liga AlGaAs). A Figura 18 ilustra o resultado gerado pelo programa. $O$ cálculo com o programa encontrou os níveis $E_{0}=$ $72,3 \mathrm{meV}$ e $E_{1}=204,3 \mathrm{meV}$, próximos aos níveis do poço parabólico infinito ideal $\left(E_{0}=69 \mathrm{meV}\right.$ e $E_{1}=207 \mathrm{meV}$ ). A absorção, nesse caso, ocorreria em $132 \mathrm{meV}$, o que corresponde a um comprimento de onda de $9,4 \mu \mathrm{m}$. O programa gerou um modelo do potencial com 13 intervalos. $\mathrm{O}$ tempo de computação foi de aproximadamente 15 minutos, realizado em um processador core2duo (1.83GHz) com 2GB de memória RAM (com 11 intervalos o tempo de computação foi de aproximadamente 4,5 minutos e produziu resultados menos precisos).

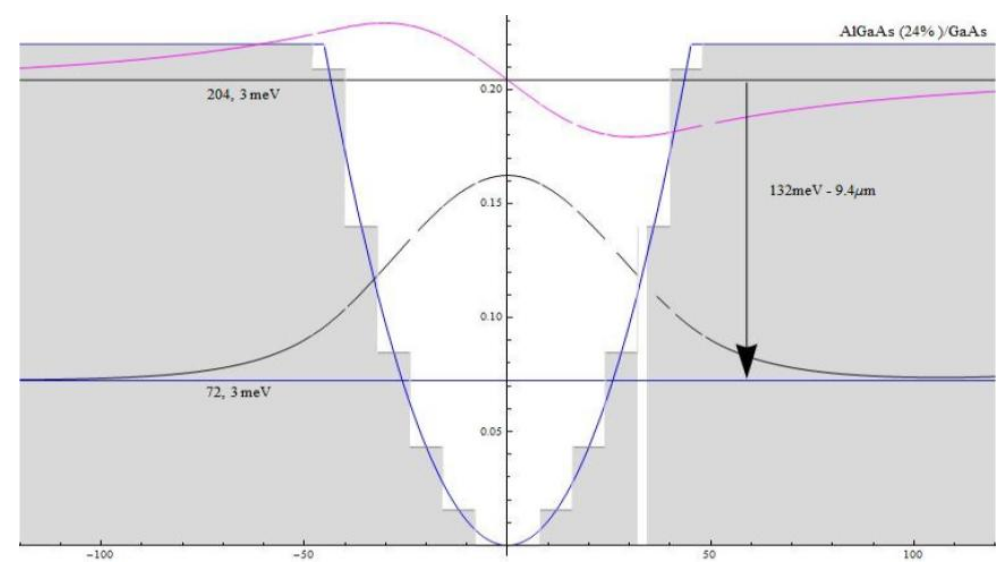

Figura 18: Solução do poço parabólico de AlGaAs/GaAs com barreira de $24 \%$ de Al, utilizando o método da matriz de transferência. 


\subsubsection{Formação de minibandas em um QWIP}

Uma aplicação interessante que foi desenvolvida durante este trabalho foi o estudo do acoplamento entre a função de onda do estado excitado de múltiplos poços quânticos próximos uns dos outros. Este tipo de estrutura costuma formar uma super-rede cujas minibandas permitem o surgimento de canais de condução em ressonância com os estados excitado dos poços. No exemplo da Figura 19, vemos um QWIP formado por poços de GaAs de $50 \AA$ de largura com barreiras de $\mathrm{Al}_{0,2} \mathrm{Ga}_{0,8} \mathrm{As}$ de $50 \AA$ de espessura e barreiras extras de $\mathrm{Al}_{0,4} \mathrm{Ga}_{0,6} \mathrm{As}$ de $50 \AA$. Essa estrutura permite o acoplamento ressonante entre o primeiro estado excitado do poço com uma minibanda da super-rede (na Figura 19, essa transição está ilustrada pelas setas vermelhas). Após a transição para a minibanda o elétron ainda deve tunelar através da barreira a partir da aplicação de uma voltagem de polarização (bias) ao QWIP (processo ilustrado pelas setas pretas pontilhadas, na Figura 19) por meio do acoplamento ressonante com as subbandas, entre as barreiras extras (em destaque na Figura 19 na cor ciano).

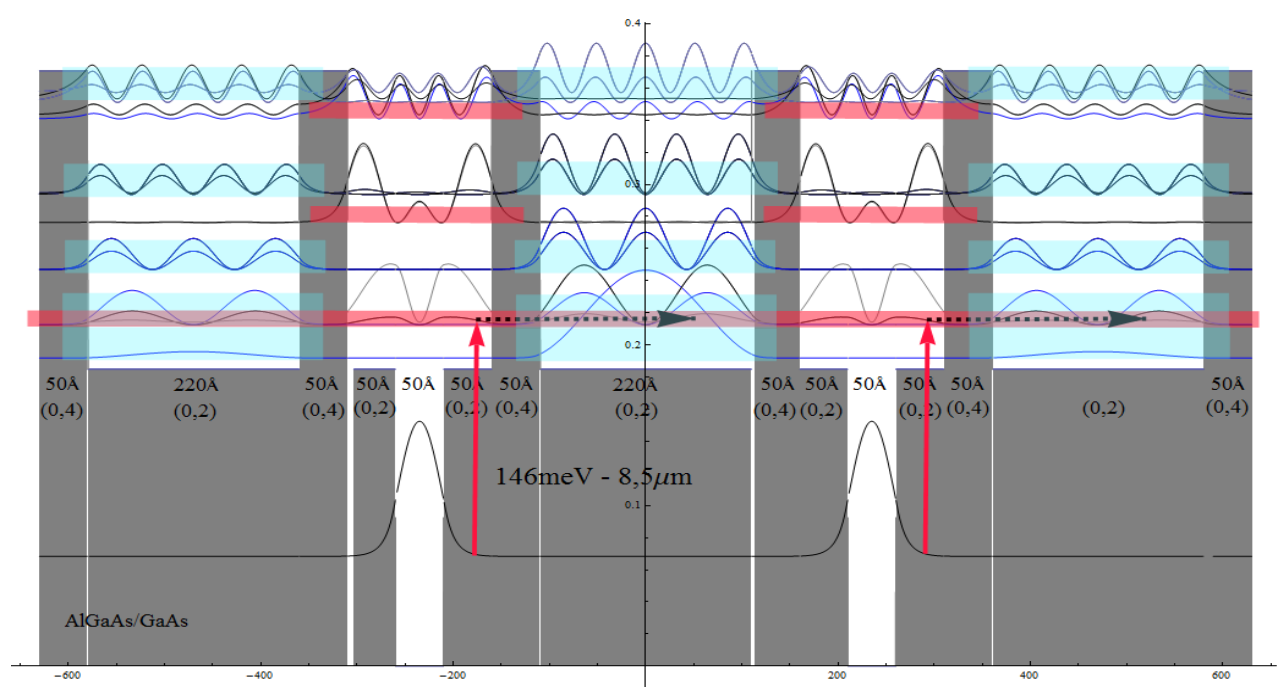

Figura 19: Exemplo de QWIP com barreiras e acoplamento do estado excitado com uma minibanda. Em vermelho estão destacados os níveis excitados dos poços e em ciano os níveis das barreiras externas. Na figura, a transição ocorre para a energia de 146meV, fornecendo uma absorção com pico em 8,5 $\mu$ m.

\subsection{Cálculo autoconsistente}

Em QWIPs do tipo intrabanda, a dopagem dos poços quânticos possibilita principalmente transições na região do infravermelho médio (MIR). A dopagem provoca uma alteração no perfil de potencial do poço e, como consequência, altera a posição dos níveis de energia e a forma das funções de onda. Um cálculo rigoroso deve, portanto, levar em conta esse efeito da dopagem. A distribuição eletrônica dentro do poço é determinada pelas funções de onda que, por sua vez, dependem do perfil do poço, que é afetado pelo potencial gerado por essa distribuição extra de 
cargas. Essa relação de interdependência não permite a solução desse sistema por meio de uma equação. Nesse caso, é preciso realizar um cálculo autoconsistente.

O cálculo autoconsistente é um cálculo por aproximações sucessivas. Esse método utiliza as funções de onda obtidas em uma iteração anterior para calcular a distribuição de cargas na estrutura e, assim, obter um novo perfil de potencial, que então é utilizado para gerar novas funções de onda, e assim sucessivamente. O potencial devido à distribuição de cargas é denominado potencial de Hartree $\left(\mathrm{V}_{\mathrm{H}}\right)$. $\mathrm{O}$ método consiste em realizarmos várias iterações até que ocorra a convergência dos resultados, ou seja, até que o resultado obtido seja aproximadamente igual ao resultado anterior, dentro do critério de convergência estabelecido.

No modelo de cálculo autoconsistente implementado, o nível de dopagem é incrementado em cada iteração. Quando a dopagem atinge o seu valor total, é feita a comparação com o nível de Fermi e com as autofunções encontradas na iteração anterior. Caso os resultados não estejam dentro do limite de convergência, o processo continua. A partir das energias obtidas na iteração anterior e do valor da dopagem $N_{i}$ na iteração corrente, dentro da região dopada $L_{z}$ do poço, o programa calcula a energia de Fermi $E_{f}$ por meio da equação 3.3. As autofunções $\phi_{n}$ obtidas na iteração anterior são utilizadas no cálculo da função de distribuição eletrônica $n(z)$, por meio da equação 3.4. Em seguida, é calculada a distribuição total de cargas $\rho(z)$ (Equação 3.5), onde $N^{+}{ }_{D}(z)$ é a distribuição das impurezas ionizadas.

$$
\begin{array}{cc}
N_{i}=\frac{m_{e}^{*} k_{B} T}{\pi \hbar^{2} L_{z}} \sum_{n} \ln \left(1+e^{\left(E_{f}-E_{n}\right) / k_{B} T}\right) & \text { Equação 3.3 } \\
n(z)=\sum_{n}\left|\phi_{n}\right|^{2} N_{i} L_{z} & \text { Equação 3.4 } \\
\rho(z)=|e|\left[-n(z)+N_{D}^{+}(z)\right] & \text { Equação 3.5 }
\end{array}
$$

Com a função da distribuição das cargas $\rho(z)$, integramos duas vezes (Equação 3.6 e Equação 3.7) para achar o potencial $V_{H}(z)$ resultante da distribuição das cargas, que é o potencial de Hartree. O potencial total resultante $V_{c}(z)$ (Equação 3.8) é dado pela soma do perfil de potencial anterior com o potencial $V_{H}(z)$ calculado. O programa do método da matriz de transferência gera a discretização do potencial $V_{c}(z)$ e realiza o cálculo das novas autofunções para a próxima iteração.

$$
\begin{array}{cc}
E(z)=\frac{1}{\varepsilon} \int_{-L / 2}^{L / 2} \rho\left(z^{\prime}\right) d z^{\prime}+E(-L / 2) & \text { Equação 3.6 } \\
V_{H}(z)=|e| \int_{-L / 2}^{z} E\left(z^{\prime}\right) d z^{\prime}+V_{H}(0) & \text { Equação 3.7 } \\
V_{c}(z)=V_{\text {offset }}(z)+V_{H}(z) & \text { Equação 3.8 }
\end{array}
$$


A Figura 20 ilustra o cálculo do potencial autoconsistente realizado para um poço quadrado de GaAs/AlGaAs $(52 \AA / 300 \AA)$ ) com dopagem do tipo $\mathrm{n}$ de $5 \times 10^{17} \mathrm{~cm}^{-3}$ dentro do poço.

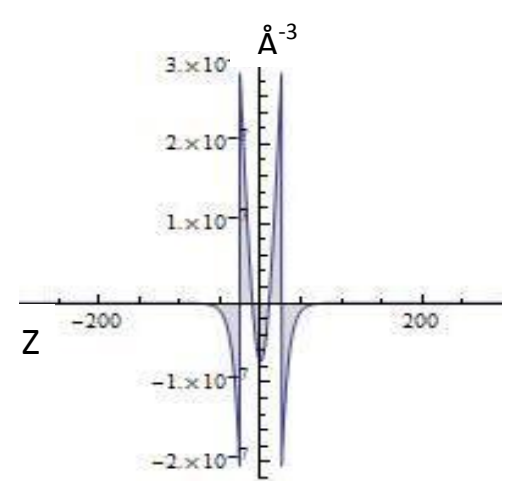

(a)

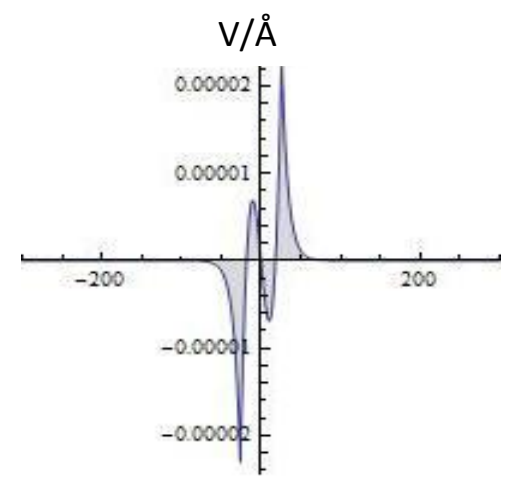

(b)

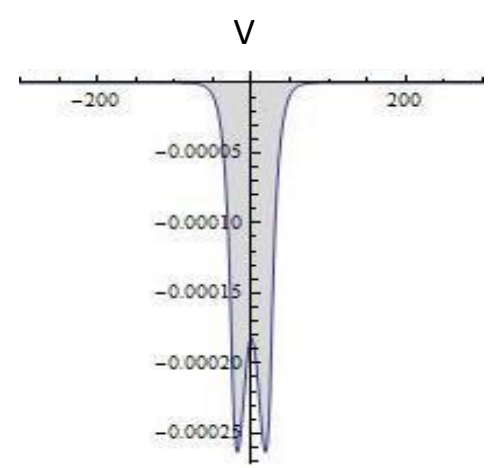

(c)

Figura 20: Cálculo autoconsistente: (a) Distribuição da carga total (elétrons + impurezas ionizadas); (b) Campo elétrico; (c) Potencial devido à distribuição de cargas.

\subsection{Solução para poços com aplicação de voltagem (bias)}

A aplicação de uma voltagem de polarização pode alterar consideravelmente os níveis de energia dos estados dos poços. A solução por meio do método da matriz de transferência utilizando funções de onda plana (como descrito na seção 3.1.1) é possível, porém, nesse caso, para que o cálculo forneça o valor correto, é necessário usar um número elevado de intervalos para discretizar o perfil de potencial. Como a complexidade computacional aumenta em uma razão geométrica com o número de intervalos discretizados, esse fato pode inviabilizar a obtenção da solução do problema. Em primeira aproximação, admitindo que as constantes dielétricas do GaAs e do AlGaAs sejam aproximadamente iguais $(\varepsilon(\mathrm{GaAs}) \sim \mathcal{E}(\mathrm{AlGaAs})=13.1)$, podemos considerar que a aplicação da voltagem no QWIP provoca uma inclinação constante no perfil de potencial dos poços quânticos, causada pelo campo elétrico aplicado ao longo da região ativa (Figura 21). Nesse caso, uma abordagem mais eficiente consiste em aplicar o método da matriz de transferência utilizando funções de Airy, ao invés de funções de onda plana [22][23]. Esse cálculo foi implementado no software Mathematica a partir da adaptação do método descrito na referência [23], que foi inicialmente empregado para uma estrutura de super-rede em que as larguras das barreiras de potencial são muito mais estreitas que as barreiras geralmente utilizadas em QWIPs. No método original (descrito no artigo), os valores das energias dos estados confinados são obtidos pela posição dos máximos do coeficiente de transmissão através das barreiras. No caso dos poços quânticos, onde as barreiras são bem mais largas essa abordagem se mostrou inviável, pois, como a largura das barreiras é consideravelmente maior o valor absoluto da transmissão é muito pequeno (da ordem do erro numérico). 
O método, adaptado para QWIPs, foi implementado para o caso de poços quadrados simples. O poço quântico é dividido em três intervalos de potencial, duas barreiras e o poço, e a esses três intervalos são adicionados mais um intervalo com potencial $V_{c}$ de entrada e um intervalo com potencial igual a zero na saída (Figura 21). Nas regiões de entrada (intervalo 0) e saída (intervalo 4), a solução admite funções de onda plana. No intervalo 0 , para uma energia $E_{n}<V_{c}$, a função de onda é dada por $\varphi_{0}=B_{0} \cdot e^{K_{0} \cdot z}$ (onde $K_{0}$ é um número real). No intervalo 4 , onde $\mathrm{V}=0$, a função de onda pode ser dada por $\varphi_{4}=A_{4} \cdot e^{i \cdot K_{4} \cdot z}$. Na região do poço quântico, nos intervalos 1,2 e 3, a função de onda pode ser escrita utilizando-se as funções de Airy $A_{i}$ e $B_{i}$ em cada intervalo $n$ :

$$
\varphi_{n}=a_{n} \cdot A_{i}\left(\beta_{n} \cdot \eta_{n}+z\right)+b_{n} \cdot B_{i}\left(\beta_{n} \cdot \eta_{n}+z\right)
$$

onde $\beta_{n}=\left(\frac{2 . m_{n}^{*} \cdot F}{\hbar^{2}}\right)^{1 / 3}$, sendo $F$ o campo elétrico e $\eta_{n}=\frac{E_{n}-V_{0}}{E}+z$, sendo $E_{n}$ a energia e $\mathrm{V}_{0} \mathrm{o}$ potencial da barreira para o poço sem aplicação de voltagem. Definidas as novas funções de onda do problema (funções de Airy), aplica-se o método da matriz de transferência (como descrito na seção 3.1.1), o que leva a

$$
\left(\begin{array}{c}
0 \\
B_{0}
\end{array}\right)=\left[\begin{array}{ll}
S_{11} & S_{12} \\
S_{21} & S_{22}
\end{array}\right] \cdot\left(\begin{array}{c}
A_{4} \\
0
\end{array}\right)
$$

Os valores das autoenergias são obtidos quando $S_{11}\left(E_{n}\right)=0$ (Na Figura 22, quando $S_{11}=0$ a figura apresenta valores mínimos, em função da precisão limitada com que o gráfico é gerado). Os valores das autoenergias do problema também podem ser obtidos por meio da função $S_{2 l}\left(E_{n}\right)$, encontrando os valores de $E_{n}$ em que essa função apresenta máximos locais. Porém, a solução do problema numérico que consiste em encontrar as raízes da função $S_{11}\left(E_{n}\right)$ se mostrou mais simples e eficiente. A principal limitação desse método está relacionada com a dificuldade em gerar as funções de onda a partir dos autovalores de energia obtidos. Como, no caso dos poços as barreiras são mais largas, em comparação com uma estrutura de super-rede, a solução se torna instável dentro das barreiras devido ao limite da precisão dos autovalores obtidos.

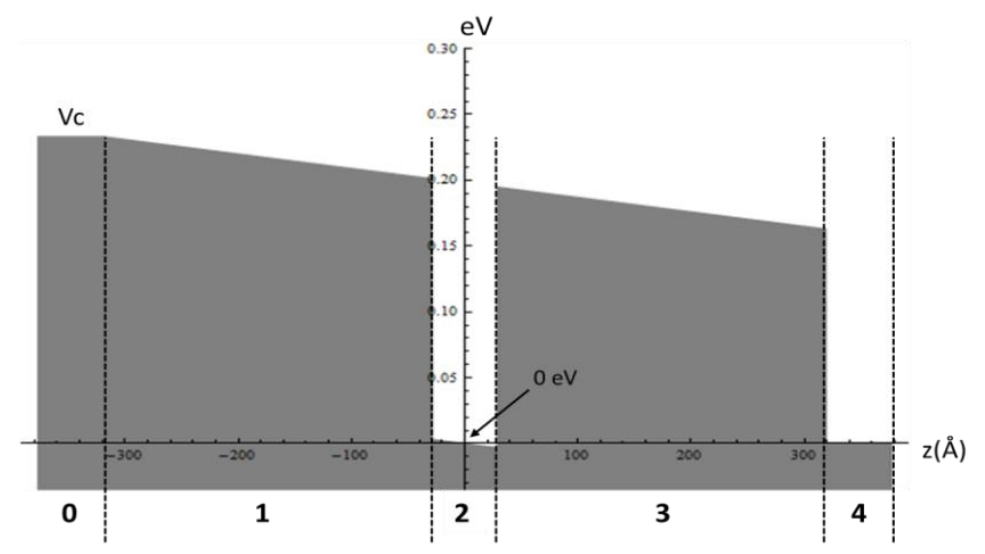

Figura 21: Diagrama mostrando os intervalos escolhidos para tratar o problema de um poço quântico submetido à aplicação de uma voltagem de polarização (bias). 


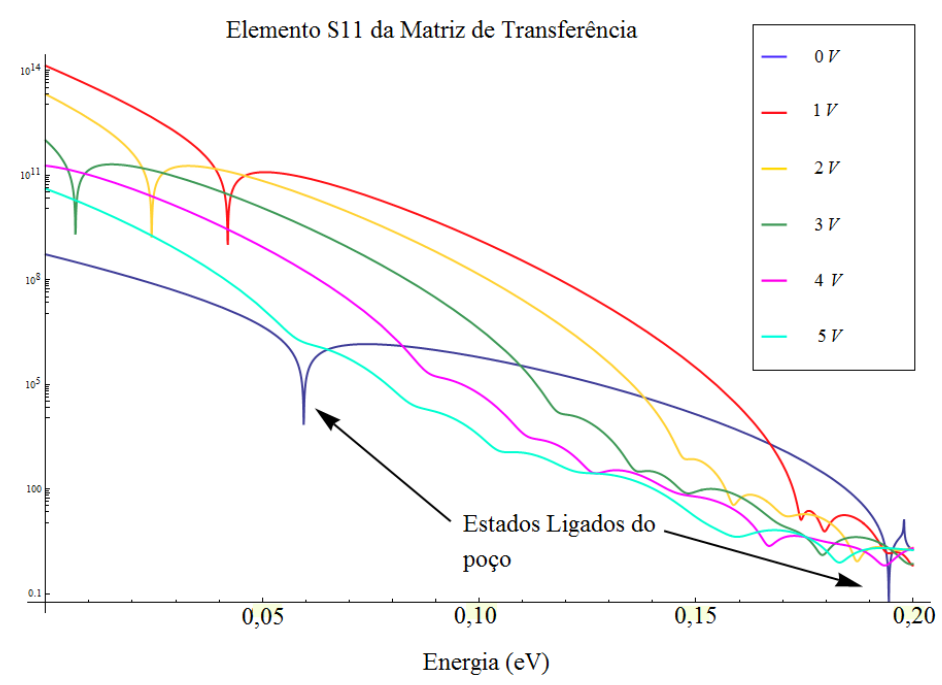

Figura 22: Gráfico da função $S_{11}$ para valores diferentes de voltagem aplicada a um poço quântico com $58 \AA ̊$ de largura e barreiras de AlGaAs com 21,3\% de Al. Cada mínimo local acentuado corresponde a um nível discreto de energia associado a um estado confinado no poço quântico.

\subsection{Absorção em QWIPs}

Poços quânticos dopados proporcionam transições intrabanda em QWIPs e permitem a utilização desses dispositivos dentro da banda do infravermelho médio (MIR). O coeficiente de absorção $\alpha\left(\mathrm{cm}^{-1}\right)$ de um material é a razão entre o número de fótons absorvidos por unidade de distância e o número de fótons incidentes.

$$
\alpha=\frac{N^{o} \text { de fótons absorvidos por unidade de volume por segundo }}{N^{o} \text { de fótons injetados por unidade de área por segundo }}
$$

Ele pode ser obtido a partir da razão entre a taxa de transição $R$ dos portadores, entre os 2 níveis de energia envolvidos, e a intensidade luminosa incidente, dada pelo módulo do vetor de Pointing $S$ em W/cm² (Equação 3.9).

$$
\alpha(\hbar \omega)=\frac{R}{(S / \hbar \omega)} \quad \text { Equação } 3.9
$$

A taxa de transição vem do hamiltoniano da interação elétron-fóton $H_{b a}^{\prime}$, entre os níveis de energia "a" e "b", e é obtida a partir da regra de ouro de Fermi [21]. O coeficiente de absorção é portanto dado por

$$
\alpha(\hbar \omega)=\frac{\hbar \omega}{\left(n \omega^{2} A_{0}^{2} / 2 \mu c\right)} \frac{2}{V} \sum_{K_{a}} \sum_{K_{b}} \frac{2 \pi}{\hbar}\left|H_{b a}^{\prime}\right|^{2} \delta\left(E_{b}-E_{a}-\hbar \omega\right)\left(f_{a}-f_{b}\right) \quad \text { Equação } 3.10
$$


onde $f_{a}$ e $f_{b}$ correspondem à ocupação dos niveis $E_{a}$ e $E_{b}$ (nível inicial e final) respectivamente, dada pela função de distribuição de Fermi-Dirac, $A_{0}$ é o módulo do potencial vetor da radiação incidente e $n$ é o índice de refração do meio de absorção. A partir do hamiltoniano da interação, podemos obter o coeficiente de absorção como função do momento de dipolo elétrico da transição $\boldsymbol{\mu}_{\boldsymbol{b a}}$. Utilizando a aproximação de dipolo $\boldsymbol{A}(\mathbf{r})=\boldsymbol{A}_{\boldsymbol{0}} \cdot \mathrm{e}^{\mathrm{i} \mathbf{K}}{ }_{\text {op }} \mathbf{r} \approx \boldsymbol{A}_{\boldsymbol{0}}$, válida para comprimentos de onda longos, onde $\mathrm{K}_{\mathrm{op}}=2 \pi / \lambda \approx 0$, e definindo o momento $\boldsymbol{p}$ em função do comutador com o operador hamiltoniano $(\boldsymbol{p}=(\mathrm{i} / \mathrm{h}) \cdot[\mathrm{H}, \boldsymbol{r}])$, obtemos

$$
H_{b a}^{\prime}=\left\langle b\left|-\left(e / m^{*}\right) \boldsymbol{A} \cdot \boldsymbol{p}\right| a\right\rangle \simeq-\boldsymbol{\mu}_{a b} \cdot \boldsymbol{E}
$$

Equação 3.11

Substituindo a função delta $\delta\left(E_{b}-E_{a}-\hbar \omega\right)$ pela função Lorentziana de largura $\Gamma$, usando $\boldsymbol{E}=$ $i \omega \boldsymbol{A}$ e escrevendo $\alpha(\hbar \omega)$ como função da densidade de elétrons $N_{a}$ e $N_{b}$ em cada banda ou nível, teremos:

$$
\alpha(\hbar \omega)=\left(\frac{2 \cdot \pi}{n_{r} \cdot \lambda \cdot \varepsilon}\right) \cdot \frac{\left|\boldsymbol{\mu}_{a b}\right|^{2} \cos ^{2} \phi(\Gamma / 2)}{\left(E_{a}-E_{b}-\hbar \omega\right)^{2}+(\Gamma / 2)^{2}} \cdot\left(N_{a}-N_{b}\right)
$$

Equação 3.12

onde $\phi$ é o ângulo entre o momento de dipolo da transição e o vetor campo elétrico da radiação incidente.

Portanto, o coeficiente de absorção é uma função que depende diretamente do momento de dipolo elétrico da transição, que é dado por

$$
\boldsymbol{\mu}_{a b}=\left\langle\Psi_{b}|e \boldsymbol{r}| \Psi_{a}\right\rangle
$$

Equação 3.13

Utilizando a aproximação da função envelope, a função de onda em um QWIP é dada pela equação 3.14 .

$$
\Psi_{k}(\boldsymbol{r})=u_{c}(\boldsymbol{r}) \frac{e^{i \boldsymbol{K}_{x y} \boldsymbol{r}(x, y)}}{\sqrt{A}} \phi_{n}(z)
$$

Equação 3.14

Esta equação é formada por uma parte atômica $u_{c}(\boldsymbol{r})$, uma parte que corresponde às funções de partícula livre em $x$ e $y, \quad\left(e^{i K_{x y} r(x, y)} / \sqrt{A}\right)$, e uma parte em $\mathrm{z}\left(\phi_{n}(z)\right)$ que corresponde ao efeito de confinamento do poço na direção do crescimento.

Em QWIPs dopados do tipo n, dentro da escala de dimensão do poço, podemos considerar a parte atômica aproximadamente constante, onde $\left\langle\mathrm{u}_{\mathrm{c}}(\mathbf{r}) \mid \mathrm{u}_{\mathrm{c}}{ }^{\prime}(\mathbf{r})\right\rangle \approx 1$ e teremos: 


$$
\boldsymbol{\mu}_{a b} \simeq\left\langle\frac{\exp \left(i K_{t}^{\prime} \cdot \boldsymbol{\rho}_{x, y}\right)}{\sqrt{A}} \Phi_{b}(z)|e \boldsymbol{r}| \frac{\exp \left(i K_{t} \cdot \boldsymbol{\rho}_{x, y}\right)}{\sqrt{A}} \Phi_{a}(z)\right\rangle
$$

Em transições intrabanda, as funções $\phi_{b}(z)$ e $\phi_{a}(z)$ possuem obrigatoriamente paridades opostas (a taxa de transição é desprezível entre funções de mesma paridade). Portanto, para que ocorra a absorção, as funções dependentes de x $\left(\phi_{b}(x)\right.$ e $\left.\phi_{a}(x)\right)$ e de y $\left(\phi_{b}(y)\right.$ e $\left.\phi_{a}(y)\right)$ devem possuir a mesma paridade. Nesse caso, podemos considerar que essas funções sejam parecidas para que ocorra a absorção. Dessa forma, o único termo do vetor $\boldsymbol{r}$ que contribui para a absorção será o termo em $z$, e assim podemos escrever

$$
\boldsymbol{\mu}_{a b} \simeq \delta_{K_{v}, K_{t}^{\prime}}\left\langle\phi_{b}(z)|e \cdot z| \phi_{a}(z)\right\rangle \hat{\boldsymbol{e}}_{z} \quad \text { Equação } 3.16
$$

\subsubsection{Regra de seleção do vetor campo elétrico}

A equação 3.16 mostra que o momento de dipolo da transição intrabanda, em QWIPs do tipo $\mathrm{n}$, só possui uma componente ao longo do eixo de crescimento (eixo $z$ ). Portanto, o cálculo do coeficiente de absorção será dado pela equação 3.12, onde

$$
\left|\boldsymbol{\mu}_{a b}\right|=\mu_{a b}=\int \phi_{b}(z) e z \phi_{a}(z) d z \quad \text { Equação 3.17 }
$$

Assim, o coeficiente de absorção (equação 3.12) dependerá do ângulo $\phi$ entre o eixo de crescimento (eixo $z$ ) e o vetor campo elétrico $\left(\alpha \propto \cos ^{2} \phi\right)$. Essa característica da absorção intrabanda em QWIPs é conhecida como a regra de seleção do campo elétrico. Esse efeito não permite a operação dos QWIPs dopados, do tipo n, com incidência normal de radiação. Esse problema pode ser contornado de duas formas: por meio da incidência em ângulo, através de uma face lateral polida com certo ângulo, geralmente $45^{\circ}$ (Figura 23), ou por meio de uma rede de difração que deve ser microfabricada na superfície do QWIP, de modo a espalhar a luz incidindo normalmente. A Figura 23 apresenta o esquema de montagem utilizado durante a caracterização dos QWIPs neste trabalho de doutorado. 


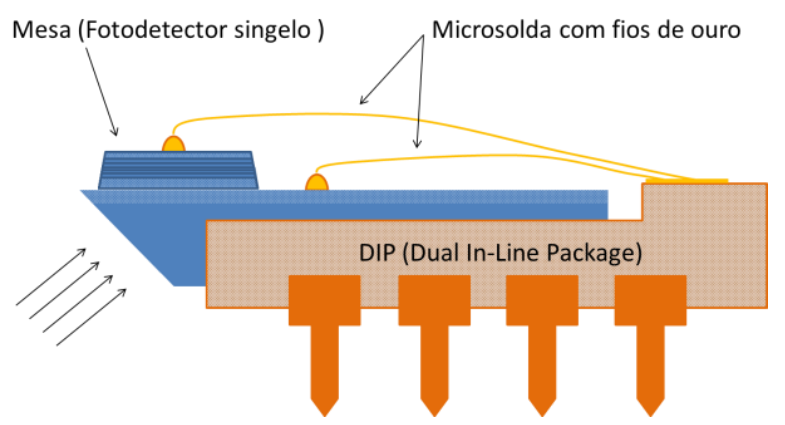

Figura 23: Esquema da montagem experimental da amostra para testar os QWIPs. Um chanfro é polido a $45^{\circ}$ numa borda da amostra para que a radiação incida normalmente sobre a superfície polida mas com um ângulo de $45^{\circ}$ sobre o QWIP (devido à limitação imposta pela regra de seleção do campo elétrico em QWIPs do tipo n).

\subsubsection{Absorção devida aos estados no contínuo}

Uma das principais características de um fotodetector é a sua curva de absorção. A simulação correta da curva de absorção é uma ferramenta poderosa para o desenvolvimento de novas estruturas e para a previsão do funcionamento do dispositivo final. A absorção ocorre por meio da promoção de um elétron no estado fundamental para um nível excitado do poço ou para um nível no contínuo de energias, acima das barreiras do poço. A absorção total é composta pela contribuição individual dos níveis do poço e dos estados no contínuo:

$$
\alpha_{\text {Total }}(\lambda)=\sum_{n=2}^{N} \alpha_{n 1}(\lambda) \quad \text { Equação } 3.18
$$

onde os termos $\alpha_{n 1}(\lambda)$ são obtidos pela equação 3.12, o índice $n$ refere-se ao estado final da transição, e o índice 1 ao estado fundamental.

O cálculo do módulo do momento de dipolo $\mu_{n 1}$ é obtido por meio da integral da equação 3.17, a partir das funções de onda do estado inicial $\phi_{1}(z)$ e do estado final $\phi_{n}(z)$ da transição. Para os níveis dentro do poço, as funções de onda são obtidas a partir do método da matriz de transferência e, em seguida, normalizadas. O contínuo é formado por um número infinito de funções de onda de partícula livre:

$$
\psi\left(E^{\prime}, z\right)=\left\{\begin{array}{lr}
A_{1} \cdot \sin \left(K_{b}\left(E^{\prime}\right) \cdot z+\varphi_{1}\right), \quad z<-\frac{L_{w}}{2} \\
\sin \left(K_{p}\left(E^{\prime}\right) \cdot z\right), \quad-\frac{L_{w}}{2} \leq z \leq+\frac{L_{w}}{2} \\
A_{2} \cdot \sin \left(K_{b}\left(E^{\prime}\right) \cdot z+\varphi_{2}\right), \quad z>\frac{L_{w}}{2}
\end{array}\right.
$$


onde $L_{W}$ é a largura do poço e a energia $E^{`}$ é maior que o potencial $V_{b}$ da barreira. No contínuo as funções de onda se estendem até o infinito, e a amplitude das funções tende a zero. Um recurso muito utilizado para simular o contínuo de estados é a expansão da região em torno do poço quântico simulado e a inclusão de barreiras de potencial mais altas cercando toda essa região. Após inúmeras tentativas aplicando-se esse recurso às simulações e comparando com os resultados experimentais, verificou-se que essa abordagem não simulava corretamente os níveis no contínuo. De fato, esta técnica costuma provocar o aparecimento de falsos estados confinados no espectro de absorção final simulado que dificultam a interpretação dos resultados.

Um estado no contínuo com uma função de onda de partícula livre se estendendo ao infinito representa um estado onde a incerteza na posição do elétron é infinita. Pelo princípio da incerteza, isso significa que o valor da energia desse estado pode ser determinado com precisão absoluta. Embora esteja conceitualmente correta, essa não representa uma situação física realista. Assim, devemos partir do princípio que o estado excitado no contínuo possui uma função de onda de amplitude finita que localiza o elétron na região do poço quântico. Uma função de onda no contínuo com essas características só pode ser descrita por meio de um pacote de ondas, ou seja, deve ser formada pela combinação linear de infinitas funções de onda, levando à integral:

$$
\phi_{c}(z)=\int_{V_{b}}^{\infty} a_{E} \cdot \psi(E, z) d E
$$

Equação 3.19

onde $V_{b}$ corresponde ao potencial da barreira e a integral da equação 3.19 abrange toda a região do contínuo acima da barreira.

O coeficiente de absorção de um estado é obtido por meio da equação 3.12. Nessa equação, vemos que a intensidade da absorção é proporcional ao quadrado do módulo do momento de dipolo da transição $\boldsymbol{\mu}_{b a}$, que é dado pela equação 3.17 , sendo $\phi_{b}(\mathrm{z})$ o estado final e $\phi_{a}(\mathrm{z})$ o estado inicial. Podemos observar que o valor de $\alpha(\hbar \omega)$ será máximo, e portanto a absorção também, quando a função do estado excitado no contínuo $\phi_{c}(z)$ for igual a

$$
\phi_{c}(z)=a_{c} \cdot z \cdot \phi_{a}(z)
$$

Equação 3.20

Sendo $a_{c}$ uma constante de normalização e $\phi_{a}(z)$ a função do estado fundamental, nesse caso, o overlap, ou seja, a sobreposição das funções de onda será ideal para que ocorra absorção.

Uma abordagem empírica foi desenvolvida durante esse trabalho e apresentou bons resultados para a simulação das curvas de absorção experimentais de sistemas envolvendo poços quânticos com apenas dois níveis confinados, quando o segundo nível (primeiro excitado) se encontra muito próximo ao topo da barreira. Nesse caso, o contínuo pode ser tratado como sendo representado por um estado dado pela função $\phi_{c}(z)$ da equação 3.20 , que corresponde à função que proporciona máximo overlap para que ocorra a absorção. Essa abordagem forneceu quantitativamente o perfil correto da curva de absorção (intensidade e largura à meia altura), supondo que a energia $E_{c}$ do estado virtual no contínuo $\phi_{c}(z)$ corresponde aproximadamente à 
energia da barreira $\left(E_{c} \cong V_{b}\right)$. Dessa forma o coeficiente de absorção devido aos estados do contínuo pode ser corretamente estimado por:

$$
\alpha(\hbar \omega)=\left(\frac{2 \cdot \pi}{n_{r} \cdot \lambda \cdot \varepsilon}\right) \cdot \frac{\left(\int_{-\infty}^{\infty} \phi_{c}^{*}(z) \cdot e \cdot z \cdot \phi_{1}(z) d z\right)^{2} \cdot \cos ^{2} \varphi \cdot(\Gamma / 2)}{\left(E_{c}-E_{1}-\hbar \omega\right)^{2}+(\Gamma / 2)^{2}} \cdot\left(N_{1}-N_{c}\right) \quad \text { Equação } 3.21
$$

\subsubsection{Largura do pico de absorção}

O parâmetro $\Gamma$ nas equações 3.12 e 3.21 corresponde à largura da função Lorentziana que descreve a absorção. Esse parâmetro representa a incerteza em torno da média da energia da transição, do estado inicial para um estado final, por meio da absorção de um fóton com energia $\hbar \omega$. A incerteza na energia da transição possui duas componentes: uma experimental, devida às imperfeições nas interfaces da amostra, e uma correspondente à incerteza finita na energia do próprio fóton absorvido. A incerteza na energia do fóton pode ser estimada a partir do princípio da incerteza, $\Delta E \Delta t \geq \hbar / 2$, considerando $\Delta t \cong \lambda / c$. Do ponto de vista teórico, existe, portanto uma incerteza mínima na transição dada pela incerteza na energia do fóton, ou seja, se a incerteza experimental da amostra for suficientemente pequena, podemos considerar que o parâmetro $\Gamma$ é dado aproximadamente por:

$$
\Gamma=\hbar c / 2 \lambda
$$

Equação 3.22

\subsubsection{Exemplo de absorção em um poço simples}

Nesse ponto, é conveniente introduzir um exemplo do método para o cálculo da absorção que foi implementado no software Mathematica. Nesse exemplo, o cálculo é aplicado a um poço simples (quadrado) de GaAs com $52 \AA$ de largura, barreiras de AlGaAs com $26 \%$ de alumínio, e dopagem do tipo ' $\mathrm{n}$ ' no poço com concentração de $5 \cdot 10^{17}$ átomos de silício por centímetro cubico. O cálculo com a matriz de transferência fornece para esse poço quântico dopado dois estados confinados: um com energia $E_{1}=71,65 \mathrm{meV}$ (estado fundamental) e outro com energia $E_{2}=232,85 \mathrm{meV}$ para o estado excitado. Na Figura 24 estão ilustradas as funções de onda obtidas para esses dois estados. 


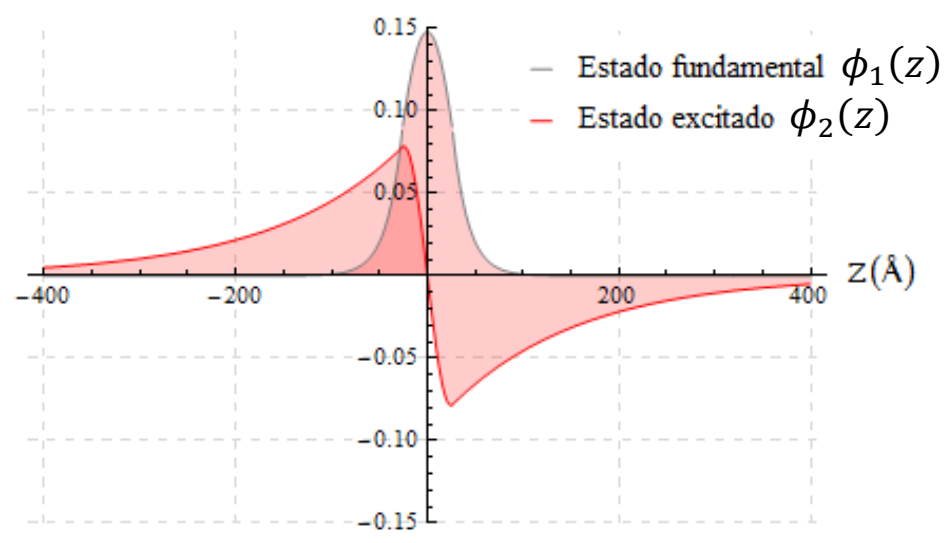

Figura 24: Funções de onda dos dois estados confinados de um poço simples de GaAs de $52 \AA$ de largura com barreiras de $\mathrm{Al}_{0.26} \mathrm{Ga}_{0.74} \mathrm{As}$.

Admitindo a identidade $\phi_{c}(z)=\mathrm{a}_{c} \cdot z \cdot \phi_{1}(z)$ (Equação 3.20) e normalizando para encontrar o valor de $\mathrm{a}_{c}$, obtemos a função $\phi_{c}(z)$ onde $\mathrm{a}_{c}$ é igual a 0,0566308 . Substituindo esses valores obtemos:

$$
\phi_{c}(z)=0,0566308 \cdot z \cdot \phi_{1}(z)
$$

Na Figura 25 está ilustrada a solução do poço simples de GaAs com $52 \AA$ de largura com barreiras de AlGaAs com $26 \%$ de alumínio, onde estão apresentados os níveis dentro do poço $(71,65 \mathrm{meV}$ e $232,85 \mathrm{meV})$ e o nível excitado com energia média de $235,19 \mathrm{meV}$, que corresponde à altura das barreiras de potencial do poço quântico.

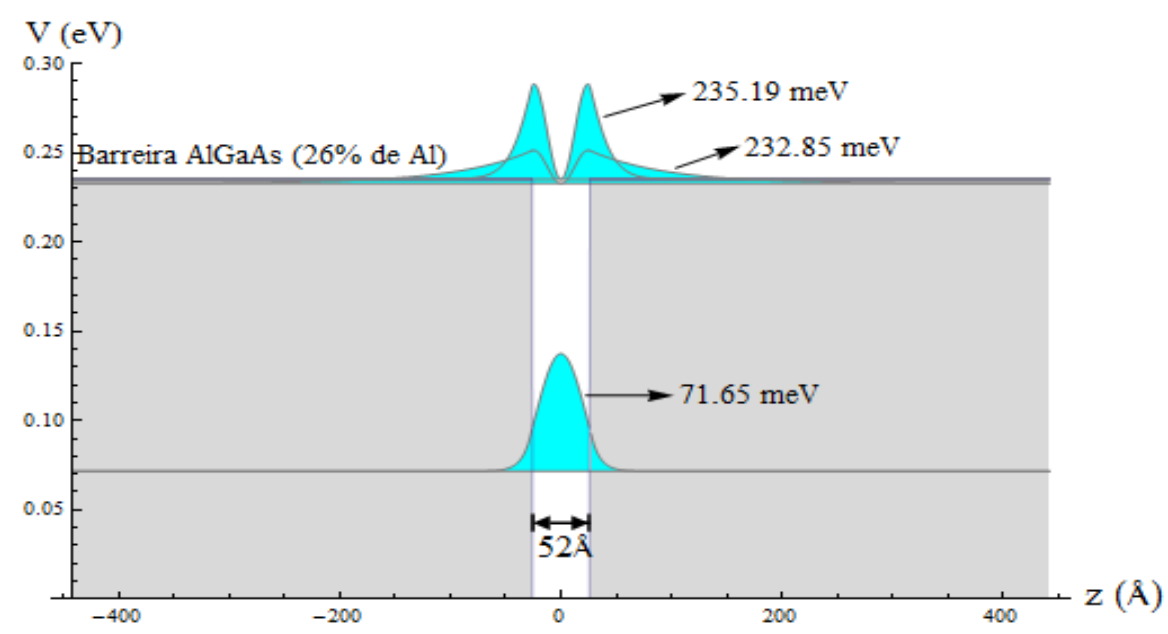

Figura 25: llustração das funções de densidade de probabilidade obtidas para os níveis dentro do poço e para o contínuo, utilizadas no calculo da curva de absorção teórica. 
O coeficiente de absorção $\boldsymbol{\alpha}(\lambda)$ pode finalmente ser obtido a partir das equações $3.12,3.18$ e 3.21, e da relação para o parâmetro $\Gamma$, dada pela equação 3.22. A Figura 26 ilustra o resultado do modelo da absorção levando em conta a absorção pelos estados do contínuo, fora do poço. A curva em azul corresponde à absorção entre o estado fundamental 1 e o primeiro estado excitado 2 (dentro do poço quântico), a curva em vermelho corresponde à absorção entre o estado 1 e o segundo estado excitado (fora do poço quântico) que leva em conta a absorção devida aos estados no contínuo, e a curva cinza corresponde a absorção total dada pela soma das contribuições individuais dessas duas curvas de absorção.

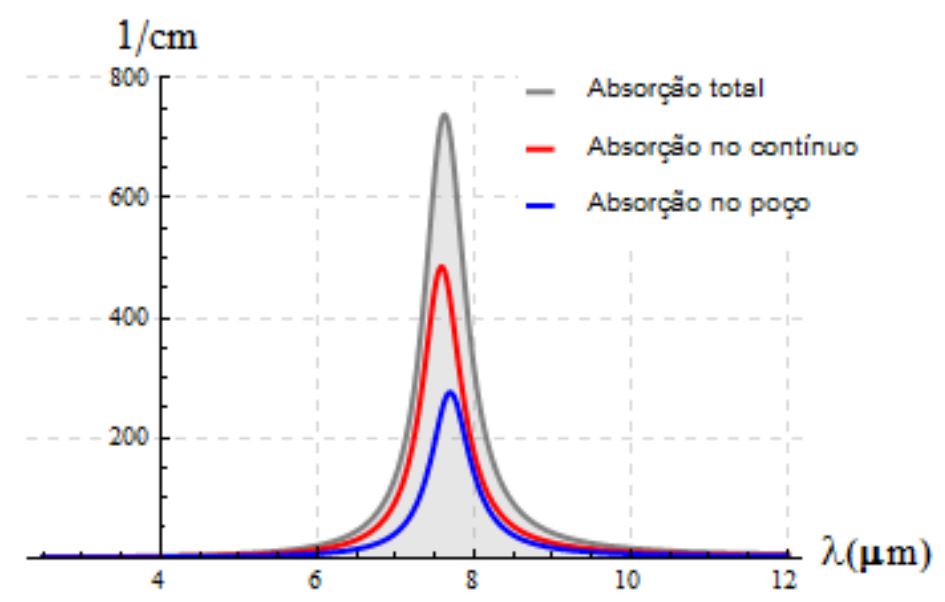

Figura 26: Curva de absorção teórica calculada para um poço simples de GaAs de $52 \AA$ de largura com barreiras de $\mathrm{Al}_{0,26} \mathrm{Ga}_{0,74} \mathrm{As}$.

Foi crescida por MBE uma amostra de QWIPs composta por 20 poços quânticos nominalmente iguais aos poços estudados neste exemplo e a curva de absorção dos poços dessa amostra foi obtida experimentalmente. Na Figura 27 estão apresentadas as duas curvas, teórica e experimental obtidas. Comparando a curva teórica, obtida com o método aqui apresentado, com a curva experimental, vemos que o pico de absorção experimental está em 8,2 $\mu \mathrm{m}$, enquanto que o pico obtido da teoria está em 7,6 $\mu \mathrm{m}$. No cálculo realizado para a simulação foi utilizada a aproximação de bandas parabólicas que, em geral, provoca o deslocamento do pico de absorção para comprimentos de onda menores. Nesse tipo de poço quântico, em que o primeiro estado excitado está bem próximo da altura da barreira, uma pequena redução, da ordem de $1 \%$, na composição de Al na liga das barreiras também pode explicar essa diferença na posição dos picos. $\mathrm{O}$ acordo entre a intensidade máxima e a largura das curvas teórica e experimental é excelente. Para a curva teórica, o valor da intensidade do pico obtido foi de $738 \mathrm{~cm}^{-1}$, enquanto que para a curva experimental a intensidade medida foi de $750 \mathrm{~cm}^{-1}$. A largura à meia altura dos dois picos possui exatamente o mesmo valor $(0,7 \mu \mathrm{m})$. Esse resultado ilustra a eficácia do método empírico proposto e também demonstra a qualidade dos poços crescidos, homogêneos e com interfaces abruptas. Pode-se observar que a função de onda do estado no contínuo mostrado na Figura 27 aparece muito mais confinada do que se esperaria para este tipo de estado, o que é uma consequência direta desta técnica que visa maximizar a absorção. 


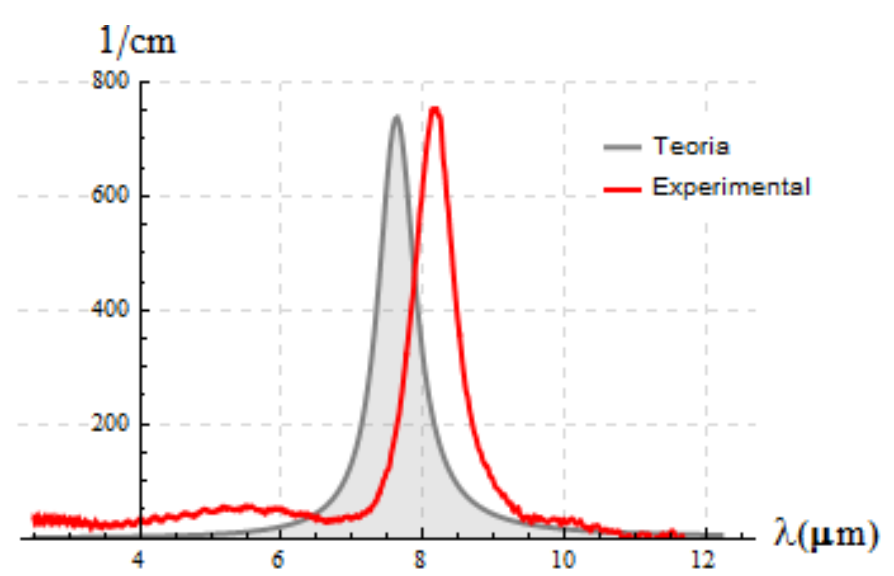

Figura 27: Comparação entre a curva de absorção experimental e a curva teórica calculada sem nenhum parâmetro experimental para um poço simples de GaAs de $52 \AA$ de largura com barreiras de $\mathrm{Al}_{0,26} \mathrm{Ga}_{0,74} A s$.

\subsection{Estados zero-dimensionais de impurezas confinadas em poços quânticos}

$\mathrm{Na}$ dopagem de semicondutores, os dopantes (ou impurezas) são átomos que se ligam à estrutura cristalina do semicondutor por meio da substituição de átomos da rede original, e provocam o excesso ou a falta de elétrons. Para que isso ocorra, o átomo dopante deve possuir um excesso ou uma falta de elétrons de valência em relação ao átomo substituído.

No caso de uma impureza dopante, isolada em um semicondutor, o portador em excesso permanece ligado fracamente à impureza pela ação do potencial central coulombiano. O confinamento tridimensional gerado por esse potencial dá origem a estados confinados nas três dimensões, que podemos chamar de estados zero-dimensionais (ou estados 0D). Nessa configuração, a solução da equação de Shrödinger para a impureza será dada pela generalização da solução para o átomo de hidrogênio, apenas substituindo no problema a massa efetiva do portador de carga e as constantes dielétricas do semicondutor em questão. Assim, as funções de onda do portador de carga ligado à impureza terão a mesma forma que as funções $\left(1 \mathrm{~s}, 2 \mathrm{~s}, 2 \mathrm{p}_{\mathrm{xy}}, 2 \mathrm{p}_{\mathrm{z}}, \ldots\right)$ do átomo de hidrogênio, o que faz com que esses estados confinados das impurezas recebam o nome de estados hidrogenóides.

A condutividade de um semicondutor depende da concentração de portadores livres na sua banda de condução, que é uma função da dopagem e da probabilidade de ionização das impurezas, ela mesma função da temperatura (eq. da distribuição de Fermi). Consequentemente, podemos melhorar a condutividade de um semicondutor aumentando a dopagem ou a temperatura. Porém, existe um limite de densidade a partir do qual a condutividade não depende mais da temperatura, ou seja, todas as impurezas permanecem ionizadas independentemente da temperatura. Esse limite é a definição do fenômeno chamado de transição de Mott [24]. A transição de Mott ocorre quando a densidade de impurezas é tal que a distância média entre elas é de aproximadamente 5 vezes o 
raio de Bohr da impureza $\left(\mathrm{a}_{0}\right)$. Quando isso ocorre, o nível de energia discreto da impureza, que estava localizado dentro do gap do material semicondutor, entra na banda de condução adjacente, e surge um gás de elétrons tridimensional. No caso do GaAs a transição de Mott ocorre quando a densidade de impurezas é da ordem de $10^{16} \mathrm{~cm}^{-3}$.

Ao doparmos o interior de um poço quântico com uma densidade inferior à necessária para ocorrer a transição de Mott, as impurezas podem ser consideradas isoladas umas das outras. Os elétrons em excesso ligados às impurezas no interior de um poço quântico estão sujeitos, além do próprio potencial central de confinamento coulombiano, ao potencial de confinamento do poço quântico. O potencial de confinamento adicional do poço deforma as funções de onda dos estados hidrogenóides originais e leva a uma deformação das funções de onda, o que provoca a diminuição do raiode Bohr dos elétrons dentro do poço quântico. Com a presença deste efeito, é possível aumentar a dopagem dos poços acima do que seria possível no material bulk, sem que ocorra a transição de Mott [25]. Desse modo, poderia ser viável fabricar um QWIP onde as transições ópticas ocorrem entre os estados zero-dimensionais da impureza [26]. Os QWIPs cuja operação se baseia nesse princípio ainda estão em um estagio de desenvolvimento inicial, e não existem atualmente dispositivos completamente desenvolvidos ou caracterizados. Uma das principais dificuldades reside na complexidade da simulação dos processos físicos em três dimensões. Espera-se que esse tipo de QWIP tenha alta absorção e baixa corrente de escuro, e que as funções de onda zero-dimensionais possibilitem melhores características de ruído [26].

Para o estudo das transições zero-dimensionais em poços quânticos, foi implementado no ambiente Mathematica um programa para o cálculo dos níveis de energia e das funções de onda de um elétron (ligado à impureza) submetido a um potencial coulombiano no interior de um poço quântico. Além do cálculo nos permitir prever com exatidão a energia desta transição, também é uma ferramenta para o projeto e otimização de novos QWIPs baseados nesse princípio de operação. O cálculo implementado foi realizado a partir do estudo minucioso da referência [27].

As transições entre níveis de uma impureza hidrogenóide em um poço e as transições entre os níveis do poço, ocorrem dentro da mesma banda, ou seja a energia dos dois tipos de transição dentro do mesmo poço são próximas uma da outra. O cálculo foi obtido a partir de uma extensa dedução algébrica, em que o potencial coulombiano em três dimensões é reduzido a um potencial unidimensional equivalente, na mesma direção de confinamento do poço. Nesse método as funções de onda são assumidas como sendo compostas pelo produto de três funções: uma que é combinação das funções do átomo hidrogenoide $\Phi_{n l m}(\lambda, r, z, \varphi)$, uma que vem da solução do potencial coulombiano unidimensionalizado $\mathrm{W}_{\lambda \mathrm{nlm}}(z)$, e uma função exponencial $e^{\lambda \cdot\left(\frac{\left(r^{2}+\left(z-z_{0}\right)^{2}\right)^{1 / 2}}{a_{0}}\right)} / \sqrt{f_{n l m}(\lambda, z)}$, onde as funções estão em coordenadas cilíndricas e a variável $\lambda$ corresponde ao parâmetro variacional. Assim, a função de onda dos estados ligados à impureza têm a forma:

$$
\Psi_{n l m}(x, y, z)=\left(e^{\lambda \cdot\left(\frac{\left(r^{2}+\left(z-z_{0}\right)^{2}\right)^{1 / 2}}{a_{0}}\right)} / \sqrt{f_{n l m}(\lambda, z)}\right) \cdot W_{n l m}^{\lambda}(z) \cdot \Phi_{n l m}(\lambda, r, z, \varphi)
$$


As funções $f_{n l m}$ para os estados $1 \mathrm{~s}, 2 \mathrm{p}_{\mathrm{xy}}$ e $2 \mathrm{sp}_{\mathrm{z}}$ estão listadas no Apêndice. Nas expressões para o potencial unidimensionalizado $\left(V_{z}\right), d f_{n l m}$ e $d d f_{n l m}$ correspondem à primeira e à segunda derivada em ' $x$ ' das funções $f_{n l m}$, respectivamente.

\subsubsection{Estado fundamental $\left(1 \mathrm{~s}\left(1_{100}\right)\right)$}

A solução para o estado fundamental pode ser obtida a partir da função de onda do estado fundamental do átomo hidrogenóide $\Phi_{1 s}$, sendo

$$
\Phi_{1 s}(r, z)=\frac{1}{\sqrt{\pi}} \frac{1}{a_{0}^{3 / 2}} \operatorname{Exp}\left[-\frac{\sqrt{r^{2}+\left(z-z_{0}\right)^{2}}}{a_{0}}\right] .
$$

A função $W_{n l m}^{\lambda}(z)$ é a solução do potencial unidimensionalizado $V_{z}$, ou seja, $H_{z} W_{1 s}^{\lambda}(z)=V_{z} W_{1 s}^{\lambda}(z)$ para o estado fundamental. Nesta equação,

$V_{z}=\left\{\begin{array}{c}V_{p}(z),|z|<a \\ V_{c}+V_{b}(z),|z| \geq a\end{array}\right.$, sendo $a$ a largura do poço quântico e $V c$ o potencial da barreira.

$V_{p}(z)=\frac{\hbar^{2} \lambda^{2}}{2 m_{p}^{*} a_{0}^{2}}-R_{y p}-\frac{\hbar^{2} \lambda}{2 m_{p}^{*} a_{0}} \cdot \frac{\left(f_{11 s}(\lambda, z)+\left|z-z_{0}\right| d f_{11 s}(\lambda, z)\right)}{f_{1 s}(\lambda, z)}-\frac{\hbar^{2}}{2 m_{p}^{*}} \cdot\left(\frac{d f_{1 s}(\lambda, z)^{2}}{4 f_{1 s}(\lambda, z)^{2}}-\frac{d d f_{1 s}(\lambda, z)}{2 f_{1 s}(\lambda, z)}\right)$

$V_{b}(z)=-\frac{m_{p}^{*} R_{y p}}{m_{b}^{*}}+\frac{\hbar^{2} \lambda^{2}}{2 m_{b}^{*} a_{0}^{2}}-\frac{\hbar^{2} \lambda}{2 m_{b}^{*} a_{0}} \cdot \frac{\left(f_{11 s}(\lambda, z)+\left|z-z_{0}\right| d f_{11 s}(\lambda, z)\right)}{f_{1 s}(\lambda, z)}-\frac{\hbar^{2}}{2 m_{b}^{*}} \cdot\left(\frac{d f_{1 s}(\lambda, z)^{2}}{4 f_{1 s}(\lambda, z)^{2}}-\frac{d d f_{1 s}(\lambda, z)}{2 f_{1 s}(\lambda, z)}\right)+\frac{1}{4 \pi}$. $\left(\frac{m_{p}^{*}}{m_{b}^{*} \epsilon_{p}}-\frac{1}{\epsilon_{b}}\right) \cdot \frac{f_{11 s}(\lambda, z)}{f_{1 s}(\lambda, z)}$

Onde $R_{y p}$ corresponde à constante de Rydberg calculada a partir da constante dielétrica e da massa efetiva do material do poço (equação 3.23).

$$
R_{y p}=\frac{m_{p} \cdot e^{4}}{2 .\left(4 \pi \epsilon_{p}\right)^{2} \cdot \hbar^{2}} \quad \text { Equação } 3.23
$$

\subsubsection{Primeiro estado excitado $\left(2 \mathrm{p}_{\mathrm{xy}}\left(2_{21 \pm 1}\right)\right)$}

Para a solução do primeiro estado excitado partimos da função $\Phi_{2 p x y}$ do átomo hidrogenóide, sendo

$$
\Phi_{2 p x y}(r, z, \varphi)=\frac{1}{8 \sqrt{\pi}} \cdot \frac{1}{a_{0}^{5 / 2}} \cdot r \cdot \operatorname{Exp}\left[-\frac{\sqrt{r^{2}+\left(z-z_{0}\right)^{2}}}{2 a_{0}}\right] \cdot e^{i \varphi}
$$


O potencial unidimensionalizado dentro do poço para o estado $2 p_{x y}$ é dado por:

$V_{p}(z)=\frac{\hbar^{2} \lambda^{2}}{2 m_{p}^{*} a_{0}^{2}}-\frac{R_{y p}}{4}-\frac{\hbar^{2} \lambda}{2 m_{p}^{*} a_{0}} \cdot \frac{\left(f_{12 p x y}(\lambda, z)+\left|z-z_{0}\right| d f_{12 p x y}(\lambda, z)\right)}{f_{2 p x y}(\lambda, z)}-\frac{\hbar^{2}}{2 m_{p}^{*}} \cdot\left(\frac{d f_{2 p x y}(\lambda, z)^{2}}{4 f_{2 p x y}(\lambda, z)^{2}}-\frac{d d f_{2 p x y}(\lambda, z)}{2 f_{2 p x y}(\lambda, z)}\right)$

Fora do poço (nas barreiras), o potencial é dado por:

$V_{b}(z)=-\frac{m_{p}^{*} R_{y p}}{4 m_{b}^{*}}+\frac{\hbar^{2} \lambda^{2}}{2 m_{b}^{*} a_{0}^{2}}-\frac{\hbar^{2} \lambda}{2 m_{b}^{*} a_{0}} \cdot \frac{\left(f_{12 p x y}(\lambda, z)+\left|z-z_{0}\right| d f_{12 p x y}(\lambda, z)\right)}{f_{2 p x y}(\lambda, z)}-\frac{\hbar^{2}}{2 m_{b}^{*}} \cdot\left(\frac{d f_{2 p x y}(\lambda, z)^{2}}{4 f_{2 p x y}(\lambda, z)^{2}}-\right.$

$\left.\frac{d d f_{2 p x y}(\lambda, z)}{2 f_{2 p x y}(\lambda, z)}\right)+\frac{1}{4 \pi} \cdot\left(\frac{m_{p}^{*}}{m_{b}^{*} \epsilon_{p}}-\frac{1}{\epsilon_{b}}\right) \cdot \frac{f_{12 p x y}(\lambda, z)}{f_{2 p x y}(\lambda, z)}$

\subsubsection{Segundo estado excitado $\left(2 \mathrm{sp}_{\mathrm{z}}\right)$}

Para descrever o segundo estado excitado é necessário partir de uma função $\Phi_{n l m}(\lambda, r, z, \varphi)$ que seja combinação das funções dos estados 2 s $\left(2_{200}\right)$ e $2 \mathrm{p}_{z}\left(2_{210}\right)$ do átomo hidrogenóide. A combinação dessas funções depende de um segundo parâmetro variacional $\lambda_{1}$ :

$$
\Phi_{2 s p z}(r, z)=\Phi_{2 s}(r, z)+\lambda_{1} \frac{\sqrt{r^{2}+\left(z-z_{0}\right)^{2}}}{z-z_{0}} \Phi_{2 p z}(r, z)
$$

e resulta na função

$$
\Phi_{2 s p z}(r, z)=\frac{1}{4 \sqrt{2 \pi}} \cdot \frac{1}{a_{0}^{3 / 2}} \cdot\left(2-\left(\left(1-\lambda_{1}\right) \cdot \frac{\sqrt{r^{2}+\left(z-z_{0}\right)^{2}}}{a_{0}}\right)\right) \cdot \operatorname{Exp}\left[-\frac{\sqrt{r^{2}+\left(z-z_{0}\right)^{2}}}{2 a_{0}}\right] .
$$

No cálculo implementado, foi utilizada a relação $\lambda_{1} \approx 7 \lambda-18 \lambda^{2}$, entre o parâmetro $\lambda_{1}$ e o parâmetro variacional $\lambda$. Essa é uma relação aproximada onde, no limite $z_{0} \rightarrow \infty$, a função $\Phi_{2 s p z}(r, z)$ converge para a função $\Phi_{2 s}(r, z)$ da impureza hidrogenóide dentro da barreira, e para $z_{0}=0$ e $\lambda=1 / 6$, a função $\Phi_{2 s p z}(r, z)$ no limite $(r \rightarrow 0, z \rightarrow 0)$ é precisamente dada pela função $\Phi_{2 p z}(r, z)$ da impureza hidrogenóide no material do poço [27].

O potencial unidimensionalizado dentro do poço nesse caso é dado por:

$V_{p}(z)=\frac{\hbar^{2} \lambda^{2}}{2 m_{p}^{*} a_{0}^{2}}-\frac{R_{y p}}{4}-\frac{f_{22 p s z}(\lambda, z)}{f_{2 p s z}(\lambda, z)}-\frac{\hbar^{2} \lambda}{2 m_{p}^{*} a_{0}} \cdot \frac{\left(f_{12 p s z}(\lambda, z)+\left|z-z_{0}\right| d f_{12 p s z}(\lambda, z)\right)}{f_{2 p s z}(\lambda, z)}-\frac{\hbar^{2}}{2 m_{p}^{*}} \cdot\left(\frac{d f_{2 p s z}(\lambda, z)^{2}}{4 f_{2 p s z}(\lambda, z)^{2}}-\right.$ $\left.\frac{d d f_{2 p s z}(\lambda, z)}{2 f_{2 p s z}(\lambda, z)}\right)$ 
O potencial unidimensionalizado fora do poço é dado por:

$$
\begin{gathered}
V_{b}(z)=-\frac{m_{p}^{*} R_{y p}}{4 m_{b}^{*}}+\frac{\hbar^{2} \lambda^{2}}{2 m_{b}^{*} a_{0}^{2}}-\frac{f_{32 p s z}(\lambda, z)}{f_{2 p s z}(\lambda, z)}-\frac{\hbar^{2} \lambda}{2 m_{b}^{*} a_{0}} \cdot \frac{\left(f_{12 p s z}(\lambda, z)+\left|z-z_{0}\right| d f_{12 p s z}(\lambda, z)\right)}{f_{2 p s z}(\lambda, z)}-\frac{\hbar^{2}}{2 m_{b}^{*}} . \\
\left(\frac{d f_{2 p s z}(\lambda, z)^{2}}{4 f_{2 p s z}(\lambda, z)^{2}}-\frac{d d f_{2 p s z}(\lambda, z)}{2 f_{2 p s z}(\lambda, z)}\right)+\frac{1}{4 \pi} \cdot\left(\frac{m_{p}^{*}}{m_{b}^{*} \epsilon_{p}}-\frac{1}{\epsilon_{b}}\right) \cdot \frac{f_{12 p s z}(\lambda, z)}{f_{2 p s z}(\lambda, z)}
\end{gathered}
$$

A partir do potencial unimensionalisado $V_{z}(z)$, as funções de onda $\mathrm{W}_{\lambda \text { nlm }}(z)$ foram obtidas por meio da utilização do programa da matriz de transferência, onde o parâmetro $\lambda$ foi variado de forma iterativa de modo a minimizar a energia final de cada estado.

\subsubsection{Projeto de um QWIP baseado em transições zero-dimensionais de impurezas}

Para o projeto de um QWIP baseado em transições entre os estados de impureza dentro dos poços, é necessário estabelecer algumas diretrizes: primeiro, a distância entre o nível fundamental da impureza e o nível fundamental do poço (levemente mais alto) deve ser a maior possível para evitar a fuga dos portadores. Segundo, a força do oscilador para a transição entre os estados confinados do poço deve ser a menor possível para favorecer as transições entre os níveis das impurezas.

Os portadores disponíveis dentro do poço se distribuem entre os estados disponíveis, tanto entre os estados zero-dimensionais da impureza quanto entre os estados do poço. A distribuição de portadores entre os estados é dada pela distribuição de Fermi-Dirac. Portanto, quanto maior a separação entre os estados fundamentais, da impureza e do poço, maior será a população de portadores no estado fundamental da impureza (que tem menor energia que o estado fundamental do poço). Da mesma forma, quanto menor a absorção entre os estados do poço (menor força de oscilador), mais a absorção a partir do estado fundamental da impureza poderá se tornar dominante.

Seguindo essas diretrizes, foi projetado um QWIP com poços de GaAs com $50 \AA$ de largura e barreiras de AlGaAs com 23\% de alumínio na sua composição. Todos os cálculos foram feitos para uma temperatura de $80 \mathrm{~K}$ que pode ser facilmente mantida em um criostato de $\mathrm{N}_{2}$ líquido. Nessa temperatura, o poço possui apenas um nível de confinamento, com energia de 72,4 meV (tomando como referência o fundo do poço), e os níveis de energia dos estados zerodimensionais, confinados na impureza, são $59,0 \mathrm{meV}$ para o estado fundamental $1 \mathrm{~s}, 68,5 \mathrm{meV}$ para o estado $2 \mathrm{p}_{\mathrm{xy}}$, e $209,5 \mathrm{meV}$ para o estado $2 \mathrm{sp}_{\mathrm{z}}$. Na Figura 28 estão ilustradas as curvas de nível das funções densidade de probabilidade para os três estados mais importantes, o estado $1 \mathrm{~s}$ em azul, o estado $2 p_{x y}$ em verde e o estado $2 s p_{z}$ representado em amarelo (o plano $x y$ do poço está orientado horizontalmente na Figura 28). 


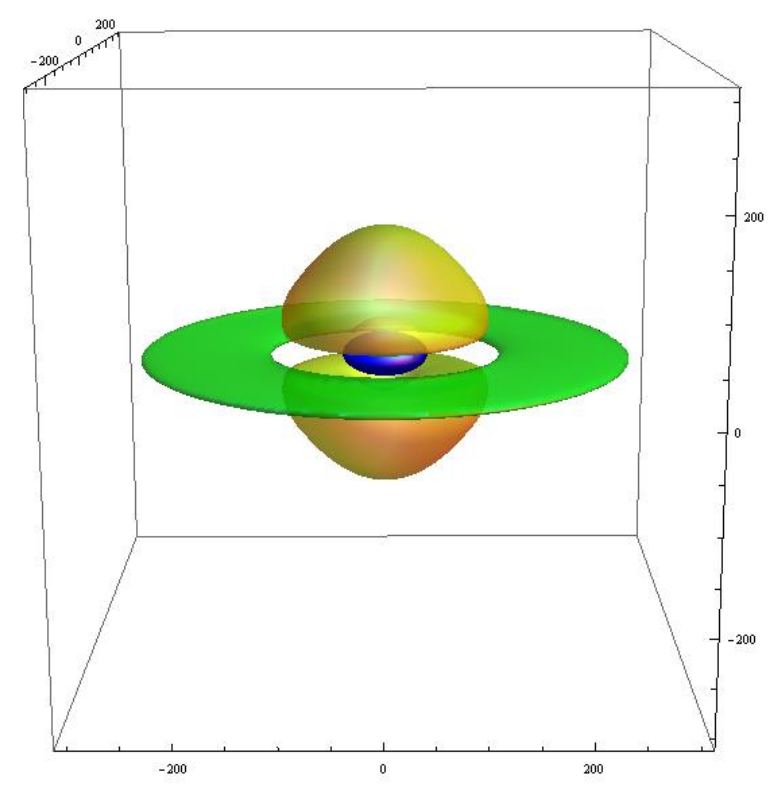

Figura 28: Estados de impureza não ionizada confinada em um poço quântico. Em azul está representado o estado 1s, em verde o estado $2 p x y$, e em amarelo o estado $2 s p z$.

A partir dos cálculos do momento de dipolo (equação 3.13, força do oscilador), verificou-se que a transição mais intensa ocorre entre o estado $1 s$ e $2 s p_{z}$, para o qual o valor obtido para o momento de dipolo foi de $-89,3 \cdot 10^{-26} \mathrm{C} . \mathrm{cm}$. Como comparação, o momento de dipolo para a transição entre o estado fundamental e o primeiro estado excitado em um poço quântico (de $100 \AA$ de largura) com barreiras infinitas possui o valor de $-2,88 \cdot 10^{-26} \mathrm{C} . \mathrm{cm}$. Ou seja, como a absorção é proporcional ao quadrado do módulo do momento de dipolo (Equação 3.12), a absorção pelas transições entre os estados zero-dimensionais da impureza deve ser cerca de 960 vezes maior. Porém, diferentemente de um QWIP comum onde toda a região do poço pode ser dopada com alta concentração de impurezas (tipicamente $10^{18} \mathrm{~cm}^{-3}$ no caso do GaAs), para mantermos o sistema abaixo da transição de Mott, devemos reduzir a concentração de impurezas e restringir a região dopada ao centro do poço, oque reduz significativamente a quantidade total de dopante (e portanto de centros ativos). Para o estado fundamental de uma impureza posicionada no centro do poço $\left(z_{0}=0\right)$, o raio de Bohr médio do elétron é de aproximadamente 22,2 $\mathrm{A}$. No caso do GaAs Bulk, esse valor é de cerca de 103,5 A. Considerando que a regra da transição de Mott se mantenha para o caso de um poço quântico, então a dopagem máxima deve ser tal que a distância média entre as impurezas seja maior que 5 vezes o raio de Bohr médio do elétron. No caso desse QWIP, projetado para transições zero-dimensionais, a concentração da dopagem deve ser menor do que cerca de $7.10^{17} \mathrm{~cm}^{-3}$ para que as impurezas estejam isoladas. Ao doparmos com elétrons uma região central do poço com $16 \AA$ de largura, com uma concentração de dopantes de $5.10^{17} \mathrm{~cm}^{-3}$, teremos aproximadamente (na temperatura de $80 \mathrm{~K}$ ) $3,3.10^{17} \mathrm{~cm}^{-3}$ impurezas com um elétron no estado fundamental, e $5,4.10^{16} \mathrm{~cm}^{-3}$ elétrons populando o estado fundamental do poço. Nessas condições a absorção devida à transição entre os estados do poço deverá ser desprezível em comparação com a absorção devida à transição entre os estados zero-dimensionais das impurezas. Segundo os cálculos, espera-se que a absorção nesse tipo de QWIP seja cerca de 
100 vezes maior que a absorção de QWIP comum. Porém, para estimar a fotocorrente real do dispositivo, é necessária a realização de mais cálculos, pois precisa-se investigar os mecanismos físicos capazes de extrair os elétrons fotogerados para fora do poço, analisando as transições entre o estado $2 \mathrm{sp}_{z}$ das impurezas e os estados excitados do poço ou os níveis de condução no contínuo.

\subsection{Corrente no escuro}

Mesmo na ausência da radiação infravermelha de interesse, existe sempre no dispositivo uma corrente de fundo, chamada de corrente de escuro, cujos mecanismos de geração em QWIPs se resumem à geração térmica, ao tunelamento através da barreira de potencial dos poços e à geração de portadores devido à ionização por impacto. A contribuição desses dois últimos mecanismos pode ser desprezada enquanto mantivermos o campo elétrico externo aplicado suficientemente baixo ou a distância entre poços vizinhos não seja pequena demais (tipicamente inferior a $350 \AA$ ). Assim, podemos partir de um modelo relativamente simples, que leva em conta apenas os elétrons gerados termicamente. A equação 3.24 corresponde ao modelo utilizado na modelagem da corrente de escuro de QWIPs formados por poços simples [17].

$$
I_{D}=\frac{m^{*} \cdot k_{B} \cdot T}{\pi \cdot \hbar^{2} \cdot L_{N}} \cdot \exp \left[\frac{-\left(E_{c}-E_{f}\right)}{k_{B} \cdot T}\right] \cdot e \cdot \mu\left(T, N_{i}\right) \cdot \frac{V_{b}}{L_{N}} \cdot A_{d} \quad \text { Equação } 3.24
$$

Nessa equação, $L_{N}$ é a espessura da região ativa do fotodetector, $E_{c}$ é a energia de ativação que corresponde à altura da barreira do poço menos a energia do estado fundamental $\left(E_{B}-E_{l}\right)$, $E_{f}$ é a energia de Fermi, $\mu\left(T, N_{i}\right)$ é a mobilidade em função da temperatura e da dopagem, $V_{b}$ é a voltagem de polarização (bias), e $A_{d}$ a área do dispositivo. A energia de Fermi é determinada por meio da equação 3.25, igualando-se a dopagem total no poço $\left(\mathrm{N}_{\mathrm{i}}\right)$ à quantidade total de elétrons presentes nos dois níveis confinados do poço $E_{b}$ e $E_{a}(t=b$ e $t=a$, na equação 3.25$)$.

$$
N_{i}=\frac{m_{e}^{*} \cdot k_{B} \cdot T}{\pi \cdot \hbar^{2} \cdot L_{w}} \cdot \sum_{t} \ln \left(1+e^{\frac{\left(E_{f}-E_{t}\right)}{k_{B} \cdot T}}\right)
$$

Equação 3.25

A mobilidade $\mu$ é um parâmetro característico de cada banda do semicondutor e depende intrinsecamente da temperatura $T$ e da dopagem $N_{i}$. O valor da mobilidade para o GaAs pode ser obtido por meio da relação empírica dada pela equação 3.26, apresentada na referência [28]:

$$
\mu(T, N i)=\left[1,25 \cdot 10^{-4} \cdot\left(\frac{T}{300}\right)^{2,3}\right]+\left[2 \cdot 10^{-22} \cdot N i \cdot\left(\frac{300}{T}\right)^{1.5}\right]^{-1} \frac{\mathrm{cm}^{2}}{V . s} \quad \text { Equação } 3.26
$$


A Figura 29 apresenta um exemplo de aplicação desse modelo a um QWIP composto por 20 poços quânticos idênticos ao poço descrito na seção 3.4 .4 e apresentado na Figura 25, com barreiras de $300 \AA ̊$ de espessura. A comparação entre a curva experimental e a curva teórica mostra que o resultado obtido com esse modelo simples representa corretamente a corrente de escuro para esse QWIP, dentro do intervalo de voltagem aplicada entre $-2 \mathrm{~V}$ e $2 \mathrm{~V}$.

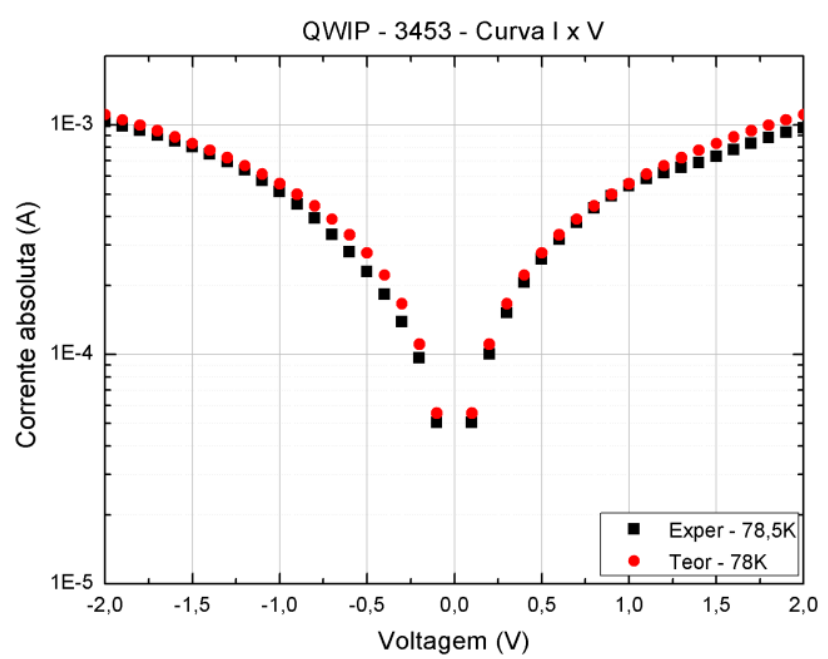

Figura 29: Comparação entre as curvas de corrente no escuro teórica e experimental para um QWIP composto por 20 poços de GaAs de $52 \AA ̊$ de largura com barreiras de Al0.26Ga0.74As de $300 \AA$ A de espessura.

\subsection{Capacitância e circuito ROIC}

Como já mencionado antes, a principal aplicação dos QWIPs se baseia na sua utilização em câmeras de imagens no infravermelho. Para a formação de imagens, é fabricada uma matriz bidimensional de pequenos fotodetectores (pixels) chamada FPA (focal plane array). A leitura do sinal dos pixels é realizada por um circuito integrado ROIC (read-out integrated circuit), fabricado em silício tipicamente com tecnologia CMOS (complementary metal-oxidesemiconductor). A medida da capacitância em função da frequência em um QWIP, ou em qualquer outro tipo de fotodetector, é um parâmetro fundamental para o projeto dos ROICs. No nível de cada pixel, o ROIC possui um circuito que subtrai a corrente de escuro, integra a fotocorrente em um capacitor, e realiza a multiplexação desses sinais, fornecendo como saída valores seriais de voltagem. Câmeras infravermelhas convencionais, com FPAs de 640x512 pixels operando com uma taxa de atualização de imagem de $60 \mathrm{~Hz}$, possuem uma taxa de leitura de cerca de 40 megapixels/s [29]. O tipo de circuito mais indicado para utilização em QWIPs é o amplificador CTIA (capacitive trans-impedance amplifier) [30]. Um esquema simplificado do circuito é apresentado na Figura 30 no bloco da direita está o amplificador CTIA básico, e no bloco da esquerda em baixo está o circuito equivalente do QWIP. No circuito equivalente do QWIP, IF é a fotocorrente, RD é a resistência do QWIP ( $\left.\mathrm{V}_{\text {bias }} / \mathrm{ID}\right)$, sendo ID a corrente de escuro, e Cd é a 
capacitância do pixel do QWIP. O amplificador operacional (op amp) do CTIA possui um ganho $\mathrm{A}$, ou seja, a voltagem de saída é dada por $\mathrm{V}_{\text {saída }}=\mathrm{A} \cdot\left(\mathrm{V}_{+}-\mathrm{V}_{-}\right)$. Nessa configuração a amplificação do sinal DC Vcom é dada pela relação $1+\frac{R F}{R c t r}$. As resistências RF e Rctr em um ROIC são na verdade obtidas com transistores MOSFET, e o valor dessas resistências é ajustado para a realização da integração do sinal da fotocorrente no capacitor CF em cada ciclo de leitura.

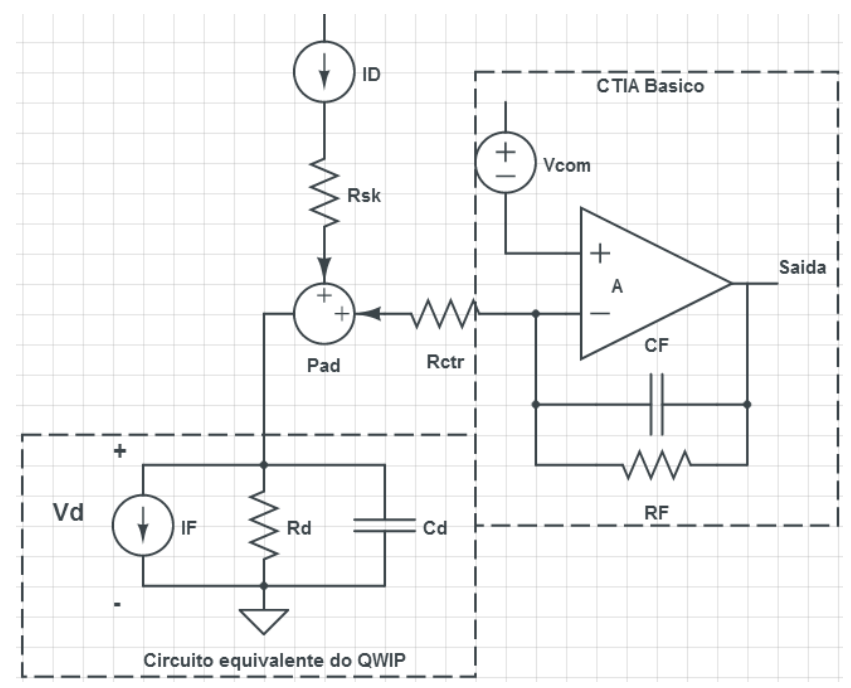

Figura 30: Esquema simplificado de um circuito amplificador CTIA utilizado para QWIPs em um pixel de um FPA.

Para utilização em QWIPs, o circuito CTIA possui como principal vantagem uma boa estabilidade em relação à tensão de polarização (bias) aplicada. Devido à variação da intensidade da radiação que chega ao detector, a fotocorrente introduz uma variação temporal no sinal. A capacitância $\mathrm{Cd}$ da amostra, na entrada inversora (-) do amplificador operacional, diminui o retorno (feedback) do circuito e o torna inerentemente instável [31]. Para assegurar a estabilidade do circuito, o valor da capacitância CF deve ser cuidadosamente escolhido, durante o design do CTIA, para um determinado QWIP. Os valores de CF e RF definem a banda de operação do CTIA, e o valor da capacitância Cd do QWIP deve ser estável $(\mathrm{Cd}(\mathrm{f}) \equiv \mathrm{Cd})$ dentro dessa banda. É portanto importante determinar experimentalmente o valor da capacitância dos QWIPs de maneira a poder desenvolver ROICs adequados para cada aplicação e dispositivo.

A interpretação física convencional da capacitância associa esta grandeza à acumulação de carga elétrica entre placas condutoras. Esse conceito simples vem da eletrostática, onde a corrente de condução é zero e a corrente total está relacionada à redistribuição de cargas no interior da estrutura (corrente de deslocamento). A capacitância, porém, é determinada a partir da variação da corrente total, que é composta pela corrente de deslocamento e pela corrente de condução. Portanto, no caso geral onde a corrente de condução pode ser diferente de zero, esse conceito 
simples não pode ser aplicado, e uma abordagem mais rigorosa é necessária. A capacitância é definida por $\mathrm{C}(\omega)=1 / \omega \operatorname{Im}(\mathrm{Y}(\omega))$, onde $\mathrm{Y}(\omega)$ é a admitância (que é o inverso da impedância, $Y=1 / Z$ ). A capacitância pode ser convenientemente expressa por meio da decomposição de Fourier de uma excitação transiente da corrente total, como [32][33]

$$
C(\omega)=\frac{1}{\Delta V} \int_{0}^{\infty} \delta I(t) \cos \omega t d t . \quad \text { Equação } 3.27
$$

Onde $\Delta V$ na (equação 3.27) é a amplitude da voltagem de excitação e $\delta I(t)=I(t)-I(\infty)$ é a corrente transiente, sendo $\mathrm{I}(\infty)$ a corrente no estado estacionário. Em geral, a corrente transiente $\delta I(t)$ contém a componente de reação instantânea, que depende da capacitância geométrica $C_{0}$, e a componente de relaxação $\delta j(t)$, dependente do tempo, ou seja, $\delta I(t)=\Delta V C_{0} \delta(t)+\delta j(t)$, sendo $\delta(t)$ a função delta. Os conceitos matemáticos aqui introduzidos servirão posteriormente, no capítulo de resultados (Capítulo 8), como fundamentos para a análise dos resultados. 


\section{Capítulo 4}

\section{Crescimento epitaxial}

As amostras de QWIPs utilizadas neste trabalho foram crescidas por meio da técnica de epitaxia de feixes moleculares (MBE) que está disponível em nosso laboratório. Na técnica MBE, feixes de átomos e moléculas são gerados por células aquecidas resistivamente contendo materiais (inicialmente sólidos) de alta pureza. Como a câmara, onde ocorre o processo, está em condições de ultra-alto vácuo (UHV, ultra-high vacum), esses átomos e moléculas possuem um livre percurso médio de dezenas de metros e vão interagir diretamente com a superfície do substrato que se encontra no centro da câmara e sobre o qual as camadas epitaxiais são depositadas. Ao incidirem sobre o substrato, os átomos e moléculas dos feixes tendem a se posicionar nos sítios disponíveis da rede cristalina (Figura 31). O termo epitaxia refere-se ao fato de que cada camada em crescimento tende a seguir a orientação cristalográfica da camada anterior e, portanto reproduz a estrutura cristalina do substrato.

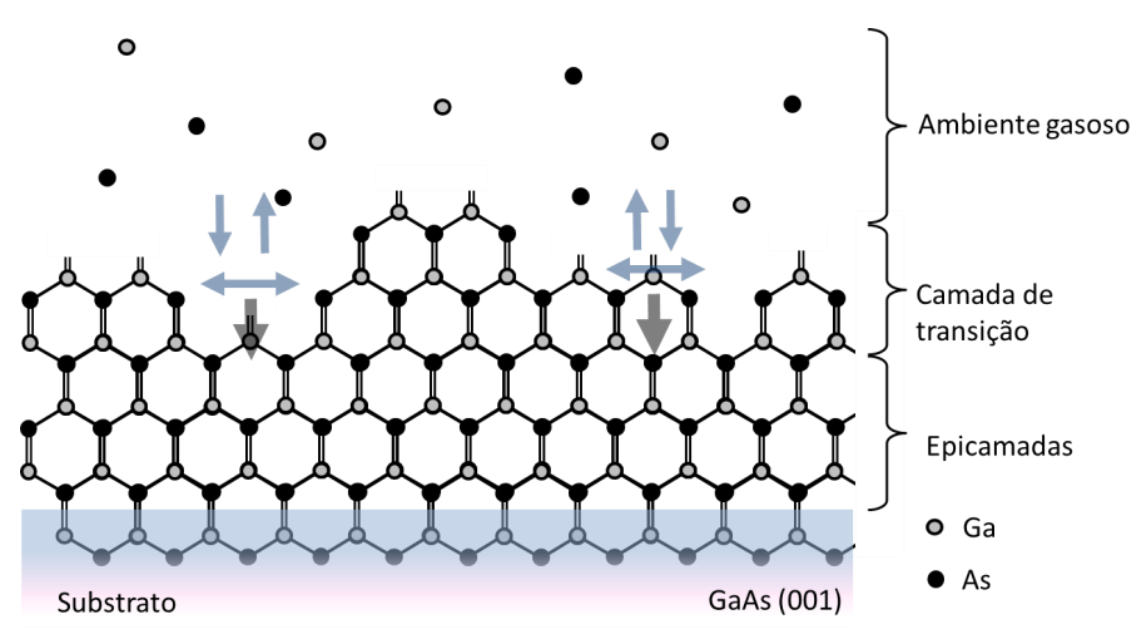

Figura 31: Representação do crescimento epitaxial sobre um substrato de GaAs [34]. O GaAs possui uma estrutura cristalina do tipo zincblend e, portanto, cada átomo de uma espécie está no centro de um tetrágono formado pelos 4 primeiros vizinhos da outra espécie.

Os feixes são gerados por meio da evaporação de cargas de materiais dentro de células de efusão em altas temperaturas, denominadas células de Knudsen. Os materiais de alta pureza (As, $\mathrm{Al}, \mathrm{Ga}, \mathrm{In}, \mathrm{Si}$ e C, no caso do nosso sistema) são mantidos em diferentes temperaturas que são controladas com alta precisão $\left(0,1{ }^{\circ} \mathrm{C}\right)$ de modo a proporcionarem diferentes taxas de deposição 
extremamente estáveis para cada material. O controle da temperatura das células e a presença de obturadores (shutters) na frente de cada célula possibilitam o crescimento de ligas de materiais (AlGaAs, InGaAs) com diferentes composições.

O substrato é aquecido a certa temperatura (geralmente entre 500 e $600{ }^{\circ} \mathrm{C}$, de maneira a propiciar às espécies incidentes uma boa mobilidade superficial), e sobre ele incidem os feixes de materiais provenientes das células de efusão. O crescimento de alguma liga específica é obtido pela abertura de obturadores pneumáticos localizados na frente das respectivas células de efusão, possibilitando a chegada dos elementos na superfície do substrato onde interagirão e serão incorporados. O crescimento ocorre em meio a diversos processos dinâmicos que acontecem simultaneamente na superfície do substrato (adsorção, difusão, incorporação e desadsorção) [34], e é controlado por um computador que regula a temperatura de cada célula e aciona os obturadores para alcançar as composições e espessuras desejadas.

No processo de adsorção, o átomo chega sobre a superfície do substrato e permanece em contato, interagindo por meio apenas de forças de Van der Waals, sem que haja nenhuma troca eletrônica. Após ser adsorvido, o átomo pode difundir lateralmente ao longo da superfície até que seja incorporado quimicamente em um sítio da rede. O processo inverso também pode ocorrer, ou seja, um átomo já incorporado pode se desprender da rede cristalina e voltar a difundir pela superfície, até sofrer desadsorção ou ser incorporado novamente em outro sítio da rede. A eficiência do crescimento depende de um equilíbrio entre todos esses processos que ocorrem no tempo de crescimento de uma monocamada atômica. Portanto, o equilíbrio do processo de crescimento depende das condições de temperatura do substrato e dos fluxos incidentes, assim como da natureza físico-química da superfície.

O regime de crescimento epitaxial em que o material depositado recobre a superfície, camada atômica após camada atômica, e assume o parâmetro de rede do substrato (5,65 ̊ para o GaAs) é conhecido como Frank-van der Merwe (regime de crescimento bidimensional). O parâmetro de rede em uma liga, como $\mathrm{Al}_{\mathrm{x}} \mathrm{Ga}_{1-\mathrm{x}} \mathrm{As}$, é dado pela lei de Vegard que estabelece uma relação linear do parâmetro de rede do GaAs $(5,65 \AA)$ com o parâmetro de rede do AlAs $(5,66 \AA)$, ou seja $\mathbf{a}=$ $5,66 x+5,65(1-x)$. É possível crescer epitaxialmente, sem problema algum, materiais com parâmetros de rede ligeiramente diferentes daquele do substrato, como no caso da liga AlGaAs depositada sobre GaAs. Ligas como o InGaAs podem também ser crescidas de maneira epitaxial sobre GaAs, mas, devido à maior diferença entre o parâmetro de rede do GaAs e do InAs $(6,06 \AA$ ) , apenas algumas combinações de espessura de camada e composição podem ser obtidas com sucesso. A introdução dos átomos de In no GaAs gera uma tensão mecânica no cristal que levará, inicialmente, à acumulação de uma energia elástica no sistema inteiro. O crescimento continuará de maneira epitaxial, no regime de Frank-van der Merwe, até atingir uma espessura crítica de material além da qual a energia elástica armazenada será tão grande que linhas de deslocações poderão ser introduzidas nas camadas epitaxiais para que o material depositado possa adotar o seu parâmetro de rede natural, levando assim à uma minimização da energia total do sistema, Em alguns materiais, pode haver um outro mecanismo de relaxação parcial da energia mecânica, anteriormente à formação das deslocações, que consiste na formação de pequenas ilhas de 
materiais na superfície do substrato, na beira das quais o parâmetro de rede é levemente relaxado. Estas nanoestruturas são muito usadas atualmente para obter pontos quânticos diretamente durante o processo de crescimento (sem qualquer necessidade de processamento posterior da amostra), e este modo de crescimento recebeu o nome de modo de Stranski-Krastanov [35].

\subsection{O sistema MBE}

As amostras utilizadas neste trabalho foram crescidas no sistema MBE disponível em nosso laboratório (Laboratório de Novos Materiais Semicondutores - LNMS). Este sistema foi adquirido da empresa Varian, e está em operação desde 1991. Ele possui três câmaras fabricadas em aço inoxidável, operando em ambiente de ultra alto vácuo, e isoladas entre si por válvulas do tipo gaveta (Figura 32). Essas câmaras são a câmara de entrada e saída, a câmara intermediária e a câmara de crescimento, e cada uma possui o seu próprio sistema de bombeamento. A câmara de crescimento possui um sistema formado por uma bomba iônica de 400 1/s e uma bomba auxiliar, de sublimação de titânio, que pode ser ligada antes do crescimento por alguns minutos. A câmara intermediária possui uma bomba iônica de 220 1/s. A câmara de entrada e saída possui uma bomba iônica de 60 1/s e um sistema de pré-vácuo, formado por uma bomba mecânica seca (sem óleo) e uma bomba turbomolecular de 400 1/s refrigerada a água. O sistema de pré-vácuo também pode ser utilizado para bombear as outras câmaras, quando for necessário, por meio de tubulações e válvulas. O sistema de pré-vácuo é geralmente utilizado na câmara de entrada e saída para a introdução de novos substratos ou a saída das amostras crescidas, assim como após períodos de manutenção do sistema MBE, em que as três câmaras são levadas à pressão ambiente. $\mathrm{O}$ acesso da câmara de entrada e saída é o único acesso ao interior do sistema MBE, e encontra-se dentro de uma sala limpa para minimizar a contaminação pelo ambiente. A quebra do vácuo é feita por meio de um fluxo de nitrogênio $\left(\mathrm{N}_{2}\right)$ gasoso até que seja atingida uma pressão positiva que minimiza a entrada de contaminantes na câmara.

A câmara de entrada e saída e a câmara intermediária são percorridas por um trilho onde podemos movimentar um "carrinho" que transporta os substratos. Este carrinho possui capacidade para 16 blocos de molibdênio de 3" onde os substratos são fixados ou colados com In. Dessa maneira, as amostras podem ser transferidas de uma câmara para outra e para fora do sistema. A transferência das amostras entre a câmara intermediária e a câmara de crescimento é feita por meio de braços transferidores que se encaixam nos blocos de molibdênio e são manipulados externamente por meio de imãs. Após a introdução do carrinho na câmara de entrada, com os novos substratos para o crescimento, a câmara é evacuada até cerca de $10^{-7}$ Torr. A partir dessa pressão, a câmara é aquecida a uma temperatura de $200^{\circ} \mathrm{C}$ para que ocorra a desgaseificação da câmara e do carrinho contendo os blocos com os substratos. No final desta etapa, a pressão deve chegar a $\sim 3 \times 10^{-8}$ Torr na câmara de entrada, e o carrinho pode ser transferido para a câmara intermediária onde os blocos com os substratos esperam pelo crescimento. Essa câmara é equipada com um forno no qual é realizada a desgaseificação individual de cada bloco por cerca de 30 minutos à temperatura de $350^{\circ} \mathrm{C}$ antes de cada crescimento. Finalmente, os blocos com os 
substratos são transferidos para a câmara de crescimento e orientados para a posição de crescimento.

O sistema MBE possui oito células: duas de arsênio (As), duas de gálio ( $\mathrm{Ga}$ ), uma de alumínio (Al), uma de índio (In) e as células dos dopantes: silício ( $\mathrm{Si}$ ) e carbono (C). A célula de carbono possui um elemento resistivo de grafite como fonte de carbono. Nesta configuração, o sistema MBE permite o crescimento apenas de arsenetos: arseneto de gálio (GaAs), arseneto de alumínio (AlAs), arseneto de índio (InAs) e suas ligas ternárias AlGaAs, InGaAs e InAlAs e quaternárias AlGaInAs. Em substratos de GaAs com orientação (100), o silício é utilizado em geral para dopagem do tipo n e o carbono é utilizado para dopagem do tipo p. No interior das células de efusão, o material é acondicionado em cadinhos de PBN (nitreto de boro pirolítico).

Antes de iniciar o crescimento, as células de efusão são aquecidas até a temperatura adequada para obter o fluxo de material compatível com a taxa de deposição desejada. A câmara de crescimento é resfriada internamente por meio de um painel criogênico no interior do qual circula um fluxo constante de $\mathrm{N}_{2}$ líquido. $\mathrm{O}$ painel criogênico mantém uma pressão baixa na câmara (atuando como uma bomba criogênica) e realiza o isolamento térmico entre as células. Cada célula é monitorada por um termopar, e a sua temperatura é controlada por uma ou duas fontes de potência, dependendo da célula. Essas fontes de potência funcionam de maneira automática por meio de um controle do tipo P.I.D. (Proportional-Integral-Derivative). Durante o crescimento, o substrato é mantido aquecido, geralmente entre $500^{\circ} \mathrm{C}$ e $600^{\circ} \mathrm{C}$, por meio de um sistema resistivo homogêneo, e a sua temperatura é controlada por um termopar, montado no estágio de aquecimento que suporta o substrato, e pode ser lida diretamente por meio de um pirômetro infravermelho externo.
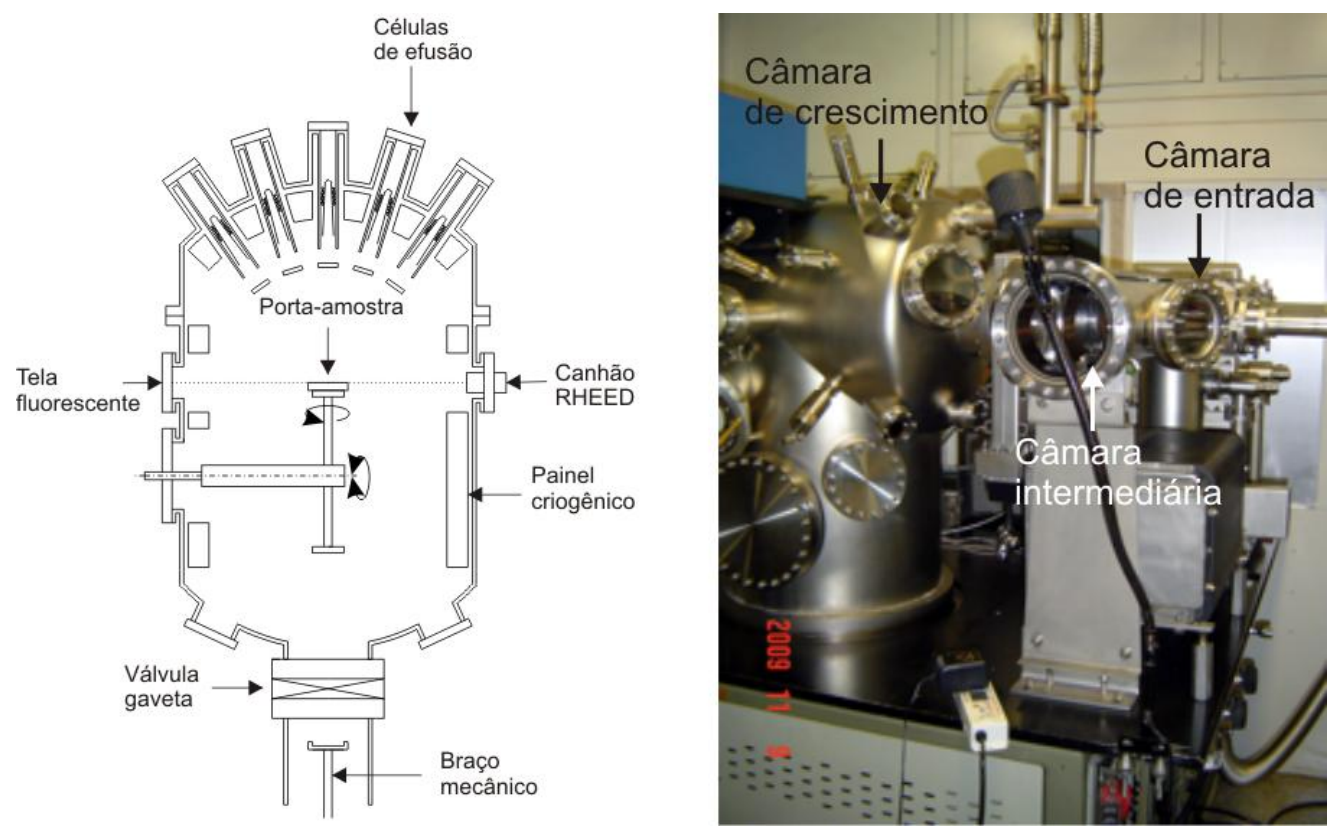

Figura 32: Detalhes da câmara de crescimento (à esquerda) e do sistema MBE (à direita) disponível em nosso laboratório. 
A deposição dos materiais é controlada por um programa que foi desenvolvido no ambiente LabWindows e possibilita a introdução dos parâmetros de crescimento, tais como as taxas de crescimento de cada liga, e a natureza e espessura de cada camada da estrutura a ser fabricada. $\mathrm{O}$ crescimento é monitorado por medidores de pressão e fluxo, e pode ser acompanhado in situ em tempo real por meio de um sistema RHEED (Reflection High-Energy Electron Diffraction).

\subsection{0 sistema RHEED}

O sistema RHEED é utilizado na calibração das taxas de crescimento e no acompanhamento do crescimento da amostra, e é uma ferramenta poderosa para a análise in situ da superfície da amostra em nível atômico, assim como dos processos físicos que nela ocorrem. Nessa técnica, um feixe de elétrons de alta energia ( $\sim 8 \mathrm{keV}$ em nosso caso) é gerado por um canhão de elétrons e incide em ângulo rasante (aproximadamente $1^{\circ}$ ) sobre a superfície da amostra. $\mathrm{O}$ feixe projeta, em uma tela de fósforo localizada do lado oposto ao canhão, o padrão de difração resultante da interação (reflexão especular + difração) dos elétrons com os átomos do arranjo cristalino da superfície da amostra. A Figura 33 ilustra a disposição do sistema RHEED no interior da câmara de crescimento.

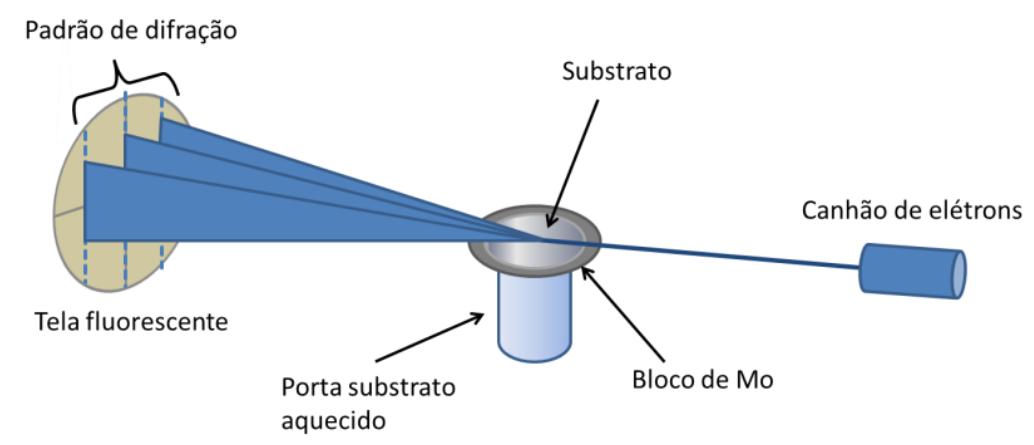

Figura 33: Disposição do sistema RHEED no interior da câmara de crescimento.

O ângulo de incidência rasante do feixe produz um padrão de difração que representa a interação com apenas as primeiras monocamadas atômicas do filme, o que faz da técnica uma ferramenta excepcional para a análise dos fenômenos de superfície. A formação do padrão RHEED pode ser entendida a partir da técnica de construção da esfera de Ewald no espaço recíproco [36] [37]. Como a interação ocorre com um sistema quase bidimensional (apenas as primeiras camadas atômicas da superfície), temos um padrão de linhas ao invés de um padrão de pontos, como seria no caso de uma interação do feixe de elétrons com uma rede cristalina em 3D. O padrão típico de RHEED é constituído por um conjunto de linhas paralelas e por um ponto brilhante relacionado com a reflexão especular do feixe de elétrons pela superfície. O espaçamento 
entre as linhas depende do parâmetro de rede do cristal e da orientação cristalográfica do plano de incidência em relação ao feixe. A Figura 34 ilustra a construção da esfera de Ewald no espaço recíproco formado por bastões (ao invés de pontos) devido à interação do feixe de elétrons com um sistema bidimensional [37]. Na Figura 34, $\lambda$ é o comprimento de onda dos elétrons incidentes, k0 é o vetor de onda dos elétrons do feixe incidente, $k$ é o vetor de onda do feixe espalhado e $\mathrm{G}$ é um vetor da rede recíproca dado pela condição $G=k-k 0$, sendo $|k|=|k 0|$. As intersecções entre a esfera de Ewald e os bastões no espaço recíproco determinam as condições de difração permitidas que se manifestam na tela de fósforo pela presença de segmentos de reta como função da espessura da esfera de Ewald proveniente da não monocromaticidade ideal do feixe de elétrons.

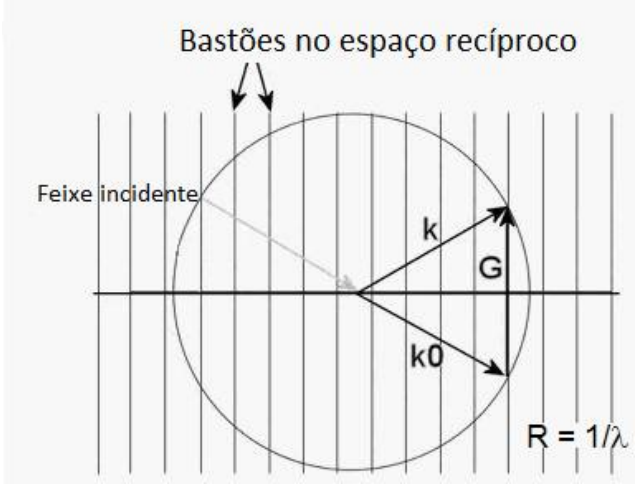

Figura 34: Esfera de Ewald para o caso de um espalhamento bidimensional do feixe eletrônico. $R$ é o raio da esfera, $\lambda$ é o comprimento de onda dos elétrons, $k 0$ é o vetor de onda do feixe de elétrons incidentes, $k$ é o vetor de onda do feixe espalhado, e $G$ é um vetor da rede recíproca.

Durante o crescimento, a formação sucessiva das monocamadas atômicas produz uma oscilação da intensidade do feixe especular (parte do feixe incidente que é refletida diretamente pela superfície de maneira especular), que também é detectada sobre a tela de fósforo. O processo de formação das monocamadas altera periodicamente a rugosidade da superfície do substrato (nucleação de pequenas ilhas de materiais que atuam como centros espalhadores do feixe de elétrons) e, portanto, tem efeito na sua refletividade, tornando-a mais ou menos refletora. $\mathrm{O}$ feixe especular refletido pela amostra incide na tela de fósforo com intensidade máxima quando a rugosidade é mínima (a última camada atômica esta completamente preenchida), e com intensidade mínima quando a rugosidade é máxima (a camada superficial está preenchida na metade e repleta de pequenas ilhas bidimensionais). O período de oscilação da intensidade do feixe especular corresponde, portanto, ao tempo de formação de uma monocamada completa. Consequentemente, é possível determinarmos as taxas de crescimento de todos os materiais e ligas com precisão de uma fração de monocamada atômica. Por meio de um sistema formado por uma câmera de vídeo CCD (apontada para a tela de fósforo onde o padrão de difração é visualizado) e de um computador, podemos gravar, acompanhar e analisar em tempo real as oscilações da intensidade luminosa do feixe especular durante o crescimento (Figura 35). 


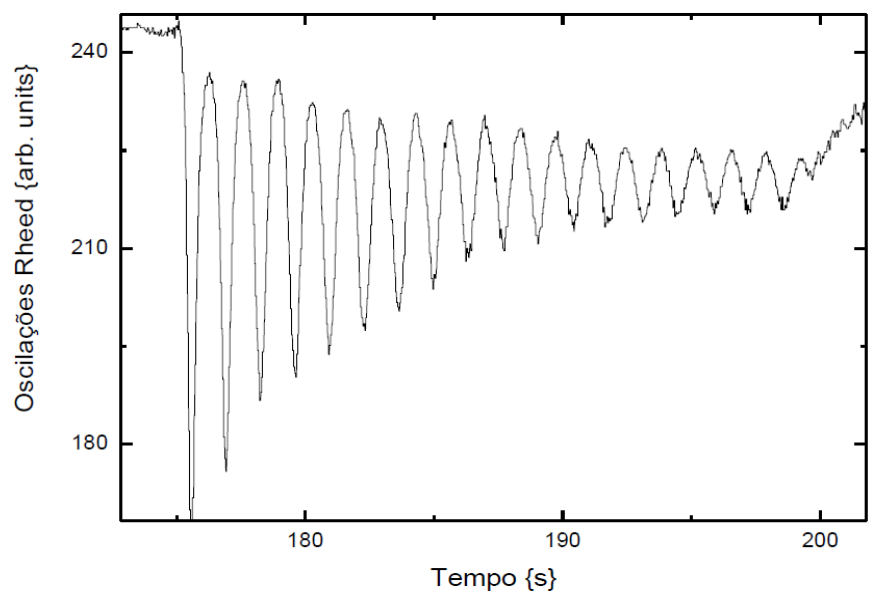

Figura 35: Registro das oscilações do ponto especular do padrão de difração do sistema RHEED durante o crescimento de camadas de GaAs sobre um substrato de GaAs.

A técnica MBE permite o crescimento de heteroestruturas com excelente qualidade cristalina sobre substratos de grande tamanho (até 6 polegadas de diâmetro no caso do GaAs), com interfaces abruptas, perfis de potencial variados e controle da espessura das camadas em nível atômico. Por isso, essa técnica é considerada ideal para a fabricação de QWIPs. 


\section{Capítulo 5}

\section{QWIPs crescidos por MBE}

Para o desenvolvimento dos QWIPs, foram escolhidas estruturas com absorção nas duas janelas atmosféricas (Figura 10), nas bandas de $3 \mu \mathrm{m}$ a $5 \mu \mathrm{m}$ e de $8 \mu \mathrm{m}$ a $12 \mu \mathrm{m}$. Para isso, foram crescidos QWIPs de GaAs/AlGaAs com dopagem do tipo n, crescidos sobre substrato de GaAs.

\subsection{QWIPs com transição intrabanda na janela atmosférica de $8 \mu \mathrm{m}$ a $12 \mu \mathrm{m}$}

As amostras 3453 e 3495 foram crescidas com estruturas nominalmente idênticas (Figura 36 (a)). Essa estrutura serviu de base para os primeiros estudos de reprodutibilidade do crescimento e do processamento das amostras para a fabricação dos dispositivos (fotodetectores). As amostras 3494 e 3504 foram crescidas com barreiras adicionais de AlGaAs fora dos poços, com diferentes valores de dopagem dentro dos poços (Figura $36(b)$ ). Essas barreiras melhoram o coeficiente de absorção do QWIP, porém possuem também um efeito potencialmente negativo, já que podem barrar uma parte da fotocorrente. A amostra 3517 corresponde a um QWIP padrão para transições intrabanda ocorrendo do estado fundamental para um estado excitado fracamente ligado, próximo ao nível do potencial da barreira do poço, quase no contínuo (Figura $36(c)$ ). Essa configuração, segundo a literatura [17][18][21], fornece a melhor relação entre o coeficiente de absorção e a corrente de escuro. Essa amostra (3517) foi desenvolvida em conjunto com os pesquisadores Gustavo Soares Vieira e Ângelo Pássaro do IEAv - CTA, de São José dos Campos. A amostra 3559 corresponde a um QWIP no qual os poços de potencial são formados por uma liga de $\mathrm{Al}_{0,13} \mathrm{Ga}_{0,87} \mathrm{As}$ ao invés de um poço convencional de GaAs (Figura $36(d)$ ). Essa amostra foi preparada para analisarmos o efeito dos poços de AlGaAs sobre o desempenho do QWIP. Nesse caso as barreiras são mais altas, de modo a inibir a injeção de portadores dos contatos que contribuem para a corrente de escuro.

A região ativa de um QWIP é geralmente afetada pela presença das camadas dopadas de contato adjacentes, que provocam o realinhamento do nível de Fermi dos poços quânticos devido à redistribuição de cargas ao longo da estrutura [38], produzindo assim uma deformação do perfil das bandas nos poços quânticos que compõem a região ativa do QWIP. A amostra 3517 foi projetada de modo a minimizar esse efeito, já que, nesse QWIP, a dopagem das duas regiões foi otimizada de maneira que os níveis de Fermi dos poços e dos contatos estejam inicialmente alinhados, evitando assim qualquer transferência de carga. 


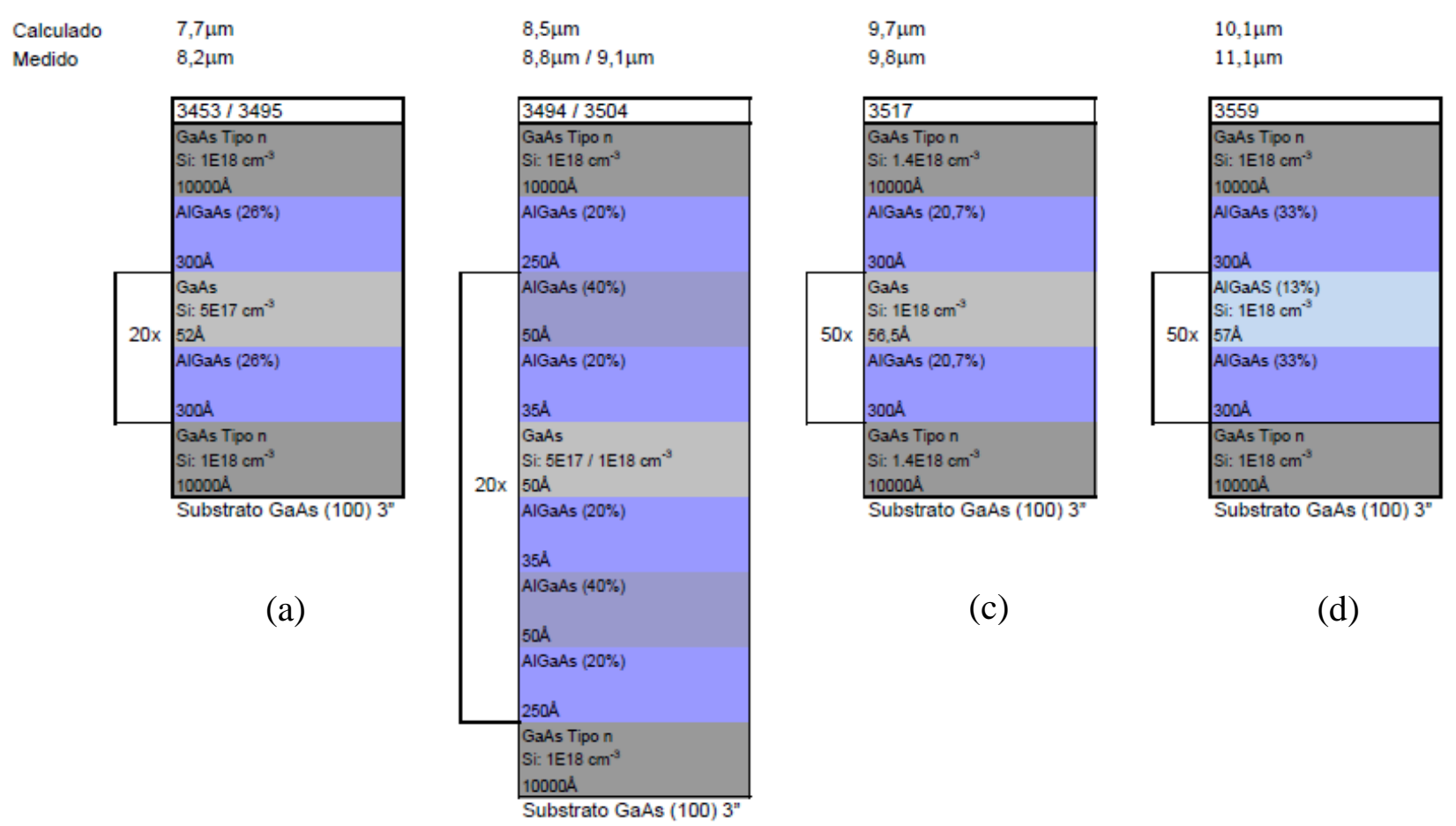

(b)

Figura 36: Esquema da estrutura das amostras de QWIPs projetados para transição intrabanda entre $8 \mu m$ e $12 \mu \mathrm{m}$; (a) Amostra padrão de QWIP usada como referência no início desta tese; (b) QWIP com barreiras externas suplementares; (c) QWIP desenvolvido em conjunto com pesquisadores do IEAv - CTA em São José do Campos; (d) QWIP com poços de $A l_{x} G a_{1-x} A s / A l_{y} G a_{1-y}$ As. Os valores teóricos e experimentais do comprimento de onda de operação são mostrados acima de cada estrutura.

\subsection{QWIPs com transição intrabanda na janela atmosférica de $3 \mu \mathrm{m}$ a $5 \mu \mathrm{m}$}

Foram crescidos três QWIPs para absorção na janela atmosférica entre $3 \mu \mathrm{m}$ e $5 \mu \mathrm{m}(3498$, 3564 e 3570) (Figura 37). As amostras 3564 e 3570 correspondem à mesma estrutura para

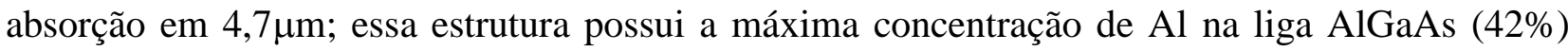
para que haja ainda uma transição de gap direto. Essas amostras foram crescidas com dopagens diferentes nos poços, $2 \times 10^{18} \mathrm{~cm}^{-3}$ e $1 \times 10^{18} \mathrm{~cm}^{-3}$, respectivamente, de modo a estabelecermos o melhor valor de dopagem. Como, para essas amostras, a barreira de potencial de AlGaAs é mais alta, a dopagem dos poços foi aumentada, na tentativa de compensar a perda na fotocorrente, sem comprometer a sua performance com o aumento esperado da corrente de escuro e do ruído. Todas as amostras de QWIPs foram projetadas com o programa que foi desenvolvido para o cálculo dos níveis de energia e das funções de onda dos poços quânticos. 


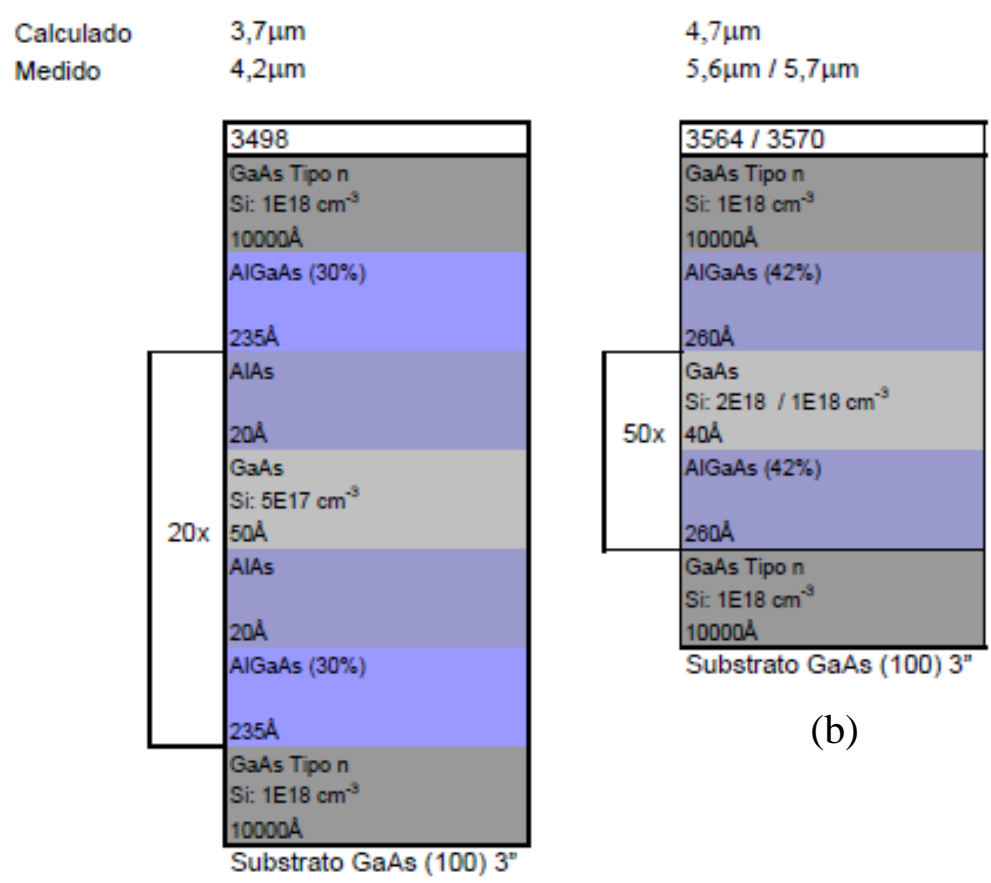

(a)

Figura 37: Esquema da estrutura das amostras de QWIPs projetados para transição intrabanda entre 3 um e $5 \mu \mathrm{m}$; (a) Amostra de QWIP com barreiras externas suplementares; (b) QWIP com maior concentração de Al nas barreiras, que ainda permita transição de gap direto.

A utilização de barreiras extras nas amostras 3495, 3498 e 3504 provou-se geralmente desvantajosa, pois, embora melhore a absorção, apresenta-se como uma barreira extra para os elétrons fotogerados, o que diminui a fotocorrente.

\subsection{Amostras de QWIPs para transição entre estados zero-dimensionais}

Quando um átomo de silício é usado como dopante do tipo n (entrando por exemplo como impureza substitucional no sítio do Ga na rede cristalina do GaAs), o elétron disponibilizado na estrutura ainda permanece ligado ao átomo de silício por meio da atração coulombiana com o núcleo. Para produzirmos um excesso de portadores de cargas livres no semicondutor, é necessário dopar o semicondutor com uma concentração de dopantes alta o suficiente para, que esses portadores de carga não enxerguem mais apenas o potencial coulombiano do núcleo das impurezas de origem e passem a se comportar como portadores livres. Essa transição semicondutor-metal é conhecida como transição de Mott [24] e acontece quando o nível discreto de energia atribuído às impurezas entra na banda de condução do material hospedeiro. No GaAs maciço (bulk), essa transição ocorre para concentrações de dopantes da ordem de $10^{16}$ átomos de silício por centímetro cúbico [25]. No caso de poços quânticos, essa transição ocorre geralmente para dopagens mais altas, entre $10^{17}$ e $10^{18}$ átomos de silício por centímetro cubico [25][26], dependendo dos parâmetros dos poços. Para impurezas isoladas (baixa concentração de dopantes) contribuindo 
apenas com um elétron para a dopagem num material maciço, as funções de onda são parecidas com as funções de onda do átomo de hidrogênio (impurezas hidrogenóides). Nos poços quânticos usados nos QWIPs, as barreiras modulam as funções de onda e aumentam o efeito de confinamento espacial dos elétrons, provocando assim um 'atraso' na transição de Mott. Este efeito foi pouco estudado até o momento em QWIPs com transições entre estados zero-dimensionais das impurezas hidrogenóides, mas tudo indica que este tipo de dispositivo deve apresentar baixa corrente de escuro e ótimas características de ruído [26]. Até onde sabemos, nenhum trabalho experimental completo foi publicado até o momento a respeito de QWIPs operando com este princípio.

As amostras apresentadas na Figura 38 (3571, 3572 e 3591) foram crescidas para estudar os QWIPs com transição entre estados zero-dimensionais. Elas foram projetadas com a ajuda dos cálculos implementados especificamente para esse objetivo (Seção 3.5). As amostras 3571 e 3572 possuem estrutura idêntica, diferindo apenas pela densidade da dopagem na região central dos poços. Nesse tipo de estrutura, é importante não dopar o poço muito próximo às barreiras, pois nessas regiões, o efeito de confinamento que ajuda a manter os elétrons nos estados zerodimensionais diminui progressivamente. A amostra 3591 foi crescida sem as camadas de contato de GaAs dopado com $\mathrm{Si}$, pois essa amostra irá servir para a realização de medidas de transporte, de forma a analisarmos a transição de Mott nesse tipo de sistema.
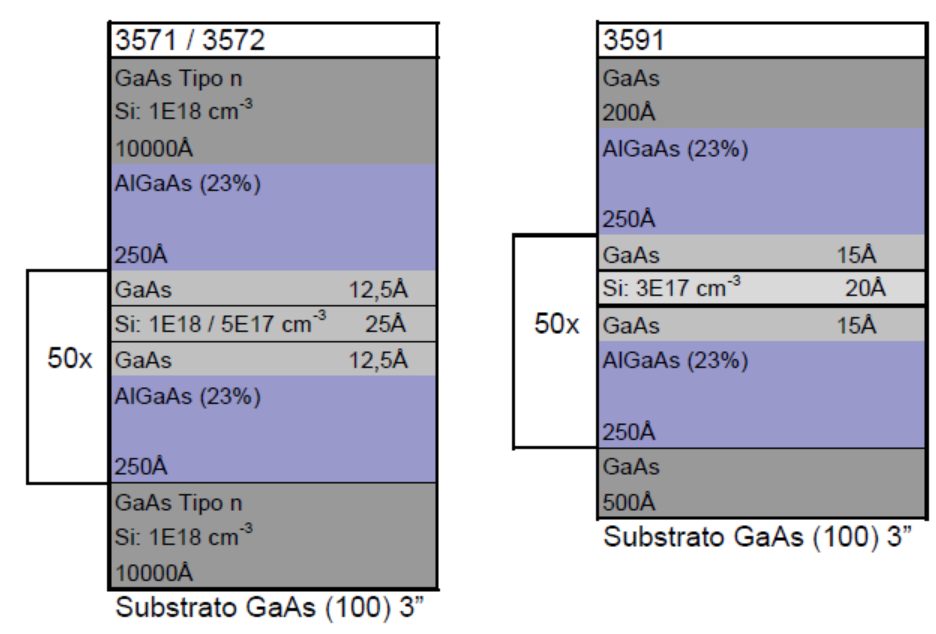

Figura 38: Representação da estrutura das amostras de QWIPs crescidos para investigar a transição entre níveis zero-dimensionais de uma impureza hidrogenóide. 


\section{Capítulo 6}

\section{Fabricação dos fotodetectores (QWIPs)}

A estrutura básica dos fotodetectores é formada por duas camadas espessas e dopadas (condutoras), onde serão feitos posteriormente os contatos elétricos do dispositivo, entre as quais é localizada a região ativa responsável pela detecção da radiação de interesse e pela geração da fotocorrente. Partindo da amostra já crescida, a fabricação de um QWIP consiste basicamente em quatro etapas: a formação das mesas que definem o tamanho físico dos dispositivos, a deposição de finos filmes metálicos em certas regiões para a formação dos contatos metálicos, o polimento do chanfro numa beira da amostra para a incidência em $45^{\circ}$ na região ativa, e finalmente a montagem do dispositivo sobre o seu suporte (Figura 23).

Primeiramente, o padrão de uma máscara, que determinará a geometria e o tamanho dos futuros dispositivos, é transferido sobre a amostra utilizando técnicas convencionais de fotolitografia, e é seguido por um ataque químico para a formação das mesas. O objetivo do ataque químico é definir o tamanho físico dos fotodetectores e expor a camada de contato (dopada) inferior, onde um dos contatos metálicos será depositado. Na sequência é realizada uma segunda etapa de fotolitografia, com uma máscara diferente, para definir as regiões da amostra onde serão depositados os filmes metálicos que formarão os contatos elétricos. A Figura 39 ilustra o resultado do processamento para a formação dos fotodetectores.

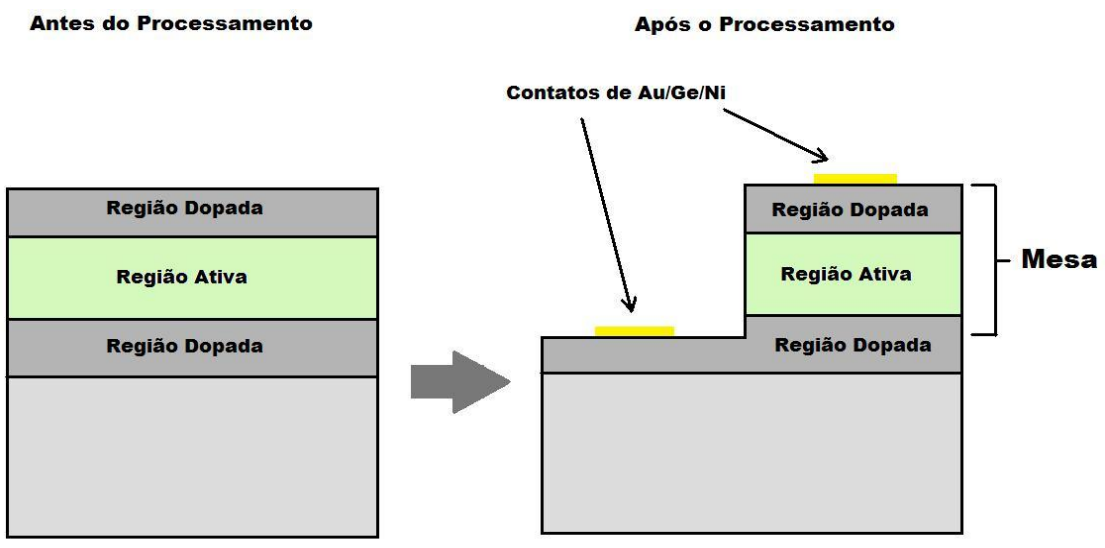

Figura 39: Esquema do processamento para tornar a amostra inicial (à esquerda) em um fotodetector que poderá ser testado (à direita). 


\subsection{Fotolitografia óptica}

A fotolitografia transfere um padrão geométrico de uma máscara para a superfície da amostra crescida. $\mathrm{O}$ processo de transferência envolve o recobrimento da superfície da amostra com uma fina camada de resina fotossensível (fotorresiste) e a exposição desse filme, parcialmente protegido pelo padrão da máscara, à radiação UV de uma fotoalinhadora de máscara (Figura 40).

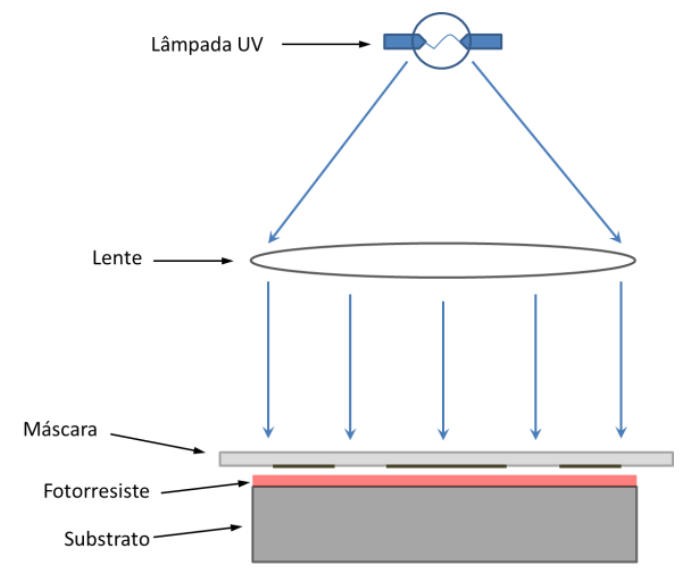

Figura 40: Desenho esquemático da técnica de fotolitografia óptica.

O espalhamento da fina camada de fotorresiste sobre a superfície da amostra é realizado num spinner. A amostra é fixada na base do spinner por um sistema de sucção por vácuo, e a sua superfície é previamente coberta com algumas gotas de um promotor de adesão (HMDS). A amostra é então colocada para girar em alta velocidade (4000 rpm) durante um minuto para espalhar o HMDS de maneira homogênea sobre a superfície. A seguir, algumas gotas de fotorresiste (que deve estar à temperatura ambiente para possuir a viscosidade correta) são colocadas sobre a amostra, e o spinner é novamente acionado por $30 \mathrm{~s}$ a $4000 \mathrm{rpm}$. Neste trabalho, foi utilizado o fotorresiste positivo AZ3312 para a definição das mesas. Para estes parâmetros do spinner e uma temperatura do fotorresiste de $20 \pm 2{ }^{\circ} \mathrm{C}$, a espessura final da camada de fotorresiste é de cerca $1,4 \mu \mathrm{m}$. A amostra passa então por um processo de cura a $110^{\circ} \mathrm{C}$ por 2 minutos (soft baking) para eliminar o solvente presente no fotorresiste, antes de ser posicionada na alinhadora de máscaras onde ela é novamente segurada por um sistema de sucção. Na alinhadora, a máscara possuindo o padrão das mesas é posicionada sobre a amostra, que é alinhada com algum eixo cristalino da amostra para facilitar uma eventual clivagem posterior, e o conjunto é submetido a uma radiação ultravioleta, por um certo tempo (Com uma lâmpada emitindo uma intensidade de radiação UV. Este período de exposição depende principalmente da lâmpada, da espessura e do tipo de fotorresiste utilizados). A amostra é então retirada da alinhadora e mergulhada numa solução reveladora (AZ400MIF) que dissolverá as regiões do fotorresiste que foram diretamente expostas (sensibilizadas) à radiação ultravioleta, e deixará intactas as regiões protegidas pelo padrão presente sobre a máscara (no caso de um fotorresiste negativo, o contrário aconteceria). No final desta etapa de revelação, a amostra possui na sua superfície um padrão em fotorresiste idêntico ao presente na máscara, e ainda precisa passar por um segundo processo de cura a $120^{\circ} \mathrm{C}$ por 20 minutos (hard baking), para aumentar a resistência do filme de modo a resistir ao ataque químico seguinte. 


\subsection{Corrosão química da superfície}

$\mathrm{O}$ ataque químico da superfície das amostras para a formação das estruturas de "mesas" foi realizado utilizando-se uma solução de água deionizada $\left(\mathrm{H}_{2} \mathrm{O}\right.$ D.I.), água oxigenada $\left(\mathrm{H}_{2} \mathrm{O}_{2}\right)$ e ácido sulfúrico $\left(\mathrm{H}_{2} \mathrm{SO}_{4}\right)$ nas proporções 40:8:1 em volume. Essa solução fornece normalmente uma taxa de corrosão para o GaAs de cerca de $1 \mu \mathrm{m}$ por minuto, mas essa taxa pode variar significativamente dependendo da qualidade dos produtos químicos utilizados e da temperatura final da solução, uma vez que a reação química entre os reagentes é exotérmica. Para assegurar que o ataque químico corroa até aproximadamente à metade da camada de contato inferior da estrutura, recomendasse que a corrosão seja feita em duas etapas, e que a altura das mesas seja medida com um perfilômetro a cada etapa. É aconselhado repetir a medida em vários lugares da amostra para evitar qualquer problema proveniente da eventual variação de espessura do fotorresiste. Para interromper instantaneamente o ataque químico e possibilitar medidas confiáveis com o perfilômetro, a amostra deve ser enxaguada em água corrente e seca com nitrogênio gasoso. Quando a altura desejada das mesas é alcançada, o fotorresiste que cobre as mesas pode ser removido facilmente num banho de acetona, seguido por um enxague em metanol (ou isopropanol) e uma secagem com nitrogênio gasoso.

\subsection{Deposição dos contatos metálicos e recozimento térmico rápido}

Contatos ôhmicos sobre GaAs podem ser obtidos a partir da deposição de filmes metálicos de $\mathrm{Ni} / \mathrm{Ge} / \mathrm{Au}$, seguida por um processo de recozimento térmico rápido (RTA - rapid thermal annealing). Esses metais são depositados em sequência, sob a forma de filmes finos, por sputtering, evaporação térmica ou por feixe de elétrons (e-beam). Por meio de uma segunda etapa de fotolitografia, o padrão geométrico dos contatos (contido numa outra máscara) é transferido para a superfície da amostra. Como os fotodetectores desenvolvidos nessa tese são destinados a serem usados futuramente em FPAs, sobre cada mesa é depositado um contato elétrico, e na base das mesas é depositado um outro contato, comum a todos os dispositivos, em cima da camada de contato inferior inteira que foi exposta durante a corrosão química (Figura 39). A ideia desta etapa de fotolitografia é diferente da primeira, uma vez que agora é necessário mascarar a amostra de modo que o filme metálico seja depositado apenas nas regiões onde serão formados posteriormente os contatos elétricos. Para isso, as etapas anteriores de fotolitografia são novamente repetidas, desta vez com a máscara de contatos, até a fase de revelação. Nesse processo, o fotorresiste é sensibilizado pela radiação UV que passa através das áreas definidas pela máscara, nas quais o fotorresiste é removido durante a revelação, de modo a expô-las para a deposição dos filmes metálicos. Com tais características esse processo é definido como um processo fotolitográfico positivo, onde são utilizados um fotorresiste positivo e uma mascara do tipo campo escuro, com janelas abertas nos lugares onde se pretende formar os contatos metálicos. Nessa etapa, é necessário realizar o alinhamento da máscara de contatos na fotoalinhadora com o padrão das mesas abaixo, previamente obtidas na etapa anterior de litografia. Na maioria das 
vezes, dependendo do padrão da máscara de contatos, uma máscara de campo escuro torna difícil esse alinhamento e nesse caso podemos utilizar um processo fotolitográfico negativo, onde a região do fotorresiste que permanece na amostra é a região que foi exposta à radiação UV. No processo negativo utiliza-se um fotorresiste negativo e uma máscara negativa, ou máscara de campo claro. Essa abordagem é necessária em alguns casos em que a área opaca da máscara de campo escuro bloqueia boa parte da visão do padrão abaixo e inviabiliza o alinhamento dos dois padrões. Nesta tese, dependendo da disponibilidade, foram utilizados nesta etapa, tanto o fotorresiste positivo AZ3312 como o fotorresiste AZ5214E, em modo positivo. O fotorresiste AZ5214E pode ser usado também como um fotorresiste negativo que, após uma etapa suplementar de exposição sem máscara (chamada flood), possibilita realizar processos fotolitográfico negativos (este procedimento se chama inversão de imagem). Este procedimento é mais complexo, mas costuma produzir um perfil negativo no filme de fotorresiste que o torna mais adequado para a deposição dos filmes metálicos e para a fase seguinte de lift off. Por simplicidade, usamos na maioria das vezes uma máscara de campo escuro (em óxido de ferro) e o fotorresiste AZ5214E em modo positivo. Para possibilitar um bom alinhamento das pequenas janelas da máscara com as mesas anteriormente gravadas na amostra, a máscara foi feita com uma camada de óxido de ferro, que é parcialmente transparente no visível, mas é opaca na região UV usada pela alinhadora. As nossas máscaras foram desenhadas no software CleWin e confeccionadas na UFMG em uma laser writer, a partir da colaboração com o Prof. Wagner Nunes Rodrigues. Os parâmetros usados durante a segunda etapa de litografia foram $4000 \mathrm{rpm}$ e $30 \mathrm{~s}$ no spinner para obtermos uma camada de cerca de $1,4 \mu \mathrm{m}$ de espessura a $20 \pm 2{ }^{\circ} \mathrm{C}$, e um tempo de revelação (na solução 1:1 $\mathrm{H}_{2} \mathrm{O}$ (D.I.)/AZ400MIF) entre $20 \mathrm{~s} \mathrm{e} 40 \mathrm{~s}$. Em alguns casos, a estrutura da amostra é tão espessa que as mesas chegam a ter mais de 3 ou $4 \mu \mathrm{m}$ de altura. É então aconselhável depositar uma maior espessura de fotorresiste para cobrir melhor as partes laterais das mesas. Isto pode ser feito usando uma frequência de rotação menor da amostra (e eventualmente outro fotorresiste capaz de produzir naturalmente camadas mais grossas) ou então aplicando duas camadas seguidas de fotorresiste com os parâmetros usuais.

Uma vez que a amostra foi revelada e está com as janelas abertas no fotorresiste para a deposição dos filmes metálicos ela deve ser submetida a um plasma de oxigênio $\left(50 \mathrm{sccm} \mathrm{de} \mathrm{O}_{2}\right.$, $100 \mathrm{~W}$ por 2 minutos) para remover os eventuais resíduos de fotorresiste que possam ter permanecido nas janelas após a revelação. Durante o processo, íons de oxigênio e radicais livres são gerados pelo plasma e reagirão com o fotorresiste e com qualquer outro material orgânico presente sobre a amostra, gerando $\mathrm{CO}_{2}$ e água que serão evacuados pelo sistema de bombeamento.

A deposição das camadas metálicas pode ser realizada por evaporação térmica, por sputtering ou feixe de elétrons. A qualidade e o controle do filme são geralmente melhores por feixe de elétrons, e essa técnica também costuma facilitar a remoção do filme que foi depositado fora das regiões de interesse (isto é, sobre o fotorresiste e não nas janelas abertas no fotorresiste). Existem várias receitas para obter bons contatos ôhmicos sobre camadas de GaAs dopadas do tipo n, e a grande maioria usa $\mathrm{Ni}$, Ge e $\mathrm{Au}$, às vezes separadamente, às vezes em ligas eutéticas (Au-Ge, 8812). Foram testadas várias receitas para os contatos ôhmicos em GaAs dopado tipo $n$, mas a receita que utilizamos na maioria das vezes foi Ni/Ge/Au (250/550/1500 $\AA$ ou 350/500/2000 $\mathrm{A})$. Uma vez depositado, o fotorresiste e o filme metálico acima dele devem ser removidos (processo 
chamado lift off). Isto é realizado mergulhando a amostra em acetona para dissolver o fotorresiste (pelas bordas das janelas) e soltar o filme metálico daquelas regiões. Após um enxague em isopropanol e uma secagem com nitrogênio gasoso, a amostra passa num sistema de recozimento térmico rápido (RTA, rapid thermal annealing) onde é aquecida a $420{ }^{\circ} \mathrm{C}$ por $20 \mathrm{~s}$. Este equipamento possibilita uma rampa de temperatura na subida de até $100{ }^{\circ} \mathrm{C} / \mathrm{s}$, e na descida de até $40{ }^{\circ} \mathrm{C} / \mathrm{s}$. A interação entre os filmes de $\mathrm{Ni} / \mathrm{Ge} / \mathrm{Au}$ e o substrato de GaAs é bastante complicada. O processo de RTA forma na superfície do contato metálico uma liga condutora ôhmica de AuGe bastante estável, o principal papel do filme de Ni sendo incrementar a adesão entre os metais e o GaAs, tornando o contato mais homogêneo e promovendo a interação Au-Ge com o GaAs. O Ge é um elemento do grupo IV e atua como um dopante no GaAs [39]. Em geral, bons contatos ôhmicos são observados em amostras nas quais, na interface com o GaAs, são formados compostos de $(\alpha, \beta)-\mathrm{AuGa}, \mathrm{NiAs}(\mathrm{Ge})$ e NiGe [39]. A grossa camada de Au é necessária para possibilitar as microssoldas com finos fios de ouro que serão realizadas na etapa final do processamento.

\subsection{Polimento para a formação do guia de onda}

Geralmente, os QWIPs do tipo n não possuem uma boa absorção em incidência normal, e precisam de uma grade de difração ou de um chanfro para serem testados em boas condições. Neste trabalho, optamos pelo polimento do chanfro lateral a $45^{\circ}$ numa das beiras da amostra, por ser mais fácil e rápido (Figura 23). A superfície superior dos substratos comerciais usados no crescimento é plana em nível atômico, e a epitaxia não gera rugosidade (quando é bem sucedida). Assim, a radiação incidente atravessa o chanfro e penetra na amostra, atingindo a região ativa com um ângulo de $45^{\circ}$. Após atravessar a região ativa, a radiação atinge a superfície da amostra, sofre reflexão interna total, e a atravessa novamente. Para garantir que a radiação incidente através do chanfro seja absorvida de forma homogênea em toda a extensão da mesa, a superfície inferior do substrato também deve ser polida de modo a formar um guia de onda por múltiplas reflexões ao longo da amostra. O polimento é feito com as ferramentas e métodos desenvolvidos por nós, mostrados na Figura 41. Inicialmente, um pedaço da amostra é colado com uma cera especial (facilmente removível com acetona) sobre um cilindro cuja extremidade foi cortada com um ângulo de $45^{\circ}$ (Figura 41 (c)). Este cilindro é inserido num guia cilíndrico e oco que será usado para realizar um polimento otimizado, homogeneizando a força aplicada na superfície da amostra e minimizando o erro do ângulo de polimento (Figura 41 (b)). A beira da amostra que ultrapassa levemente o topo do cilindro interno é então desbastada sobre uma lixa d'agua com granulosidade 2500. Após alguns minutos, o chanfro já é formado e precisa agora ser polido. Isto é feito utilizando um feltro, colado sobre uma superfície plana de vidro, e uma suspensão de partículas de alumina em água. Um pouco desta solução é dispersa sobre o feltro, e a amostra é então polida usando uma solução com partículas de $1 \mu \mathrm{m}$ de diâmetro. Durante esse processo a amostra e o feltro passam por alguns enxagues com um sistema de água ultrapura, e uma pistola de nitrogênio gasoso é utilizada para a secagem. É muito importante realizar alguns enxagues com água 
ultrapura durante o polimento, pois isso elimina partículas que podem provocar riscos profundos na superfície espelhada e que podem prejudicar os testes ópticos e elétricos. Após esses procedimentos, a amostra é desprendida do cilindro num banho de acetona quente, enxaguada em acetona e em seguida em isopropanol, e finalmente é seca com nitrogênio gasoso.

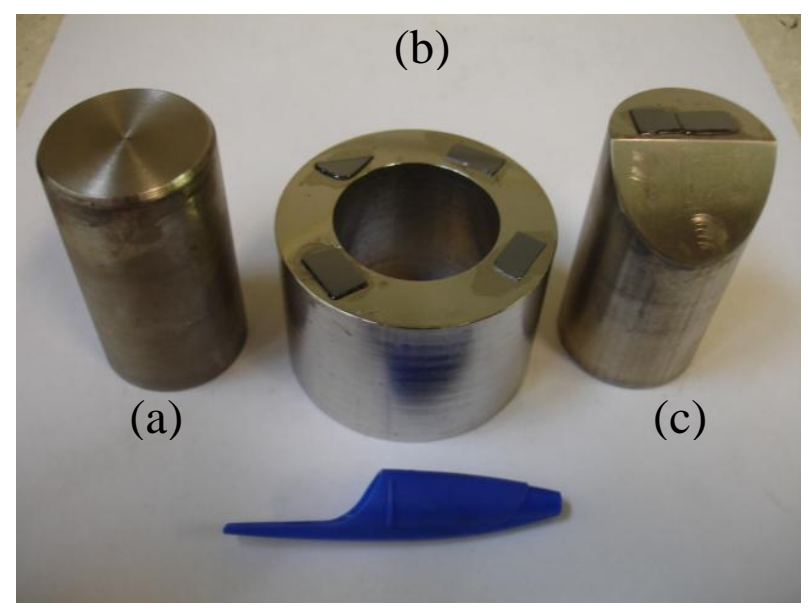

Figura 41: Suportes de aço inox para o polimento. (a) polimento de face plana; (b) guia cilíndrico; (c) polimento de face em $45^{\circ}$.

Antes de qualquer processamento fotolitográfico apresentado nos parágrafos anteriores a determinação da curva de absorção das amostras é realizada de maneira rápida por FTIR. Neste caso, costuma-se transformar a amostra num guia de onda, no qual a radiação entra por um chanfro, é refletida várias vezes internamente (reflexão total) pelas superfícies superiores e inferiores (polidas) da amostra, e sai por um chanfro paralelo do lado oposto para ser analisada pelo sistema FTIR. Para que isso seja possível, os dois chanfros e a superfície inferior da amostra devem ser polidos usando o procedimento detalhado acima para que a radiação seja refletida especularmente pelas superfícies e não espalhada pela alta rugosidade.

\subsection{Montagem do detector}

A Figura 42 (a) mostra uma foto de um QWIP completamente processado. Atualmente, nosso processamento produz mesas quadradas com dimensões de $400 \mu \mathrm{m}$ de lado e contatos superiores de $100 \mu \mathrm{m}$, enquanto que o contato inferior pode ser individual e possuir também um tamanho de $100 \mu \mathrm{m}$, ou então pode ser um contato comum a todas as bases, cobrindo a camada de contato inferior do dispositivo, como na foto. 
Após o processamento e o polimento do chanfro, a amostra é montada sobre um suporte (chip carrier) de cerâmica do tipo DIP14 (Dual In-line Package, com 14 pinos) que é cortado ao meio para permitir a montagem do QWIP para incidência em $45^{\circ}$. A amostra é colada no fundo do suporte por meio de uma tinta de prata ou de grafite, e a conexão elétrica entre os pads de ouro do suporte e os contatos de cada dispositivo é realizada com finos fios de ouro com $25 \mu \mathrm{m}$ de diâmetro, por meio de uma microssoldadora (wire bonder) capaz de realizar microssoldas sobre contatos de até $80 \mu \mathrm{m}$ de diâmetro. O processo de microssolda escolhido foi o de ball bonder (minibolas de ouro formadas na extremidade dos fios e pressionadas por ultrassom contra a superfície dos contatos) para os contatos sobre a mesa, e de wedge bonder (fio pressionado por ultrassom e seccionado) para os contatos sobre os pads do suporte. A Figura 42 (b) mostra o suporte dos dispositivos instalado sobre o porta amostra de cobre montado no dedo frio do criostato que foi projetado e fabricado para as medidas com incidência a $45^{\circ}$.
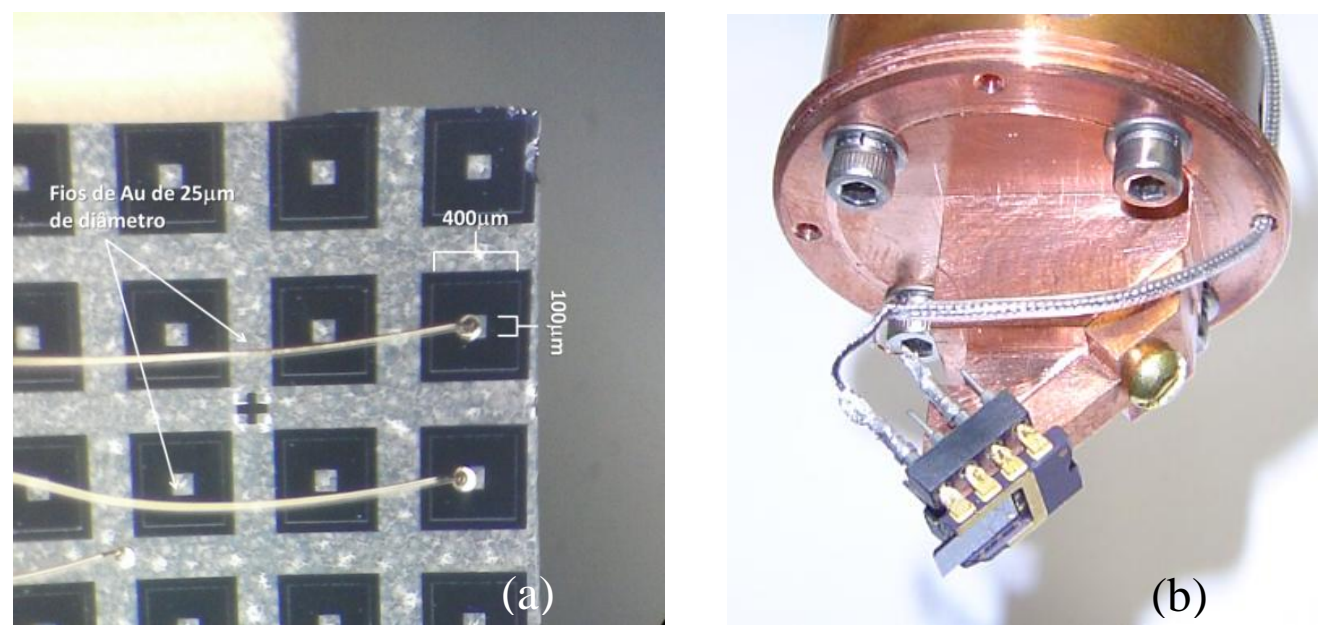

Figura 42: (a) Superfície de um QWIP após processamento completo com microssoldas, mesas de $400 \mu \mathrm{m}$ de lado e contatos superiores de $100 \mu \mathrm{m}$ de lado. (b) Amostra montada no seu suporte (DIP14) $e$ instalada sobre o dedo frio do criostato para a realização de medidas com incidência em ângulo de $45^{\circ}$.

No início desse trabalho, as mesas dos dispositivos desenvolvidos em nosso laboratório tinham $2 \mathrm{~mm}$ de lado e eram obtidas com máscaras feitas com uma impressora laser sobre uma transparência, enquanto que os contatos elétricos eram confeccionados a partir de pequenas bolas de In difundidas nas amostras por processo térmico num forno resistivo comum. Apesar de termos amostras e estruturas de excelente qualidade, os dispositivos produzidos não eram de boa qualidade e nem reprodutíveis, e também não dispúnhamos na época dos equipamentos necessários para sua caracterização. No decorrer do trabalho de doutorado, o laboratório foi adquirindo toda a infraestrutura indispensável para testar completamente os fotodetectores, e passamos a processar as amostras em laboratórios externos (Laboratório de Microeletrônica (LME) e de Sistemas integráveis (LSI) da Escola Politécnoica da USP, Laboratório de Microfabricação do Laboratório Nacional de Luz Síncrotron (LNLS), Laboratório de Pesquida em 
Dispositivos (LPD) e Centro de Componentes Semicondutores (CCS) da Unicamp), que possuíam as instalações adequadas e com os quais desenvolvemos colaborações. Infelizmente, a etapa de processamento se tornou rapidamente um obstáculo durante esta pesquisa em fotodetectores, pois tínhamos que enfrentar longas filas de espera em razão do grande número de usuários ou da manutenção prolongada de alguns equipamentos. Por isso, o LNMS resolveu adquirir também parte da infraestrutura de processamento, e hoje já é possível fazer intra muros o ataque químico das mesas, as medidas de altura com um perfilômetro, a limpeza de superfície com plasma de oxigênio, o recozimento térmico rápido dos contatos, as microssoldas com finos fios de ouro, e os testes elétricos rápidos dos dispositivos com uma probe station e um analisador de parâmetros semicondutores. Atualmente, ainda estão sendo realizados nos laboratórios externos (principalmente no LPD) os procedimentos de fotolitografia, gravação e metalização dos contatos, que são certamente os mais importantes e aqueles que costumam apresentar mais problemas. Porém, graças a um recente auxílio da FINEP, já estamos importando uma alinhadora de máscaras, uma evaporadora por feixe de elétrons, um microscópio de força atômica, e uma nova sala limpa será instalada em breve para a realização das operações mais delicadas. Esperamos assim que, no decorrer de 2013, o LNMS consiga processar completamente este tipo de dispositivos, e se torne assim um dos poucos laboratórios do país (talvez o único) capazes de realizar todas as etapas de design, crescimento, processamento e caracterização necessárias para a produção de fotodetectores de radiação infravermelha de alto desempenho. 


\section{Capítulo 7}

\section{Técnicas experimentais}

O desenvolvimento dos QWIPs é realizado em três etapas: crescimento da estrutura por MBE, processamento das amostras e caracterização dos dispositivos. Neste capítulo são apresentadas e descritas as técnicas utilizadas em cada etapa. A técnica de crescimento por MBE já foi descrita separadamente no capítulo 4, e envolve vários parâmetros que influenciam de forma geral a qualidade das amostras crescidas. Todas as técnicas de caracterização dos nossos fotodetectores foram implementadas durante este trabalho de doutorado, juntamente com outros alunos do grupo.

No início deste trabalho de doutorado, apenas o sistema MBE e um experimento de fotoluminescência (PL, photoluminescence) estavam disponíveis no laboratório. Amostras de poços quânticos foram crescidas, variando-se as principais condições de crescimento, e caracterizadas pela técnica de fotoluminescência para encontrarmos os melhores parâmetros experimentais para a obtenção de nanoestruturas de alta qualidade óptica e cristalina.

Em paralelo, desenvolvemos os primeiros cálculos teóricos, assim como o processo de fabricação dos fotodetectores utilizando técnicas convencionais de fotolitografia, ataque químico e metalização dos contatos. Todas as técnicas de caracterização necessárias para avaliar o desempenho dos fotodetectores fabricados foram implementadas de maneira a possibilitar a determinação do comprimento de onda de operação, da responsividade, do ruído intrínseco e da corrente no escuro dos nossos QWIPs.

\subsection{Fotoluminescência}

A fotoluminescência é o fenômeno que ocorre em um material quando um par elétron-buraco é formado pela absorção de fótons de uma fonte luminosa externa (no nosso caso um laser) e, em seguida, recombina, gerando um fóton com a energia característica do material sob investigação. No caso de um material semicondutor maciço e intrínseco, a recombinação ocorre entre o fundo da banda de condução e o topo da banda de valência, gerando um fóton com a energia correspondente ao gap do semicondutor menos a energia do éxciton formado (par elétron-buraco). A técnica de PL é bastante utilizada na caracterização de semicondutores, pois fornece informações valiosas sobre a estrutura de bandas e a qualidade cristalina e óptica do material.

Quando um elétron em um estado fundamental na banda de valência absorve um fóton com energia maior que a energia do gap do material, esse elétron é excitado para um estado na banda 
de condução, acima do gap, e deixa para trás um estado disponível na banda de valência. Como a carga resultante na banda de valência fica positiva, podemos tratar o estado disponível como sendo um estado ocupado por uma carga positiva que chamamos de "buraco". O elétron excitado para um nível acima do gap, dentro da banda de condução, passa pelo processo de termalização (perda de energia em excesso por emissão de fônons) até alcançar o fundo da banda, e recombina de maneira radiativa com o buraco (que termaliza até o topo da banda de valência). Esse processo é ilustrado na Figura 43. A termalização é um processo não radiativo que envolve a troca de energia com fônons disponíveis na rede cristalina.

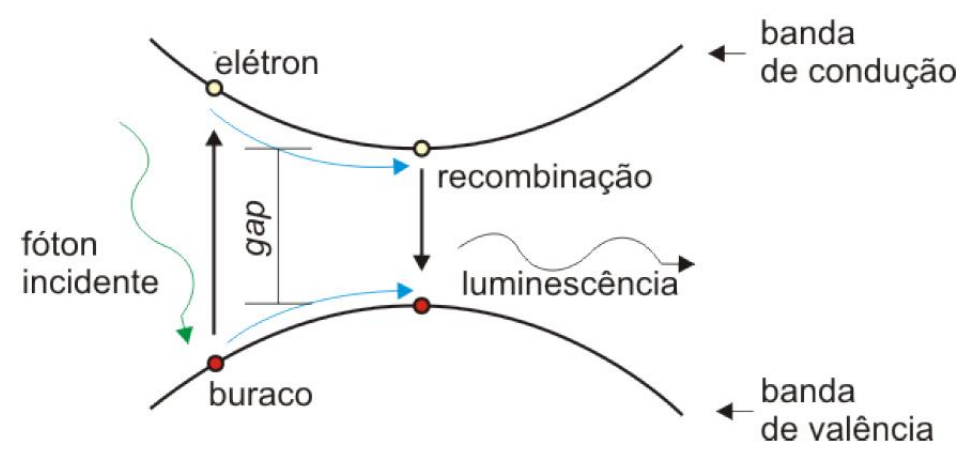

Figura 43: llustração do processo de fotoluminescência.

A interação coulombiana do elétron na banda de condução com o buraco na banda de valência cria um estado ligado, chamado éxciton. Portanto, o fóton gerado pela recombinação do elétron com o buraco possui uma energia ligeiramente menor que a energia do gap do material.
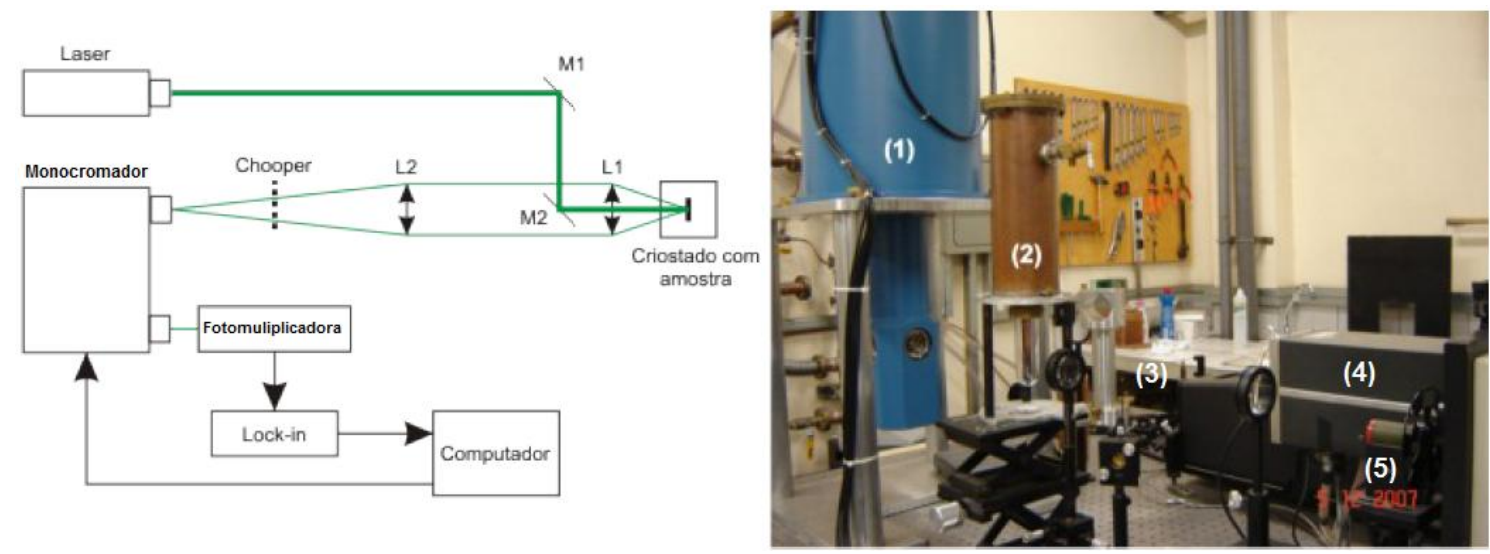

Figura 44: (Esquerda) Esquema da instalação do experimento de PL em nosso laboratório: M1 e M2 são os espelhos e L1 e L2 são as lentes. (Direita) Arranjo experimental de PL. Podemos ver: (1) o criostato refrigerado por He líquido; (2) o criostato para resfriamento com $\mathrm{N}_{2}$ líquido; (3) o monocromador, (4) a fotomultiplicadora utilizada na detecção da fotoluminescência dos poços quânticos e (5) o chopper [40]. 
A Figura 44 mostra a instalação utilizada nas medidas de $P L$. Estão disponíveis dois tipos de criostato em nosso laboratório: um menor que é resfriado por nitrogênio $\left(\mathrm{N}_{2}\right)$ líquido até a temperatura de $77 \mathrm{~K}$, e outro, maior, que utiliza uma imersão em hélio (He) líquido e pode ser resfriado até 1,4 $\mathrm{K}$ quando o vapor de hélio é bombeado. O criostato de hélio está ligado a um sistema de aquecimento que pode variar a temperatura da amostra até $300 \mathrm{~K}$. Como fonte de radiação, para a formação dos pares elétron-buraco, utilizamos um laser de argônio com comprimento de onda de excitação de $5145 \AA$ A. A potência desta linha do laser pode ser variada continuamente e pode chegar até cerca de $2,4 \mathrm{~W}$.

Durante a medida, o feixe do laser é refletido nos espelhos M1 e M2 e passa por uma lente L1 antes de incidir perpendicularmente na superfície da amostra. $\mathrm{O}$ sinal de fotoluminescência emitido pela amostra é recolhido pela lente L1 e focalizado pela lente L2, que o faz incidir na fenda de entrada do monocromador, no interior do qual o sinal luminoso passa por uma rede de difração que o decompõe nas suas componentes fundamentais. A posição da rede de difração é controlada por um motor de passo ligado a um sistema automático conectado a um computador, e seleciona qual comprimento de onda deve ser direcionado para a fenda de saída do equipamento. A intensidade do sinal de fotoluminescência de cada componente do espectro pode ser medida por meio de um detector de germânio (Ge), resfriado por $\mathrm{N}_{2}$ líquido, ou por meio de uma fotomultiplicadora (PMT, photomultiplier) de GaAs, refrigerada por efeito Peltier. A escolha do detector a ser usado na medida (Ge ou PMT) depende da faixa de comprimentos de onda que deverá ser analisada. O detector de Ge é utilizado em uma faixa de comprimentos de onda entre aproximadamente $0,95 \mu \mathrm{m}$ e $1,8 \mu \mathrm{m}$, enquanto que a PMT é preferida entre $0,2 \mu \mathrm{m}$ e $0,95 \mu \mathrm{m}$. A leitura do sinal oriunda do detector escolhido é realizada por um lock-in acoplado a um chopper, localizado na frente da fenda de entrada do monocromador. O Lock-in amplifica e sincroniza a leitura do sinal do detector com a frequência do chopper, e transmite o sinal para um PC, controlado por um programa de aquisição dos dados que registra a intensidade luminosa do comprimento de onda presente no sinal proveniente da amostra.

Em poços quânticos, a recombinação ocorre na região do poço; logo, a escolha do detector é feita dependendo do material do poço. Como o InGaAs possui gap menor que o do GaAs, em poços de InGaAs com barreiras de GaAs utilizamos, geralmente, o detector de Ge, enquanto que, em poços de GaAs com barreiras de AlGaAs, utilizamos a PMT (nesta faixa, a PMT é muito mais sensível que o detector de Ge).

\subsection{Medidas do coeficiente de absorção}

O coeficiente de absorção de uma amostra pode ser determinado a partir da medida de absorbância definida segundo a relação:

$$
\text { Absorbância }=-\log _{10}\left[I / I_{0}\right]=-\log _{10}\left[e^{-\alpha x}\right] \quad \text { Equação } 7.1
$$


onde $\mathrm{I}=\mathrm{I}_{0} \mathrm{e}^{-\alpha \mathrm{x}}$ é a intensidade da radiação após atravessar uma espessura $\mathrm{x}$ de material, e $\mathrm{I}_{0}$ é a intensidade da radiação que incide na superfície da amostra. As medidas de absorbância podem ser feitas por meio de um espectrômetro de infravermelho por transformada de Fourier (FTIR, Fourier transform infrared spectroscopy). A espectroscopia no infravermelho baseia-se no fato das moléculas possuírem frequências específicas nas quais elas vibram ou rotacionam (modos normais de vibração). Esta técnica é muito usada para determinar o espectro de absorção no infravermelho de uma molécula, que constitui uma assinatura característica da sua natureza e geometria, e resulta da excitação de um ou vários desses modos de vibração que possuem uma energia discreta bem específica. No caso dos QWIPs, o espectro de absorção provém das transições entre níveis quantizados de energia provenientes do efeito de confinamento quântico produzido pelos poços quânticos presentes nas amostras.

Em uma medida convencional de transmissão no infravermelho por FTIR, a radiação infravermelha gerada pela fonte do equipamento (um filamento aquecido por uma corrente elétrica passando nele) é injetada em um interferômetro de Michelson que possui um espelho móvel que oscila com uma velocidade conhecida. O padrão de interferência, gerado no interferômetro pela mistura de todos os comprimento de onda emitidos pelo filamento, incide na superfície da amostra e, depois de atravessá-la, forma um interferograma característico da transmissão que pode ser captado pelo detector interno do equipamento em função da velocidade do espelho móvel. O sinal luminoso é convertido em sinal elétrico que é enviado a um computador, onde um programa específico realiza a transformada de Fourier do interferograma para determinar a absorbância em função do comprimento de onda. A partir dessa transformação, obtém-se o espectro resultante característico do padrão de transmissão ou absorção da amostra estudada.

O sistema instalado em nosso laboratório é um espectrômetro comercial com faixa de detecção na região do infravermelho médio de 2,5 a $25 \mu \mathrm{m}$ (Figura 45) e um detector interno de DLaTGS (deuterated L-alanine doped triglycene sulphate). O padrão de interferência é produzido por um interferômetro de Michelson equipado com um divisor de feixe (beam splitter) de brometo de potássio (KBr). O sinal total medido pelo detector do FTIR corresponde a uma convolução do espectro de emissão, gerado pelo filamento da fonte (parecido com um espectro de corpo negro), com a resposta de cada componente do sistema óptico do equipamento (espelhos, divisor de feixe), e com a curva espectral do próprio detector de DLaTGS, sem esquecer de levar em conta o ambiente interno do equipamento (ar, ar seco, nitrogênio, etc.). Para levar todos esses fatores em conta, uma medida de absorção por FTIR, sempre envolve uma medida preliminar de referência (background) tomada sem a amostra, cujo sinal será subtraído posteriormente da medida realizada com a amostra, de modo a poder separar a absorção proveniente da amostra do sinal total que chega ao detector. 


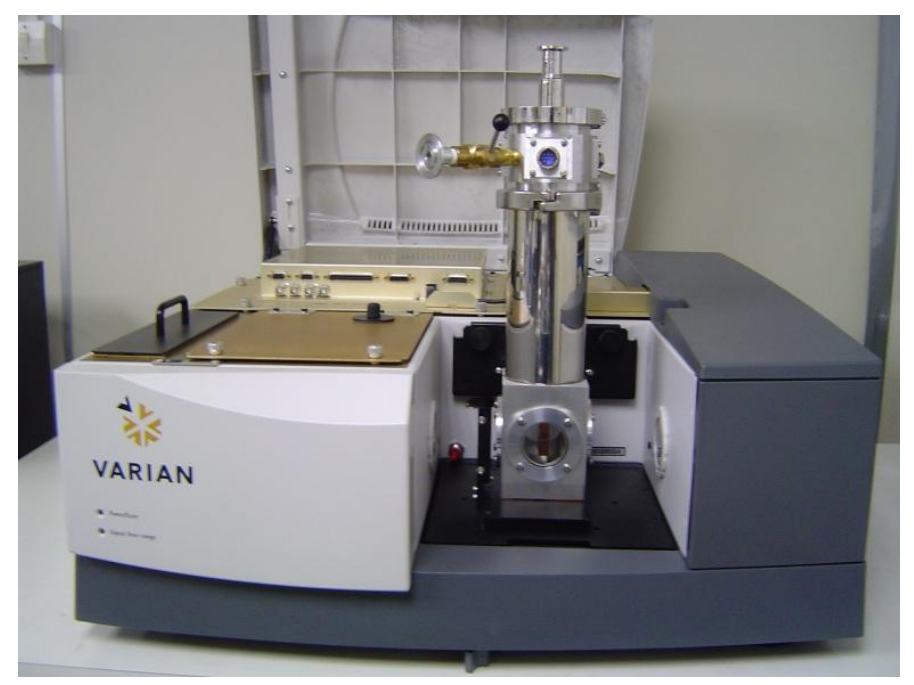

Figura 45: Apresentação do FTIR adquirido recentemente pelo LNMS.

Em amostras de QWIPs dopados do tipo n, sabemos que a absorção (equação 3.12) depende do ângulo $\phi$ entre a normal à superfície e o vetor campo elétrico da radiação $\left(\alpha \equiv \alpha_{0} \cos ^{2} \phi\right)$. Assim, a absorbância será dada por:

$$
\text { Absorbância }=\cos ^{2} \phi \cdot \log _{10}\left[e^{\alpha_{0} L_{o p}}\right] \quad \text { Equação } 7.2
$$

onde $\alpha_{0}$ é a absorção com incidência paralela à superfície $(\phi=0)$ e $L_{o p}$ é o caminho óptico percorrido pela radiação no interior da região ativa. Portanto, a absorção é nula para a incidência de radiação normal à superfície $\left(\phi=90^{\circ}\right)$.

\subsubsection{Medidas da absorção em QWIPs pela técnica do guia de ondas}

Os QWIPs possuem geralmente uma absorção baixa (1-10 \%) que dificulta a medida do coeficiente de absorção. Uma forma de aumentar o sinal de absorção é provocar múltiplas passagens através da região ativa utilizando a geometria de guia de onda [6, 17] (Figura 46). Nessa configuração, o feixe de radiação do sistema FTIR incide perpendicularmente sobre uma das bordas da amostra, cuja superfície foi polida a um ângulo de $45^{\circ}$, e atravessa várias vezes a região ativa do QWIP por reflexão interna total, aumentando assim sua absorção, antes de sair pela borda paralela oposta, também polida a $45^{\circ}$, e ser direcionado para o detector padrão do FTIR. Para ter reflexão especular interna na amostra, tanto a face inferior da amostra quanto os dois chanfros (fabricados a $45^{\circ}$ ) devem ser polidos de tal maneira que a rugosidade da superfície seja muito menor que o comprimento de onda da radiação que se deseja refletir. 


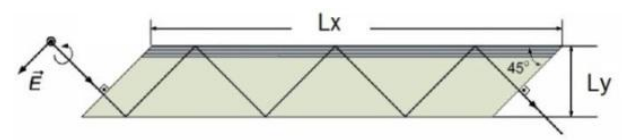

Figura 46: Amostra na configuração de guia de onda. A radiação incide sobre o chanfro da esquerda e atravessa 6 vezes (ida e volta) a região ativa representada pela faixa mais escura na parte superior da figura.

Em geral, a absorção pela região ativa é pequena em comparação com outros efeitos presentes na amostra, como o espalhamento na interface semicondutor/ar (que é diminuído consideravelmente pelo polimento, mas não eliminado completamente) e a absorção de parte da radiação nos contatos dopados. Uma forma muito eficiente de medir a absorção na região ativa é realizar a medida do espectro de fundo (background) utilizando um polarizador para eliminar a componente do campo elétrico, normal ao plano da região ativa, da radiação incidente. Assim, o espectro de fundo obtido inclui todos os efeitos indesejados, menos o efeito da absorção na região ativa (regra de seleção do campo elétrico). Após girarmos o polarizador de $90^{\circ}$, realizamos a medida agora com a componente normal ao plano da região ativa e, subtraindo o espectro de fundo, podemos obter o espectro de absorbância da amostra. Após a obtenção da curva de absorbância, é possível obter a curva de absorção a partir das equações 7.3 e 7.4. A Figura 47 mostra o esquema da medida de absorção.

De um modo geral, podemos escrever a absorbância, para incidência em $45^{\circ}$, como função do ângulo de polarização $\theta_{p}$

$$
\text { Absorbância }=\frac{\operatorname{sen}^{2} \theta_{p}}{2} \cdot \log _{10}\left[e^{\alpha_{0} L_{o p}}\right] \quad \text { Equação } 7.3
$$

onde utilizamos $\cos \phi=\frac{\operatorname{sen} \theta_{p}}{\sqrt{2}} \mathrm{p} /$ incidência $\mathrm{a} 45^{\circ}$.

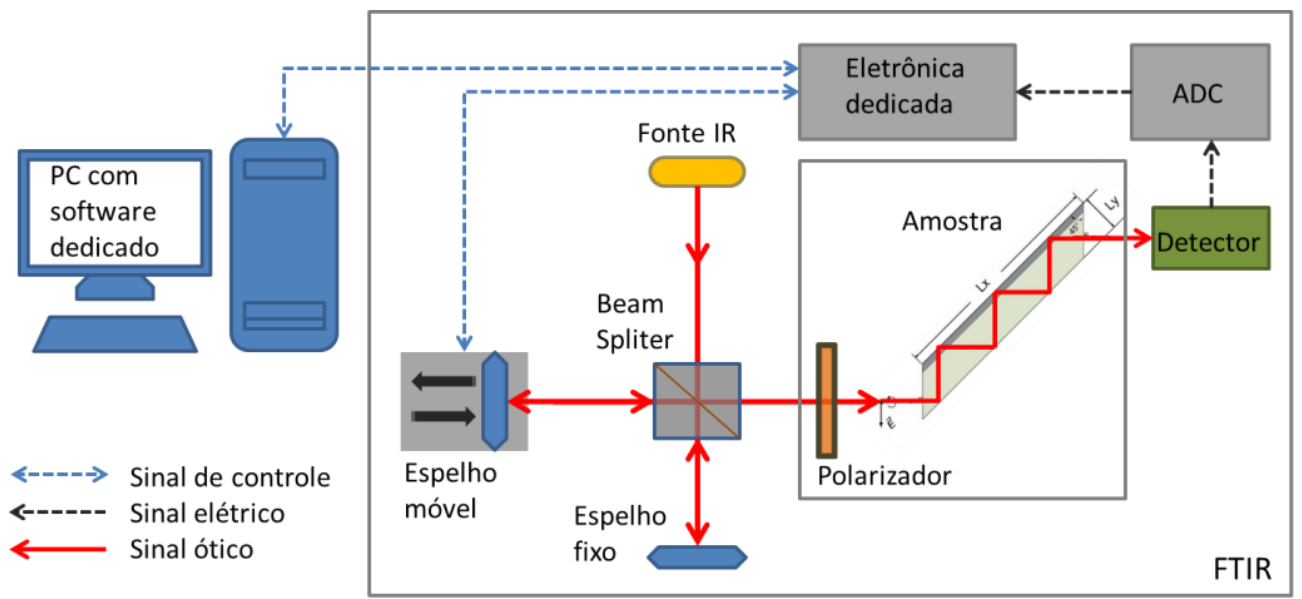

Figura 47: Esquema da medida de absorção com FTIR na configuração de guia de onda. 
O percurso ótico $L_{\mathrm{op}}$ na região ativa da amostra depende do número de reflexões $n_{r}$ (na Figura 47, $n_{r}=3$ ) e da espessura da região ativa $r_{a t}$. Na configuração de guia de onda, $L_{\mathrm{op}}$ é calculado pela relação

$$
L_{o p}=n_{r} \cdot 2 \cdot \sqrt{2} \cdot r_{a t}, \text { onde } \quad n_{r}=\frac{L x}{2 L y}
$$

sendo $L_{x}$ e $L_{y}$ as dimensões da amostra definidas na Figura 46.

Dessa forma, o coeficiente de absorção $\alpha_{0}$ pode finalmente ser calculado como função da absorbância (medida no FTIR), do número de reflexões e da espessura da região ativa:

$$
\begin{gathered}
p / \theta_{p}=90^{\circ} \\
\alpha_{0}=\frac{\ln \left(10^{\text {Absorbância }}\right)}{n_{r} \cdot \sqrt{2} \cdot r_{a t}} \quad \text { Equação } 7.4
\end{gathered}
$$

\subsubsection{Preparação da amostra em guia de ondas}

A preparação da amostra na configuração de guia de ondas, para a medida da curva de absorção por FTIR, é feita por meio de três etapas de polimento (seção 6.4). Na primeira etapa é feito o polimento da superfície inferior (rugosa) do substrato, onde é utilizado o cilindro para polimento de face plana (Figura 41 (a)). Na segunda etapa é feito um chanfro a $45^{\circ} \mathrm{em}$ uma das faces clivadas da amostra com o cilindro com a extremidade cortada com ângulo de $45^{\circ}$ (Figura 41 (c)). A terceira e última etapa consiste na repetição da segunda etapa na face oposta, para obtenção do chanfro a $45^{\circ}$, paralelo ao chanfro da segunda etapa (Figura 46).

Outro aspecto importante na realização dessa medida foi a necessidade de projetar um portaamostras para incidência a $45^{\circ}$ (Figura 48). Como as amostras possuem diferentes dimensões, o suporte projetado por mim possui a liberdade de ajuste da altura da amostra, de modo que possamos maximizar o nível do sinal antes de cada medida. Ele possui, ainda, uma canaleta para montagem do polarizador e uma janela antes da amostra, para definir melhor a área de incidência da radiação. O suporte foi inteiramente fabricado em latão, e recoberto com zinco preto para minimizar a reflexão do feixe infravermelho no interior da câmara de medidas. 

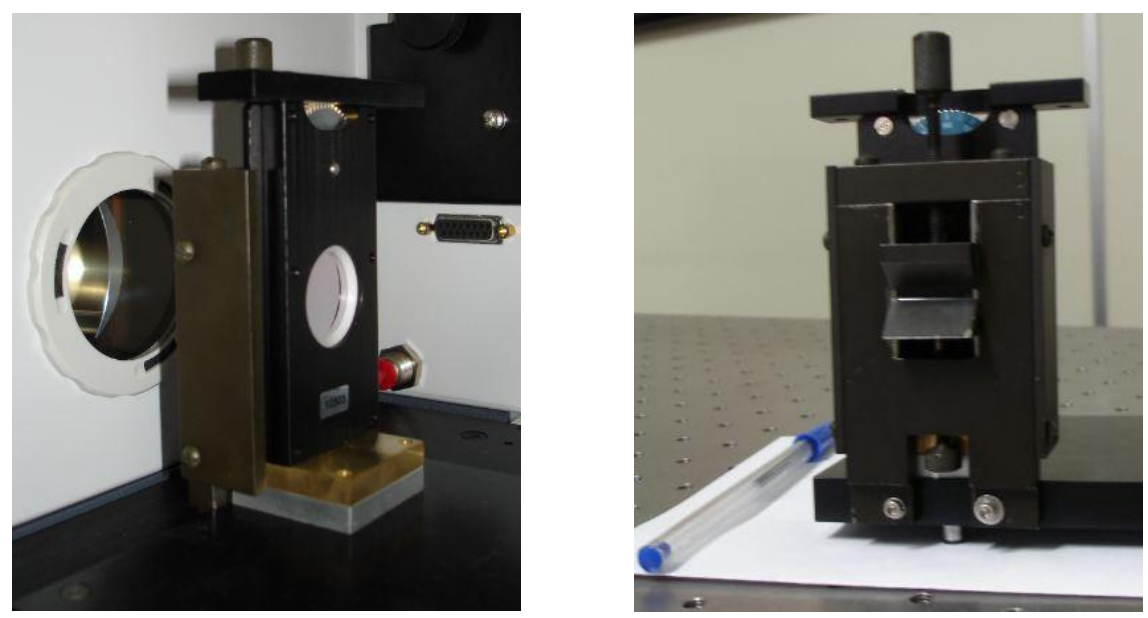

Figura 48: Detalhe do porta-amostras montado na câmara do sistema FTIR para medidas de absorção com incidência a $45^{\circ}$, já com o polarizador montado.

\subsection{Montagem nos criostatos}

A caracterização optoeletrônica dos QWIPs deve ser realizada em baixas temperaturas para diminuir a corrente de escuro dos dispositivos; para este efeito, os QWIPs são montados dentro de criostatos. Usamos dois tipos de criostato: um de $\mathrm{N}_{2}$ líquido, capaz de operar entre $300 \mathrm{~K}$ e $77 \mathrm{~K}$, e um de circuito fechado de He, capaz de chegar a 9K. Dentro dos criostatos, a amostra (conectada ao chip carrier) é encaixada num soquete montado sobre um suporte de cobre (dedo frio), fabricado especificamente para possibilitar a incidência da radiação a $45^{\circ}$ ou $90^{\circ}$ (Figura 49). De modo a melhorar o contato térmico entre o chip carrier e o dedo frio, costuma-se aplicar uma graxa especial para baixas temperaturas e alto vácuo (Apiezon $\mathrm{N}$ ) entre as duas superfícies de contato.

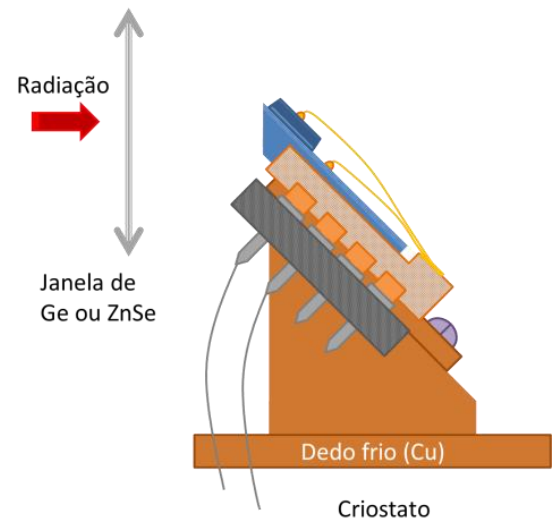

Figura 49: Esquema de montagem da amostra a $45^{\circ}$ no criostato. 
A radiação incide na amostra, dentro do criostato, através de uma janela. As janelas dos criostatos, originalmente de quartzo, foram substituídas por janelas de $\mathrm{ZnSe}$ (seleneto de zinco) ou Ge (germânio), uma vez que o quartzo é transparente no infravermelho apenas para comprimentos de onda inferiores a cerca de 2,5 $\mu \mathrm{m}$. Esses dois materiais ( $\mathrm{Ge}$ e $\mathrm{ZnSe}$ ) foram utilizados, pois são praticamente transparentes em boa parte do infravermelho médio, onde as medidas são realizadas, e absorvem boa parte da radiação visível. As janelas de $\mathrm{ZnSe}$ e Ge foram caracterizadas por FTIR (Figura 50), e as curvas de transmissão foram utilizadas nos cálculos da potência total incidente na amostra. A janela de ZnSe é transparente no infravermelho médio e em parte do espectro visível, o que possibilita a visualização da amostra através da janela. A janela de Ge é totalmente opaca no visível e possui um filme antirefletor (por causa do seu alto índice de refração) que maximiza sua transmissão no intervalo de $8 \mu \mathrm{m}$ a $12 \mu \mathrm{m}$. A janela de Ge foi geralmente utilizada na caracterização dos QWIPs fabricados para absorção dentro da janela atmosférica de $8 \mu \mathrm{m}$ a 12 $\mu \mathrm{m}$.

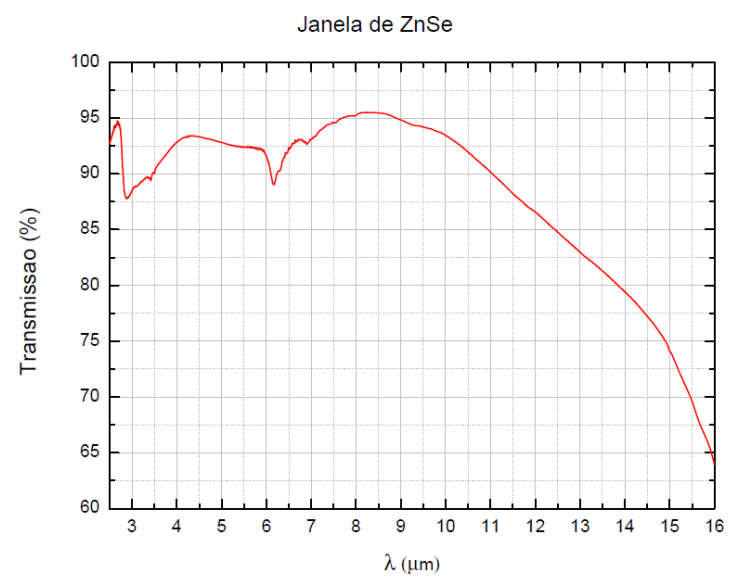

(a)

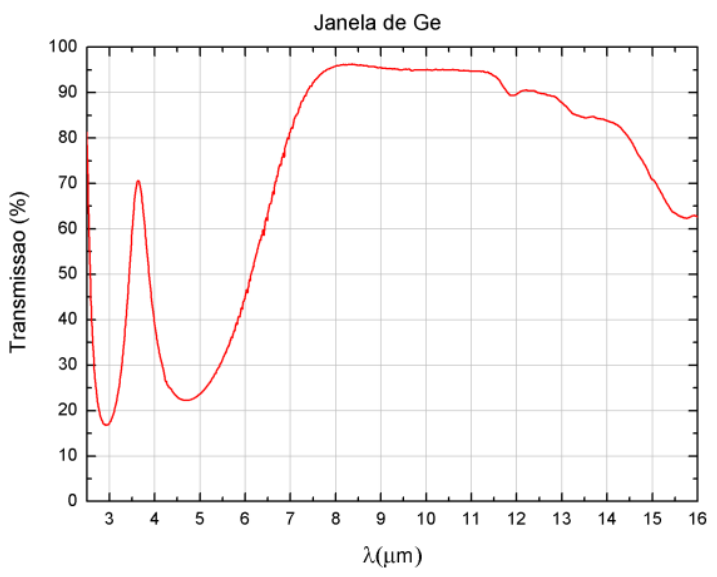

(b)

Figura 50: Transmissão das janelas de ZnSe (a) e de Ge (b), medidas por FTIR.

A Figura 51 mostra em detalhe o arranjo interno dos criostatos. Na Figura 51 (a), a amostra foi montada na extremidade do dedo frio do criostato de $\mathrm{He}$, a $45^{\circ}$, para medidas no claro, enquanto que na Figura 51 (b), a amostra foi montada no criostato de $\mathrm{N}_{2}$ líquido, com o escudo térmico (cold shield) em sua volta, para realização de medidas no escuro. O cold shield (também feito em cobre) é utilizado nas medidas de corrente no escuro e de ruído, e serve como um escudo térmico, que mantém a amostra no escuro e evita que ela seja atingida pela radiação térmica ambiente durante essa medida. Ele está em contato térmico com a extremidade do dedo frio e, portanto, está sempre na mesma temperatura que a amostra.

O criostato é percorrido por dois cabos coaxiais finos, dedicados para baixas temperaturas, que são conectados aos terminais do soquete do porta-amostras. Na outra extremidade, os cabos são ligados a dois conectores coaxiais externos para vácuo, montados em flanges fabricadas em teflon para manter os sinais dos dispositivos isolados da carcaça do criostato que está aterrada. 
Para diminuir o ruído, optamos por medir em modo diferencial. Por isso, o condutor central dos dois cabos é soldado aos dois terminais do soquete que vão até os dois contatos de cada dispositivo, e as malhas dos cabos são colocadas em contato elétrico uma com a outra na extremidade dos cabos dentro do criostato. Essa configuração permite aterrarmos as malhas a um terra comum externo, tomando todos os cuidados para evitar os circuitos fechados de terra (ground loops). Para a caracterização optoeletrônica a tensão de polarização (bias) é aplicada com o polo positivo ' + ' no contato em cima da mesa.

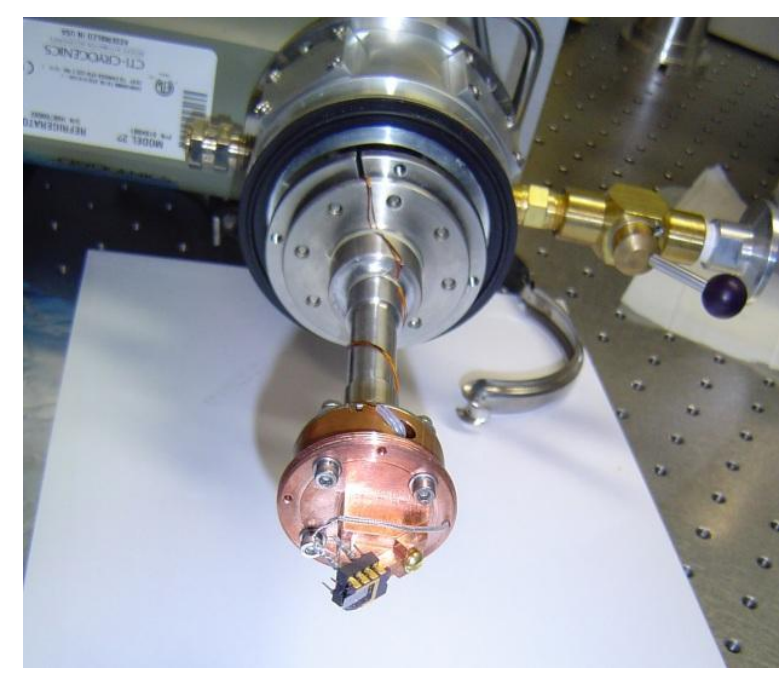

(a)

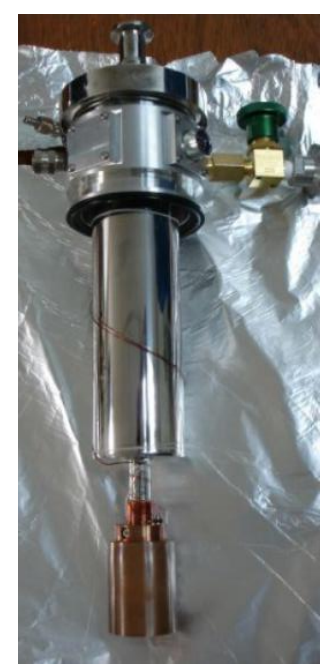

(b)

Figura 51: (a) Porta-amostras de cobre com a amostra montada na extremidade do dedo frio no criostato de circuito fechado de He; (b) Vista da parte interna do criostato de $\mathrm{N}_{2}$ líquido, com a amostra protegida pelo copo de cobre utilizado nas medidas de corrente no escuro.

\subsection{Resposta espectral}

O sistema FTIR recebeu um upgrade que permite que o usuário conecte um detector externo para ser utilizado no lugar do detector DLaTGS padrão. Logo, o sistema FTIR pode ser utilizado de dois modos diferentes. No primeiro modo, podemos realizar medidas de absorbância convencionais em amostras na configuração de guia de ondas (como descrito na seção 7.2) usando o detector DLaTGS interno do equipamento. No segundo modo, para testar dispositivos completamente processados e possuindo contatos elétricos, conectamos nossa amostra como um detector externo, a ser utilizado no lugar do detector padrão, e podemos assim obter a resposta espectral da nossa amostra processada em função da voltagem aplicada.

O criostato com a amostra é posicionado na câmara de medida, no caminho ótico do sistema FTIR. Um pré-amplificador de transimpedância (conversor corrente-voltagem) de baixo ruído é utilizado para aplicar a voltagem de polarização na amostra e fazer a leitura da fotocorrente no dispositivo. O conversor corrente-voltagem (pré-amplificador) gera na sua saída uma voltagem 
DC proporcional à corrente lida, aplicando um ganho que pode variar de $10^{3}$ a $10^{10} \mathrm{~V} / \mathrm{A}$. A voltagem gerada na saída do conversor corrente-voltagem é enviada ao circuito de processamento de sinal do sistema FTIR, substituindo assim o sinal do detector padrão (Figura 52). Essa voltagem deve estar entre 0 e $1 \mathrm{~V}$ para que sistema FTIR possa fazer a leitura sem apresentar problemas de saturação. O procedimento de medida é o seguinte: a voltagem de polarização é aplicada na amostra e, com a amostra protegida do feixe de radiação do sistema FTIR, ajustamos o ganho para a medida da fotocorrente que virá em seguida. Na sequencia, a corrente de fundo (sem radiação) é medida e utilizando um recurso do próprio pré-amplificador (current suppress), é suprimida, dando assim um sinal de saída nulo. Tirando agora o anteparo que estava na frente da amostra, podemos realizar a medida da fotocorrente, obtendo assim uma leitura que corresponde apenas ao sinal gerado no nosso detector pela incidência da radiação de interesse em função do seu comprimento de onda.

Para obter a curva de resposta espectral do QWIP, o sinal medido é multiplicado pelo fator de normalização da curva da radiação de fundo do FTIR, obtida com o detector padrão de DLaTGS. Assim, esta medida não nos fornece uma informação quantitativa precisa da resposta dos nossos fotodetectores, pois a curva da radiação de fundo do FTIR não pode ser medida simultaneamente, junto com o QWIP, e nas mesmas condições. Estamos agora desenvolvendo um novo arranjo experimental, baseado numa fonte de radiação mais intensa (globar) que a do sistema FTIR (cerâmica aquecida termicamente) acoplada a um monocromador e um detector calibrado de $\mathrm{HgCdTe}$, que será capaz de determinar simultaneamente o espectro de absorção e a responsividade absoluta dos dispositivos em fase de desenvolvimento em nosso laboratório.

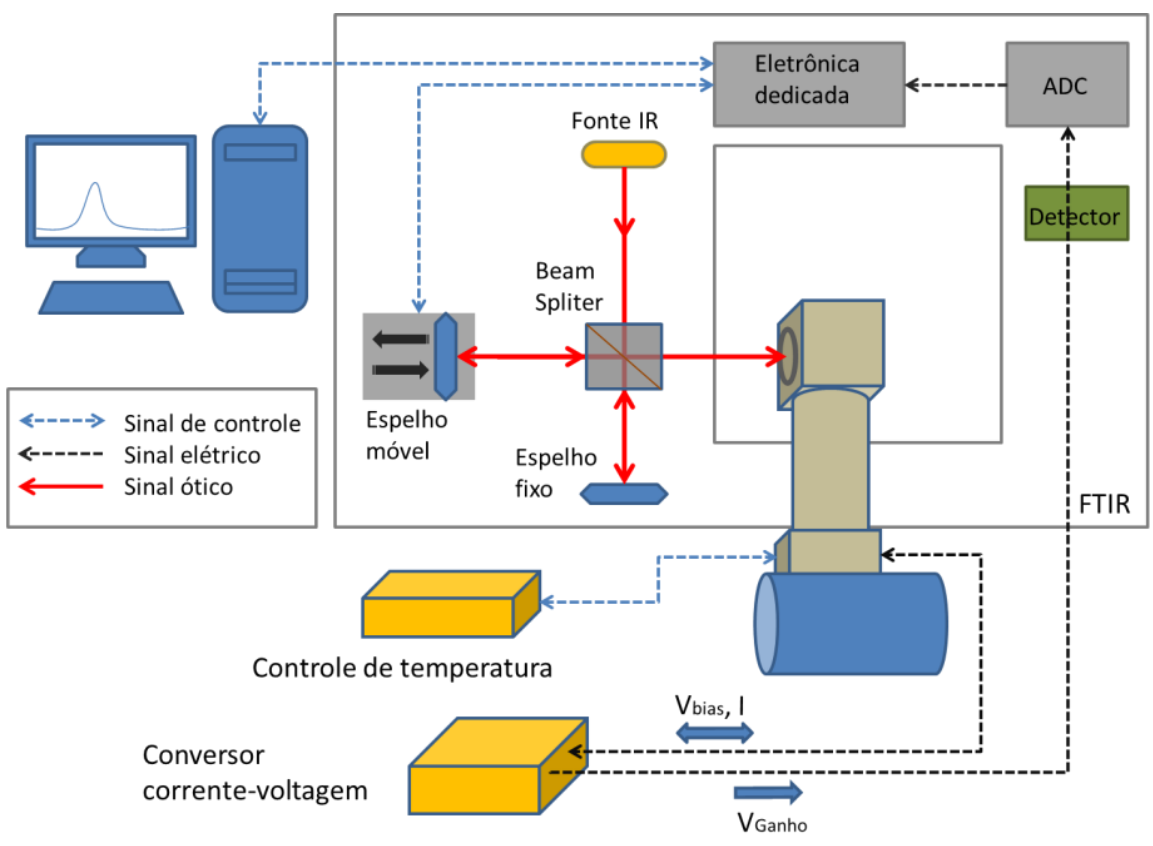

Figura 52: Esquema da medida de resposta espectral obtida por FTIR. O detector interno do sistema FTIR (caixa verde) não é mais usado e é substituído pelo próprio QWIP a ser analisado. 


\subsection{Responsividade total com corpo negro}

Para uma medida precisa da responsividade absoluta, devemos conhecer a taxa de incidência de fótons sobre a área do sensor, para cada comprimento de onda, e medir a fotocorrente correspondente gerada no detector. A razão entre o sinal elétrico obtido e o fluxo de radiação incidente nos fornece a responsividade. Como vimos anteriormente (seção 2.2.1), um corpo negro ideal é uma fonte de radiação que emite um espectro de radiação característico a uma dada temperatura que é descrito exatamente pela Lei de Planck. Em nossas medidas, foi utilizado um corpo negro comercial, calibrado, que possui um controle digital de temperatura e uma cavidade esférica, fabricada em cerâmica e envolta por uma resistência elétrica responsável pelo aquecimento homogêneo da cavidade. O controle digital de temperatura é feito por um microcontrolador ( $\mathrm{PID}$, proporcional, integral, derivativo) que mede a temperatura com um termopar calibrado e regula a corrente circulando na resistência elétrica. A cavidade possui uma abertura circular de 1 polegada de diâmetro (por onde é emitida a radiação) munida de uma roda com aberturas de diâmetros menores, de forma a limitar a área de emissão de radiação se for necessário. O orifício de saída pode ser resfriado com água para evitar que a roda seja aquecida e interfira na radiação emitida. A emissividade do corpo negro é $\varepsilon=0.995$ (um corpo negro ideal possui $\varepsilon=1$ ), e a precisão da temperatura é de $\pm 0,1^{\circ} \mathrm{C}$.

A aplicação da voltagem de polarização na amostra e a medida da corrente correspondente são realizadas pelo conversor de corrente-voltagem (pré-amplificador de transimpedância). A saída do pré-amplificador (fornecendo uma voltagem proporcional à fotocorrente) é conectada a um lockin, em uma configuração semelhante à descrita nas medidas de fotoluminescência. Por meio de uma frequência de referência fornecida pelo chopper, que é posicionado na saída do corpo negro, o lock-in faz a leitura da fotocorrente, separando-a do sinal devido à corrente de fundo (posição fechada do chopper), composta pela corrente de escuro e pela radiação gerada pelo ambiente. A montagem experimental está esquematizada na Figura 53.

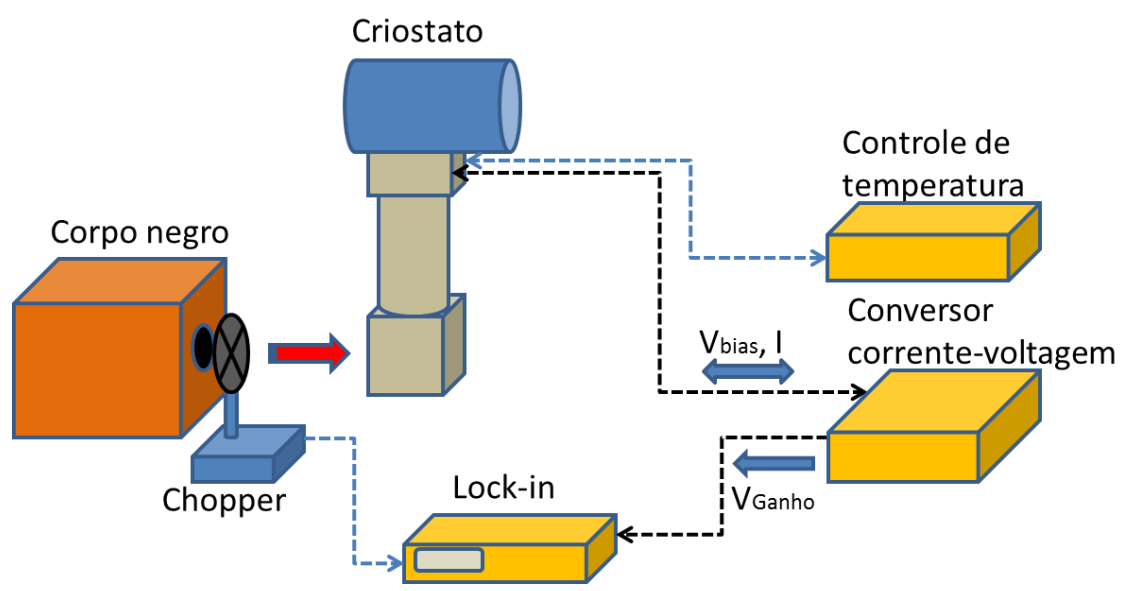

Figura 53: Esquema da medida de fotocorrente e responsividade com corpo negro. 


\subsubsection{Influência da radiação de fundo}

Nos experimentos com QWIPs possuindo uma absorção entre $8 \mu \mathrm{m}$ e $12 \mu \mathrm{m}$, as medidas são dificultadas, pois nessa região a radiação proveniente do ambiente e da própria janela do criostato são mais intensas que a radiação do corpo negro (Figura 54). A radiação é emitida pelo corpo negro através de uma abertura circular com diâmetro um pouco maior que $1 \mathrm{~cm}$, distante de algumas dezenas de centímetros da amostra. Em relação à janela do criostato, que está a apenas alguns centímetros da amostra, a abertura do corpo negro está bem mais distante. Isso faz com que o ângulo sólido da janela do criostato seja muito maior em relação ao ângulo sólido da abertura do corpo negro, vistos pelo detector, fazendo com que a intensidade da radiação vindas do ambiente e da própria janela do criostato supere em muito à intensidade da radiação oriunda do corpo negro. Em geral, o ambiente pode ser modelado como um corpo negro e emite radiação como tal, seguindo a lei de Planck. A janela do criostato pode ser modelada aproximadamente como um corpo cinza. No caso da janela de Ge, para a qual a transmissão é de cerca de $95 \%$, no intervalo de interesse, temos que a reflexão é inferior a 0,05 . Como a emissividade é dada por $\varepsilon=1-\mathrm{R}$, temos portanto que $\varepsilon \geq 0,95$, ou seja, a emissividade da janela é próxima de um. O pico da radiação emitida na temperatura de $300 \mathrm{~K}$ (pela lei de Planck) está em torno de $10 \mu \mathrm{m}$ e está localizado dentro da faixa de operação dos QWIPs, entre $8 \mu \mathrm{m}$ e $12 \mu \mathrm{m}$. Logo, para a realização das medidas, é importante considerar a influência da radiação de fundo (ambiente + janela) na escolha dos parâmetros que serão utilizados durante a medida (temperatura do corpo negro, abertura do corpo negro, distância entre o detector e o corpo negro, etc...). A Figura 54 apresenta um exemplo da radiação que chega à janela do criostato, dentro do ângulo sólido ‘visto' pelo detector.

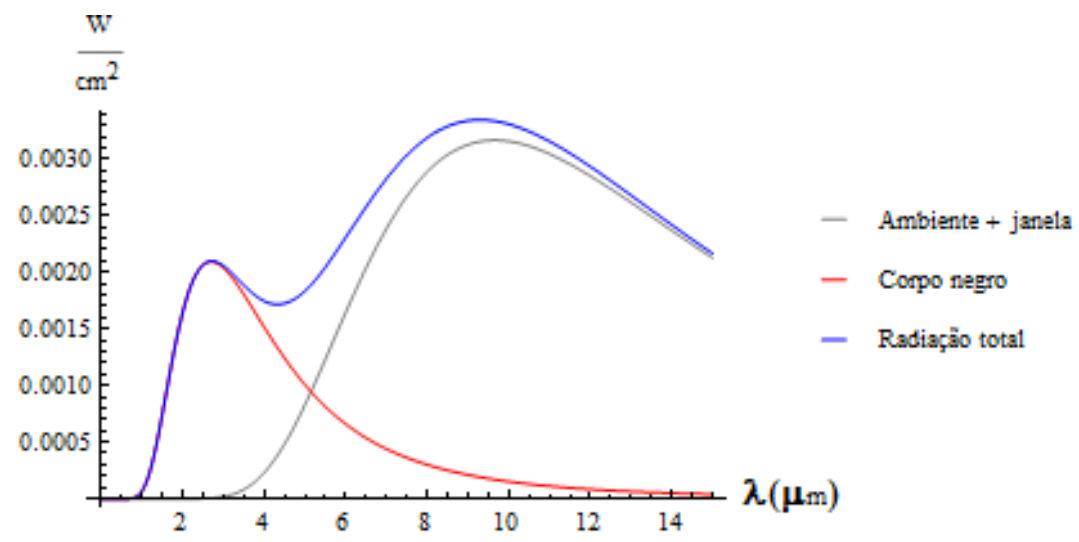

Figura 54: Exemplo da radiação total que chega ao detector no interior do criostato na configuração típica utilizada nas medidas; temperatura do corpo negro de $800^{\circ} \mathrm{C}$, abertura no corpo negro de 12,7mm de diâmetro e distância do detector de $15 \mathrm{~cm}$. 


\subsubsection{Fotocorrente}

O sinal obtido no lock-in não corresponde diretamente ao valor da fotocorrente no dispositivo. O lock-in mede o valor RMS (root mean square) da componente fundamental do sinal elétrico detectado na frequência do chopper. Para obtermos o valor correto da fotocorrente, o valor do sinal medido diretamente no lock-in deve ser dividido por um fator de modulação que leva em conta a geometria da saída de radiação do corpo-negro e a geometria dos furos do disco do chopper. [15]. Em nosso sistema, foi utilizada uma abertura circular de 12,7 mm de diâmetro (meia polegada) na saída do corpo negro, enquanto que o chopper consiste num disco em rotação com aberturas trapezoidais dispostas radialmente. Na configuração utilizada, o fator de modulação é de 0,404549, e foi calculado a partir da referência [15]. Assim, o valor da fotocorrente é obtido a partir da medida realizada pelo lock-in e corrigida pelo cálculo do fator de modulação $(M F)$, segundo a equação 7.5:

$$
\text { Fotocorrente }=\frac{\text { Voltagem } R M S \text { do Lockin }}{M F \cdot \text { Ganho }}
$$

Equação 7.5

Usando a expressão da lei de Planck (equação 2.7), a área óptica do detector $A_{d}$ (a superfície de uma mesa, levando eventualmente em conta o tamanho do contato superior ou o ângulo de incidência), o ângulo sólido $\Omega$ entre a amostra e o orifício do corpo negro, a emissividade $\varepsilon_{b b}$ do corpo negro e a transmissão $T_{J C}$ da janela do criostato, podemos calcular a potência total incidente na amostra (equação 7.6):

$$
\text { Potência total } I R=\int P_{\mu m}(\lambda, T) d \lambda
$$

onde

$$
P_{\mu m}(\lambda, T)=T_{J C} \cdot \varepsilon_{b b} \cdot L_{w}(\lambda, T) \cdot \Omega \cdot A_{d}\left(\frac{W}{\mu m}\right) \quad \text { Equação } 7.6
$$

O ângulo sólido $\Omega$ é dado por $\Omega=\pi \cdot \frac{(d / 2)^{2}}{D^{2}+(d / 2)^{2}}$, sendo $D$ a distância do orifício de saída do corpo negro até a amostra, e $d$ o diâmetro do orifício.

Assim, por meio das equações 7.5 e 7.6, podemos calcular o valor da responsividade total com o corpo negro,

$$
R=\frac{\text { Fotocorrente }}{\text { Potência IR }} \quad\left(\frac{A}{W}\right) \quad \text { Equação } 7.7
$$




\subsection{Corrente no escuro}

A corrente no escuro de um fotodetector é a corrente elétrica que circula no dispositivo na ausência de radiação externa, e é obtida na forma de uma curva corrente - voltagem (I-V) medida no escuro, cercando a amostra com um escudo térmico (em equilíbrio térmico com a amostra), para evitar a incidência de radiação sobre ela. Fisicamente, é um parâmetro importante que nos permite verificar características intrínsecas dos fotodetectores por meio da comparação com a equação 3.24, e também possibilita fazer uma estimativa do ruído dos nossos fotodetectores (equação 2.15). Do ponto de vista operacional, a corrente de escuro é um sinal indesejado que prejudica o desempenho dos dispositivos em alta temperatura e precisa ser minimizada. Por isso, uma análise criteriosa dos mecanismos físicos responsáveis pela sua geração é de grande valia para otimizar este tipo de dispositivo.

A caracterização da corrente de escuro é realizada por meio de um sistema automático de medida de curvas I - V, composto por um criostato ligado a um controlador de temperatura, um sub-femtoamperímetro capaz de gerar rampas de voltagens e medir simultaneamente correntes de até $10^{-17} \mathrm{~A}$, e um PC com interface GPIB controlado por um programa desenvolvido no ambiente LabView (Figura 55). O copo de cobre (Figura 51 (b)) é rosqueado sobre o dedo frio, envolvendo a amostra durante toda a medida.

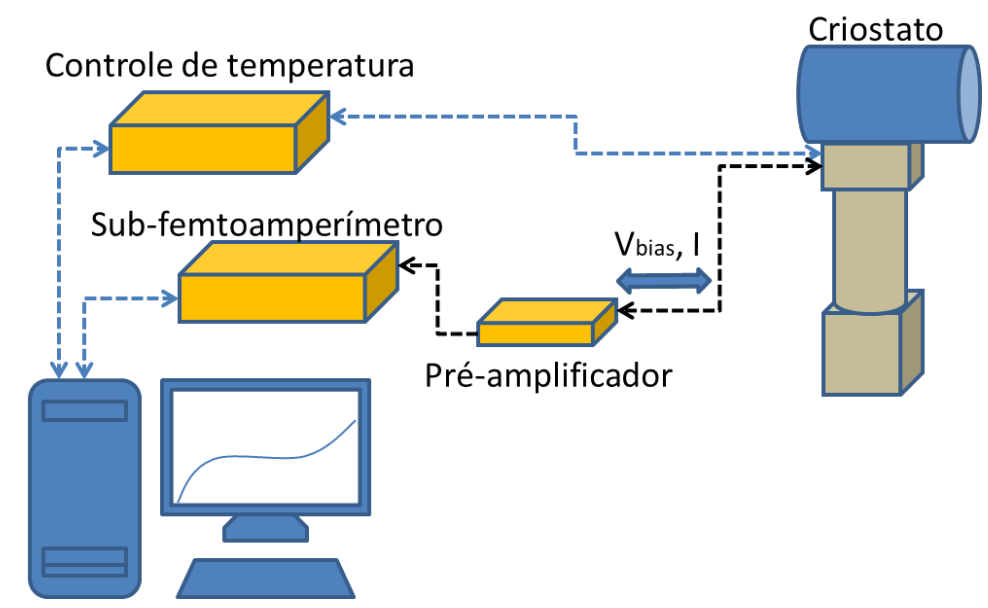

Figura 55: Esquema experimental utilizado nas medidas de corrente no escuro (curvas I-V). 


\subsection{Ruído}

O ruído de um sinal pode ser entendido como a variação aleatória em torno do valor médio desse sinal, causada pela soma de uma série de oscilações independentes. Portanto, por meio da transformada de Fourier desse sinal, podemos obter a intensidade absoluta e a frequência exata da contribuição de cada oscilação no ruído total. Na prática, em um fotodetector, o ruído gerado por fontes intrínsecas possui características completamente aleatórias (processos estocásticos), e, nesse caso, o espectro de Fourier do ruído deve apresentar uma intensidade constante, chamado de ruído branco, pois nesse caso nenhuma oscilação deve ser privilegiada (mais intensa) em relação a outra. O ruído em fotodetectores pode ter várias origens: 1/f, térmico (Johnson), GR, etc. A descrição de cada uma das fontes de ruído e sua respectivas fórmulas estão apresentadas na seção 2.3.4.

A medida do ruído da corrente de escuro pode fornecer parâmetros físicos importantes, como o tempo de vida dos portadores e a probabilidade de captura dos poços. Também é uma figura de mérito importante na caracterização de fotodetectores que é usada para definir outros parâmetros de operação, como a detectividade. Em aplicações práticas de fotodetectores, a relação sinal/ruído deve ser estabelecida para que os limites de operação do dispositivo sejam conhecidos. Uma medida de ruído de boa qualidade é extremamente complexa, pois deve levar em conta todas as fontes de ruído eletromagnético, externas e internas, relacionadas com os equipamentos usados na medida e com a montagem experimental dos cabos e conectores.

Em nossas medidas, utilizamos um analisador de espectros por FFT (fast Fourier transform) que realiza digitalmente em tempo real a transformada de Fourier do sinal de entrada para gerar o espectro das intensidades de cada frequência contida no sinal elétrico produzido pelo QWIP. O conversor de corrente-voltagem é ligado à amostra, e é responsável por aplicar a voltagem de polarização (bias) no detector, ler a corrente gerada no dispositivo, e fazer a conversão numa voltagem DC a partir da aplicação de um ganho entre $10^{3}$ e $10^{8}$ V/A. A voltagem DC de saída do conversor é enviada ao analisador de espectro que realiza a transformada de Fourier do sinal e exibe o espectro na tela (Figura 56).

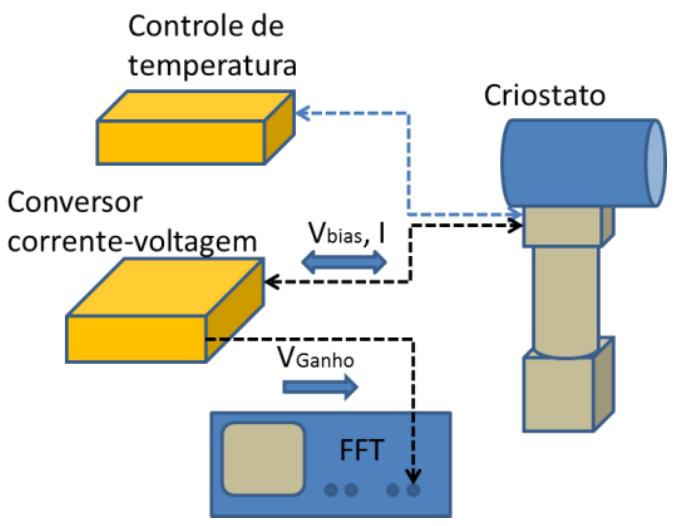

Figura 56: Esquema do sistema de medidas de ruído. 
Para cada medida são escolhidas três frequências do espectro, longe da região do ruído $1 / \mathrm{f}$ e dos harmônicos da rede elétrica, de modo a determinar a intensidade do sinal de ruído no patamar do ruído branco. Para dar a medida nas unidades corretas, o analisador de espectros deve estar configurado no modo de densidade espectral (power density) de tal maneira que o ruído encontrado já esteja normalizado pela banda de frequência analisada e esteja expresso em $\mathrm{V}^{2} / \mathrm{Hz}$ (ou $\mathrm{V} / \mathrm{Hz}^{1 / 2}$ ). Para minimizar o ruído proveniente do arranjo experimental e da rede elétrica, tivemos que usar cabos coaxiais para baixas temperaturas, conectores isolados da carcaça do criostato por flanges de teflon, medidas em modo diferencial (apenas os condutores centrais dos 2 conectores coaxiais são usados nas medidas), e um aterramento específico para eliminar os circuitos de terra (ground loops). Em especial, encontramos maiores dificuldades com as medidas feitas com o criostato de circuito fechado de $\mathrm{He}$, devido à necessidade de isolarmos o sistema do ruído induzido pelo compressor de He (sinais de potência no compressor, indução eletromagnética e ruído triboelétrico devido às vibrações geradas pelo pistão). Além disso, os manuais de todos os equipamentos envolvidos na medida (pré-amplificador de corrente e analisador de espectros) devem ser lidos com cuidado para encontrar uma expressão matemática descrevendo o ruído de cada um em função dos parâmetros usados (escalas, ganhos, filtros, etc.).

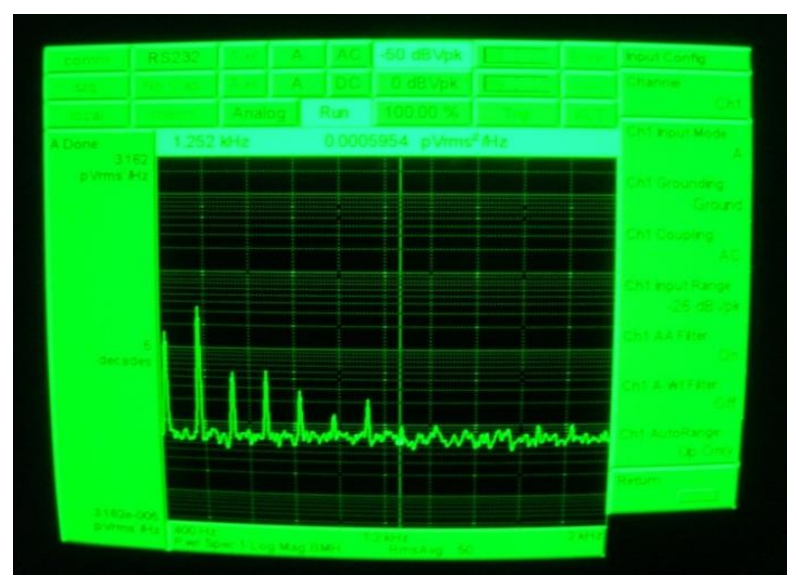

Figura 57: Tela do analisador de espectros por FFT mostrando uma medida de ruído Johnson de um circuito de testes formado por resistências ôhmicas e uma bateria (Figura 58) (valor medido de $\left.5,95 \times 10^{-16} \mathrm{~V}^{2} / \mathrm{Hz}\right)$.

De modo a podermos medir apenas o ruído proveniente das nossas amostras, descontando corretamente todas as outras fontes de ruído, realizamos uma etapa de calibração de todo o sistema, que consiste na medida do ruído Johnson de várias resistências ôhmicas conhecidas. Como o ruído Johnson de uma resistência pode ser calculado facilmente, aperfeiçoamos o arranjo experimental até sermos capazes de medir este tipo de ruído com uma precisão melhor que $5 \%$. O ruído Johnson das resistências foi medido também em baixas temperaturas, onde alcançando valores mais baixos, permitiu o aperfeiçoamento do aparato experimental e a caracterização de todas as outras fontes de ruído. Este grau de precisão foi mais que suficiente para possibilitar 
medidas de ruídos de boa qualidade em nossos fotodetectores. A Figura 57 apresenta o espectro do ruído de um circuito formado por resistências ôhmicas e uma bateria para aplicação de voltagem (Figura 58). Nessa figura, está apresentada a imagem da tela do analisador de espectros, no momento da medida do ruído, onde podemos identificar claramente os picos harmônicos referentes ao ruído produzido pela rede elétrica e o patamar horizontal de ruído branco indicando o valor do ruído Johnson do circuito. O valor teórico do ruído equivalente era de $5,92 \times 10^{-16} \mathrm{~V}^{2} / \mathrm{Hz}$ no circuito de teses e o valor experimental obtido foi de $5,95 \times 10^{-16} \mathrm{~V}^{2} / \mathrm{Hz}$. O circuito medido está representado na Figura 58.

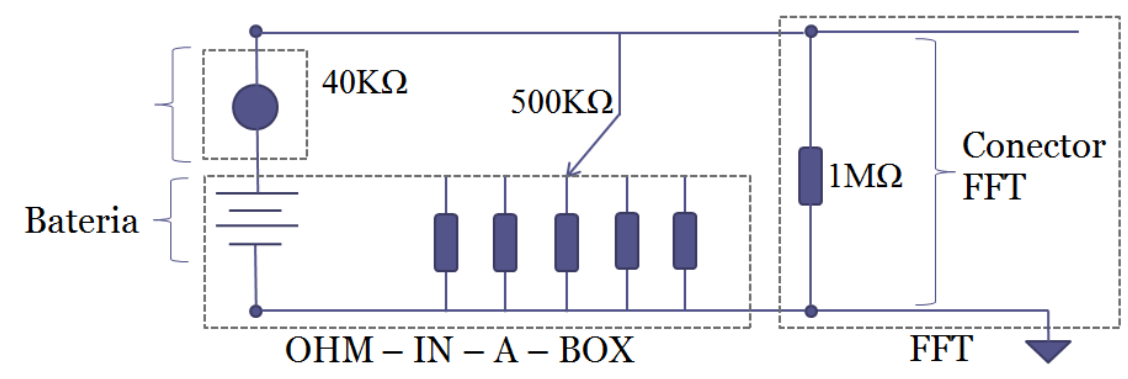

Figura 58: Circuito para teste do aparato experimental utilizado nas medidas de ruído.

\subsection{Detectividade específica}

A detectividade específica é o melhor parâmetro quando se deseja comparar o desempenho de detectores diferentes, sem ter a influência de fatores geométricos dos dispositivos ou elétricos das medidas. A detectividade não é obtida diretamente, mas sim calculada a partir da responsividade $R$ e do valor do ruído na corrente de escuro $I_{d n}$, por meio da relação:

$$
D_{b b}^{*}=\frac{R \cdot \sqrt{A_{d}}}{I_{d n} / \sqrt{\Delta f}}\left(\frac{c m \cdot H z^{1 / 2}}{W}\right)
$$

Equação 7.8

Sendo $\mathrm{A}_{d}$ a área ativa do detector e $\Delta f$ a largura da banda (para comparação com a literatura utiliza-se $\Delta f=1 \mathrm{~Hz}$ ). 


\subsection{Capacitância}

Para uma utilização prática dos fotodetectores em um dispositivo comercial, como um fotodetector singelo ou um FPA, deve-se acoplar o fotodetector a um chip a base de silício (ROIC - Read-out integrated circuit) que realiza a integração da fotocorrente e a multiplexação do sinal de cada pixel do FPA. Um parâmetro importante para a integração do detector ao ROIC é a capacitância do detector que define principalmente as especificações dos componentes do ROIC. No QWIP 3517, foram feitas medidas de capacitância a 78K. Em geral, os ROICs de silício disponíveis comercialmente possuem uma temperatura mínima de operação de cerca de $70 \mathrm{~K}$, podendo chegar até $60 \mathrm{~K}$. As medidas de capacitância foram realizadas no criostato de $\mathrm{N}_{2}$ líquido a 78K. A amostra (no interior do criostato) foi conectada diretamente ao analisador de parâmetros semicondutores do laboratório que possibilita a realização de medidas de capacitância em função da voltagem $(\mathrm{C}-\mathrm{V})$ e da frequência $(\mathrm{C}-\mathrm{f})$. Um aspecto importante a ser destacado é que esse sistema não é propriamente um sistema de medidas de capacitância, e sim um sistema de medidas de impedância, que por meio da relação $C(\omega)=\left(\omega \cdot \operatorname{Im}\left(z(\omega)^{-1}\right)\right)^{-1}$ realiza a medida da impedância $z(\omega)$ e a converte em valores de capacitância. 


\section{Capítulo 8}

\section{Resultados}

A estrutura dos QWIPs consiste geralmente na repetição de um grande número de poços quânticos (podendo chegar a mais de 50) para melhorar o sinal de absorção. Por esta razão, no início do trabalho foram realizados testes de crescimento, em amostras com um único poço de GaAs/AlGaAs ou InGaAs/GaAs, e em amostras com múltiplos poços de modo a otimizar os parâmetros experimentais durante o crescimento. Esses testes serviram para verificar se não havia alguma perda de qualidade nos poços ao longo do processo de crescimento de múltiplos poços quânticos e para conferir a homogeneidade deles. A análise do crescimento foi realizada por meio de medidas de PL em baixas temperaturas para determinar a largura e intensidade do sinal do espectro de emissão, e investigar o desempenho das amostras em função do número de poços.

Durante este trabalho de doutorado, foram crescidos 15 QWIPs possuindo 8 estruturas diferentes. Inicialmente, em três deles $(3453,3454$ e 3455), foram variadas as dopagens nos contatos e no interior dos poços, de modo a encontrar as condições iniciais para as medidas, e estabelecer na sequência os melhores parâmetros de dopagem para o processamento (fabricação de contatos ôhmicos) e para a caracterização dos primeiros QWIPs. Dois outros QWIPs, para absorção na região de 8 a $12 \mu \mathrm{m}$, idênticos (3453 e 3495) mas crescidos com intervalo de tempo de 6 meses (Figura $36(a)$ ), foram analisados para verificarmos a reprodutibilidade do crescimento e processamento, e foi observado que uma variação de $1 \%$ na concentração de $\mathrm{Al}$ na barreira de AlGaAs era capaz de produzir um deslocamento significativo e um alargamento do pico de absorção. Mais dois QWIPs para absorção na região de 8 a $12 \mu \mathrm{m}$ com barreiras extras mais altas ao redor dos poços (3494 e 3504) foram crescidos numa tentativa de reduzir a corrente de escuro e melhorar a absorção (Figura $36(b)$ ). Verificamos que as barreiras auxiliam a absorção e diminuem bastante a corrente de escuro, mas também reduzem consideravelmente a fotocorrente. O QWIP 3517, para absorção na região de 8 a $12 \mu \mathrm{m}$, consiste em múltiplos poços simples (retangulares) onde a concentração da dopagem nos poços e nas camadas de contatos foi planejada de modo a alinhar naturalmente o nível de Fermi das camadas de contato e dos poços quânticos (Figura 36 (c)). A amostra 3559, também para absorção na região de 8 a $12 \mu \mathrm{m}$, consiste em múltiplos poços de $\mathrm{Al}_{0,13} \mathrm{Ga}_{0,87} \mathrm{As}$ com barreiras de $\mathrm{Al}_{0.33} \mathrm{Ga}_{0.77} \mathrm{As}$ (Figura $36(d)$ ). Nessa amostra as barreiras são mais altas, de modo a inibir a injeção de portadores dos contatos que contribuem para a corrente de escuro. Outros três QWIPs (3498, 3564 e 3570) foram crescidos para absorção entre 4 e $5 \mu \mathrm{m}$ (Figura 37). O QWIP 3498 possui barreiras extras mais altas ao redor dos poços e apresentou absorção em 4,2 $\mu \mathrm{m}$ mas, assim como no caso dos QWIPs 3494 e 3504, a fotocorrente obtida foi muito baixa e os QWIPs 3564 e 3570 apresentaram absorção fora do intervalo desejado. Esses QWIPs possuem nas barreiras uma grande quantidade de Al (42\% na composição da liga de AlGaAs) que é um elemento que possui menor mobilidade superficial durante o crescimento das 
camadas epitaxiais e provoca o aumento da rugosidade entre as camadas depositadas. Essa característica também dificulta a calibração das taxas de deposição por meio do RHEED. Para a investigação de QWIPs funcionando por transição entre níveis zero-dimensionais, foram crescidos três QWIPs (3571, 3572 e 3591) (Figura 38), porém somente uma medida de reposta espectral no QWIP 3572 pode ser feita. Essa medida apresentou uma absorção muito baixa indicando que provavelmente, devido a uma maior largura da região dopada, tenha ocorrido à transição de Mott dos portadores para os níveis dos poços.

No decorrer do trabalho, as condições de processamento foram melhorando e sendo otimizadas, possibilitando no final um processamento reprodutível e de boa qualidade das amostras por fotolitografia, com mesas quadradas de $400 \mu \mathrm{m}$ de lado e contatos quadrados de 100 $\mu \mathrm{m}$ de lado depositados numa evaporadora usando um feixe de elétrons. Duas amostras, foram processadas em excelentes condições, uma com absorção em 9,3 $\mu \mathrm{m}$ (3517) e outra com absorção em 10,5 $\mu \mathrm{m}$ (3559), e em seguida caracterizadas de maneira sistemática em baixa temperatura (70K, 50K, 30K e 10K), utilizando o criostato de circuito fechado de He. A partir dessas medidas foi então calculada a responsividade desses dois QWIPs. O QWIP 3517 apresentou boa responsividade e foi completamente caracterizado, tendo sido realizadas também medidas de ruído e de capacitância, o que possibilitou o cálculo da sua detectividade específica. A responsividade do QWIP 3559 foi medida, e o resultado ficou aquém do esperado. Em função da facilidade de controle da largura dos poços e da altura das barreiras, é possível crescer uma grande variedade de estruturas diferentes de QWIPs. Como a caracterização dos QWIPs pode também ser feita de várias formas, com incidência no ângulo de Brewster, em incidência a $45^{\circ}$ ou com incidência normal utilizando-se uma rede de difração, com filme antirreflexivo, com ou sem corpo negro, etc, é às vezes difícil encontrar na literatura as curvas de mérito de QWIPs que possibilitem uma comparação direta com os resultados apresentados na literatura.

No caso do QWIP 3517, foram realizadas várias simulações (absorção, corrente de escuro) e feita uma análise das curvas de ruído em baixa temperatura a partir de um modelo do ruído que depende da corrente no escuro, do tempo de recaptura do elétron foto-excitado e da velocidade de deriva do elétron. $\mathrm{O}$ tempo de recaptura foi obtido a partir das funções de onda calculadas pelo método da matriz de transferência. A velocidade de deriva foi obtida a partir do ajuste da velocidade de saturação do GaAs aos dados experimentais em 70K, utilizando-se um modelo para a velocidade de deriva do GaAs obtido da literatura [41]. A partir de todas essas informações, foi possível determinar a velocidade de saturação em função da temperatura para esse QWIP.

\subsection{Fotoluminescência}

Para a operação em torno de $8 \mu \mathrm{m}$, uma solução foi usar poços quânticos de $\mathrm{AlGaAs} / \mathrm{GaAs}$ com barreiras de $\mathrm{Al}_{0,26} \mathrm{Ga}_{0,74} \mathrm{As}$ e poços de $52 \AA$ de largura [6]. Como se tratava do primeiro QWIP a ser desenvolvido em nosso grupo, foi com esses poços que realizamos os testes iniciais de 
qualidade e reprodutibilidade em função dos parâmetros de crescimento e do número de poços na estrutura.

A intensidade e largura a meia altura dos picos presentes num espectro de PL são parâmetros por meio dos quais podemos comparar a qualidade dos poços crescidos. Em geral, quanto mais intenso e mais estreito o pico, melhor é a qualidade dos poços, o que significa que as interfaces são abruptas e a qualidade cristalina é boa, com poucos defeitos atuando como centros não radiativos. Algumas amostras de poços múltiplos foram crescidas com os mesmos parâmetros utilizados em amostras de poços simples, de modo a verificarmos a qualidade e reprodutibilidade do crescimento dos poços, quando repetidos várias vezes. A Figura 59 mostra os resultados da comparação dos espectros de PL para uma amostra de poço simples e outra com 20 poços de GaAs com $52 \AA$ de largura separados por barreiras de $\mathrm{Al}_{0,26} \mathrm{Ga}_{0,74} \mathrm{As}$ com espessura de $300 \AA$. A largura a meia altura da amostra com 20 poços não apresentou nenhum aumento em relação à amostra com um único poço, comprovando que, com as condições corretas de crescimento, não há degradação da qualidade cristalina e nem da estrutura dos poços, e que o sistema MBE possui condições extremamente estáveis que possibilitam a repetição de 20 poços com larguras idênticas em nível atômico. O fato do espectro de PL da amostra com 20 poços ser apenas 8 vezes mais intenso que o da amostra com um único poço vem da grande absorção da radiação incidente e da captura dos pares elétrons-buracos pelos primeiros poços. É também pela mesma razão que a largura a meia altura do espectro da amostra com 20 poços é até levemente menor que a da outra amostra. Como a camada buffer crescida nos dois casos foi relativamente fina (2000 ̊), a qualidade cristalina e a rugosidade dos últimos poços é levemente melhor que a dos primeiros. Na amostra com os 20 poços, apenas os últimos são detectados no espectro de PL, enquanto que, na outra amostra, todo o sinal vem do primeiro (e único) poço.

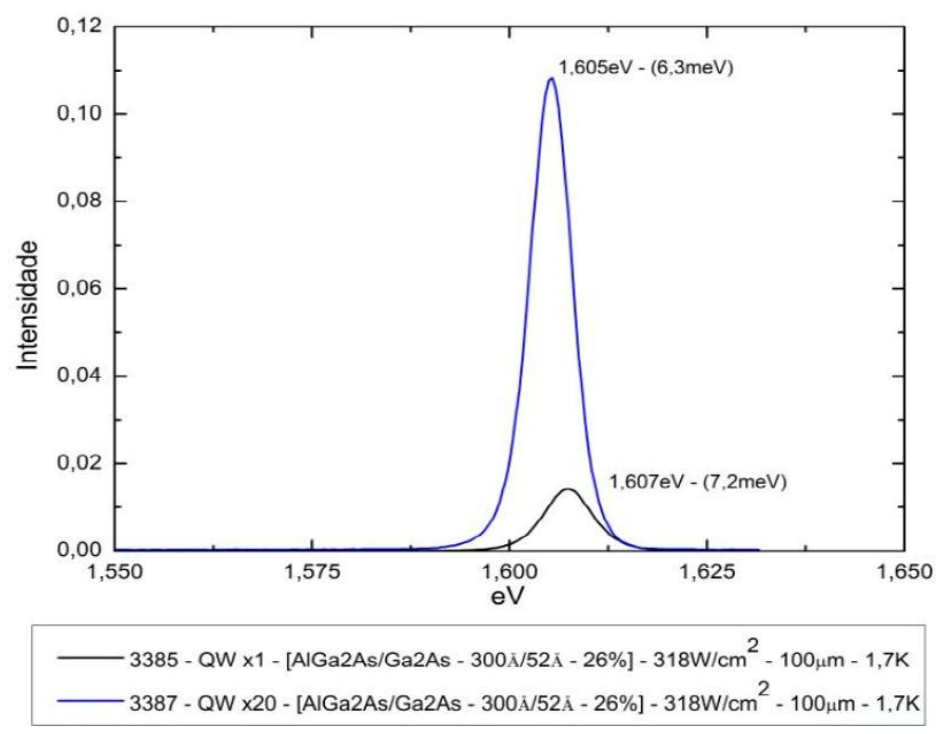

Figura 59: Comparação do espectro de PL de uma amostra contendo um único poço de $52 \AA$ de GaAs e barreiras de $A l_{0,26} G a_{0,74} A s$ de $300 \AA$ de largura (3385), e de outra amostra com 20 desses mesmos poços e barreiras (3387). As medidas foram realizadas a 1,7 K com densidade de potência de 318 $W / \mathrm{cm}^{2}$. 
A partir da estrutura nominal dos poços, foram feitas simulações para comparar a posição do pico de PL medido experimentalmente com a expectativa teórica. Para isso, fizemos o cálculo dos níveis de energia de confinamento para os elétrons e para os buracos pesados, na temperatura de 1,7K (a mesma da medida experimental). A energia do gap do GaAs nessa temperatura foi estimada em 1,508 eV, a partir da fórmula empírica descrita na referencia [42]. O primeiro nível de elétrons foi calculado em $0,0724 \mathrm{eV}$ e o primeiro nível de buracos em 0,0198 eV. A energia do éxciton na transição deve ser considerada, e para esse poço é de aproximadamente $10 \mathrm{meV}$ [43]. Portanto, a energia da transição interbanda estimada para essa amostra foi de 1,590 eV. O valor experimental obtido foi de 1,607 eV, para amostra com um único poço, e de 1,605 eV para a amostra de 20 poços. A diferença de $15-17 \mathrm{meV}$ entre o valor calculado e o valor medido experimentalmente pode ter origem nos parâmetros utilizados no cálculo (massa efetiva, band offset, etc.) e nas incertezas experimentais da própria amostra durante a calibração e o crescimento, como a concentração de $\mathrm{Al}$ na liga e a largura do poço.

\subsection{Absorção}

Uma vez que encontramos os melhores parâmetros de crescimento possibilitando a repetição de um grande número de poços quânticos na estrutura dos QWIPs sem perda de qualidade, pudemos começar a analisar a eficiência da absorção da radiação infravermelha em função de vários parâmetros e estruturas de fotodetectores em fase de desenvolvimento. Isto pode ser feito rapidamente, antes de qualquer processamento sofisticado, polindo a superfície traseira da amostra e dois chanfros paralelos em bordas laterais opostas (Figura 46). A partir dos espectros de absorbância medidos à temperatura ambiente por FTIR, usando a configuração de guia de onda (Figura 47) com um polarizador, foi possível calcular o coeficiente de absorção das amostras por meio da equação:

$$
\alpha=\frac{1}{\sqrt{2} \cdot n_{R} \cdot z_{r a}} \cdot \ln \left(10^{\text {Absorbância }}\right) \quad \text { Equação } 8.1
$$

onde $n_{R}$ é o numero de reflexões na face onde está localizada a região ativa, e $z_{r a}$ é a espessura da região ativa da amostra.

Vale lembrar que essas medidas de absorção fornecem apenas uma primeira caracterização rápida, à temperatura ambiente, das amostras crescidas. Quando as amostras são processadas e testadas em baixas temperaturas, nas reais condições de funcionamento dos dispositivos, existe um pequeno deslocamento do pico de absorção para comprimentos de onda menores em razão da temperatura mais baixa, que muda o gap dos materiais e a posição do nível de Fermi do sistema, e da presença da voltagem aplicada (bias), que gera um campo elétrico que altera o perfil de potencial da estrutura. 


\subsubsection{Regra de seleção do campo elétrico nos QWIPs}

Em QWIPs dopados do tipo n, um teste fácil para saber se um pico de absorção é proveniente da região ativa, e não de um artefato, é conferir se a absorção é sensível ao ângulo de polarização da radiação incidente. Isto vem do fato que as transições eletrônicas em poços quânticos só podem ocorrer na presença de uma componente vertical do vetor polarização (equação 7.3). A Figura 60 (a) ilustra a medida de absorbância de um QWIP (amostra 3495) em função do ângulo de polarização da radiação incidindo no chanfro $\left(\mathrm{a} 45^{\circ}\right.$ ) da amostra, usando incrementos de $15^{\circ}$. Quando o ângulo do polarizador é nulo, a direção do vetor campo elétrico (polarização) é paralela ao plano da região ativa, e $\theta_{p}=0$, na equação 7.3, levando a uma absorção nula. Ao aumentar o ângulo de polarização da luz incidente, a absorbância tem que aumentar proporcionalmente a $\operatorname{sen}^{2} \theta_{\mathrm{p}}$, conforme mostrado pelo resultado na Figura $60(b)$.

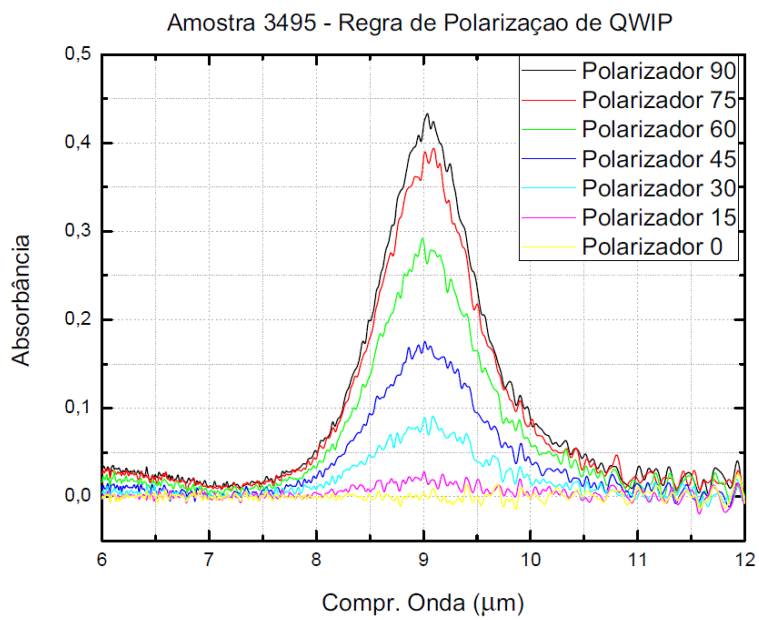

(a)

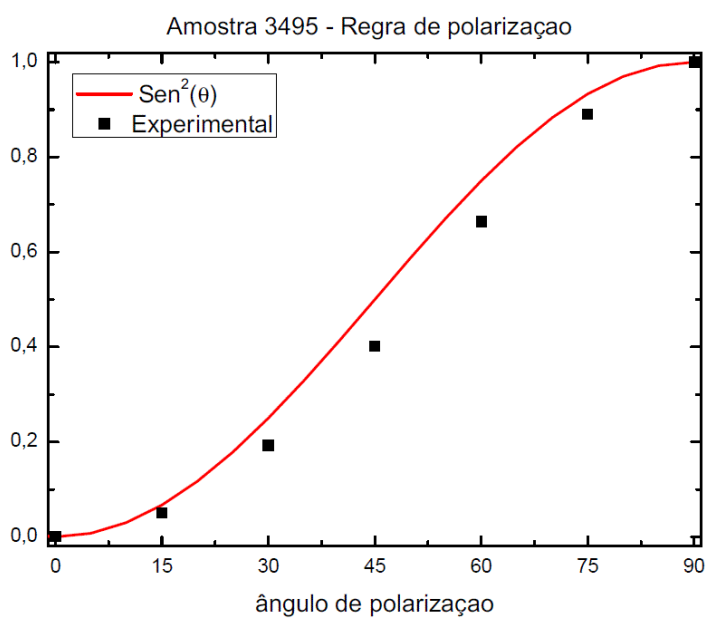

(b)

Figura 60: Verificação da regra de polarização para transições intrabanda em QWIPs do tipo $n$ (equação 7.3). (a) Medidas de absorbância para vários ângulos de polarização da radiação incidente; (b) Gráfico do máximo da absorbância normalizada em função do ângulo de polarização. As medidas foram obtidas por FTIR, usando a geometria de guia de onda a 300K.

A Figura 61 mostra os resultados das medidas de absorção realizadas na maioria dos QWIPs crescidos. A amostra 3504 foi a que apresentou maior absorção, pois sua estrutura foi projetada utilizando-se barreiras suplementares de potencial para modular a absorção do poço. Dentre as amostras crescidas, a 3517 foi projetada para operar em $9,7 \mu \mathrm{m}$, e apresentou um pico de absorção em $9,8 \mu \mathrm{m}$, comprovando um excelente acordo com a estrutura projetada. Isto vem também do fato que a dopagem dos contatos e da região ativa foi otimizada para minimizar a transferência de portadores entre estas duas regiões. 


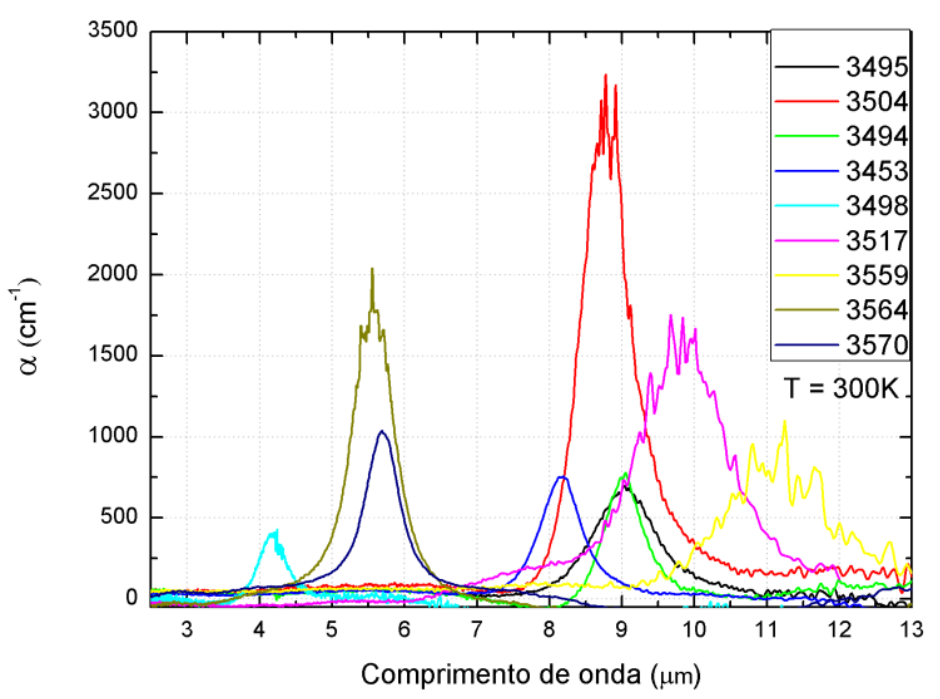

Figura 61: Curvas de absorção para várias amostras. O gráfico mostra o coeficiente de absorção (equação 7.3) obtido a partir das medidas de absorbância. As medidas foram obtidas por FTIR, usando a geometria de guia de onda à temperatura ambiente.

A amostra 3559 possui o seu pico de absorção em $11 \mu \mathrm{m}$, sendo que sua estrutura, que consiste em poços de $\mathrm{Al}_{0,13} \mathrm{Ga}_{0,87} \mathrm{As} / \mathrm{Al}_{0,33} \mathrm{Ga}_{0,67} \mathrm{As}$, foi projetada para absorção em $10 \mu \mathrm{m}$. Esta discrepância pode ser explicada pelas dificuldades encontradas durante a calibração das taxas de deposição das fontes de $\mathrm{Al}$ e $\mathrm{Ga}$, para a formação das ligas de $\mathrm{AlGaAs}$ dos poços e das barreiras. A calibração de taxas, para ligas com concentração de alumínio muito diferentes (por exemplo $13 \%$ nos poços e $33 \%$ nas barreiras), apresenta certas dificuldades que prejudicam a precisão das taxas de deposição. Outra discrepância observada foi a intensidade medida do pico de absorção $\left(800 \mathrm{~cm}^{-1}\right)$, uma vez que, pelos cálculos, a intensidade da absorção estaria próxima de $3000 \mathrm{~cm}^{-1}$. Esses resultados foram analisados por meio de simulação do pico de absorção obtido (Figura 62). Pela simulação o resultado obtido corresponde ao resultado que seria esperado para um poço semelhante ao projetado para o QWIP 3559, porém com barreiras de $31 \%$ de alumínio ao invés de $33 \%$, e com a dopagem de $4 \times 10^{17} \mathrm{~cm}^{-3}$ ao invés de $1 \times 10^{18} \mathrm{~cm}^{-3}$, como foi projetado. Essa discrepância, entre o valor da dopagem projetado e o valor inferido pela simulação dos resultados, pode ser explicada se considerarmos que a energia de Fermi dentro dos poços é bem mais alta em relação à energia de Fermi nos contatos dopados, de modo que ocorre uma difusão dos elétrons da região dos poços para a região dos contatos. Como o poço é formado pela liga $\mathrm{Al}_{0,13} \mathrm{Ga}_{0,87} \mathrm{As}$, e os contato dopados são formados por GaAs, a diferença entre os níveis de Fermi é ainda maior do que a diferença que se obtém geralmente com poços de GaAs, e chega a ser de $130 \mathrm{meV}$ nesse caso específico. Esse efeito de 'fuga' dos elétrons da região ativa provoca o acumulo de cargas positivas, que por sua vez dão origem a um potencial atrativo que altera todo o perfil de potencial da região ativa, tornando esse um problema complexo e autoconsistente. 


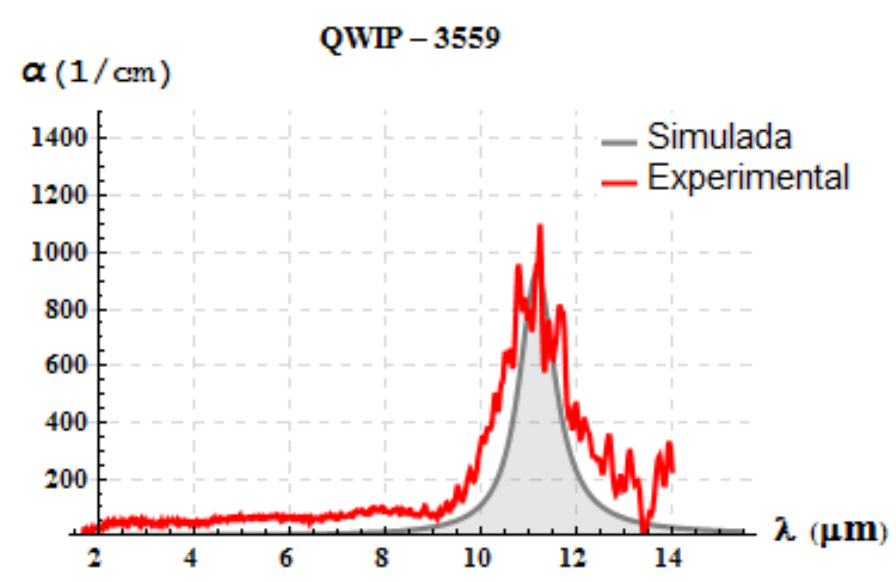

Figura 62: Simulação da curva experimental obtida para a amostra 3559, com poços de $\mathrm{Al}_{0,13} \mathrm{Ga}_{0,87} \mathrm{As}$ e barreiras de $\mathrm{Al}_{0,33} \mathrm{Ga}_{0,67} \mathrm{As}$. Por meio da curva simulada teoricamente foi possível analisar o erro experimental na amostra e o efeito de difusão dos portadores da região ativa para os contatos.

As amostras 3564 e 3570 possuem picos de absorção em torno de 5,6 $\mu \mathrm{m}$. Como esperado, a amostra 3564 apresenta maior absorção em relação à amostra 3570 que possui a mesma estrutura, mas com menor dopagem nos poços.

De modo a verificarmos a reprodutibilidade das estruturas obtidas em dias diferentes, as amostras 3453 e 3495 foram crescidas com estruturas nominalmente iguais (Figura 36 (a)). Os espectros de absorção dessas duas amostras são mostrados na Figura 63. A amostra 3453 apresentou o pico em 8,2 $\mu \mathrm{m}$, com largura a meia altura de $0,7 \mu \mathrm{m}$, e a amostra 3495 apresentou o pico em 9,1 $\mu \mathrm{m}$, mais largo e um pouco menos intenso, com largura de 0,9 $\mu \mathrm{m}$. Essa diferença entre a posição dos picos foi estudada por meio do programa desenvolvido para simulação dos poços quânticos. A comparação entre os resultados experimentais e a simulação das curvas de absorção mostrou que, nesses poços, uma pequena diminuição de cerca de $1 \%$ na concentração da liga das barreiras de $\mathrm{AlGaAs}$ pode produzir um deslocamento de cerca de $1 \mu \mathrm{m}$ em relação à posição esperada do pico de absorção para essa estrutura. Também foi observado que a variação na largura dos poços, de alguns angstrons (uma monocamada atômica), não deve conduzir a esse resultado. Nessa estrutura, o segundo nível de energia é bem próximo do topo da barreira e, possivelmente, este seja o motivo principal que leva essa estrutura a ser mais afetada por variações da composição da liga da barreira. A diminuição da concentração de $\mathrm{Al}$ na barreira, e consequentemente a diminuição no potencial de confinamento do poço, provoca a diminuição da diferença de energia entre os dois estados do poço, o que leva a uma transição com maior comprimento de onda. $\mathrm{O}$ aumento da largura da curva na amostra 3495 provavelmente está relacionado à presença de poços menos iguais, devido a uma instabilidade maior das condições de crescimento. De modo a obtermos boa reprodutibilidade para o crescimento de amostras, com a mesma estrutura em dias diferentes, é necessário realizar a etapa de calibração das células, antes do crescimento, de forma mais minuciosa do que aquela já realizada normalmente, e os parâmetros do sistema MBE devem ser monitorados constantemente e controlados durante todo o crescimento. Duas outras estruturas idênticas, crescidas em dias diferentes (3564 e 3570), não apresentaram este problema (Figura 61). 


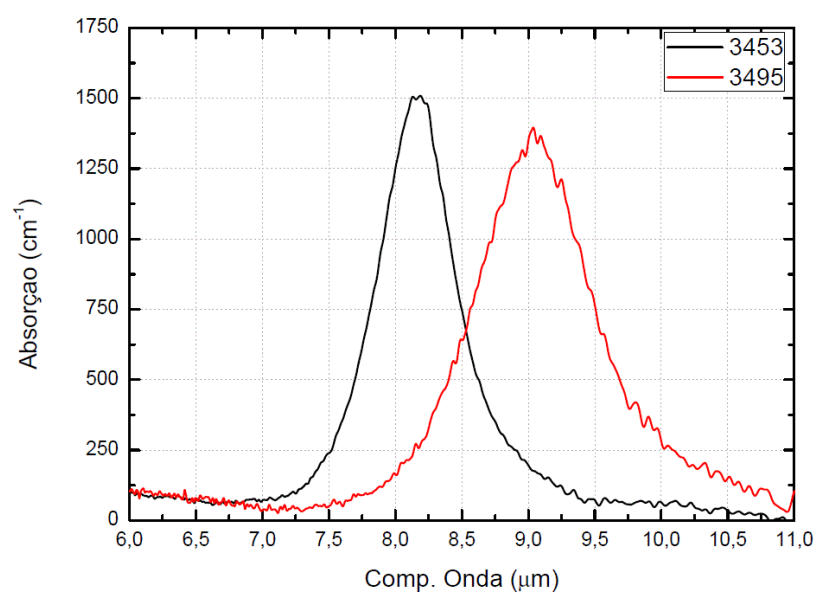

Figura 63: Curvas de absorção das amostras 3453 e 3495 possuindo a mesma estrutura, mas crescidos em dias diferentes. As medidas foram obtidas por FTIR, usando a geometria de guia de onda a 300K.

As Figuras 64 e 65 apresentam a comparação entre as curvas de absorção obtidas experimentalmente e as curvas obtidas por meio do cálculo teórico, sem qualquer tipo de ajuste experimental (exemplo na seção 3.4.4). Na Figura 64 temos o resultado para um QWIP (3453) com 20 poços idênticos de GaAs de $52 \AA$ separados por barreiras de $\mathrm{Al}_{0,26} \mathrm{Ga}_{0,74} \mathrm{As}$ de $300 \AA$. Observamos que a intensidade e a largura das curvas possuem um excelente acordo, porém os máximos dos picos de absorção possuem uma diferença de cerca de $0,5 \mu \mathrm{m}$. Esse pequeno deslocamento está dentro da incerteza experimental, proveniente dos parâmetros usados durante o crescimento epitaxial. A largura da curva de absorção experimental está muito próxima do valor mínimo (teórico), o que mostra que os poços foram crescidos de maneira bastante uniforme, e com interfaces abruptas (a principal vantagem do crescimento pela técnica MBE).

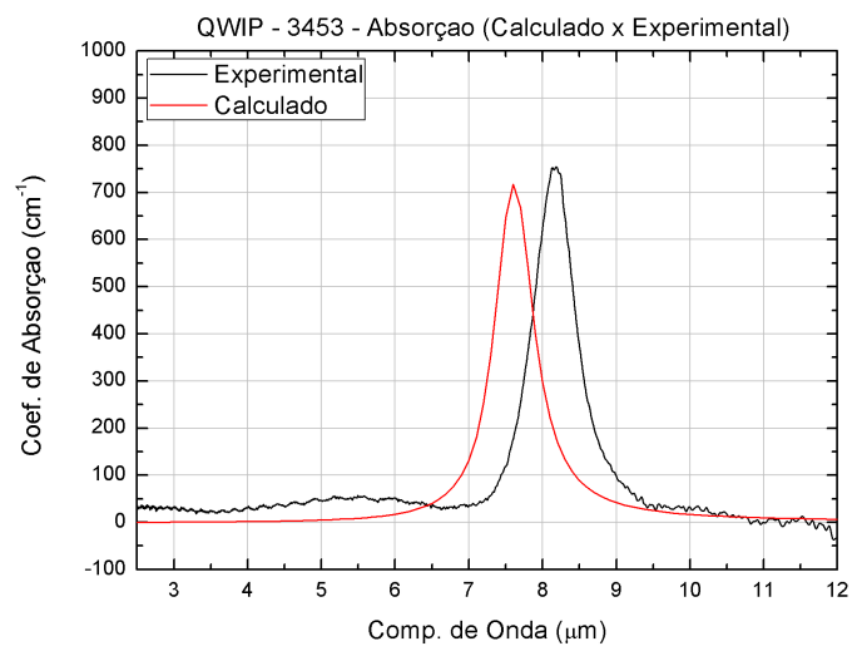

Figura 64: Comparação entre a curva de absorção obtida experimentalmente e a curva simulada do QWIP 3453 com 20 poços quânticos com $52 \AA$ de GaAs separados por barreiras de $A l_{0,26} \mathrm{Ga}_{0,74} A$ s com $300 \AA$ A de largura. As medidas foram obtidas por FTIR, usando a geometria de guia de onda a $300 \mathrm{~K}$. 
A Figura 65, apresenta os resultados experimental e teórico obtidos para um QWIP (3517) com 50 poços idênticos de GaAs com $56,5 \AA$ de largura separados por barreiras de $\mathrm{Al}_{0,21} \mathrm{Ga}_{0,79} \mathrm{As}$ de $300 \AA$ A. Podemos observar o excelente acordo no valor da intensidade e do comprimento de onda dos picos para as duas curvas (teórica \& experimental). Porém, aparece que a largura da curva experimental é maior em relação à curva teórica. Essa tendência de alargamento da curva experimental pode estar ligada ao fato de termos nessa amostra um número grande de poços (50). Nesse caso, o tempo de crescimento da amostra é maior, possibilitando, portanto, uma maior flutuação nos valores dos parâmetros durante o crescimento epitaxial.

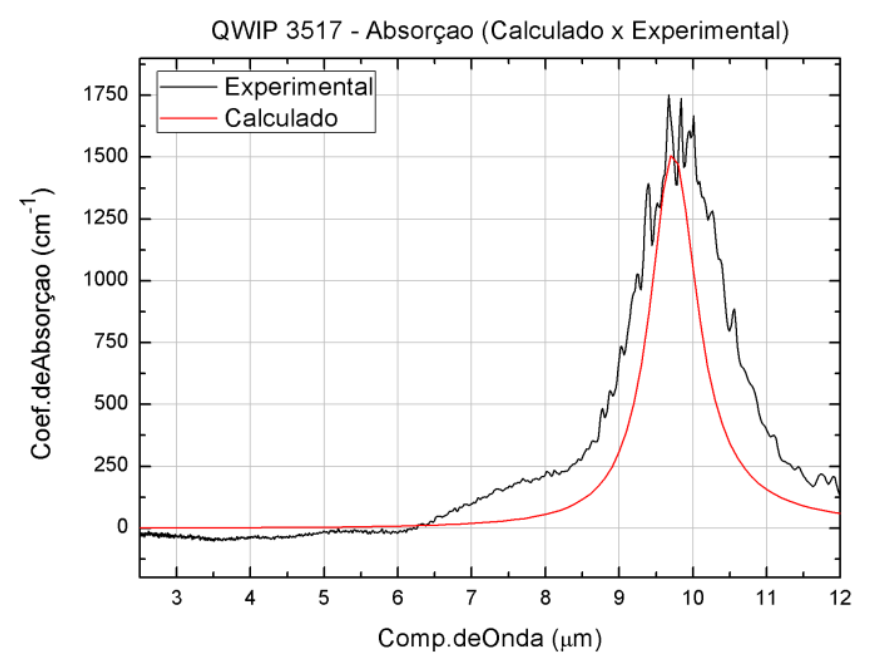

Figura 65: Comparação entre a curva de absorção obtida experimentalmente e a curva simulada para o QWIP 3517 com 50 poços quânticos com $56,5 \AA$ de GaAs separados por barreiras de $A l_{0,21} G a_{0,79} A s$ com $300 \AA$ de largura. As medidas foram obtidas por FTIR, usando a geometria de guia de onda a $300 \mathrm{~K}$.

\subsection{Resposta espectral}

Na Figura 66 estão os resultados da medida de resposta espectral a 10K do QWIP 3517 completamente processado, utilizando o próprio QWIP como detector do FTIR (seção 7.4). Comparando com o resultado da absorção à temperatura ambiente, também mostrado na figura, podemos observar que o pico de absorção deslocou-se cerca de $0,5 \mu \mathrm{m}$, para um comprimento de onda mais baixo, em torno de $9,3 \mu \mathrm{m}$. Baseado nos resultados de simulação, essa diferença se deve provavelmente à variação do gap e do nível de Fermi com a mudança de temperatura. Também podemos observar, nessa figura, que as medidas indicam que a melhor resposta do detector é obtida para voltagens de polarização entre $2,0 \mathrm{~V}$ e 3,5V. As curvas entre $2,0 \mathrm{~V}$ e 3,5V apresentam boa intensidade de sinal e boa relação sinal/ruído. Nas curvas a partir de $4,0 \mathrm{~V}$ podemos observar 
que a relação sinal/ruído se deteriora progressivamente na medida em que a voltagem de polarização aumenta. Enquanto a voltagem está baixa, ela não é suficiente para permitir que todos os elétrons foto excitados participem da fotocorrente e atravessem a estrutura sem serem recapturados de volta nos poços. Por isso, enquanto a voltagem aumenta a partir de $0,5 \mathrm{~V}$, a fotocorrente também aumenta, até alcançar seu valor máximo. Ao aumentar a voltagem no detector, a corrente de escuro também aumenta. Porém, quando a fotocorrente começa a se estabilizar perto do seu valor máximo, a corrente de escuro continua a aumentar em quanto aumentamos a voltagem. Como consequência temos uma deterioração na relação sinal/ruído do QWIP, pois o ruído no detector é proporcional à raiz da corrente de escuro (equação 2.15). Outro fator que contribui para deterioração do sinal em alta voltagem é a injeção de portadores dos contatos na região ativa, o que provoca o aumento da densidade de portadores nos estados de condução contribuindo para aumentar a corrente de escuro.

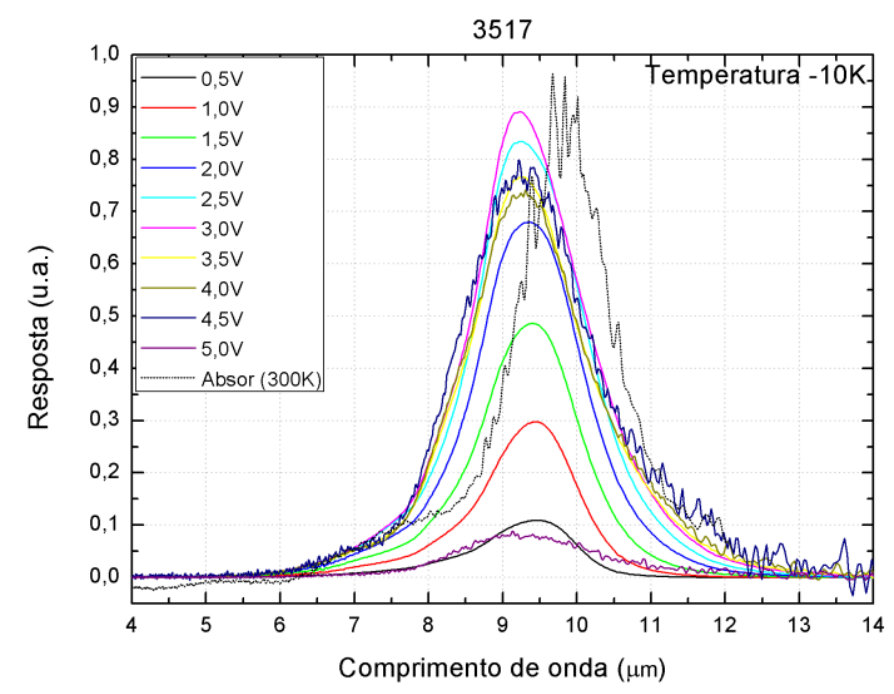

Figura 66: Resposta espectral a 10K do QWIP 3517 completamente processado em função da voltagem aplicada. Neste caso, a medida foi obtida por FTIR com uma mesa localizada diretamente acima do chanfro, usando o QWIP como detector externo do sistema FTIR. A curva de absorção a $300 \mathrm{~K}$ também está mostrada (curva pontilhada) para comparação. 


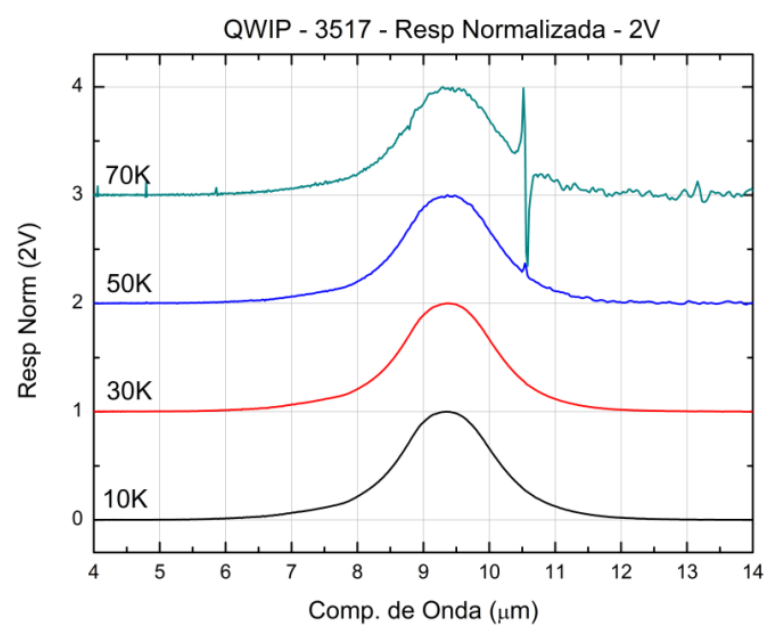

Figura 67: Resposta espectral normalizada do QWIP 3517 em função da temperatura, para uma voltagem de $2 \mathrm{~V}$.

Na Figura 67 são apresentadas as curvas de resposta espectral do QWIP 3517 obtidas com a aplicação de uma voltagem de polarização de $2,0 \mathrm{~V}$ para quatro temperaturas diferentes $(10 \mathrm{~K}, 30 \mathrm{~K}$, 50K e 70K). Verificamos que a posição do pico de absorção não se altera significativamente com a variação da temperatura do QWIP no intervalo medido, e permanece em torno de $9,4 \mu \mathrm{m}$. O pico de absorção medido para a amostra 3517 está bem dentro de uma das janelas de transparência atmosféricas (Figura 10), onde a radiação infravermelha pode atravessar a atmosfera com um mínimo de absorção, principalmente pelo vapor d'água. Essa característica permite a utilização desse QWIP em aplicações para observação e monitoramento remoto, em câmeras infravermelhas ou em sensores individuais.

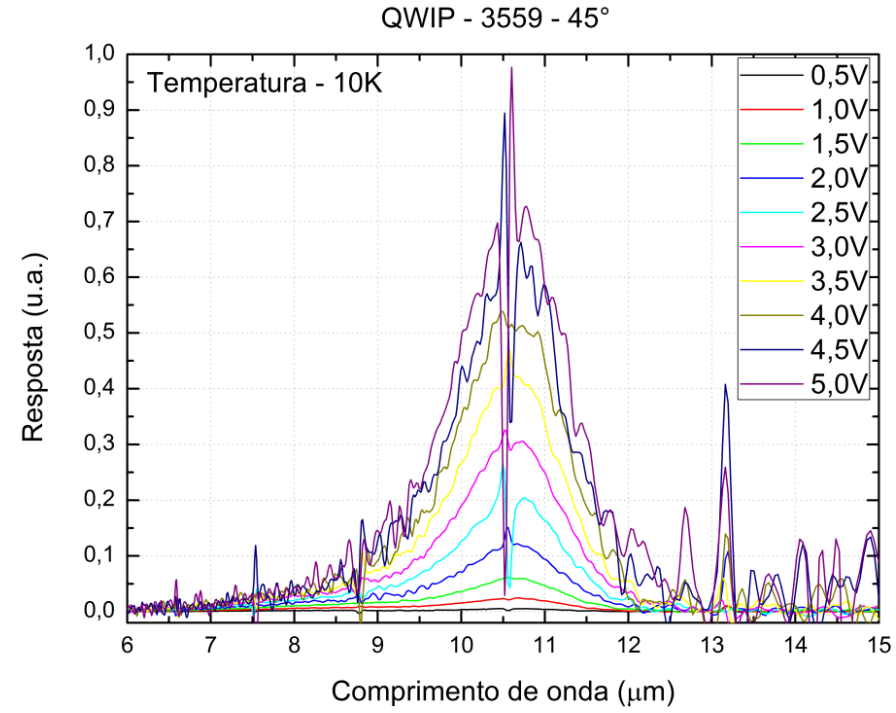

Figura 68: Resposta espectral a 10K para o QWIP 3559 completamente processado com aplicação de diferentes valores de voltagem. 
A Figura 68 mostra a resposta espectral do QWIP 3559 completamente processado, obtida por FTIR com uma mesa localizada logo acima do chanfro (Figura 23). O QWIP 3559 apresenta o pico de absorção em 10,6 $\mu \mathrm{m}$, próximo ao limite de uma das janelas atmosféricas, entre $8 \mu \mathrm{m}$ e $12 \mu \mathrm{m}$ (Figura 10). Comparando essa curva com a curva de absorção obtida a 300K com guia de onda (Figura 61), notamos que, para o dispositivo em operação, o pico da absorção deslocou-se cerca de 0,4 $\mu \mathrm{m}$ no sentido dos comprimentos de onda menores, como no caso do QWIP 3517. Diferentemente do que aconteceu no caso do QWIP 3517, a resposta do QWIP 3559 aumenta sucessivamente à medida que aumentamos a voltagem aplicada de $0,5 \mathrm{~V}$ até $5,0 \mathrm{~V}$. Nessa medida não foi observada a diminuição do sinal para voltagens maiores, possivelmente devido à liga das barreiras possuírem alta concentração de $\mathrm{Al}$ (33-31\%), que deve ter funcionado como barreira para a injeção de portadores vindos dos contatos. Uma particularidade daquelas curvas é que elas são bastante ruidosas. Em comprimentos de onda tipicamente maiores que $10 \mu \mathrm{m}$, a intensidade da fonte de radiação do FTIR é mais fraca, o que introduz uma dificuldade a mais na medida. Quando a fotocorrente se torna muito pequena em relação à corrente de fundo (composta pela corrente de escuro e pela fotocorrente gerada pela radiação ambiente), a supressão da corrente de fundo, por meio do conversor corrente-voltagem, introduz um ruído na medida proporcional ao ganho utilizado, que nesse caso deve ser maior para compensar a diminuição do sinal.

Os gases $\mathrm{O}_{2}$ e $\mathrm{O}_{3}$ possuem uma linha de absorção próxima a 10,5 $\mu \mathrm{m}$. Apesar da atmosfera do sistema FTIR ser purgada constantemente com nitrogênio gasoso, a câmara onde o criostato é inserido no caminho óptico do sistema é exposta ao ar ambiente. É esta linha de $\mathrm{O}_{2} / \mathrm{O}_{3}$ que é detectada nos espectros dessas duas figuras, principalmente quando o sinal da fotocorrente é fraco e precisa ser ampliado.

\subsection{Responsividade total com corpo negro}

A medida de responsividade fornece uma calibração da resposta elétrica do detector em função da intensidade da radiação incidente. $\mathrm{O}$ arranjo disponível em nosso laboratório só permite determinar a responsividade em função da radiação total que chega ao detector a partir de um corpo negro calibrado. Durante as medidas, o corpo negro foi ajustado na temperatura fixa de $800^{\circ} \mathrm{C}(1073 \mathrm{~K})$, e a abertura circular escolhida para a saída da radiação foi de $12,7 \mathrm{~mm}$ (meia polegada) de diâmetro. Todas as medidas foram realizadas no criostato de circuito fechado de He, com um chanfro polido a $45^{\circ}$ (Figura 49), na mesma configuração utilizada nas medidas de resposta spectral. Para as amostras medidas possuindo absorção na região de $8 \mu \mathrm{m}$ a $12 \mu \mathrm{m}$, foi utilizada no criostato a janela de Ge recoberta com um filme antirefletivo que maximiza a transmissão através da janela nesse intervalo de comprimentos de onda (95\%) (Figura 50 (b)). Sem este filme, a janela apresentaria um coeficiente de reflexão muito grande (cerca de $50 \%$ ) por causa do alto índice de refração do Ge $(\approx 4)$ em relação ao do ar $(1)$. A responsividade total para cada voltagem aplicada é obtida a partir do valor da fotocorrente medido pelo lock-in e corrigido pelo fator de modulação (Equação 7.5) que na configuração utilizada foi de 0,404549. O cálculo 
da potência da radiação incidente foi obtido a partir da equação 7.6, usando a largura a meia altura dos espectros de absorção medidos na seção anterior (Figura 66 e Figura 68).

A Figura 69 mostra a medida de responsividade total com corpo negro para a amostra 3517. Podemos observar que o valor da responsividade não se altera significativamente com o aumento da temperatura, o que indica que a dopagem da estrutura foi adequada. Os resultados também mostram que existe uma leve assimetria das curvas, sendo os valores levemente maiores para voltagens positivas. Esse efeito é geralmente atribuído à pequena segregação dos dopantes, nesse caso os átomos de silício, que ocorre nos poços na direção de crescimento durante a deposição das camadas epitaxiais [18]. Para o cálculo da responsividade, foi considerada apenas a faixa espectral da radiação proveniente do corpo negro que corresponde ao intervalo de comprimentos de onda dentro do qual o detector é sensível, e que pode ser aproximado pela largura a meia altura do pico de absorção do dispositivo. A área efetiva do detector que recebe a radiação corresponde à área da mesa ( $400 \times 400 \mu \mathrm{m}^{2}$ ) projetada a $45^{\circ}$ sobre a superfície polida onde incide a radiação (chanfro). Para essa medida, a frequência do chopper foi $277 \mathrm{~Hz}$. A amostra foi posicionada a $19 \mathrm{~cm}$ da abertura do corpo negro, e o cálculo da potência da radiação incidente no detector forneceu o valor de $3,3 \cdot 10^{-7} \mathrm{~W}$. Esse cálculo é feito a partir da expressão da curva de Planck, e leva em conta os parâmetros geométricos utilizados durante a medida, a geometria da amostra, a emissividade real do corpo negro (0.995) e a transmissão da janela do criostato.

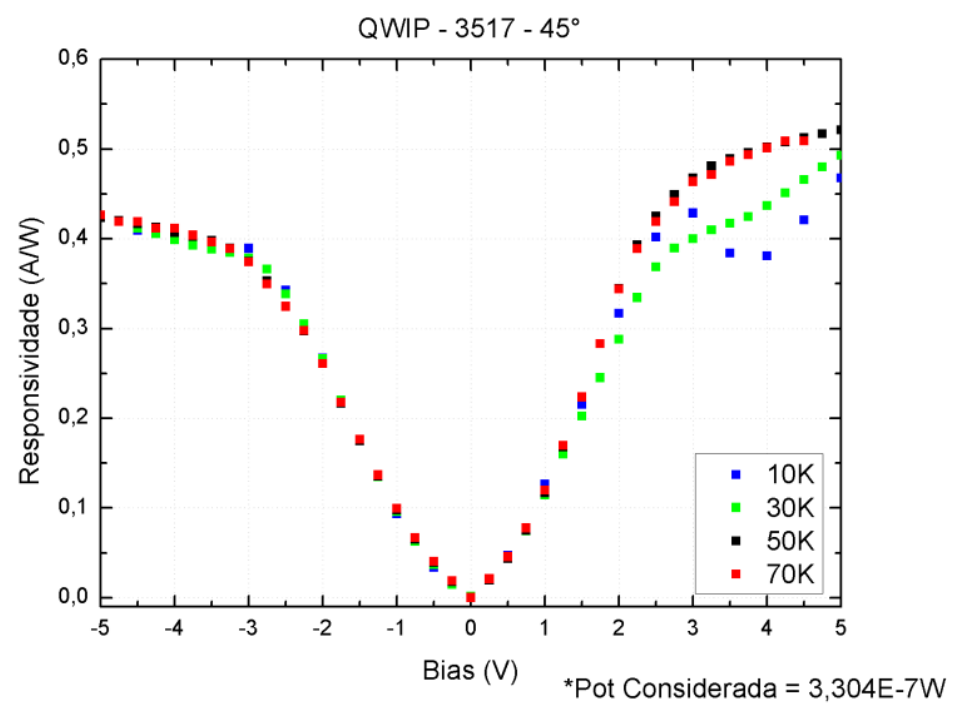

Figura 69: Curva de responsividade total do QWIP 3517 em quatro temperaturas diferentes.

A curva de responsividade do QWIP 3559 (Figura 70) apresenta valores inferiores em comparação com o QWIP 3517. Isso possivelmente se deve, como explicado anteriormente (seção 8.2), a uma pequena redução (-2\%) na concentração de alumínio das barreiras, devida às dificuldades experimentais de calibração, e a provável fuga de portadores da região ativa nesse QWIP. O pico de absorção ocorre em 10,6 $\mu \mathrm{m}$ (Figura 68). Nas condições em que é feita a medida 
de fotocorrente, essa característica coloca esse detector próximo ao limite onde a corrente de fundo, gerada pela radiação ambiente e pela corrente de escuro, limita a qualidade da medida. Devido ao aumento da corrente de escuro com a temperatura e à saturação da fotocorrente, originada pela radiação de fundo, não foi possível realizar as medidas para as voltagens mais altas. Mesmo ao aplicar o menor ganho disponível no pré-amplificador $\left(10^{3} \mathrm{~V} / \mathrm{A}\right)$, a tensão de saída provocou a saturação do lock-in, pois a corrente de fundo não pôde ser suprimida completamente. Para que fosse possível realizar essa medida, o criostato com a amostra foi trazido o mais perto possível do corpo negro, de modo a incrementar o ângulo sólido do corpo negro "visto" pelo detector. Nessa medida, a frequência de rotação utilizada no chopper foi $388 \mathrm{~Hz}$, a amostra foi posicionado a $14 \mathrm{~cm}$ da abertura do corpo negro, e a potência da radiação oriunda do corpo negro incidindo nesse QWIP foi calculada em $4,302 \times 10^{-7} \mathrm{~W}$.

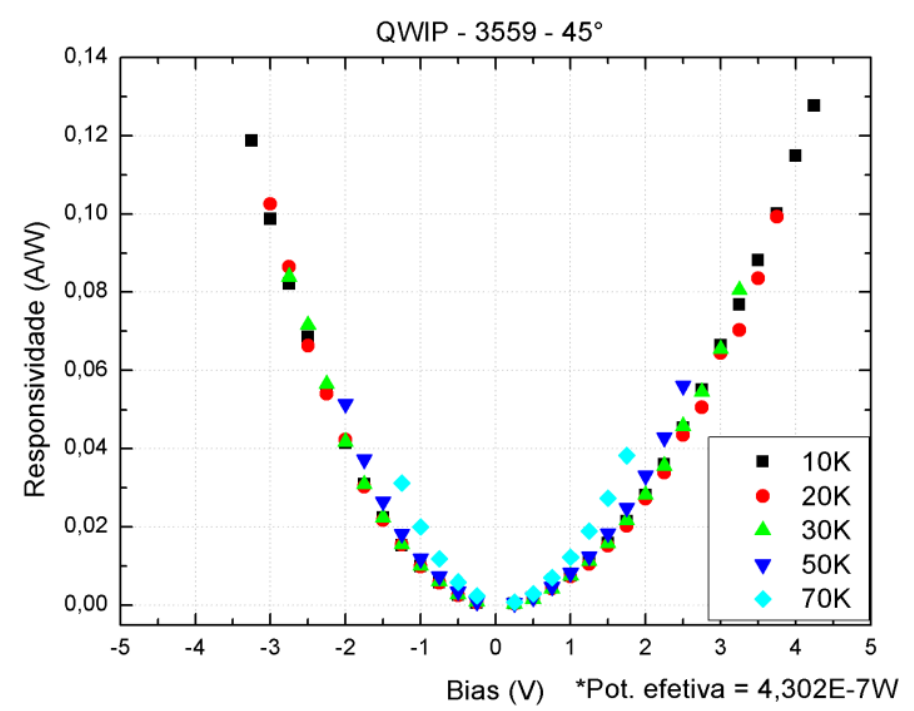

Figura 70: Curvas de responsividade total do QWIP 3559 para cinco temperaturas diferentes.

\subsection{Corrente no escuro (curvas I-V)}

Um dos primeiros testes de qualidade de um dispositivo é a realização de uma curva I-V. No caso de um fotodetector, ela pode ser realizada no claro (na presença da radiação infravermelha de interesse) para conferir o bom funcionamento do dispositivo, ou no escuro para avaliar as fontes parasitas de corrente elétrica (excitação térmica, tunelamento, corrente de superfície, mau processamento). $\mathrm{O}$ arranjo experimental de medida de curvas $\mathrm{I}-\mathrm{V}$ foi o primeiro montado no laboratório durante este trabalho de doutorado, e foi inicialmente usado para verificar a qualidade e a reprodutibilidade do processamento das amostras. Uma forma de fazer isso foi comparar as medidas experimentais com resultados teóricos fornecidos pela equação 3.24. Inicialmente, as máscaras eram confeccionadas em nosso laboratório usando uma impressora laser e transparências para retroprojetor, levando assim a mesas quadradas de $2 \mathrm{~mm}$ de lado, enquanto que os contatos elétricos eram realizados com pequenas bolas de In difundidas nas amostras no interior de um 
pequeno forno elétrico. Aos poucos, as condições de processamento foram melhorando, e as curvas experimentais de corrente de escuro se aproximaram das curvas teóricas simuladas a partir do modelo da corrente de escuro, válido para campo elétrico pequeno. As duas curvas, teórica e experimental, da amostra 3453 estão apresentadas na Figura 71. Observamos um acordo excelente entre a teoria e a curva experimental. Vale ressaltar que a utilização desse modelo simples para corrente de escuro (Equação 3.24), leva em conta somente os elétrons termicamente excitados acima das barreiras e serviu apenas como um parâmetro de avaliação do processamento e do aparato experimental. Para baixas temperaturas, tipicamente menores que $70 \mathrm{~K}$, a excitação térmica diminui consideravelmente, e o tunelamento através das barreiras passa a ser relevante. Para voltagens altas, a deformação que o campo elétrico provoca no perfil de potencial da região ativa se torna geralmente tão grande que surge também um mecanismo de tunelamento por efeito de campo.

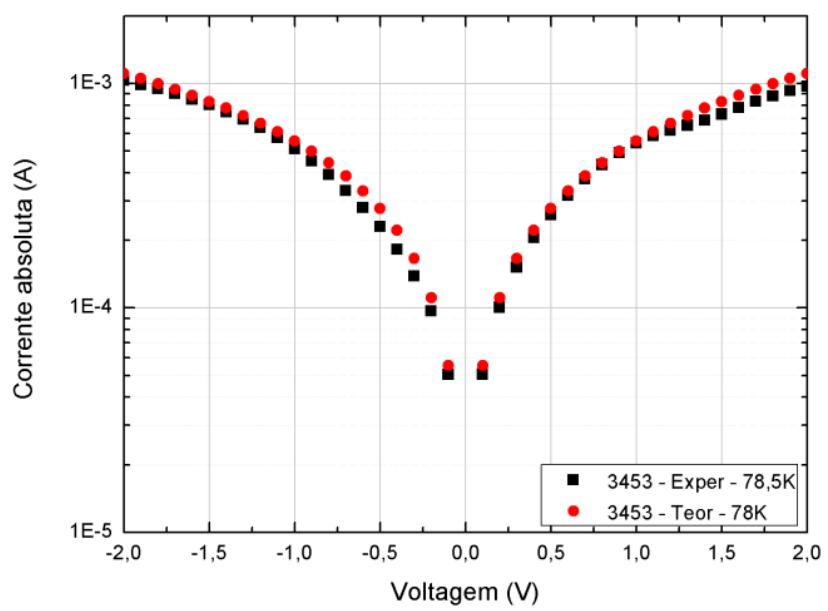

Figura 71: Comparação entre o resultado teórico e experimental da corrente de escuro da amostra $3453 \mathrm{com}$ voltagem de polarização pequena.

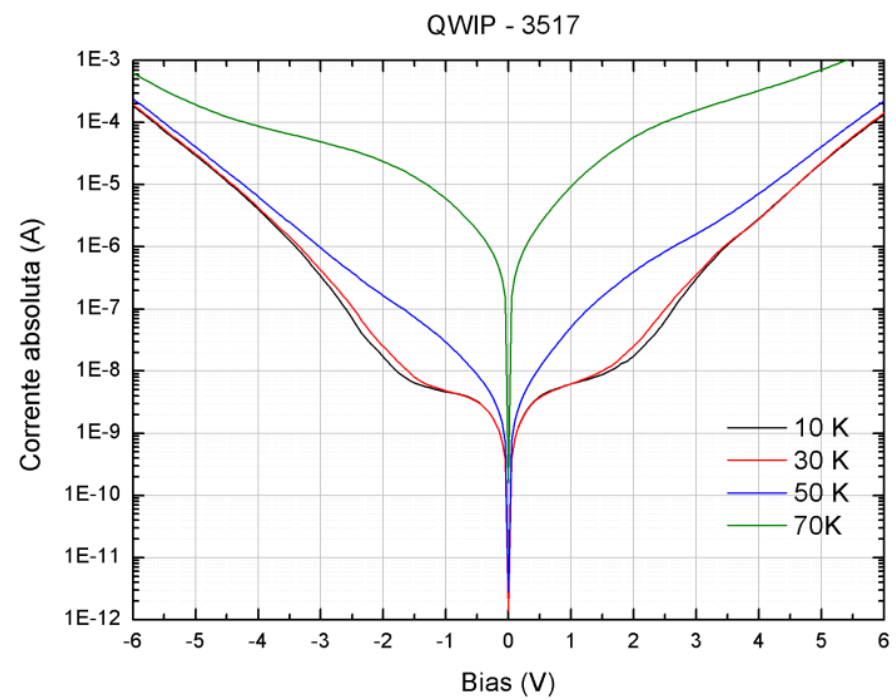

Figura 72: Curva de corrente de escuro para o QWIP 3517 para quatro temperaturas diferentes. 
Os resultados obtidos para a medida da corrente de escuro do QWIP 3517 são mostrados na Figura 72. Como explicado anteriormente, nas medidas de corrente de escuro é montado ao redor da amostra um copo de cobre que é mantido na mesma temperatura que a amostra (escudo de radiação frio), de modo a isolar a amostra de qualquer fonte de radiação externa (Figura 51 (b)). Observa-se que, nas temperaturas de $10 \mathrm{~K}$ e $30 \mathrm{~K}$, as curvas são praticamente superpostas, mostrando uma insensibilidade à temperatura, enquanto que, à medida que o QWIP é aquecido, elas mudam de forma e se distanciam das vizinhas. Esse comportamento é esperado [18], pois, à medida que a temperatura aumenta, o nível de Fermi dos poços aumenta e a energia de ativação diminui ${ }^{1}$. Com essa redução na energia de ativação, mais elétrons são termicamente excitados acima da barreira de AlGaAs, para o contínuo de estados, e um número maior de elétrons fica disponível para participar da corrente de escuro que, acima de $50 \mathrm{~K}$ é predominantemente de origem térmica. Analisando o perfil da corrente de escuro para $10 \mathrm{~K}$ e $30 \mathrm{~K}$, notamos que as duas curvas seguem bem próximas uma da outra para todos os valores de tensão aplicados, sugerindo que elas sejam independentes da temperatura e que, portanto, a corrente de escuro não seja dominada por efeitos térmicos. Além disso, elas possuem um comportamento peculiar entre $-2 \mathrm{~V}$ e $2 \mathrm{~V}$, apresentando uma espécie de patamar no qual a corrente quase não varia mais com a voltagem aplicada. Esse comportamento pode ser explicado pela presença de tunelamento entre poços vizinhos através da barreira de potencial. $\mathrm{O}$ tunelamento ocorre entre os níveis fundamentais de cada poço devido à formação de uma minibanda de condução [44]. Na medida em que a tensão aplicada aumenta, a barreira de potencial (retangular) começa a se deformar e a exibir um perfil triangular de tal maneira que a diferença entre o nível do potencial da barreira e o nível do estado excitado diminui, assim como a espessura da barreira 'vista' pelo nível excitado. Esse efeito é conhecido como regime de tunelamento por efeito de campo, que leva a um aumento da corrente de escuro que passa a aumentar exponencialmente com a voltagem, como indicado nas curvas da Figura 72 acima de $3 \mathrm{~V}$, entre 10 e $30 \mathrm{~K}$.

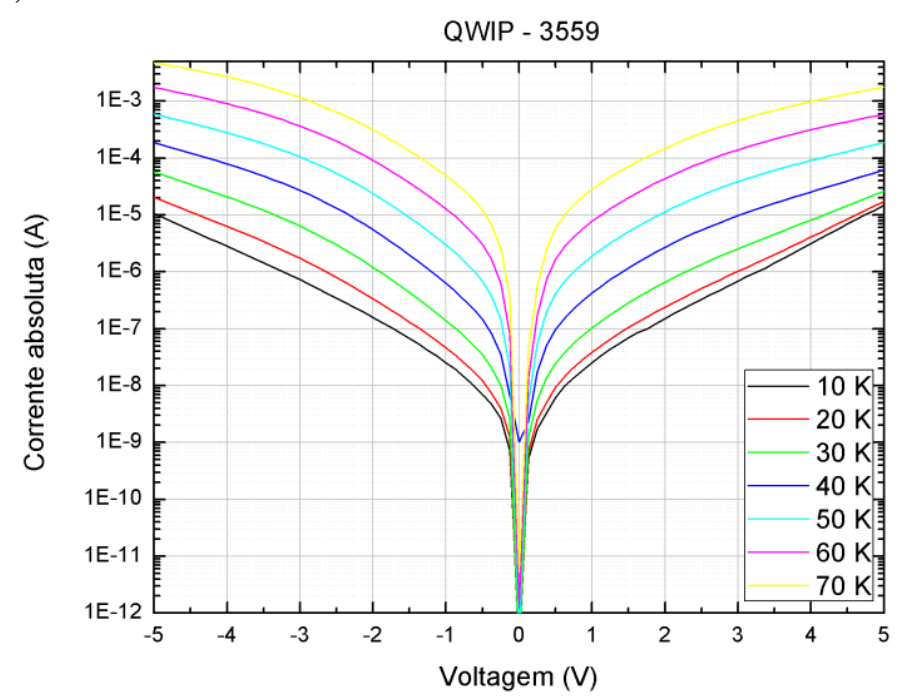

Figura 73: Curvas de corrente de escuro do QWIP 3559 para temperaturas entre 10K e 70K.

\footnotetext{
${ }^{1}$ A energia de ativação corresponde à diferença de energia entre o topo da barreira de AlGaAs e o nível de Fermi da estrutura.
} 
As curvas da corrente de escuro do QWIP 3559 estão apresentadas na Figura 73. Essas curvas não apresentam o mesmo comportamento observado no QWIP 3517 para baixas temperaturas (10K e 30K). Para QWIPs com barreiras não muito largas, como o caso dos QWIPs 3517 e 3559 , que possuem barreiras com $300 \AA$ de largura, espera-se que entre $10 \mathrm{~K}$ e $30 \mathrm{~K}$, a corrente de escuro possua uma componente de tunelamento independente da temperatura, como observado para o QWIP 3517. No QWIP 3559, a corrente de escuro aumenta com o aumento da temperatura mesmo para as temperaturas mais baixas. O aumento da corrente de escuro em baixas temperaturas indica que existe uma energia de ativação muito pequena para o processo de transporte dos elétrons. No período em que foi crescido o QWIP 3559, acreditamos que o alumínio estava contaminado devido a um problema ocorrido na câmara de crescimento do sistema MBE, dias antes. Devido a essa contaminação é possível que as barreiras foram contaminadas com impurezas que introduziram níveis de energia no interior do gap das barreiras de AlGaAs fazendo com que se criassem minibandas de condução. Esse efeito foi também observado em outro QWIP (3558) que foi crescido para o trabalho de mestrado de outro aluno do grupo.

\subsection{Condição BLIP}

A condição BLIP ocorre enquanto a corrente de escuro está abaixo da fotocorrente gerada pela radiação de fundo do ambiente que chega ao detector. No caso das medidas realizadas, a radiação de fundo é composta pela radiação do ambiente, que atravessa a janela do criostato, e pela radiação emitida pela própria janela do criostato em equilíbrio térmico com o ambiente a 300K. Toda radiação que atravessa a janela e aquela emitida pela própria janela que incide no chanfro da amostra com um ângulo inferior a $34^{\circ}$ penetra na amostra com um ângulo inferior a $5^{\circ}$, devido à diferença de índice de refração entre o vácuo e o GaAs $(n=3,24)$. Dessa forma, podemos considerar que toda essa radiação é direcionada pelo guia de ondas para a região ativa e deve ser contabilizada como radiação de fundo. Para a simulação do ambiente foi considerada a radiação emitida por um corpo negro a $300 \mathrm{~K}$ (lei de Planck) atravessando a janela com transmissão de 95\% (Figura 50), e a radiação emitida pela própria janela do criostato foi calculada utilizando a lei de Planck com emissividade $\varepsilon=0,95^{2}$. A potência de fundo calculada, incidente na amostra, foi de aproximadamente $6,4 \times 10^{-6} \mathrm{~W}$, e as curvas de responsividade dos QWIPs 3517 e 3559 foram multiplicadas por esse valor de modo a obter as curvas para condição BLIP (Figura 74).

\footnotetext{
${ }^{2}$ Onde $\varepsilon=1-\mathrm{R}$, sendo $\mathrm{R}$ a refletividade, dada por $\mathrm{R}=1-\mathrm{T}$, e $\mathrm{T}$ a transmissão da janela de Ge entre 9 e $11 \mu \mathrm{m}$.
} 


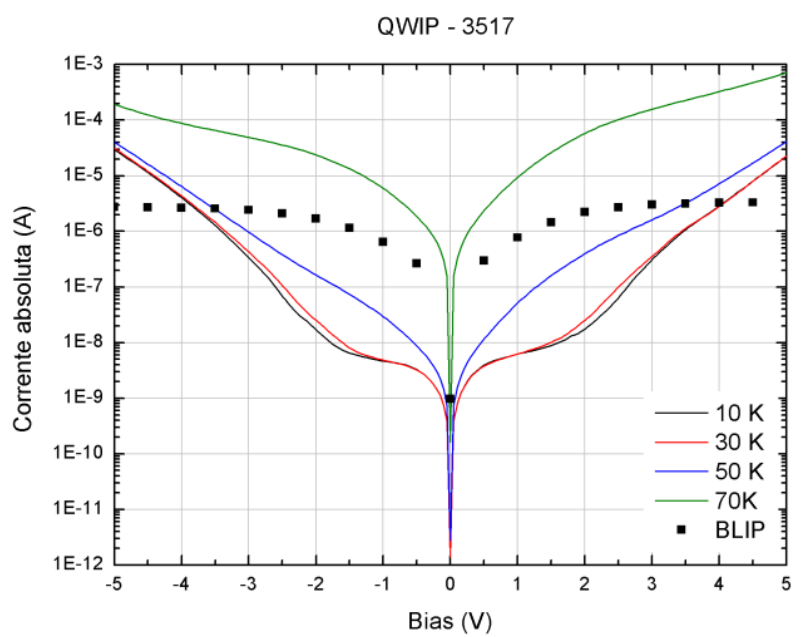

(a)

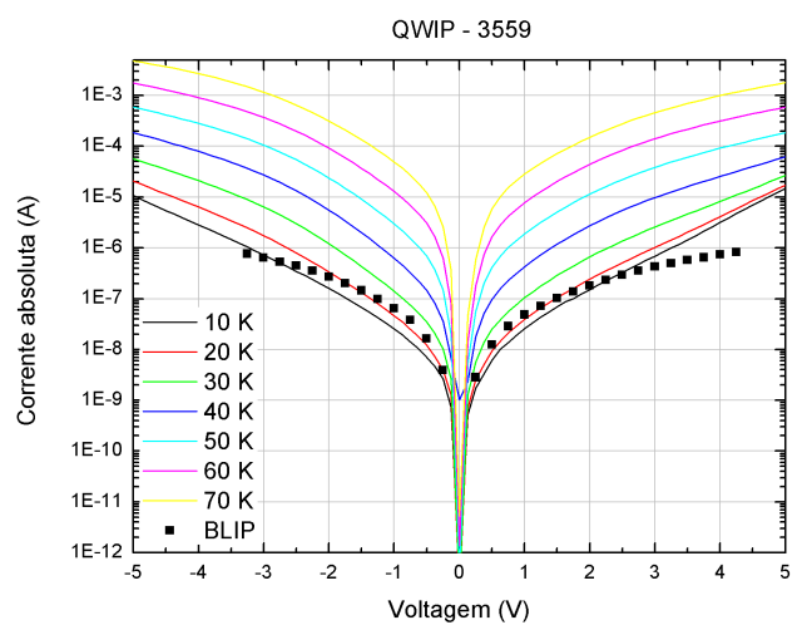

(b)

Figura 74: Comparação entre as medidas de corrente no escuro e a fotocorrente gerada pela radiação de fundo para determinar a condição BLIP no caso do (a) QWIP 3517 e (b) QWIP 3559.

A Figura 74 (a) e (b) apresenta as curvas de corrente de escuro em comparação com a condição BLIP, para os QWIPs 3517 e 3559 respectivamente. Para o QWIP 3517, a condição BLIP ocorre para qualquer voltagem de polarização entre $-3 \mathrm{~V}$ e $+3 \mathrm{~V}$, quando a temperatura é menor que $50 \mathrm{~K}$. Ou seja, numa aplicação tecnológica desse detector, o ideal é que a sua temperatura de operação fique abaixo de 50K. No caso do QWIP 3559, o desempenho foi muito pior, pois, para esse QWIP, a temperatura ideal de operação ficaria abaixo de $20 \mathrm{~K}$ e restrita a uma faixa de voltagem entre $-2 \mathrm{~V}$ e $+2 \mathrm{~V}$.

\subsection{Caracterização completa da amostra 3517}

\subsubsection{Medidas de ruído}

As medidas de ruído foram realizadas manualmente, pois os dados são extremamente sensíveis a fatores externos (estabilidade da rede elétrica, ruídos parasitas, mau aterramento do sistema) e precisam de uma intervenção humana para a escolha dos intervalos do espectro onde as medidas de amplitude do ruído serão tomadas (especialmente com o criostato de circuito fechado de hélio que gera muito ruído elétrico e magnético devido ao compressor e ao pistão). Os dados foram obtidos variando-se a tensão de polarização entre $-5 \mathrm{~V}$ e $5 \mathrm{~V}$, em passos de $0,5 \mathrm{~V}$, e ajustando o ganho no conversor de corrente-voltagem entre $10^{3}$ e $10^{7}$ V/A para cada temperatura. Cada valor foi obtido a partir da média das medidas realizadas em três pontos diferentes do espectro entre $250 \mathrm{~Hz}$ e $3,6 \mathrm{KHz}$. 


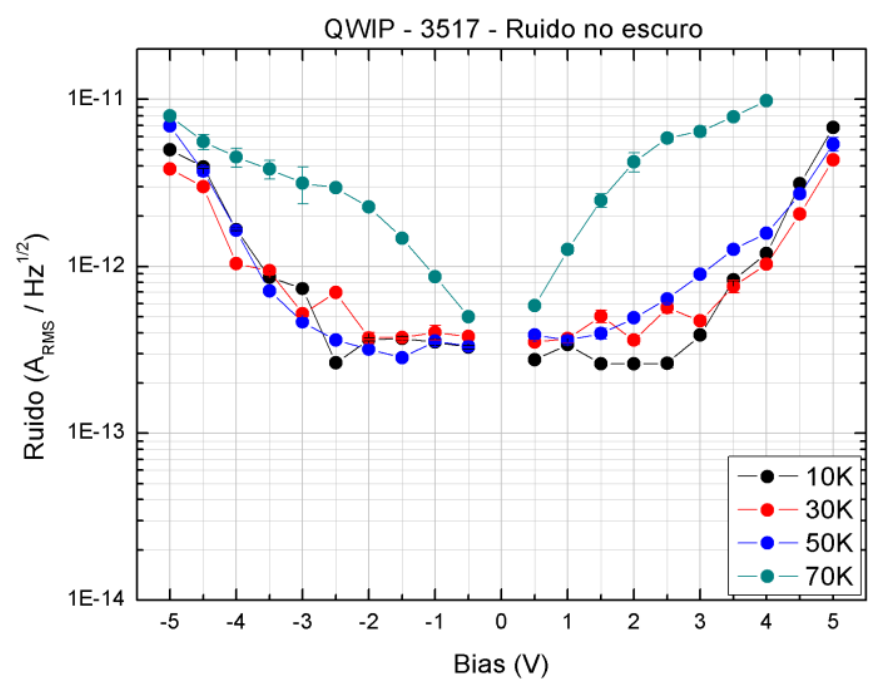

Figura 75: Curvas de ruído da amostra 3517 medidas na faixa de frequências de $250 \mathrm{~Hz}$ a 3,6KHz.

Na Figura 75 estão apresentados os resultados experimentais obtidos para o QWIP 3517. Podemos observar que os valores do ruído medido para as temperaturas entre $10 \mathrm{~K}$ e $50 \mathrm{~K}$ permanecem próximos em todo o intervalo de voltagens, e que parece existir um patamar, entre $2,5 \mathrm{~V}$ e $2,5 \mathrm{~V}$, onde o ruído parece estar constante $\left(3-4 \times 10^{-13} \mathrm{~A}_{\mathrm{RMS}} / \mathrm{Hz}^{1 / 2}\right)$ apesar da corrente de escuro variar por várias ordens de grandeza nesse intervalo. Esse fato indica que estas medidas foram possivelmente afetadas pela limitação do setup experimental, cujo ruído intrínseco deve ser da ordem de $3-4 \times 10^{-13} \mathrm{~A}_{\mathrm{RMS}} / \mathrm{Hz}^{1 / 2}$, como será mostrado mais adiante. A partir de $70 \mathrm{~K}$, o ruído começa a aumentar rapidamente em baixa voltagem, e segue a tendência das curvas de corrente de escuro cujo valor sobe consideravelmente em razão da excitação térmica.

\subsubsection{Detectividade}

A partir dos dados experimentais obtidos para a responsividade e o ruído, foram determinadas as curvas de detectividade do QWIP 3517, para $10 \mathrm{~K}, 30 \mathrm{~K}, 50 \mathrm{~K}$ e $70 \mathrm{~K}$, usando a equação 2.17 . Para a área do detector o valor utilizado foi $\mathrm{A}_{\mathrm{d}}=1,13 \times 10^{-3} \mathrm{~cm}^{2}$, que corresponde a área da mesa projetada a $45^{\circ}$, de modo a levar em conta o ângulo de incidência da radiação na região ativa. $\mathrm{O}$ valor $\Delta \mathrm{f}=1 \mathrm{~Hz}$ foi utilizado na equação 2.17 de modo a expressar o resultado em espectro de potencia, onde os valores são normalizados pela banda de frequências utilizada na medida. Os resultados da detectividade estão apresentados na Figura 76. As curvas indicam que a melhor condição para a operação deste QWIP ocorre para as temperaturas entre $10 \mathrm{~K}$ e $50 \mathrm{~K}$ com a aplicação de uma tensão de polarização entre $-2 \mathrm{~V}$ e $-3 \mathrm{~V}$ (ou $+2 \mathrm{~V}$ a $+3 \mathrm{~V})$. Isso se deve ao fato de, nesta faixa de voltagem, a responsividade ser razoavelmente alta e o ruído ainda ser muito baixo (no limite do patamar de ruído intrínseco do arranjo experimental). A partir de $70 \mathrm{~K}$, a detectividade cai rapidamente, pois, apesar de ainda apresentar uma responsividade alta, o dispositivo agora possui um ruído muito mais alto que prejudica o seu desempenho. 


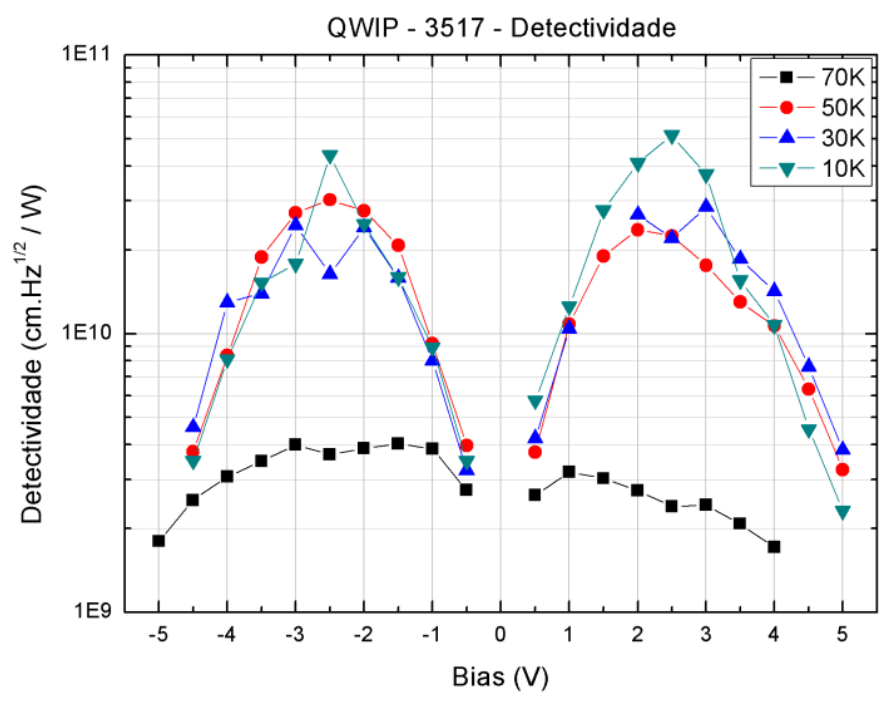

Figura 76: Detectividade específica da amostra 3517, obtida a partir dos resultados experimentais de responsividade e ruído, obtida por meio da equação 2.17.

Para termos uma ideia da qualidade desses resultados, podemos comparar os valores de detectividade obtidos para o QWIP 3517 (Figura 76) com o caso de um fotodetector fotocondutivo comercial de $\mathrm{HgCdTe}$ com absorção no intervalo de $8 \mu \mathrm{m}$ a $10 \mu \mathrm{m}$, operando a $77 \mathrm{~K}$, esse tipo de fotodetector de $\mathrm{HgCdTe}$ possui uma detectividade de aproximadamente $1-2 \times 10^{10} \mathrm{~cm} \sqrt{\mathrm{Hz}} / \mathrm{W}$ [29] que é bem maior que o valor de detectividade obtido para o QWIP 3517 a $70 \mathrm{~K}\left(4 \times 10^{9}\right.$ $\mathrm{cm} \sqrt{\mathrm{Hz}} / \mathrm{W})$. Todavia, como já mencionado, os QWIPs possuem uma alta corrente de escuro nessa temperatura, e devem operar a mais baixas temperaturas para ter um bom desempenho. De fato, abaixo de 50K, o QWIP 3517 supera o valor da detectividade do detector de HgCdTe cujo desempenho não varia muito abaixo de $77 \mathrm{~K}$ [45]. Na comparação direta com os QWIPs comerciais de $\mathrm{AlGaAs} / \mathrm{GaAs}$ fabricados pela empresa norte-americana FLIR (referência mundial na fabricação de câmeras infravermelhas) [29], e operando nas mesmas condições, o nosso QWIP 3517 possui maior detectividade, $4 \times 10^{9} \mathrm{~cm} \sqrt{\mathrm{Hz}} / \mathrm{W}$ contra $6,5 \times 10^{8} \mathrm{~cm} \sqrt{\mathrm{Hz}} / \mathrm{W}$ a $70 \mathrm{~K}$.

\subsubsection{Capacitância}

A capacitância geométrica no caso de placas condutoras paralelas é dada por $\mathrm{C}_{0}=\varepsilon \cdot A / d$. Para o QWIP 3517, a área $A$ do detector é de $1,6 \times 10^{-3} \mathrm{~cm}^{2}, d$ é a largura da região ativa $1,8125 \times 10^{-4} \mathrm{~cm}$ e $\varepsilon$ é dado por $12,85 . \varepsilon_{0}\left(\varepsilon_{0}=8,85 \times 10^{-14} \mathrm{~F} / \mathrm{cm}\right)$, com esses parâmetros o valor calculado para a capacitância geométrica é de aproximadamente $10 \mathrm{pF}$. No caso de um FPA, com pixels quadrados com $25 \mu \mathrm{m}$ de lado, a capacitância geométrica seria de $0,04 p F$.

A capacitância do QWIP 3517 foi medida no criostato de $\mathrm{N}_{2}$ líquido usando um analisador de parâmetros semicondutores. A medida de capacitância não é importante em si para avaliar o 
desempenho de um fotodetector singelo, mas é vital quando se trata de acoplar o dispositivo a um circuito eletrônico que será encarregado do tratamento do sinal. No caso do desenvolvimento de FPAs para futuras câmeras de radiação infravermelha, esta medida de capacitância servirá para nortear o projeto de um circuito ROIC que está sendo desenvolvido pelo grupo do Professor Davies Williams (da UFMG), no âmbito do INCT - DISSE. Em geral, circuitos ROIC comerciais são feitos em Si, projetados e caracterizados para operação na temperatura ambiente e para dispositivos bem específicos. Entretanto, como os QWIPs precisam ser refrigerados em temperaturas criogênicas para operarem em boas condições, esses ROICs devem ser capazes de alcançar temperaturas de $77 \mathrm{~K}$, ou mesmo inferiores.

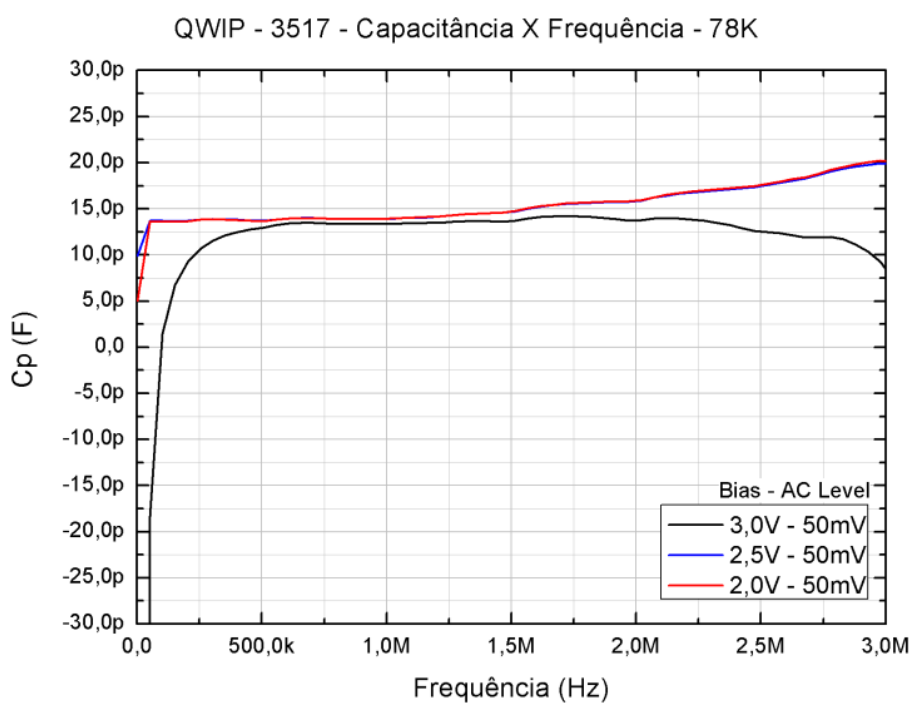

Figura 77: Medidas de capacitância do QWIP 3517 para várias voltagens. As voltagens de operação (em $V$ ) e de modulação (em $\mathrm{mV}$ ) estão indicadas.

Na Figura 77, está apresentada a medida da capacitância do dispositivo em função da frequência. A partir dos resultados da curva de detectividade do QWIP 3517 (Figura 76), definimos os valores $2.0 \mathrm{~V}, 2.5 \mathrm{~V}$ e $3.0 \mathrm{~V}$ para as voltagens de prova, e uma modulação de $50 \mathrm{mV}$ para a voltagem de excitação AC. Para as curvas de 2,0V e 2,5V ocorre uma queda no valor medido para frequências inferiores a $50 \mathrm{kHz}$, enquanto que para a curva de $3,0 \mathrm{~V}$ essa queda foi mais acentuada e ocorre a partir de cerca de $500 \mathrm{KHz}$, sendo que se torna negativa para frequências inferiores a 100KHz. A amplitude da componente negativa $I(\infty)$ da corrente transiente $\delta I(t)=I(t)-I(\infty)$ aumenta, na medida em que aumentamos a voltagem $(I(\infty)=I(V))$, e passa a dominar a corrente transiente em frequências mais baixas [33]. Para uma medida correta da capacitância em baixas frequências é necessário alterar os parâmetros de medida no sistema por meio do aumento do tempo de integração do sinal. O valor medido da capacitância da amostra nas três curvas é muito parecido, cerca de $13,5 p F$, e próximo ao valor da capacitância geométrica calculada $(10 p F)$. Esse efeito ocorre quando o tempo característico da componente de relaxação $\delta j(t)$ varia lentamente em relação à velocidade $\omega$, da oscilação da função cosseno na equação 3.27. Esse corresponde ao caso de uma integral de um produto de uma função harmônica tendendo a zero, quando $\omega \rightarrow \infty$ [33]. É 
bom ressaltar, como explicado na seção 7.9, que esse sistema não é propriamente um sistema de medidas de capacitância, e sim um sistema de medidas de impedância e envolve todo o circuito dos cabos e conectores e não apenas só a amostra. Para obtenção da capacitância do QWIP 3517 foi feita previamente uma medida da capacitância apenas dos cabos e conectores, de modo a descontarmos essas contribuições no valor final da capacitância do circuito. Para as frequências mais altas, acima de 2,0MHz, observa-se um comportamento peculiar: em geral, em QWIPs com grande número de poços quânticos (50 poços nesse caso), a excitação transiente de alta frequência provoca ondas de deslocamento espacial dos portadores injetados [33], que pode explicar o desvio das curvas em alta frequência.

\subsection{Mecanismos de transporte em QWIPs deduzidos a partir das medidas de ruído}

O ruído da corrente de escuro $I_{d n}$ é o ruído predominante em QWIPs. Esse ruído, em geral, corresponde ao ruído de geração-recombinação, ou simplesmente ruído GR. O ruído GR tem origem na flutuação estatística do número de portadores disponíveis e na variação do comprimento de deriva, percorrido pelo portador de carga na estrutura, antes de ocorrer a recapturapelo poço. Para um QWIP com $N$ períodos, esse ruído é dado por [18],

$$
I_{d n}=\sqrt{\left(\frac{1}{p_{c}}-\frac{1}{2}\right) \cdot \frac{4 . e}{N} \cdot I_{d}(E) \cdot \Delta f} \quad \text { Equação } 8.2
$$

onde $I_{d}(E)$ é a corrente de escuro e $p_{c}$ é a probabilidade de recaptura de um elétron foto-excitado do poço. A probabilidade de captura é um parâmetro que depende intrinsecamente do tempo médio de trânsito $\left(\tau_{\text {Trans }}\right)$ que um elétron leva para percorrer um período do QWIP $\left(L_{P}\right)$, e do tempo de recaptura $\tau_{c}$, que é o tempo médio que um elétron excitado permanece à disposição no estado excitado para participar da corrente, antes de ser recapturado para o estado fundamental do poço de origem (tempo de vida do elétron no estado excitado).

$$
\boldsymbol{p}_{\boldsymbol{c}}=\frac{\boldsymbol{\tau}_{\text {Trans }}}{\boldsymbol{\tau}_{\text {Trans }}+\boldsymbol{\tau}_{\boldsymbol{c}}} \quad \text { Equação } 8.3
$$

O tempo $\tau_{\text {Trans }}$ é dado por $\boldsymbol{\tau}_{\text {Trans }}=\frac{\boldsymbol{L}_{\boldsymbol{P}}}{\boldsymbol{v}_{\boldsymbol{D r i f t}}} \quad$ Equacão 8.4

onde $v_{\text {Drift, }}$ é a velocidade de deriva do elétron na estrutura que, em primeira aproximação, é um parâmetro que depende da mobilidade do material e do campo elétrico aplicado. Para valores do campo elétrico suficientemente pequenos, os elétrons se deslocam no contínuo da banda de 
condução com menor energia. Nesse caso, a mobilidade pode ser considerada como uma constante $\left(\mu_{o}\right)$, e a velocidade de deriva é dada simplesmente por,

$$
\boldsymbol{v}_{\text {Drift }}=\mu_{o} \cdot E
$$

sendo $E$ o campo elétrico gerado na região ativa pela aplicação da voltagem no dispositivo.

Um modelo realista da velocidade de deriva para altos campos deve levar em conta a população de elétrons gerada em outras bandas de condução. Diferentes bandas de condução possuem valores diferentes de mobilidade. No caso de campos elétricos maiores, a população dessas bandas, por elétrons de condução, deve ser considerada para a obtenção de um valor realista para a velocidade de deriva. No caso do GaAs, podemos calcular, a partir de um modelo semiempírico, a velocidade de deriva como função do campo elétrico aplicado. Esse modelo foi obtido da referência [41]:

$$
\boldsymbol{v}_{\text {Drift }}=\frac{\mu_{o} E+\left[\left(3 v_{m}-2 \mu_{o} E_{m}\right) \cdot\left(\frac{E}{E_{m}}\right)^{2}\right]+\left[v_{s} \cdot\left(\frac{2 v_{m}-\mu_{o} E_{m}}{v_{m}-v_{S}}\right) \cdot\left(\frac{E}{E_{m}}\right)^{3}\right]}{1+\left[\left(\frac{2 v_{m}-\mu_{o} E_{m}}{v_{m}-v_{S}}\right) \cdot\left(\frac{E}{E_{m}}\right)^{3}\right]}
$$

Equação 8.5

Esse modelo depende essencialmente de quatro parâmetros: a velocidade de saturação $v_{s}$, a velocidade máxima $v_{m}$, a mobilidade $\mu_{o}$ para baixos campos elétricos e o parâmetro $E_{m}$, que possui dimensão de campo elétrico. No caso desses parâmetros serem funções dependentes da temperatura, temos então a velocidade de deriva no GaAs também como função da temperatura.

Nos QWIPs, o ruído e o ganho fotocondutivo são fortemente influenciados pelo tempo de recaptura $\tau_{c}$. A abordagem teórica padrão é feita por meio da regra de ouro de Fermi, e o cálculo do tempo de recaptura é realizado a partir da determinação do Hamiltoniano do processo de espalhamento que leva ao decaimento do elétron excitado. Esses processos ocorrem pela interação do elétron com fônons da rede cristalina ou pelo espalhamento por outros elétrons e impurezas (interação Coulombiana). A interação mais relevante em QWIPs do tipo n, em geral, é a interação com fônons longitudinais ópticos (LO). Essa interação é conhecida como interação de Fröhlich. O valor da energia do fônon longitudinal óptico $\left(E_{L O}\right)$, no GaAs, corresponde a cerca de $36 \mathrm{meV}$. O cálculo preciso do tempo de recaptura leva em consideração as funções de onda do estado fundamental e do estado excitado, $\Psi_{1}$ e $\Psi_{2}$ respectivamente, e é dado por [18],

$$
\begin{aligned}
\frac{1}{\tau_{c}}=\frac{m^{*} e^{2} E_{L O}}{4 \hbar^{3}} \cdot( & \left.\frac{1}{\epsilon_{\infty}}-\frac{1}{\epsilon_{s}}\right) \cdot \iint d z_{1} d z_{2}\left[\Psi_{2}^{*}\left(z_{1}\right) \Psi_{2}\left(z_{2}\right) \Psi_{1}\left(z_{1}\right) \Psi_{1}^{*}\left(z_{2}\right)\right] \\
& \times \int_{0}^{2 \pi} d \varphi\left[\frac{\exp \left[-\left[K_{2}^{2}+K_{1}^{2}-\left(2 \cdot K_{2} K_{1} \cos (\varphi)\right)\right]^{1 / 2} \cdot\left|z_{2}-z_{1}\right|\right]}{\left.\left[K_{2}^{2}+K_{1}^{2}-\left(2 \cdot K_{2} K_{1} \cos (\varphi)\right)\right]^{1 / 2}\right]} \quad \text { Equação } 8.6\right.
\end{aligned}
$$

sendo $K_{1}=\sqrt{\frac{2 m^{*} E_{1}}{\hbar}}$ e $K_{2}=\sqrt{\frac{2 m^{*} E_{2}}{\hbar}}$. 
$\mathrm{O}$ ângulo $\varphi$ representa o ângulo entre os vetores de onda $K_{1} e K_{2}$ do elétron no estado inicial e final, respectivamente. As constantes $\boldsymbol{\epsilon}_{\infty}$ e $\boldsymbol{\epsilon}_{\mathbf{S}}$ correspondem, respectivamente, as constantes dielétricas dinâmica e estática do GaAs. Para altas temperaturas, a equação 8.6 também deve ser multiplicada por um termo de ocupação da banda de fônons LO, dado por um fator de BoseEinstein. Porém, nas temperaturas típicas de operação de QWIPs, esse termo pode ser desprezado.

A partir do modelo da estrutura do QWIP 3517 e das funções de onda obtidas pela simulação com o método da matriz de transferência, foi possível calcular o tempo de recaptura pela equação 8.6. Os cálculos foram feitos para as temperaturas $10 \mathrm{~K}, 30 \mathrm{~K}, 50 \mathrm{~K}$ e $70 \mathrm{~K}$, usando os parâmetros do GaAs resumidos na Tabela 2, e levaram aos valores de tempo de recaptura mostrados na Tabela 3.

\begin{tabular}{|l|}
\hline$E_{L O}=36,5056 \cdot\left(1-\left(4 \times 10^{-5}\right) \cdot \mathrm{T}\right) \mathrm{meV}^{*}$ \\
\hline$\epsilon_{\infty}=10,6 \cdot\left(1+\left(9 \times 10^{-5}\right) \cdot \mathrm{T}\right) \cdot \epsilon_{0}{ }^{* *}$ \\
\hline$\epsilon_{\mathrm{S}}=12,4 \cdot\left(1+\left(1,2 \times 10^{-4}\right) \cdot \mathrm{T}\right) \cdot \epsilon_{0}{ }^{* *}$ \\
${ }^{*}$ Da referência [42] \\
${ }^{* *}$ Da referência [46]
\end{tabular}

Tabela 2: Parâmetros do GaAs utilizados nos cálculos do tempo de recaptura.

\begin{tabular}{|c|c|c|c|c|}
\hline$\tau_{\boldsymbol{c}}$ & $70 \mathrm{~K}$ & $50 \mathrm{~K}$ & $30 \mathrm{~K}$ & $10 \mathrm{~K}$ \\
\hline Valor calculado $^{*}$ & $2,15.10^{-12} \mathrm{~s}$ & $2,17.10^{-12} \mathrm{~s}$ & $2,18.10^{-12} \mathrm{~s}$ & $2,19.10^{-12} \mathrm{~s}$ \\
\hline
\end{tabular}

* Valor obtido a partir da equação 8.6.

Tabela 3: Valores calculados do tempo de recaptura $\tau_{c}$ para várias temperaturas.

\subsubsection{Análise do ruído e determinação da velocidade de saturação em QWIPs}

Devido à sua importância na fabricação de dispositivos optoeletrônicos, o GaAs é um material semicondutor bastante estudado, e os parâmetros utilizados no modelo semiempírico da velocidade de deriva (Equação 8.5) são em geral disponíveis na literatura. Alguns deles são fornecidos como função da temperatura, obtidos por meio de funções empíricas que foram construídas a partir da determinação dos valores para várias temperaturas [42].

A partir das equações 8.2, 8.3 e 8.4, vemos que o ruído de um QWIP depende intrinsecamente de três parâmetros físicos fundamentais: a corrente no escuro, o tempo de recaptura e a velocidade de deriva dos portadores. As medidas das curvas de corrente-voltagem no escuro foram substituídas na equação 8.2, enquanto que os valores calculados do tempo de 
recaptura (Tabela 3) foram usados na equação 8.3 da probabilidade de captura $p_{c}$. As barreiras do QWIP 3517 possuem uma concentração de alumínio baixa (20,7\%), e o mesmo modelo semiempírico utilizado para o GaAs (Equação 8.5) foi utilizado para modelar a velocidade de deriva $\left(v_{\text {Drift }}\right)$ em toda a região ativa do QWIP, deixando apenas a velocidade de saturação $\left(v_{S}\right)$ como parâmetro de ajuste do modelo aos dados experimentais de ruído em baixas temperaturas (70K, 50K, 30K e 10K). Como ponto de partida foram estudados dois modelos da velocidade de saturação como função da temperatura: um para o GaAs (Allan, 1990) [47] e outro para o $\mathrm{Al}_{\mathrm{x}} \mathrm{Ga}_{1-\mathrm{x}} \mathrm{As}$ (Quay, 2000) [48]. Os modelos semiempíricos para o GaAs (válido em princípio para $\mathrm{T} \geq 300 \mathrm{~K}$ ) e para o $\mathrm{Al}_{\mathrm{x}} \mathrm{Ga}_{1-\mathrm{x}} \mathrm{As}$, foram comparados com o modelo obtido para o QWIP 3517, do ajuste da velocidade de saturação aos dados experimentais de ruído (Figura 78). O ajuste das curvas de ruído experimental em função da velocidade de saturação é um processo difícil de ser executado, principalmente para baixas temperaturas, onde o valor do ruído se torna pouco sensível ao valor da velocidade de saturação (mesmo quando deixamos o valor da velocidade de saturação variar em torno de $50 \%$ o valor calculado do ruído ainda apresenta valores compatíveis com os dados experimentais). Para estimar o valor da velocidade de deriva em baixas temperaturas $(50 \mathrm{~K}, 30 \mathrm{~K}$ e $10 \mathrm{~K})$, o ajuste experimental foi feito para o ruído a $70 \mathrm{~K}$ e então o valor das velocidades de saturação para $50 \mathrm{~K}, 30 \mathrm{~K}$ e $10 \mathrm{~K}$ foram estimados a partir de uma reta $\log -\log$ conectando o valor obtido em $70 \mathrm{~K}$ ao valor da velocidade de saturação do GaAs na temperatura ambiente $\left(6,0.10^{6} \mathrm{~cm} / \mathrm{s}\right.$ a $300 \mathrm{~K}$ [42]). Para esse QWIP, onde a concentração de alumínio nas barreiras é relativamente baixa $(20,7 \%)$, os valores da velocidade de saturação devem ser comparáveis com os valores da velocidade de saturação do GaAs em baixas temperaturas. Para os tempos de recaptura calculados, apresentados na Tabela 3, o ruído do QWIP 3517 foi simulado e comparado sucessivamente com o ruído experimental obtido a 70K, $50 \mathrm{~K}, 30 \mathrm{~K}$ e $10 \mathrm{~K}$.

A Figura 78 apresenta o resultado da curva calculada com o ajuste da velocidade de saturação $v_{S}$ aos dados experimentais do ruído a $70 \mathrm{~K}$, e a comparação com as curvas calculadas com os modelos de $\boldsymbol{v}_{\boldsymbol{S}}$ para o GaAs (Allan, 1990) e para $\mathrm{Al}_{\mathrm{x}} \mathrm{Ga}_{1-\mathrm{x}} \mathrm{As}$ (Quay, 2000). Podemos observar que a curva ajustada possui uma concordância excelente com a curva experimental especialmente para os valores de voltagem maiores. O melhor ajuste da curva experimental de ruído a $70 \mathrm{~K}$ foi obtido usando o valor $v_{S}=2,3 \cdot 10^{7} \mathrm{~cm} / \mathrm{s}$. É interessante notar que a curva de ruído simulada com o modelo de $v_{S}$ para o GaAs (Allan, 1990), apesar de ser válida para $\mathrm{T} \geq 300 \mathrm{~K}$, representa melhor o resultado experimental, em relação a curva simulada com o modelo de $\boldsymbol{v}_{\boldsymbol{S}}$ para o $\mathrm{Al}_{0.297} \mathrm{Ga}_{0.703} \mathrm{As}$ (Quay, 2000) que por princípio é valida em baixas temperaturas e representa a liga das barreiras que é majoritária na estrutura do QWIP. 


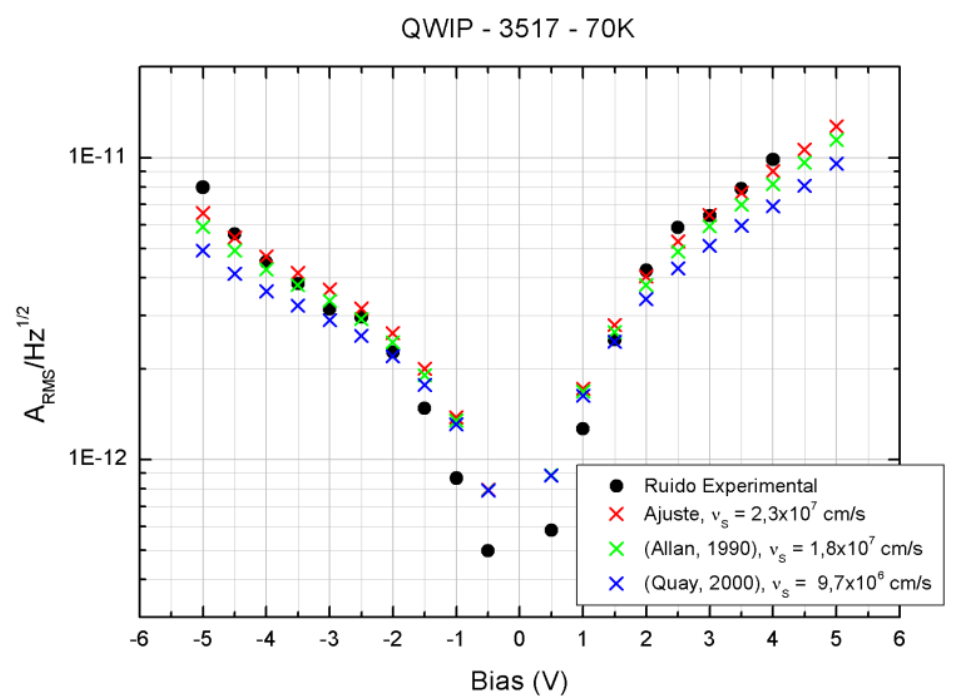

Figura 78: Ruído experimental e o ruído calculado a partir do ajuste do valor de $v_{S}$ para o QWIP 3517 a 70K, e comparação com as curvas calculadas com os modelos de v $v_{S}$ para o GaAs (Allan, 1990) e para Al ${ }_{x} G a_{1-x} A s$ (Quay, 2000).

Num gráfico log-log, uma reta que passa pelo valor obtido para o ajuste em $70 \mathrm{~K}\left(2,3.10^{7}\right.$ $\mathrm{cm} / \mathrm{s})$ e pelo valor na temperatura ambiente para o GaAs $\left(6,0.10^{6} \mathrm{~cm} / \mathrm{s}\right.$ a $\left.300 \mathrm{~K}\right)$ obedece à relação descrita pela equação

$$
v_{s a t}(T)=\frac{1,1695.10^{9}}{T^{0,925}}
$$

Equação 8.7

Os valores da velocidade de saturação utilizados na equação da velocidade de deriva (Equação 8.5), para a simulação das curvas experimentais do ruído, estão apresentados na Figura 79 (quadrados pretos), para as temperaturas de $10 \mathrm{~K}, 30 \mathrm{~K}, 50 \mathrm{~K}$ e $70 \mathrm{~K}$. Para comparação, a velocidade de saturação do GaAs maciço (Bulk) na temperatura ambiente $\left(6,0.10^{6} \mathrm{~cm} / \mathrm{s}\right.$ a $\left.300 \mathrm{~K}\right)$ também está apresentada (quadrado vermelho).

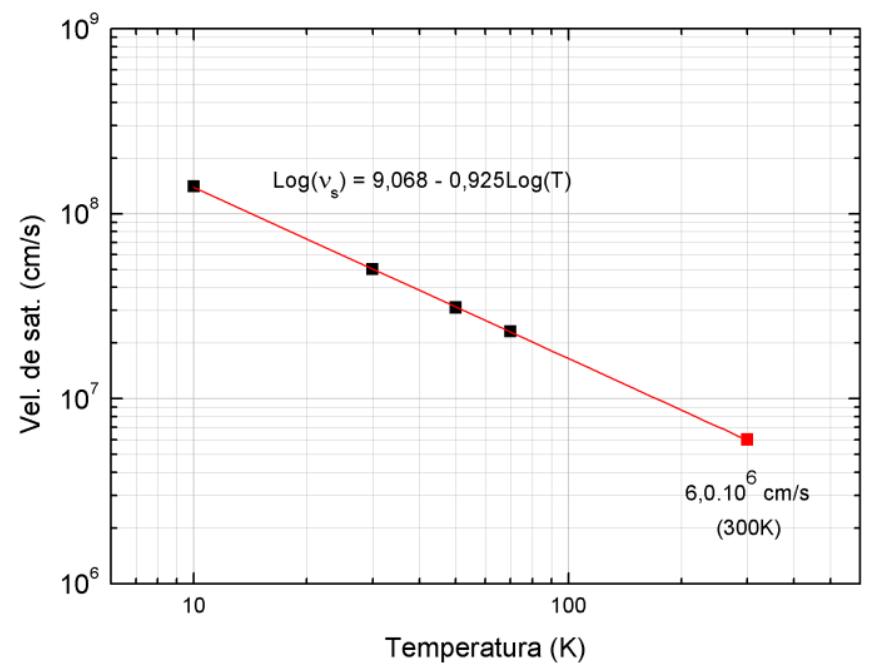

Figura 79: Velocidade de saturação, em função da temperatura, obtida a partir do ajuste das curvas experimentais de ruído. 
No cálculo da curva do ruído na temperatura de $50 \mathrm{~K}$, a simulação da curva experimental foi realizada para uma velocidade de saturação $v_{S}=3,1.10^{7} \mathrm{~cm} / \mathrm{s}$. A comparação entre a curva simulada e o resultado do ruído experimental do QWIP 3517 em 50K está apresentada na Figura 80. Podemos observar nesta figura que o ruído experimental é mais baixo que a $70 \mathrm{~K}$, como esperado, já que a corrente de escuro é menor. A curva experimental é bem simulada pelos valores calculados para as altas voltagens, mas, em mais baixas voltagens, o ruído experimental acaba saturando num valor fixo de $3-4 \times 10^{-12} \mathrm{~A}_{\mathrm{rms}} / \mathrm{Hz}^{1 / 2}$, bem superior ao valor teórico (calculado) esperado. Este patamar está relacionado com o ruído intrínseco limite do arranjo experimental utilizado, que impossibilita a medida de valores de ruído inferiores.

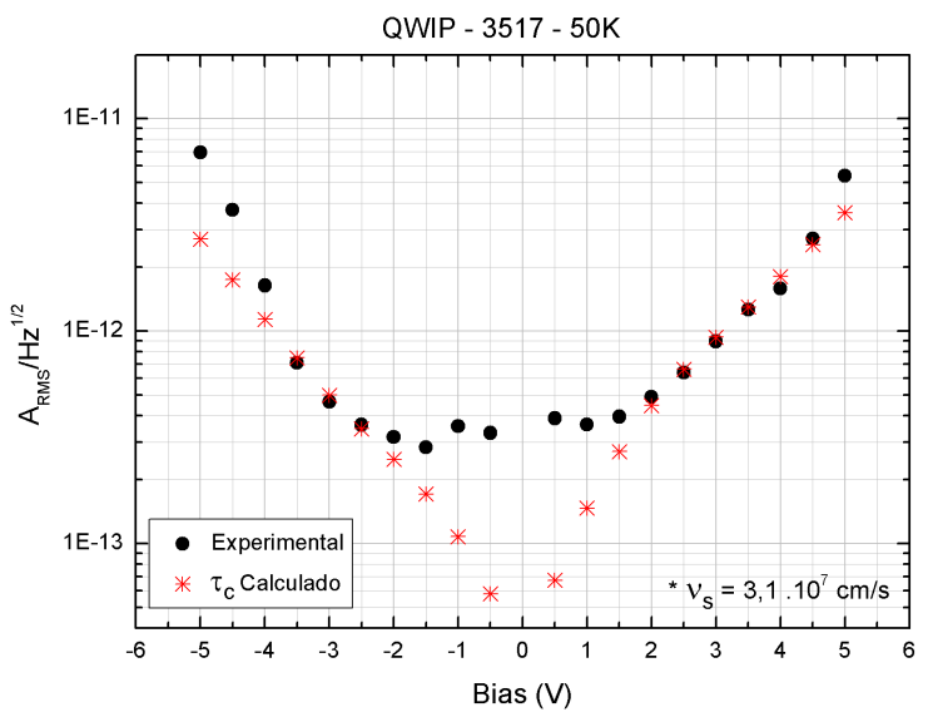

Figura 80: Comparação entre o ruído experimental e os valores calculados para o QWIP 3517 a $50 K$.

No calculo do ruído do QWIP a 30K e 10K, as simulações foram realizadas para velocidades de saturação $v_{S}=5,0.10^{7} \mathrm{~cm} / \mathrm{s}$ e $v_{S}=1,4.10^{8} \mathrm{~cm} / \mathrm{s}$, respectivamente. Os resultados da comparação entre as curvas simuladas e os dados experimentais estão apresentados na Figura $\mathbf{8 1}$ e Figura $\mathbf{8 2 .}$ Podemos também constatar que as tendências observadas nos dados a $50 \mathrm{~K}$ se confirmam: o ruído continua baixando à medida que a temperatura diminui, e o patamar em torno de $3-4 \times 10^{-12}$ $\mathrm{A}_{\mathrm{rms}} \mathrm{Hz}^{1 / 2}$ é cada vez mais visível nas curvas experimentais, uma vez que as previsões teóricas preveem valores cada vez menores de ruído. 


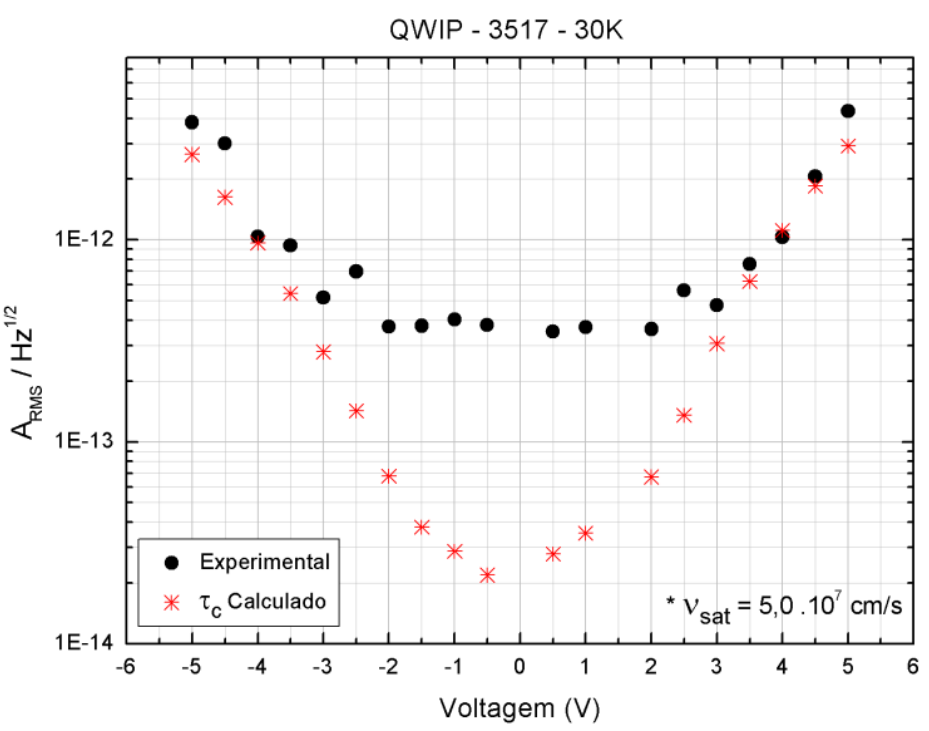

Figura 81: Comparação entre o ruído experimental e os valores calculados para o QWIP 3517 a 30K.

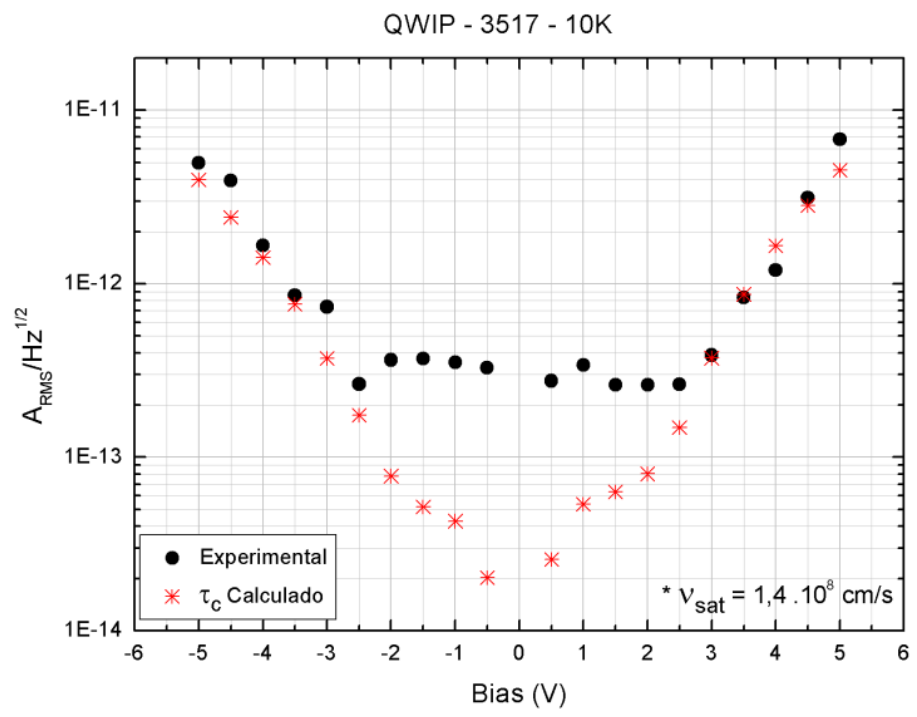

Figura 82: Comparação entre o ruído experimental e os valores calculados para o QWIP 3517 a 10K.

A Figura 83 apresenta as curvas de ruído experimental e calculado, onde foram utilizados os valores do tempo de recaptura $\left(\tau_{c}\right)$, obtidos com a equação 8.6, que estão apresentados na Tabela 3 , e com as velocidades de saturação ajustada $(70 \mathrm{~K})$ e estimadas $(50 \mathrm{~K}, 30 \mathrm{~K}$ e $10 \mathrm{~K})$. 


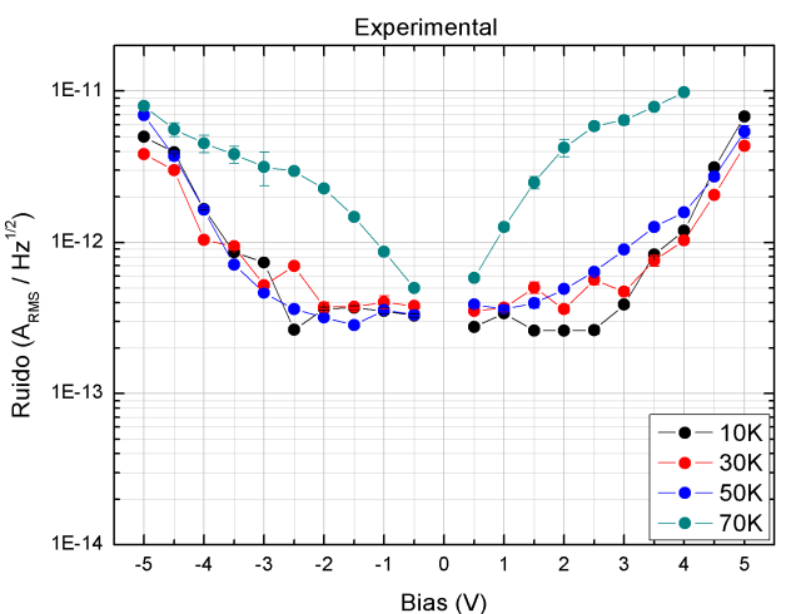

(a)

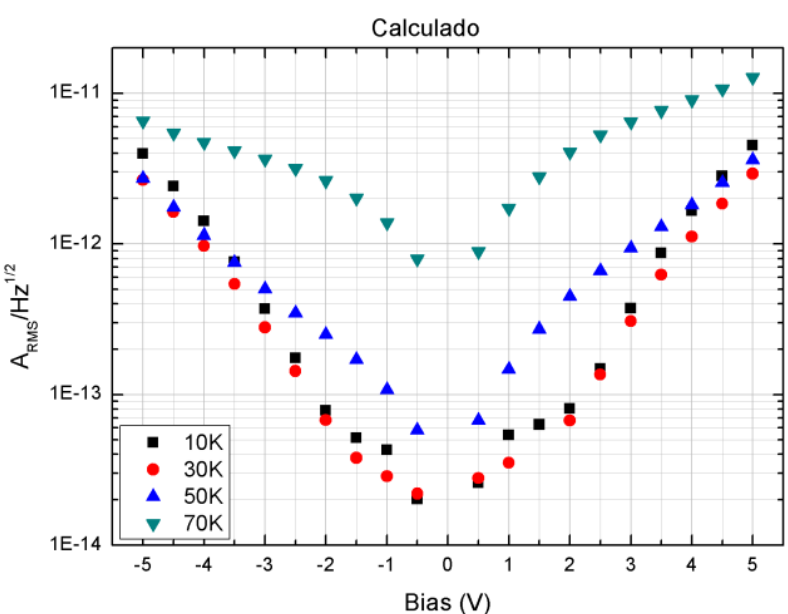

(b)

Figura 83: (a) Medidas experimentais de ruído para o QWIP 3517. (b) Cálculo do ruído a partir da curva experimental da corrente no escuro e dos cálculos do tempo de recaptura (Equação 8.6) e da velocidade de deriva (Equação 8.5) para a amostra 3517.

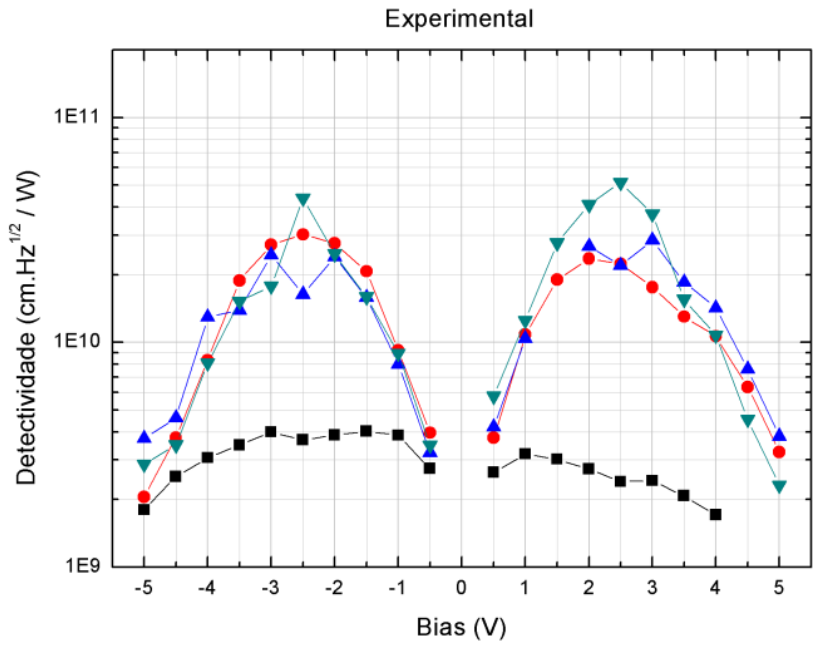

(a)

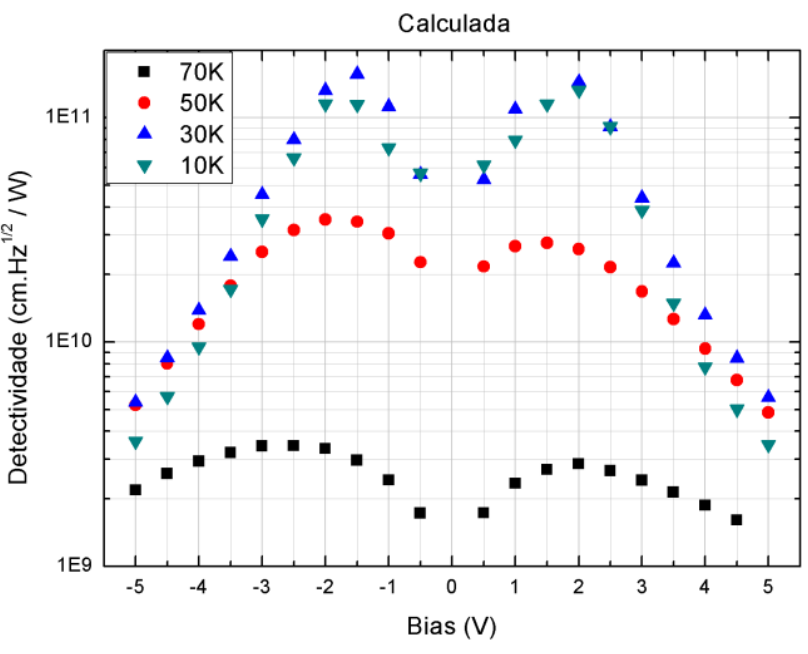

(b)

Figura 84: (a)Detectividade experimental; (b) Detectividade obtida a partir do ruído calculado.

A curva da detectividade calculada para o QWIP 3517 (Figura $84(b)$ ), foi obtida a partir dos dados experimentais da responsividade (Figura 69) e das curvas de ruído calculadas, apresentadas na Figura $83(b)$. A principal diferença com as curvas experimentais (Figura 84 (a)) pode ser observada nas temperaturas e voltagens mais baixas. De fato, como o ruído teórico ficou menor que o ruído experimental, cujo valor mínimo mensurável é limitado pelo arranjo experimental (patamar nas curvas), a detectividade teórica apresenta valores mais altos já que este parâmetro é inversamente proporcional à intensidade do ruído (Equação 7.8). 


\section{Capítulo 9}

\section{Considerações finais}

Durante este trabalho de doutorado, foram desenvolvidas e implementadas várias ferramentas teóricas para o domínio da física básica dos QWIPs e para o cálculo dos parâmetros de funcionamento importantes. Em paralelo, foram sendo instaladas as principais técnicas de caracterização dos fotodetectores: medidas da curva de absorção, da resposta espectral, da corrente no escuro, da fotocorrente com corpo negro e do ruído. A medida mais difícil de ser realizada em boas condições foi a medida de ruído, devido às dificuldades para isolar a contribuição real da amostra da contribuição dos equipamentos do próprio sistema de medidas ou de fontes externas.

Existem basicamente três tipos de fotodetectores baseados em poços quânticos: fotodetectores com transição interbanda, fotodetectores com transição intrabanda, e fotodetectores com transição entre níveis de impureza. Foi mostrado que esses dois últimos tipos possuem grande interesse, pois a transição nesses fotodetectores dá origem a uma absorção dentro das janelas atmosféricas na região do infravermelho médio, e possuem inúmeras aplicações práticas na medicina, na engenharia, em defesa e no monitoramento ambiental.

A partir do método da matriz de transferência, foram realizados cálculos dos níveis de energia de poços quânticos arbitrários, com ou sem a aplicação de voltagem. Para poços sem aplicação de voltagem, esse método também é capaz de fornecer as funções de onda dos estados confinados do poço quântico. Partindo de argumentos de física fundamental, foi elaborado um método empírico capaz de fornecer quantitativamente, de forma precisa, a curva de absorção dos QWIPs. Os resultados dos cálculos obtidos com esse método foram comparados diretamente com as medidas experimentais das curvas de absorção.

Ao longo deste trabalho, foram estudados 12 QWIPs: 6 para transição intrabanda na janela atmosférica de $8 \mu \mathrm{m}$ a $12 \mu \mathrm{m}, 3$ com transição intrabanda na janela de $3 \mu \mathrm{m}$ a $5 \mu \mathrm{m}$ e 2 QWIPs com transição zero dimensional em impurezas para a janela atmosférica de $8 \mu \mathrm{m}$ a $12 \mu \mathrm{m}$.

Para que os poços de GaAs com barreiras de AlGaAs tenham transição intrabanda, na janela atmosférica entre $3 \mu \mathrm{m}$ e $5 \mu \mathrm{m}$, essas amostras foram crescidas com barreiras mais altas de potencial em torno dos poços. Tais barreiras também melhoram consideravelmente a absorção dos QWIPs, porém são um obstáculo para a fotocorrente. Com as amostras 3564 e 3570 foram feitas tentativas de obter transições na janela atmosférica de $3 \mu \mathrm{m}$ a $5 \mu \mathrm{m}$ sem a utilização dessas barreiras. Nessas amostras foi utilizada a composição máxima de alumínio (42\%) que ainda permite a transição de gap direto. Para chegar nessa janela atmosférica, com GaAs nos poços e barreiras de AlGaAs, foi necessário aumentar consideravelmente a concentração de alumínio na liga das barreiras. Barreiras largas, como as utilizadas nos QWIPs com alta concentração de 
alumínio, são difíceis de serem obtidas com boa qualidade. Uma alta concentração de alumínio produz interfaces mais rugosas e maior quantidade de defeitos na estrutura cristalina, que podem prejudicar consideravelmente o transporte.

Dois QWIPs foram fabricados e caracterizados mais sistematicamente (QWIPs 3517 e 3559). A curva de capacitância do QWIP 3517 foi obtida utilizando-se um analisador de parâmetros semicondutores recém-adquirido no nosso laboratório, e permitirá o desenvolvimento de um circuito de leitura adequado (ROIC) no caso de ser utilizado futuramente para fabricação de um FPA.

O cálculo do tempo de recaptura do poço quântico a partir das funções de onda calculadas para o QWIP 3517 possibilitou a análise minuciosa das curvas de ruído obtidas. O ruído foi calculado a partir das medidas de corrente no escuro, e o ajuste aos dados experimentais permitiu estimar a velocidade de deriva dos elétrons ao longo da estrutura em baixas temperaturas.

O QWIP 3517 se revelou de excelente qualidade, possuindo uma detectividade de aproximadamente $3 \times 10^{10} \mathrm{~cm} . H z^{1 / 2} / W$ entre $10 \mathrm{~K}$ e $50 \mathrm{~K}$, e de $4 \times 10^{9} \mathrm{~cm} . H z^{1 / 2} / \mathrm{W}$ a $70 \mathrm{~K}$. Abaixo de 50K, o QWIP 3517 supera o valor da detectividade do detector de $\mathrm{HgCdTe}$, e a 70K ele supera o QWIP comercial de AlGaAs/GaAs fabricado pela empresa norte-americana FLIR (referência mundial na fabricação de câmeras infravermelhas).

\subsection{Progressos alcançados}

No início do trabalho, nenhuma das técnicas de caracterização e processamento estava disponível em nosso laboratório. Em um esforço conjunto, com outros alunos do grupo, instalamos e automatizamos completamente todos os arranjos experimentais, fabricamos vários porta-amostras específicos, desenvolvemos métodos de preparação de amostras, e otimizamos cada etapa do processamento das amostras.

Foram desenvolvidas várias ferramentas teóricas e cálculos para o desenvolvimento dos QWIPs que possibilitaram a previsão de alguns parâmetros de funcionamento, como a curva de corrente de escuro e a curva de absorção. Também foram desenvolvidas as ferramentas teóricas fundamentais para o projeto de QWIPs baseados em transições de impurezas hidrogenóides. Foi mostrado que é possível simular de forma realista o ruído do dispositivo a partir da curva de corrente no escuro. Por fim, foi desenvolvido e completamente caracterizado um QWIP de excelente qualidade e com desempenho superior. 


\subsection{Dificuldades encontradas}

O processamento das amostras para a fabricação dos dispositivos foi a etapa mais difícil de ser dominada em todo este trabalho. Ele envolve várias etapas tais como: litografia óptica, ataque químico, limpeza da amostra, deposição de filmes finos metálicos, recozimento térmico rápido e microssoldas. Todos esses processos devem ser realizados em um ambiente limpo e livre de contaminações. O processamento envolve equipamentos sofisticados e de alta precisão (fotoalinhadora, evaporadora, forno de recozimento térmico rápido e microssoldadora), e os reagentes químicos utilizados devem possuir grau de pureza eletrônico (com pouquíssimas impurezas e partículas indesejadas em suspensão) e devem ser manipulados e acondicionados com muitos cuidados.

Para o estabelecimento de um processo reprodutível e de boa qualidade, foram feitas várias tentativas, alterando-se os parâmetros de espalhamento do fotorresiste e da sua exposição à radiação UV, na fotoalinhadora, testando várias receitas de deposição para os filmes metálicos, várias soluções para o ataque químico, várias combinações de temperatura, tempo e rampa para o recozimento térmico, e muitos teste de contato e estabilidade com a microssoldadora. Esse processo de aprendizagem foi em grande parte um processo de tentativa e erro. Como os recursos necessários ao processamento não estavam disponíveis em nosso laboratório, tivemos que recorrer a vários laboratórios externos, tais como o LSI e LME da Escola Politécnica da USP, o LNLS em Campinas, e o LPD e CCS na Unicamp. De forma geral, esses laboratórios são intensamente solicitados pela comunidade científica e alguns deles não possuíam todos os equipamentos necessários, o que dificultou bastante o nosso agendamento e levou frequentemente a longos períodos de espera que prejudicaram o bom andamento da pesquisa.

O sistema MBE também apresentou várias vezes problemas com a célula de Al que impossibilitaram o crescimento das estruturas contendo este elemento durante cerca de um ano (juntando todas as paradas).

\subsection{Propostas para desenvolvimentos futuros}

Partindo dos modelos implementados (corrente de escuro, absorção e ruído) outros cálculo podem ser implementados, como o cálculo da fotococorrente. O modelo simples da corrente de escuro pode ser melhorado para simular o tunelamento nas minibandas, através das barreiras, e para incluir modelos mais precisos da mobilidade para altas voltagens de polarização.

Devido aos problemas mencionados acima, não houve tempo para a caracterização completa dos dois QWIPs baseados em transição zero dimensional entre níveis de impurezas. As medidas preliminares de resposta espectral usando o FTIR não apresentaram um bom sinal de absorção. Cálculos posteriores (ver no capítulo 3) mostraram que, quando a dopagem é realizada fora da 
região central dos poços quânticos, o raio de Bohr dos elétrons das impurezas aumenta drasticamente, o que acaba possibilitando a transição de Mott dentro do poço, prejudicando consideravelmente a absorção. Novas estruturas serão desenvolvidas, processadas, e testadas em breve, onde a dopagem será restrita ao centro do poço e o acoplamento entre os níveis será maximizado.

Outras estruturas que foram projetadas, mas que ainda não foram crescidas, são as estruturas de QWIPs com poços de InGaAs e barreiras de AlGaAs. Essas estruturas são difíceis de serem crescidas devido ao efeito de segregação do In durante o crescimento e à introdução de tensão na estrutura do QWIP, já que o InGaAs possui parâmetro de rede maior que o do substrato de GaAs. Poços de InGaAs, mais profundos que os poços de GaAs aqui utilizados, possibilitam transições em comprimentos de onda menores e podem possibilitar a fabricação de QWIPs com transições na região da janela atmosférica de $3 \mu \mathrm{m}$ a $5 \mu \mathrm{m}$. 


\section{Apêndice}

Funções auxiliares $f_{\text {nlm }}$ para o cálculo dos níveis de energia e funções de onda de uma impureza não ionizada confinada em um poço quântico (Seção 3.5):

Estado fundamental 1s:

$f 1 s=\frac{1}{a_{0}^{2} \cdot(1-\lambda)} \cdot\left(\left|z-z_{0}\right|+\frac{a_{0}}{2 \cdot(1-\lambda)}\right) \cdot e^{-\frac{2}{a_{0}} \cdot(1-\lambda) \cdot\left|z-z_{0}\right|}$

$f 11 s=\frac{1}{a_{0}^{2} \cdot(1-\lambda)} \cdot e^{-\frac{2}{a_{0}} \cdot(1-\lambda) \cdot\left|z-z_{0}\right|}$

Estado excitado 2p $p_{\mathrm{xy}}$ :

$f 2 p x y=\frac{1}{16 \cdot a_{0}^{2} \cdot(1-(2 \cdot \lambda))^{3}} \cdot\left(\left|z-z_{0}\right|+\frac{a_{0}}{(1-(2 \cdot \lambda))}-\left|z-z_{0}\right|^{2}-\frac{2 \cdot a_{0} \cdot\left|z-z_{0}\right|}{(1-(2 \cdot \lambda))}-\frac{2 \cdot a_{0}^{2}}{(1-(2 \cdot \lambda))^{2}}\right)$. $e^{-\frac{(1-(2 \cdot \lambda))}{a_{0}} \cdot\left|z-z_{0}\right|}$

$f 12 p x y=\frac{1}{16 \cdot a_{0}^{3} \cdot(1-(2 \cdot \lambda))^{2}} \cdot\left(\left|z-z_{0}\right|+\frac{a_{0}}{(1-(2 \cdot \lambda))}\right) \cdot e^{-\frac{(1-(2 \cdot \lambda))}{a_{0}} \cdot\left|z-z_{0}\right|}$

Estado excitado $2 \mathbf{p}_{\text {sz: }}$

$$
\begin{aligned}
& f 2 p s z=\left[\frac{1}{4 \cdot a_{0}^{2} \cdot(1-(2 \cdot \lambda))} \cdot\left(\left|z-z_{0}\right|+\frac{a_{0}}{(1-(2 \cdot \lambda))}\right)-\frac{1}{4 \cdot a_{0}^{3}} \cdot \frac{1-\lambda 1(\lambda)}{1-(2 \cdot \lambda)} \cdot\left(\left|z-z_{0}\right|^{2}+\frac{2 \cdot a_{0} \cdot\left|z-z_{0}\right|}{(1-(2 \cdot \lambda))}+\right.\right. \\
& \left.\left.\frac{2 \cdot a_{0}^{2}}{(1-(2 \cdot \lambda))^{2}}\right)+\frac{1}{16 \cdot a_{0}^{4}} \cdot \frac{(1-\lambda 1(\lambda))^{2}}{1-(2 \cdot \lambda)} \cdot\left(\left|z-z_{0}\right|^{3}+\frac{3 \cdot a_{0} \cdot\left|z-z_{0}\right|^{2}}{(1-(2 \cdot \lambda))}+\frac{6 \cdot a_{0}^{2} \cdot\left|z-z_{0}\right|}{(1-(2 \cdot \lambda))^{2}}+\frac{6 \cdot a_{0}^{3}}{(1-(2 \cdot \lambda))^{3}}\right)\right] \cdot e^{-\frac{(1-(2 \cdot \lambda))}{a_{0}} \cdot\left|z-z_{0}\right|}
\end{aligned}
$$




$$
\begin{aligned}
& f 12 p s z=\left[\frac{1}{4 \cdot a_{0}^{2} \cdot(1-(2 \cdot \lambda))}-\frac{1}{4 \cdot a_{0}^{3}} \cdot \frac{1-\lambda 1(\lambda)}{1-(2 \cdot \lambda)} \cdot\left(\left|z-z_{0}\right|+\frac{a_{0}}{(1-(2 \cdot \lambda))}\right)+\frac{1}{16 \cdot a_{0}^{4}} \cdot \frac{(1-\lambda 1(\lambda))^{2}}{1-(2 \cdot \lambda)} \cdot\left(\left|z-z_{0}\right|^{2}+\right.\right. \\
& \left.\left.\frac{2 \cdot a_{0} \cdot\left|z-z_{0}\right|}{(1-(2 \cdot \lambda))}+\frac{2 \cdot a_{0}^{2}}{(1-(2 \cdot \lambda))^{2}}\right)\right] \cdot e^{-\frac{(1-(2 \cdot \lambda))}{a_{0}} \cdot\left|z-z_{0}\right|}
\end{aligned}
$$

$$
\begin{aligned}
& f 22 p s z=\frac{\lambda 1(\lambda)}{16 \cdot a_{0}^{3} \cdot(1-(2 \cdot \lambda))} \cdot\left\{\frac{2 \cdot \hbar^{2}}{m_{p}}+\left[\left(\frac{1}{2 \cdot \pi \cdot \epsilon_{p}}-\frac{2 \cdot \hbar^{2}}{m_{p} \cdot a_{0}}-\frac{(1-\lambda 1(\lambda)) \cdot \hbar^{2}}{m_{p} \cdot a_{0}}\right) \cdot\left(\left|z-z_{0}\right|+\frac{a_{0}}{(1-(2 \cdot \lambda))}\right)\right]+\right. \\
& {\left[\left(\frac{\hbar^{2}}{4 \cdot m_{p} \cdot a_{0}^{2}}-\frac{R y_{p}}{2}-\frac{1-\lambda 1(\lambda)}{a_{0}} \cdot\left(\frac{1}{4 \cdot \pi \cdot \epsilon_{p}}-\frac{\hbar^{2}}{m_{p} \cdot a_{0}}\right)\right) \cdot\left(\left|z-z_{0}\right|^{2}+\frac{2 \cdot a_{0} \cdot\left|z-z_{0}\right|}{(1-(2 \cdot \lambda))}+\frac{2 \cdot a_{0}^{2}}{(1-(2 \cdot \lambda))^{2}}\right)\right]-} \\
& \left.\left[\frac{1-\lambda 1(\lambda)}{a_{0}} \cdot\left(\frac{\hbar^{2}}{8 \cdot m_{p} \cdot a_{0}^{2}}-\frac{R y_{p}}{4}\right) \cdot\left(\left|z-z_{0}\right|^{3}+\frac{3 \cdot a_{0} \cdot\left|z-z_{0}\right|^{2}}{(1-(2 \cdot \lambda))}+\frac{6 \cdot a_{0}^{2} \cdot\left|z-z_{0}\right|}{(1-(2 \cdot \lambda))^{2}}+\frac{6 \cdot a_{0}{ }^{3}}{(1-(2 \cdot \lambda))^{3}}\right)\right]\right\} \cdot e^{-\frac{(1-(2 \cdot \lambda))}{a_{0}} \cdot\left|z-z_{0}\right|}
\end{aligned}
$$

$$
\begin{aligned}
& f 32 p s z=\frac{\lambda 1(\lambda)}{16 \cdot a_{0}^{3} \cdot(1-(2 \cdot \lambda))} \cdot\left\{\frac{2 \cdot \hbar^{2}}{m_{b}}+\left[\left(\frac{m_{p}}{2 \cdot \pi \cdot \epsilon_{p} \cdot m_{b}}-\frac{2 \cdot \hbar^{2}}{m_{b} \cdot a_{0}}-\frac{(1-\lambda 1(\lambda)) \cdot \hbar^{2}}{m_{b} \cdot a_{0}}\right) \cdot\left(\left|z-z_{0}\right|+\frac{a_{0}}{(1-(2 \cdot \lambda))}\right)\right]+\right. \\
& {\left[\left(\frac{\hbar^{2}}{4 \cdot m_{b} \cdot a_{0}^{2}}-\frac{R y_{p} \cdot m_{p}}{2 \cdot m_{b}}-\frac{1-\lambda 1(\lambda)}{a_{0}} \cdot\left(\frac{m_{p}}{4 \cdot \pi \cdot \epsilon_{p} \cdot m_{b}}-\frac{\hbar^{2}}{m_{b} \cdot a_{0}}\right)\right) \cdot\left(\left|z-z_{0}\right|^{2}+\frac{2 \cdot a_{0} \cdot\left|z-z_{0}\right|}{(1-(2 \cdot \lambda))}+\frac{2 \cdot a_{0}{ }^{2}}{(1-(2 \cdot \lambda))^{2}}\right)\right]-} \\
& \left.\left[\frac{1-\lambda 1(\lambda)}{a_{0}} \cdot\left(\frac{\hbar^{2}}{8 \cdot m_{b} \cdot a_{0}^{2}}-\frac{R y_{p} \cdot m_{p}}{4 \cdot m_{b}}\right) \cdot\left(\left|z-z_{0}\right|^{3}+\frac{3 \cdot a_{0} \cdot\left|z-z_{0}\right|^{2}}{(1-(2 \cdot \lambda))}+\frac{6 \cdot a_{0}^{2} \cdot\left|z-z_{0}\right|}{(1-(2 \cdot \lambda))^{2}}+\frac{6 \cdot a_{0}{ }^{3}}{(1-(2 \cdot \lambda))^{3}}\right)\right]\right\} \cdot e^{-\frac{(1-(2 \cdot \lambda))}{a_{0}} \cdot\left|z-z_{0}\right|}
\end{aligned}
$$




\section{Lista de Figuras}

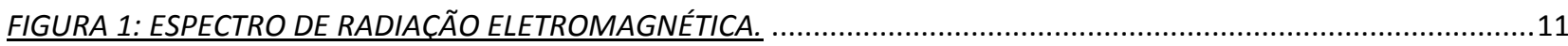

FIGURA 2: DETECTORES SINGELOS: (A) FOTODETECTOR PROCESSADO; (B) ENCAPSULAMENTO...............................15

FIGURA 3: FABRICACCÃO DE CÂMERAS DE RADIACCÃO INFRAVERMELHA: (A) FPA DE QWIPS COM REDE DE DIFRACCÃOE

CONTATOS METÁLICOS [7]; (B) CÂMERA INFRAVERMELHA PORTÁTIL FUNCIONANDO COM UM FPA. ...............15

FIGURA 4: APLICAÇÕES DE FOTODETECTORES DE RADIACCÃO INFRAVERMELHA: (A) IMAGEN DE UMA PACIENTE COM

CÂNCER DE MAMA; (B) VISUALIZACÃ̃O REMOTA DA TUBULACÃ̃O DE AR QUENTE NO TETO DE UM EDIFÍCIO; (C)

IMAGEN NO INFRAVERMELHO DE UM JATO DE ATAQUE F-22 (INVISIVEL AO RADAR, MAS COM INTENSA ASSINATURA NO INFRAVERMELHO); (D) CÂMERA INFRAVERMELHA DE VISÃO NOTURNA; (E) DISSIPACCÃO DE CALOR EM CIRCUITOS ELÉTRICOS, PARA A PREVENCCÃO DE FALHAS; (F) IMAGEM NO INFRAVERMELHO OBTIDA POR SATÉLITE METEOROLÓGICO.

FIGURA 5: ABSORÇÃO EM SEMICONDUTORES. (A) E (B) FOTODETECTOR INTRÍNSECO. (C) FOTODETECTOR

EXTRÍNSECO.

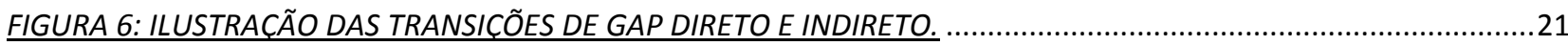

FIGURA 7: (A) ESTRUTURA DE BANDAS DO GAAS; (B) ESTRUTURA DE BANDAS DO SI [12]....................................21

FIGURA 8: FORMACCÃO DE UMA HETEROESTRUTURA. (A) SEMICONDUTORES SEPARADOS, COM GAPS DIFERENTES,

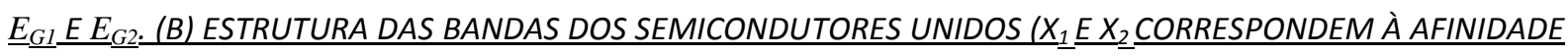

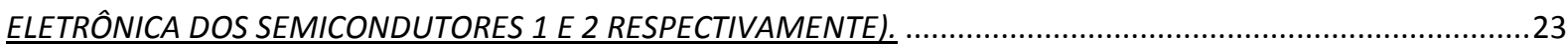

FIGURA 9: EFEITO DO CONFINAMENTO EM POCCOS QUÂNTICOS ISOLADOS. E E DISCRETOS NA BANDA DE CONDUCCÃO, E E $\underline{V}_{1} \underline{E}$ E E $E_{V 2}$ SÃO OS NÍVEIS DE ENERGIA DISCRETOS NA BANDA DE

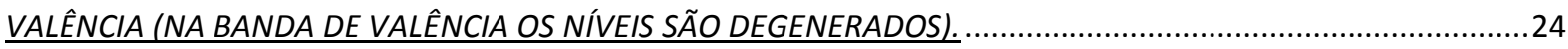

FIGURA 10: ESPECTRO DE TRANSMISSÃO E ABSORCÃO DA ATMOSFERA TERRESTRE..........................................25

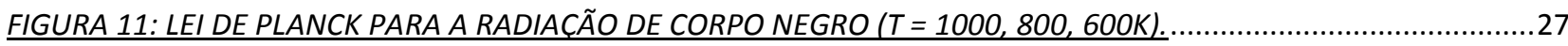

FIGURA 12: MÉTODOS DE DETECCCÃO NO INFRAVERMELHO: (A) DIFERENÇA DE TEMPERATURA DE PARTES DO CORPO HUMANO, COM CABELOS E NARIZ MAIS FRIOS; (B) TANQUE DE ÁGUA COM MANCHA DE ÓLEO, NA MESMA TEMPERATURA, MAS COM EMISSIVIDADES DIFERENTES; (C) GÁS (INVISÍVEL AO OLHO HUMANO) SAINDO DE UMA CHAMINÉ E DETECTADO PELA ABSORCÃO DA RADIACCÃO INFRAVERMELHA DO AMBIENTE. .....................28

FIGURA 13: (A) ESQUEMA DA ABSORÇÃO DE RADIAÇÃO DENTRO DE UM MATERIAL. (B) VARIAÇÃO DO FLUXO DE FÓTONS DENTRO DO MATERIAL; $\Phi_{0}$ E $\Phi(X)$ SÃO O FLUXO DE FÓTONS FORA E DENTRO DO MATERIAL (APÓS

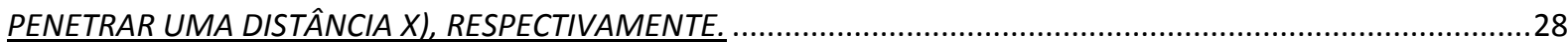

FIGURA 14: COEFICIENTE DE ABSORÇÃO DO GAAS (30OK) PARA DOIS VALORES DE DOPAGEM, $N_{\underline{D}}=10^{18} \mathrm{CM}^{-3}$

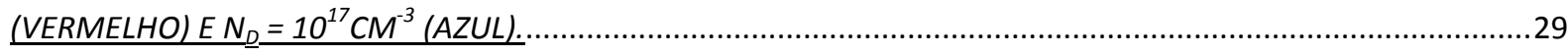

FIGURA 15: ILUSTRACÃ̃O DO ESQUEMA DA ESTRUTURA DE UM QWIP PROCESSADO, COM UMA MESA (CONTENDO A

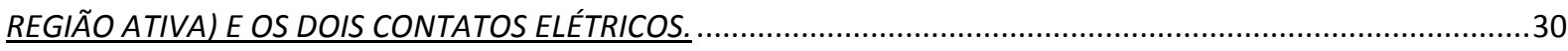

FIGURA 16: MECANISMOS DE FOTOCORRENTE EM QWIPS. (A) FOTOCORRENTE GERADA PELOS ELÉTRONS PROMOVIDOS DIRETAMENTE PARA UM ESTADO NO CONTÍNUO. (B) FOTOCORRENTE GERADA PELOS ELÉTRONS PROMOVIDOS PARA UM NÍVEL EXCITADO DO POÇO DE ONDE PODEM TUNELAR OU ACESSAR O CONTÍNUO POR

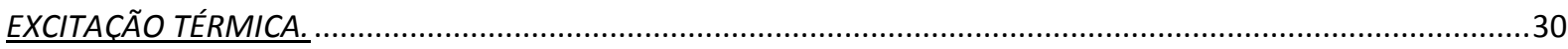

FIGURA 17: POTÊNCIA DA RADIACCÃO DE FUNDO A 30OK PARA VÁRIOS ÂNGULOS DE ABERTURA DO DETECTOR.......34 FIGURA 18: SOLUCCÃO DO POÇO PARABÓLICO DE ALGAAS/GAAS COM BARREIRA DE 24\% DE AL, UTILIZANDO O MÉTODO DA MATRIZ DE TRANSFERÊNCIA.

FIGURA 19: EXEMPLO DE QWIP COM BARREIRAS E ACOPLAMENTO DO ESTADO EXCITADO COM UMA MINIBANDA. EM VERMELHO ESTÃO DESTACADOS OS NÍVEIS EXCITADOS DOS POÇOS E EM CIANO OS NÍVEIS DAS BARREIRAS EXTERNAS. NA FIGURA, A TRANSICCÃO OCORRE PARA A ENERGIA DE 146MEV, FORNECENDO UMA ABSORÇ̃̃O

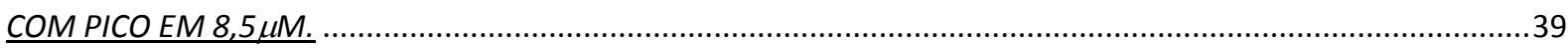

FIGURA 20: CÁLCULO AUTOCONSISTENTE: (A) DISTRIBUIÇÃO DA CARGA TOTAL (ELÉTRONS + IMPUREZAS IONIZADAS); (B) CAMPO ELÉTRICO; (C) POTENCIAL DEVIDO À DISTRIBUICCÃO DE CARGAS. 
FIGURA 21: DIAGRAMA MOSTRANDO OS INTERVALOS ESCOLHIDOS PARA TRATAR O PROBLEMA DE UM POÇO QUÂNTICO SUBMETIDO À APLICACÃ̃O DE UMA VOLTAGEM DE POLARIZACCÃO (BIAS).....................................42 FIGURA 22: GRÁFICO DA FUNCCÃO $S_{11}$ PARA VALORES DIFERENTES DE VOLTAGEM APLICADA A UM POÇO QUÂNTICO COM 58Å DE LARGURA E BARREIRAS DE ALGAAS COM 21,3\% DE AL. CADA MÍNIMO LOCAL ACENTUADO CORRESPONDE A UM NÍVEL DISCRETO DE ENERGIA ASSOCIADO A UM ESTADO CONFINADO NO POÇO

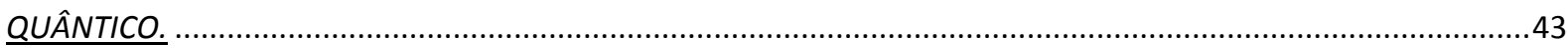

FIGURA 23: ESQUEMA DA MONTAGEM EXPERIMENTAL DA AMOSTRA PARA TESTAR OS QWIPS. UM CHANFRO É POLIDO A $45^{\circ}$ NUMA BORDA DA AMOSTRA PARA QUE A RADIACCÃO INCIDA NORMALMENTE SOBRE A SUPERFICIE POLIDA MAS COM UM ÂNGULO DE $45^{\circ}$ SOBRE O QWIP (DEVIDO À LIMITACCÃO IMPOSTA PELA REGRA DE SELECÃO DO CAMPO ELÉTRICO EM QWIPS DO TIPO N)...........................................................46 FIGURA 24: FUNCCÕES DE ONDA DOS DOIS ESTADOS CONFINADOS DE UM POÇO SIMPLES DE GAAS DE $52 \AA$ DE LARGURA COM BARREIRAS DE AL 0.26 GA ${ }_{0.74}$ AS. .................................................................................. 49 FIGURA 25: ILUSTRAÇÃO DAS FUNÇÕES DE DENSIDADE DE PROBABILIDADE OBTIDAS PARA OS NIVEIS DENTRO DO POÇO E PARA O CONTÍNUO, UTILIZADAS NO CALCULO DA CURVA DE ABSORÇÃO TEÓRICA. ….........................49 FIGURA 26: CURVA DE ABSORÇÃO TEÓRICA CALCULADA PARA UM POÇO SIMPLES DE GAAS DE 52Å DE LARGURA

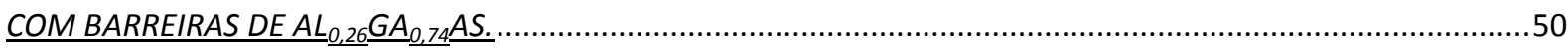
FIGURA 27: COMPARACC̃̃O ENTRE A CURVA DE ABSORCÃO EXPERIMENTAL E A CURVA TEÓRICA CALCULADA SEM NENHUM PARÂMETRO EXPERIMENTAL PARA UM POCCO SIMPLES DE GAAS DE 52Å DE LARGURA COM

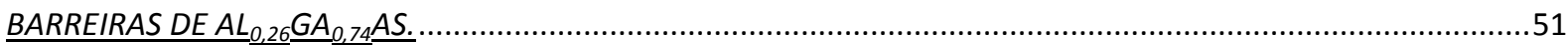
FIGURA 28: ESTADOS DE IMPUREZA NÃO IONIZADA CONFINADA EM UM POÇO QUÂNTICO. EM AZUL ESTÁ REPRESENTADO O ESTADO 1S, EM VERDE O ESTADO 2PXY, E EM AMARELO O ESTADO 2SPZ. …......................56 FIGURA 29: COMPARACCÃO ENTRE AS CURVAS DE CORRENTE NO ESCURO TEÓRICA E EXPERIMENTAL PARA UM QWIP COMPOSTO POR 20 POCCOS DE GAAS DE 52Å DE LARGURA COM BARREIRAS DE ALO.26GAO.74AS DE $300 \AA$ A DE

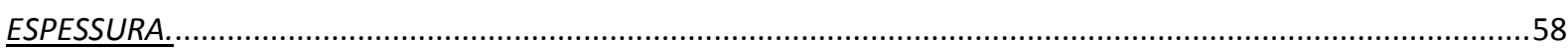
FIGURA 30: ESQUEMA SIMPLIFICADO DE UM CIRCUITO AMPLIFICADOR CTIA UTILIZADO PARA QWIPS EM UM PIXEL

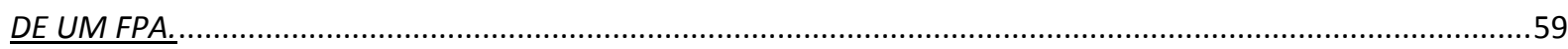
FIGURA 31: REPRESENTACCÃO DO CRESCIMENTO EPITAXIAL SOBRE UM SUBSTRATO DE GAAS [34]. ….....................61 FIGURA 32: DETALHES DA CÂMARA DE CRESCIMENTO (À ESQUERDA) E DO SISTEMA MBE (À DIREITA) DISPONÍVEL

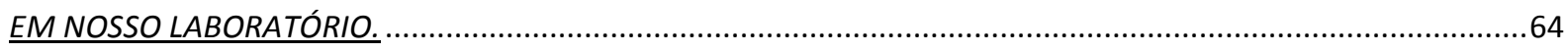

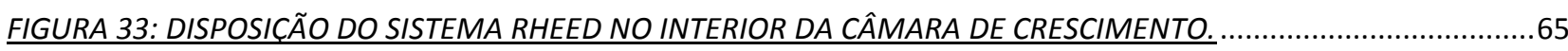
FIGURA 34: ESFERA DE EWALD PARA O CASO DE UM ESPALHAMENTO BIDIMENSIONAL DO FEIXE ELETRÔNICO. .......66 FIGURA 35: REGISTRO DAS OSCILAÇÕES DO PONTO ESPECULAR DO PADRÃO DE DIFRAÇÃO DO SISTEMA RHEED DURANTE O CRESCIMENTO DE CAMADAS DE GAAS SOBRE UM SUBSTRATO DE GAAS....................................67 FIGURA 36: ESQUEMA DA ESTRUTURA DAS AMOSTRAS DE QWIPS PROJETADOS PARA TRANSICÃO INTRABANDA ENTRE $8 \mu \mathrm{M}$ E $12 \mu \mathrm{M}$; (A) AMOSTRA PADRÃO DE QWIP USADA COMO REFERÊNCIA NO INÍCIO DESTA TESE; (B) QWIP COM BARREIRAS EXTERNAS SUPLEMENTARES; (C) QWIP DESENVOLVIDO EM CONJUNTO COM

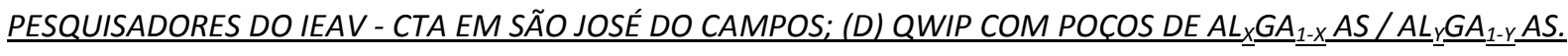
OS VALORES TEÓRICOS E EXPERIMENTAIS DO COMPRIMENTO DE ONDA DE OPERACÃO SÃO MOSTRADOS ACIMA DE CADA ESTRUTURA.

FIGURA 37: ESQUEMA DA ESTRUTURA DAS AMOSTRAS DE QWIPS PROJETADOS PARA TRANSICCÃO INTRABANDA ENTRE $3 \mu M$ E 5 $\mu M$; (A) AMOSTRA DE QWIP COM BARREIRAS EXTERNAS SUPLEMENTARES; (B) QWIP COM MAIOR CONCENTRACCÃO DE AL NAS BARREIRAS, QUE AINDA PERMITA TRANSICCÃO DE GAP DIRETO. ................70 FIGURA 38: REPRESENTACÃO DA ESTRUTURA DAS AMOSTRAS DE QWIPS CRESCIDOS PARA INVESTIGAR A TRANSICÃO ENTRE NÍVEIS ZERO-DIMENSIONAIS DE UMA IMPUREZA HIDROGENÓIDE................................................... FIGURA 39: ESQUEMA DO PROCESSAMENTO PARA TORNAR A AMOSTRA INICIAL (À ESQUERDA) EM UM FOTODETECTOR QUE PODERÁ SER TESTADO (À DIREITA) _....................................................................72 FIGURA 40: DESENHO ESQUEMÁTICO DA TÉCNICA DE FOTOLITOGRAFIA ÓPTICA. .................................................73 FIGURA 41: SUPORTES DE ACCO INOX PARA O POLIMENTO. (A) POLIMENTO DE FACE PLANA; (B) GUIA CILÍNDRICO; (C) POLIMENTO DE FACE EM 45 
FIGURA 42: (A) SUPERFÍCIE DE UM QWIP APÓS PROCESSAMENTO COMPLETO COM MICROSSOLDAS, MESAS DE $400 \mu M$ DE LADO E CONTATOS SUPERIORES DE $100 \mu \mathrm{M}$ DE LADO. (B) AMOSTRA MONTADA NO SEU SUPORTE (DIP14) E INSTALADA SOBRE O DEDO FRIO DO CRIOSTATO PARA A REALIZACÃO DE MEDIDAS COM INCIDÊNCIA EM ÂNGULO DE $45^{\circ}$. . .78

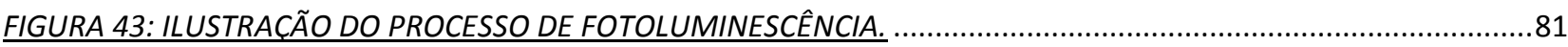
FIGURA 44: (ESQUERDA) ESQUEMA DA INSTALACCÃO DO EXPERIMENTO DE PL EM NOSSO LABORATÓRIO: M1 E M2 SÃO OS ESPELHOS E L1 E L2 SÃO AS LENTES. (DIREITA) ARRANJO EXPERIMENTAL DE PL. PODEMOS VER: (1) O CRIOSTATO REFRIGERADO POR HE LÍQUIDO; (2) O CRIOSTATO PARA RESFRIAMENTO COM N 2 LÍQUIDO; (3) $O$ MONOCROMADOR, (4) A FOTOMULTIPLICADORA UTILIZADA NA DETECCCÃO DA FOTOLUMINESCÊNCIA DOS

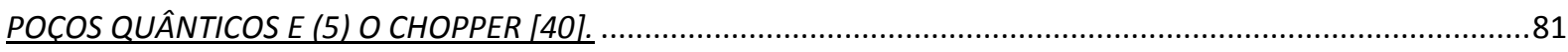

FIGURA 45: APRESENTACCÃO DO FTIR ADQUIRIDO RECENTEMENTE PELO LNMS. ................................................ FIGURA 46: AMOSTRA NA CONFIGURAÇÃO DE GUIA DE ONDA. A RADIAÇÃO INCIDE SOBRE O CHANFRO DA ESQUERDA E ATRAVESSA 6 VEZES (IDA E VOLTA) A REGIÃO ATIVA REPRESENTADA PELA FAIXA MAIS ESCURA NA

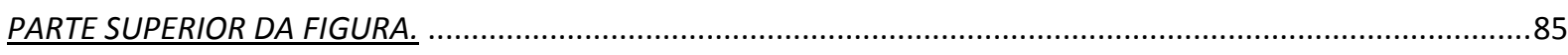
FIGURA 47: ESQUEMA DA MEDIDA DE ABSORÇÃO COM FTIR NA CONFIGURAÇÃO DE GUIA DE ONDA. .....................85 FIGURA 48: DETALHE DO PORTA-AMOSTRAS MONTADO NA CÂMARA DO SISTEMA FTIR PARA MEDIDAS DE

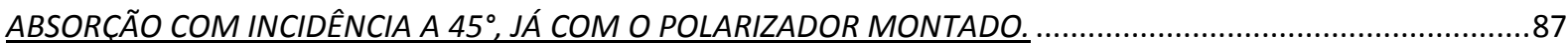

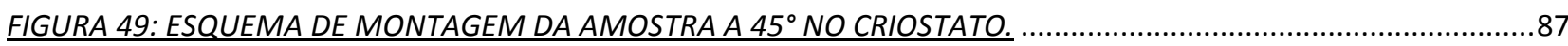
FIGURA 50: TRANSMISSÃO DAS JANELAS DE ZNSE (A) E DE GE (B), MEDIDAS POR FTIR. ……................................ 88 FIGURA 51: (A) PORTA-AMOSTRAS DE COBRE COM A AMOSTRA MONTADA NA EXTREMIDADE DO DEDO FRIO NO CRIOSTATO DE CIRCUITO FECHADO DE HE; (B) VISTA DA PARTE INTERNA DO CRIOSTATO DE N2 LÍQUIDO, COM A AMOSTRA PROTEGIDA PELO COPO DE COBRE UTILIZADO NAS MEDIDAS DE CORRENTE NO ESCURO.................89 FIGURA 52: ESQUEMA DA MEDIDA DE RESPOSTA ESPECTRAL OBTIDA POR FTIR. O DETECTOR INTERNO DO SISTEMA FTIR (CAIXA VERDE) NÃO É MAIS USADO E É SUBSTITUÍDO PELO PRÓPRIO QWIP A SER ANALISADO. ...............90 FIGURA 53: ESQUEMA DA MEDIDA DE FOTOCORRENTE E RESPONSIVIDADE COM CORPO NEGRO..........................91 FIGURA 54: EXEMPLO DA RADIACÃO TOTAL QUE CHEGA AO DETECTOR NO INTERIOR DO CRIOSTATO NA CONFIGURAÇÃO TÍPICA UTILIZADA NAS MEDIDAS; TEMPERATURA DO CORPO NEGRO DE $800^{\circ} \mathrm{C}$, ABERTURA NO CORPO NEGRO DE 12,7MM DE DIÂMETRO E DISTÂNCIA DO DETECTOR DE 15 CM. .......................................92 FIGURA 55: ESQUEMA EXPERIMENTAL UTILIZADO NAS MEDIDAS DE CORRENTE NO ESCURO (CURVAS I-V)...............94 FIGURA 56: ESQUEMA DO SISTEMA DE MEDIDAS DE RUÍDO. ……............................................................. FIGURA 57: TELA DO ANALISADOR DE ESPECTROS POR FFT MOSTRANDO UMA MEDIDA DE RUÍDO JOHNSON DE UM CIRCUITO DE TESTES FORMADO POR RESISTÊNCIAS ÔHMICAS E UMA BATERIA (FIGURA 58)(VALOR MEDIDO DE

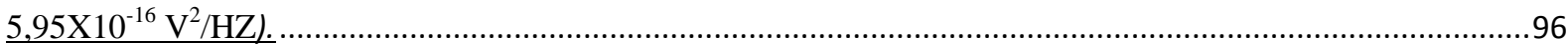
FIGURA 58: CIRCUITO PARA TESTE DO APARATO EXPERIMENTAL UTILIZADO NAS MEDIDAS DE RUÍDO.....................97 FIGURA 59: COMPARAÇÃO DO ESPECTRO DE PL DE UMA AMOSTRA CONTENDO UM ÚNICO POÇO DE 52Å DE GAASE BARREIRAS DE AL 0,26 GA 0,74 AS DE $300 \AA$ A DE LARGURA (3385), E DE OUTRA AMOSTRA COM 20 DESSES MESMOS POCOS E BARREIRAS (3387). AS MEDIDAS FORAM REALIZADAS A 1,7 K COM DENSIDADE DE POTÊNCIA DE 318

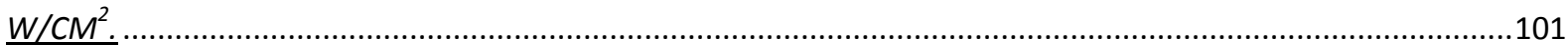

FIGURA 60: VERIFICAÇÃO DA REGRA DE POLARIZAÇÃO PARA TRANSIC̄ÕES INTRABANDA EM QWIPS DO TIPO N (EQUAÇÃO 7.3). (A) MEDIDAS DE ABSORBÂNCIA PARA VÁRIOS ÂNGULOS DE POLARIZAÇÃO DA RADIAÇÃO INCIDENTE; (B) GRÁFICO DO MÁXIMO DA ABSORBÂNCIA NORMALIZADA EM FUNCCÃO DO ÂNGULO DE POLARIZAÇÃO. AS MEDIDAS FORAM OBTIDAS POR FTIR, USANDO A GEOMETRIA DE GUIA DE ONDA A 300K. 103

FIGURA 61: CURVAS DE ABSORCÃ̃O PARA VÁRIAS AMOSTRAS. O GRÁFICO MOSTRA O COEFICIENTE DE ABSORCÃO (EQUAÇÃO 7.3) OBTIDO A PARTIR DAS MEDIDAS DE ABSORBÂNCIA. AS MEDIDAS FORAM OBTIDAS POR FTIR,

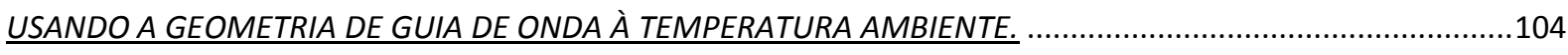

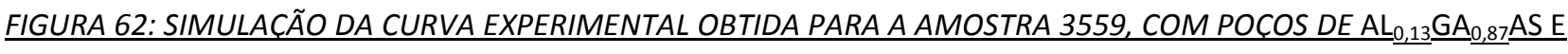

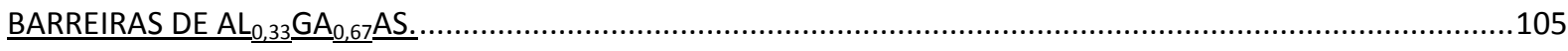


FIGURA 63: CURVAS DE ABSORCÃO DAS AMOSTRAS 3453 E 3495 POSSUINDO A MESMA ESTRUTURA, MAS CRESCIDOS EM DIAS DIFERENTES. AS MEDIDAS FORAM OBTIDAS POR FTIR, USANDO A GEOMETRIA DE GUIA DE ONDA A 300K. .106 FIGURA 64: COMPARAÇÃO ENTRE A CURVA DE ABSORÇÃO OBTIDA EXPERIMENTALMENTE E A CURVA SIMULADA DO QWIP 3453 COM 20 POÇOS QUÂNTICOS COM 52Å DE GAAS SEPARADOS POR BARREIRAS DE AL L, 26 GA $\underline{0,74}$ AS COM

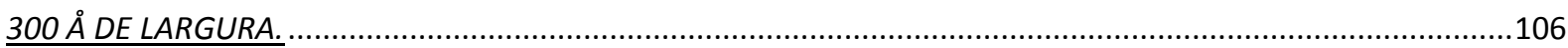

FIGURA 65: COMPARAÇÃO ENTRE A CURVA DE ABSORCC̃OO OBTIDA EXPERIMENTALMENTE E A CURVA SIMULADA PARA O QWIP 3517 COM 50 POÇOS QUÂNTICOS COM 56,5Å DE GAAS SEPARADOS POR BARREIRAS DE

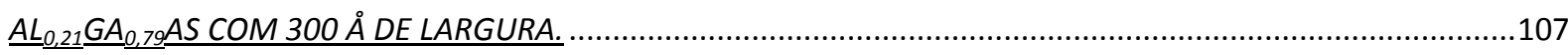
FIGURA 66: RESPOSTA ESPECTRAL A 10K DO QWIP 3517 COMPLETAMENTE PROCESSADO EM FUNCÃO DA

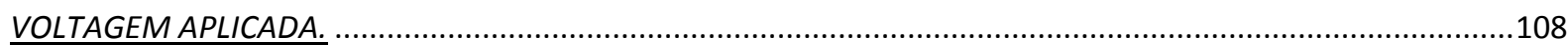
FIGURA 67: RESPOSTA ESPECTRAL NORMALIZADA DO QWIP 3517 EM FUNÇÃO DA TEMPERATURA, PARA UMA

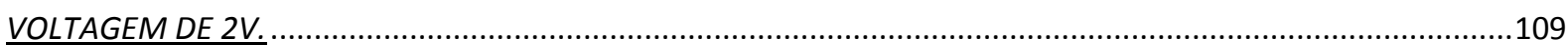
FIGURA 68: RESPOSTA ESPECTRAL A 1OK PARA O QWIP 3559 COMPLETAMENTE PROCESSADO COM APLICACCÃO DE

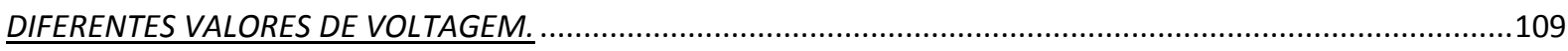
FIGURA 69: CURVA DE RESPONSIVIDADE TOTAL DO QWIP 3517 EM QUATRO TEMPERATURAS DIFERENTES. ...........111 FIGURA 70: CURVAS DE RESPONSIVIDADE TOTAL DO QWIP 3559 PARA CINCO TEMPERATURAS DIFERENTES...........112 FIGURA 71: COMPARACCÃO ENTRE O RESULTADO TEÓRICO E EXPERIMENTAL DA CORRENTE DE ESCURO DA AMOSTRA 3453 COM VOLTAGEM DE POLARIZACCÃO PEQUENA. …….................................................................113 FIGURA 72: CURVA DE CORRENTE DE ESCURO PARA O QWIP 3517 PARA QUATRO TEMPERATURAS DIFERENTES....113 FIGURA 73: CURVAS DE CORRENTE DE ESCURO DO QWIP 3559 PARA TEMPERATURAS ENTRE 1OK E 7OK................114 FIGURA 74: COMPARACCÃO ENTRE AS MEDIDAS DE CORRENTE NO ESCURO E A FOTOCORRENTE GERADA PELA RADIACCÃO DE FUNDO PARA DETERMINAR A CONDIĈÃO BLIP NO CASO DO (A) QWIP 3517 E (B) QWIP 3559. .116 FIGURA 75: CURVAS DE RUÍDO DA AMOSTRA 3517 MEDIDAS NA FAIXA DE FREQUÊNCIAS DE 25OHZ A 3,6KHZ.......117 FIGURA 76: DETECTIVIDADE ESPECÍFICA DA AMOSTRA 3517, OBTIDA A PARTIR DOS RESULTADOS EXPERIMENTAIS DE RESPONSIVIDADE E RUIDDO, OBTIDA POR MEIO DA EQUACÃO 2.17. ......................................................118 FIGURA 77: MEDIDAS DE CAPACITÂNCIA DO QWIP 3517 PARA VÁRIAS VOLTAGENS. AS VOLTAGENS DE OPERACCÃO

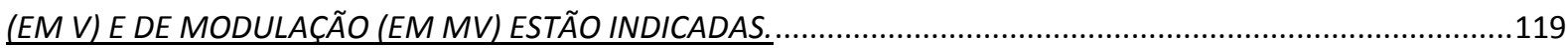
FIGURA 78: RUÍDO EXPERIMENTAL E O RUÍDO CALCULADO A PARTIR DO AJUSTE DO VALOR DE VS PARA O QWIP 3517 A 7OK, E COMPARACÃO COM AS CURVAS CALCULADAS COM OS MODELOS DE V

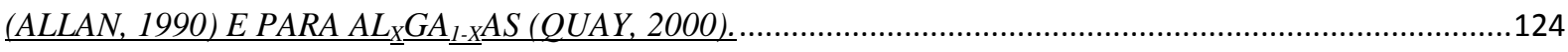
FIGURA 79: VELOCIDADE DE SATURAÇÃO, EM FUNCCÃO DA TEMPERATURA, OBTIDA A PARTIR DO AJUSTE DAS CURVAS EXPERIMENTAIS DE RUIDDO. .124 FIGURA 80: COMPARACÃO ENTRE O RUIIDO EXPERIMENTAL E OS VALORES CALCULADOS PARA O QWIP 3517 A 5OK.

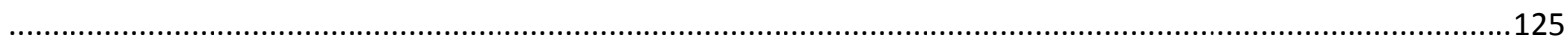
FIGURA 81: COMPARAÇÃO ENTRE O RUÍDO EXPERIMENTAL E OS VALORES CALCULADOS PARA O QWIP 3517 A $30 \mathrm{~K}$. . FIGURA 82: COMPARACÃA ENTRE O RUÍDO EXPERIMENTAL E OS VALORES CALCULADOS PARA O QWIP 3517 A 1OK.

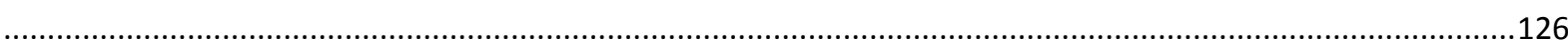

FIGURA 83: (A) MEDIDAS EXPERIMENTAIS DE RUÍDO PARA O QWIP 3517. (B) CÁLCULO DO RUÍDO A PARTIR DA CURVA EXPERIMENTAL DA CORRENTE NO ESCURO E DOS CÁLCULOS DO TEMPO DE RECAPTURA (EQUACCÃO 8.6)

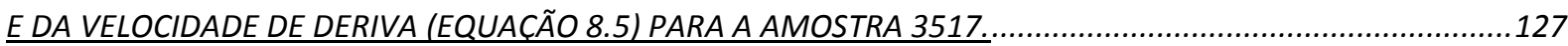
Figura 84: (a)Detectividade experimental; (b) Detectividade obtida a partir do ruído calculado. .........................127 


\section{Referências bibliográficas}

1. L. C. Chiu, J. S. Smith, S. Margalit, A. Yariv, and A. Y. Cho, Infrared Phys. 23, 93, 1983

2. D. Fan, Elect. Lett, v32, p.1726, 1996

3. Intersubband Infrared Photodetectors, Editor V. Ryzhii, Selected Topics in Electronics and Systems - Vol. 27, World Scientific 2003.

4. Gunapala et al, Semicond. Sci. Technol., Vol 20, pp 473 (2005)

5. Gunapala et al, IEEE Journal of Quantun Electr., Vol 46, No 2, 285, (2010)

6. Fabio Durante Pereira Alves, Tese de doutorado, ITA (2008)

7. H. J. Kramer, Observation of the Earth and its Environment, Survey of missions and sensors, $4^{\text {th }}$ edition, Springer, 2002

8. G. ElMasry, N. Wang, C. Vigneault, J. Qiao and A. ElSayed, LWT 41, 337 (2008)

9. Infrared Monitoring of Combustion, SPIE Vol. 1434, 1991

10. Journal of Applied Physics (Focused Review) 104, 091101, 2008

11. Bryan F. Jones, IEEE Transactions on Medical Imaging, Vol.17, No 6, Dez. 1998

12. Chelikowski, J. R., Cohen, M. L.: Phys. Rev. B14 556 (1976)

13. R. J. Anderson, Solid-St. Electron. 5, 341 (1962)

14. H. Y. Fan, Rep. Prog. Phys. 19, 107, 1956

15. Fundamentals of infrared detector operation and testing, Vincent, J. D., John Wiley \& Sons, 1990

16. A. Glatz,V. M. Vinokur, and Y.M. Galperin, Phys. Rev. Let. 98, 196401 (2007)

17. Quantum-Well infrared photodetectors, B. F. Levine, J. Appl. Phys. 74, 15 October 1993

18. Quantum Well Infrared Photodetectors, H. Schneider, H. C. Liu, Springer, 2007

19. Beck, W., Applied Physics Letters, 63, 3589, (1993)

20. Schneider, H., Applied Physics Letters, 82, 4376, (2003)

21. Physics of optoelectronic devices, S.L. Chuang, John Wiley \& Sons, 1995

22. M. Wagner and H. Mizuta, Phys. Rev. B, 48, 19, 14393,1993

23. H. Wang et al., Phys. Lett. A, 340, $347-354,2005$ 
24. N. F. Mott, Rev. Mod. Phys. 40, 677, 1968

25. M. Carras et al., Phys. Rev. B, 70, 233310, 2004

26. T. Antoni et al., Appl. Phys. Let., 97, 042102, 2010

27. Z. Liu and T. Li, J. Phys. C: Solid State Phys., 18, 691, 1985

28. Physics of Semiconductor Devices, S.M. Sze, Wiley-Interscience 2006

29. The Ultimate Infrared Handbook for R\&D, A Resource Guide for Using Infrared in the Research and Development Industry, FLIR AB (pdf)

30. Ma Wenlong et al, Journal of Semiconductors, 31, 2, 025012, 2010

31. David Westerman, Understand and apply the transimpedance amplifier, EE Times/Design, 8/8/2007 (eetimes.com)

32. Laux, S. E., IEEE Trans. Comput. Aided Des. Integ. Circuits, 4, 472 (1985)

33. Ershov M. et al, Appl. Phys. Lett. 70 (14), 1828 (1997)

34. Molecular Beam Epitaxy: Fundamental and Current Status, Springer, $2^{\text {nd }}$ Edition, M. ${ }^{\text {a }}$ Herman and H. Sitter, 1996

35. Shchukin V. A., Ledentsov N. N., Bimberg D., Epitaxy of Nanostructures, Springer (2004), pp. 104

36. Elements of X-Ray Diffraction, D.B. Cullity, Prentice Hall, 2001

37. Reflection High Energy Electron Diffraction, Ichimiya and Cohen, Cambridge, 2004

38. Ershov M. et al, Appl. Phys. Lett. 67 (21), 3147 (1995)

39. Murakami et al, J. Vac. Sci. Technol. B 4 (4), 903, Jul/Aug 1986

40. Sandro Martini, Tese de Doutorado, IFUSP (2002)

41. Physics of Semiconductor Devices, Wiley, $2^{\text {nd }}$ Edition, S. M. Sze (1981)

42. Landolt-Börnstein, Numerical Data and Functional Relationships in Science and Technology, Condensed Matter (Group III), V. 41 Semiconductors, Subvolume A1, Group IV Elements, IV-IV and III-V Compounds, Edited by U. Rössler, Springer, 2002

43. Miller et al., Phys. Rev. B, 24, 1134 (1981)

44. Catellano et al, Phys. Rev. B, 79, 205304 (2009)

45. Antoni Rogalski, Progress in Quantum Electronics, (Review), 27, 59-210 (2003) 
46. Blakemore J. S., Journal of Applied Physics, 53, R123 (1982)

47. Allam R. and Pribetich J., Electronics Letters, vol. 26, no. 11, pp.688 (1990)

48. Quay R. et al, Materials Science in Semiconductor Processing, vol. 3, pp. 149-155, (2000) 


\section{Trabalhos apresentados em conferências internacionais}

1. F. Massa Fernandes, A. Diego Bernardino Maia, M. Santos Claro, E. Conceição Fernandes da Silva e A. André Quivy, "Low-temperature electronic transport mechanisms deduced from noise measurements in quantum-well infrared photodetectors", pôster ThP2-4 apresentado na "International Conference os Superlattices, Nanostructures and Nanodevices (ICSNN 2012)", 22 - 27 de julho de 2012, Dresden, Alemanha.

2. A.D.B. Maia, F. Fernandes, M. Claro, E. da Silva e A. Quivy, "Influence of In segregation and intermixing on the optical and electronic properties of InAs/GaAs quantum dots and photodetectors", pôster TuP1-14 apresentado na "International Conference os Superlattices, Nanostructures and Nanodevices (ICSNN 2012)", 22 - 27 de julho de 2012, Dresden, Alemanha.

\section{Trabalhos apresentados em conferências nacionais}

1. A.D.B. Maia, F.M. Fernandes, E.C.F. da Silva e A.A. Quivy, "Fabricação de fotodetectores infravermelhos de alto desempenho para aplicações agropecuárias", pôster apresentado na "II Conferência Nacional sobre Defesa Agropecuária", 26-29 de maio de 2010, Belo Horizonte, MG.

2. A.D.B. Maia, F.M. Fernandes, D.T. Ferreira, E.S. Gonçalves, E.C.F. da Silva e A.A. Quivy, "Desenvolvimento de fotodetectores de radiação infravermelha baseados em nanoestruturas semicondutoras", pôster apresentado no evento "Empreendedorismo no Instituto de Física da Universidade de São Paulo", 05 de outubro de 2010, São Paulo, SP.

3. F.M. Fernandes, A.D.B. Maia, D.T. Ferreira, E.C.F. da Silva e A.A. Quivy, "High-efficiency infrared photodetectors based on quantum wells grown by molecular beam epitaxy", pôster Tu-17 apresentado no " $15^{\text {th }}$ Brazilian Workshop on Semiconductor Physics", 10-15 de abril de 2011, Juiz de Fora, MG.

4. A.D.B. Maia, F.M. Fernandes, D.T. Ferreira, E.C.F. da Silva e A.A. Quivy, "Growth, processing and testing of infrared photodetectors based on quantum dots", pôster Tu-45 apresentado no " $15^{\text {th }}$ Brazilian Workshop on Semiconductor Physics", 10-15 de abril de 2011, Juiz de Fora, MG.

5. A.D.B. Maia, F.M. Fernandes, E.C.F. da Silva e A.A. Quivy, "Calculations of the electron energy levels of InAs/GaAs quantum dots for application in infrared photodetectors", pôster Tu-44 apresentado no " $15^{\text {th }}$ Brazilian Workshop on Semiconductor Physics", 10-15 de abril de 2011, Juiz de Fora, MG.

6. M.S. Claro, F.M. Fernandes, A.D.B. Maia, A.A. Quivy e E.C.F. da Silva, "Experimental and theoretical studies of dark current in quantum-well infrared photodetectors", pôster 
apresentado no "Workshop on Infrared Technology", 5-9 de dezembro de 2011, Rio de Janeiro, RJ.

7. A.D.B. Maia, F.M. Fernandes, M.C. Santos, E.C.F. da Silva e A.A. Quivy, "Desenvolvimento de fotodetectores de radiação infravermelha para o mercado brasileiro", pôster apresentado no Mini Simpósio do IFUSP "Há uma vida após o IFUSP?", 16 de agosto de 2012, São Paulo, SP.

8. A.D.B. Maia, F.M. Fernandes, M.C. Santos, E.C.F. da Silva e A.A. Quivy, "Desenvolvimento de fotodetectores de radiação infravermelha para o mercado brasileiro", pôster apresentado na "I " Feira USP de Inovação \& Empreendedorismo", 23 a 25 de agosto de 2012, São Paulo, SP.

\section{Artigos em preparação:}

- "A model for fundamental interactions in light absorption by the continuum energy band above quantum wells", por F.M. Fernandes, M.C. Santos, A.D.B. Maia, E.C.F. da Silva e A.A. Quivy

- "Wave functions morphologies and infrared light absorption of non-ionized Impurities confined in AlGaAs/GaAs quantum wells", por F.M. Fernandes, M.C. Santos, A.D.B. Maia, E.C.F. da Silva e A.A. Quivy

- "Determination of the saturation velocity using noise measurements in quantum-well infrared photodetectors", por F.M. Fernandes, M.C. Santos, A.D.B. Maia, E.C.F. da Silva e A.A. Quivy 